\title{
Development of Testing Facilities and Procedures for Seismic Performance of Suspended Ceilings
}

by

Geoffrey Allen Davidson

A thesis submitted to the Faculty of Graduate and Postdoctoral Affairs in the partial fulfillment of the requirements for the degree of

Master of Applied Science

In

Civil Engineering

Carleton University

Ottawa, Canada

Copyright by G. Davidson, 2021 


\section{ABSTRACT}

This study presents the initiation of Phase II of an international joint collaborative research project that is being carried out by researchers in Japan, China and Canada on the seismic performance of suspended non-structural components in supertall buildings. Research infrastructure was developed in this study for testing and evaluation of seismic performance of non-structural components. In addition to the development of the new research infrastructure, the development of a research program on testing of suspended ceiling systems by using the new research facilities was also included in this research. Suspended ceilings are often found in commercial buildings as part of the building contents. They are classified as non-structural components, which are also referred to as operational and functional components in a building because they provide important services or functions to the occupants of the facilities. Non-structural components typically are not designed as part of the primary seismic force resisting system; however, these components have an impact on the safety and seismic performance of the building because of their vulnerability and their contribution to the mass, stiffness, and interaction with the main structural system during earthquakes. Traditionally, the design of non-structural components, including suspended ceilings, does not consider seismic loads and the interaction effects with the supporting structure. The damage and disruption caused by failure of non-structural components can potentially represent a significant portion of the total economic loss in an earthquake. The performance of suspended ceilings, e.g., in hospitals and schools designated as post-disaster shelters, can be critical to emergency response, and recovery during and immediately after major earthquakes. In this study, previous experimental and numerical analysis research on the seismic performance of suspended ceilings are reviewed. This study also investigates the variation in design codes between the National Building Code of Canada and the International Building Code. Finally, the current seismic testing procedure is evaluated with simulated floor response records. The aim of the study is to initiate Phase II of the ILEE Project by creating the research infrastructure required for the seismic testing of non-structural components along with analytically investigating suspended ceilings to gain insights on their seismic performance. 


\section{Acknowledgements}

I would like to express my gratitude to my supervisors David Lau and Jeffrey Erochko for the useful comments, remarks and engagement through the learning process of this master thesis. I would like to thank Prof. Kazuhiko Kasai of Tokyo Institute of Technology Prof. Huanjun Jiang of Tongji University for leading this successful collaboration. I am grateful to the teams at Tongji University and Tokyo Institute of Technology for their collaboration. I am also grateful to the Canadian Foundation of Innovation for the funding to make this research possible. I would like to express my appreciation to MTS, Armstrong Ceilings, E2M, Boyd Brothers and Loucon Metals for their partnership and guidance with this Joint Research Project. Thank you to the Carleton Laboratory staff for their guidance and hard work.

I would like to send a huge thank you to my family. Mom and Dad, it appears you did a good job on raising two good sons. Thanks for all the support mentally and financially through the years! Greg and Abby, thank you for being great role models to look up to.

I would like to thank all my friends who have been there through this process. All of you have been great for stress relief and encouragement through this process.

Do not worry I did not forget about you. I always was told to save the best for last and as such I would like to express a special thanks to Meghan Donovan. Meg, you inspired me to push myself and expand my knowledge. I would not have been able to do all this without you. You have helped me through such stressful times, and I Love you for that. I am truly excited for what the future has in store for us......

To everyone who had to put up with me through this process....I AM FINALLY DONE! 


\section{Table of Contents}

Abstract
Acknowledgements
Table of Contents
List of Figures
List of Tables

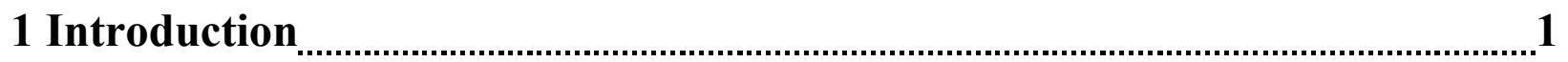

1.1 Suspended Ceiling Systems

1.2 Failure of Suspended Ceiling Systems

1.3 Economical Impact from Failure of Suspended Ceilings _............................................ 8

1.4 Objectives of Research

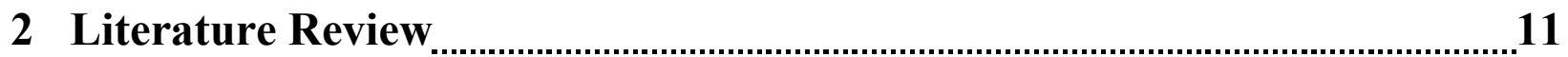

2.1 Progress of Experimental Testing

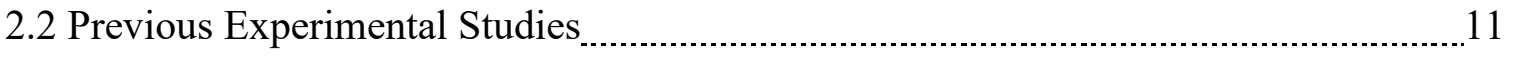

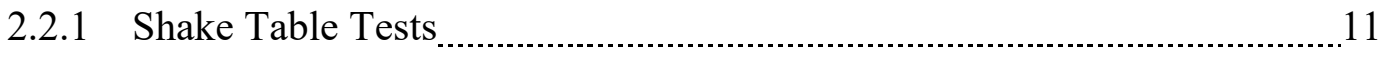

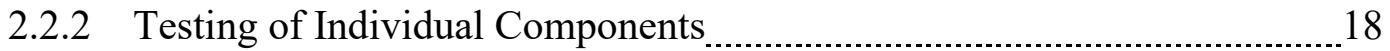

2.3 Numerical Models

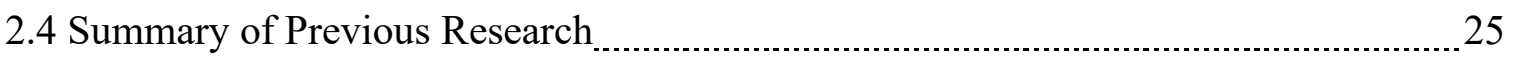

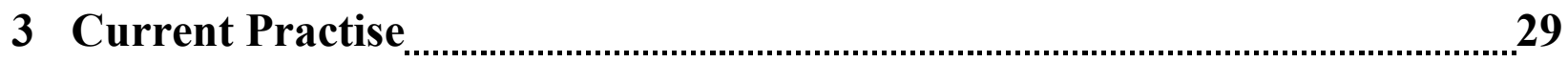

3.1 Current Installation and Design Standards _.................................................................2 29

3.2 Standards of Installation

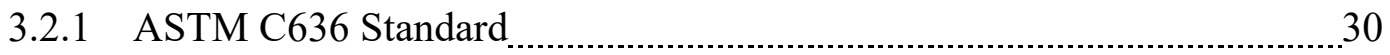

3.2.2 ASTM E580 (Section 1.4 and Section 1.6) _............................................. 31

3.2.2.1 Free Floating Suspended Ceilings (Section 1.8) _....................... 31

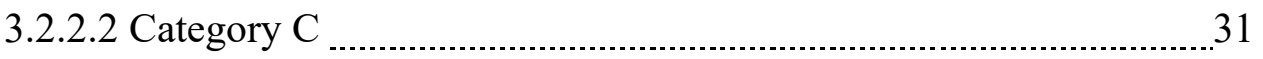




\section{Table of Contents (CONT'D)}

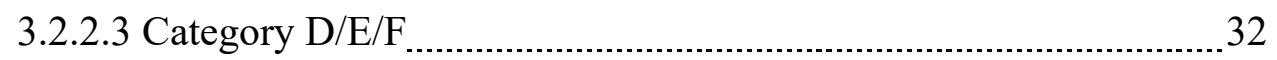

3.2.2.4 Typical Standards for all Ceiling Categories in ASTM E580 ..........33

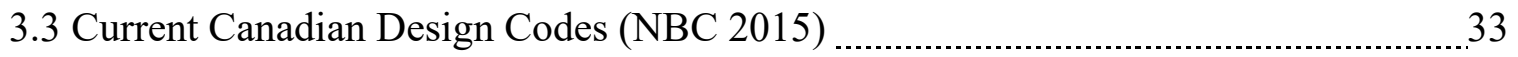

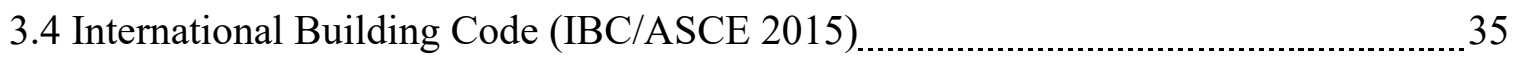

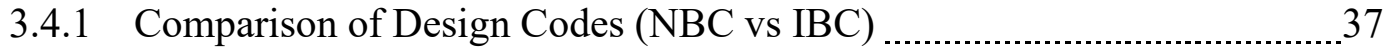

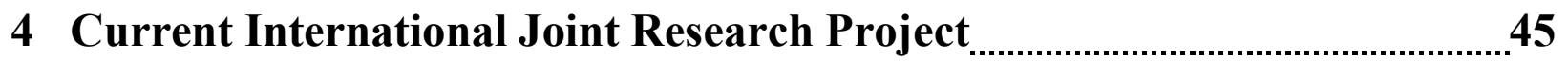

5 Design of Test Frame for Non-Structural Components ………………............5

5.1 Layout of Shake Tables

5.1.1 Installation of Tables _....................................................... 51

5.1.2 Design Criteria

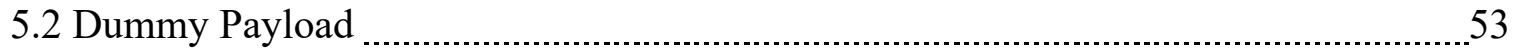

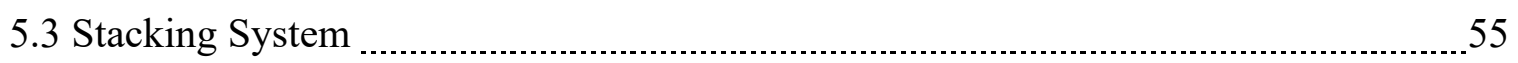

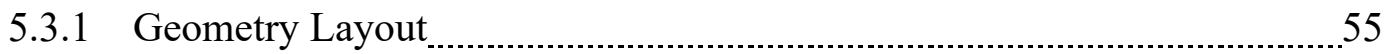

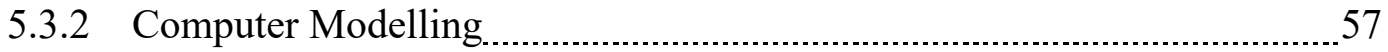

5.4 Test Frame

5.4.1 Design Criteria $\ldots \ldots$

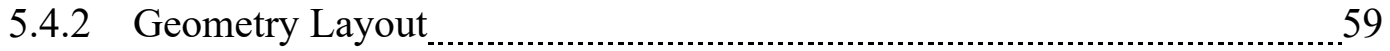

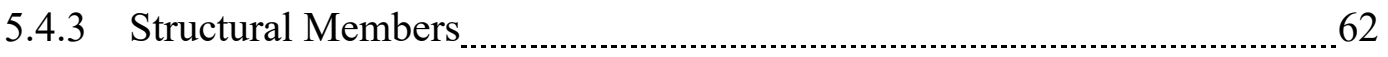

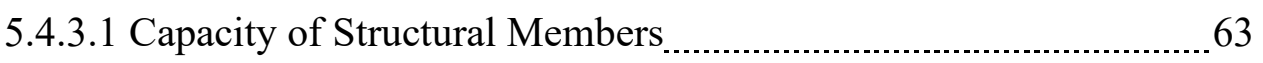

5.4.4 Stiffness Design

5.4.5 Unique Features of Test Frame Design _........................................ 68

5.4.6 Numerical Model (SAP200) _ $\quad 6$

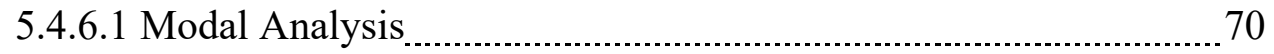

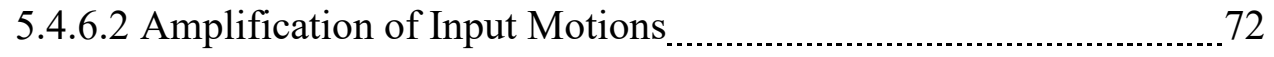

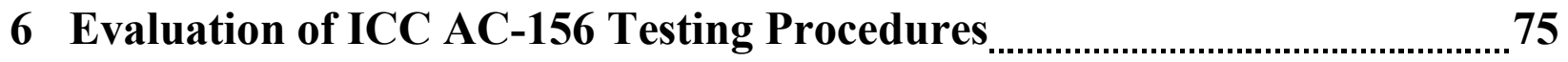

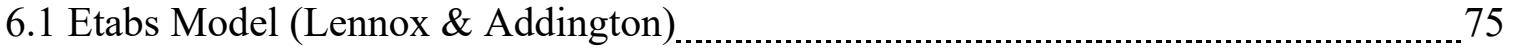




\section{Table of Contents (CONT'D)}

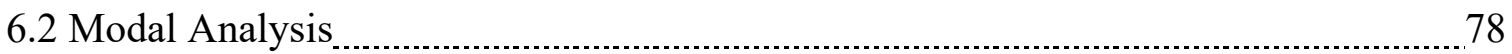

6.3 Input Ground Motions

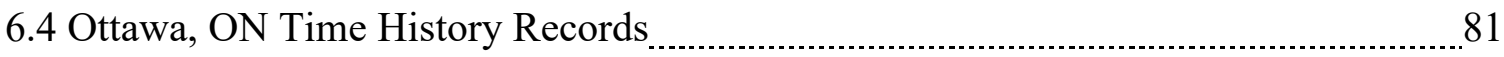

6.5 Victoria, BC Time History Records

6.6 AC-156 Required Response Spectrum (RRS) $\ldots$

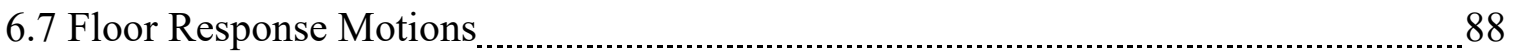

6.8 Summary of the AC-156 Test Standard

7 OpenSees Model of Suspended Ceiling Panel ……….............................................

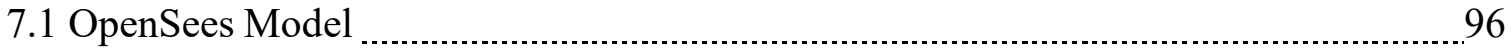

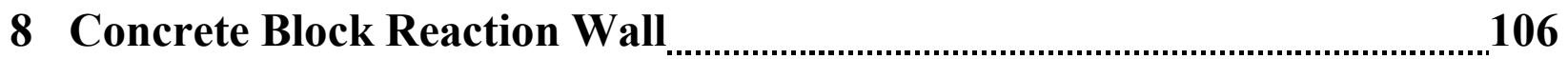

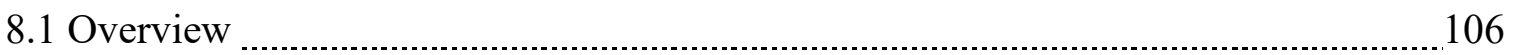

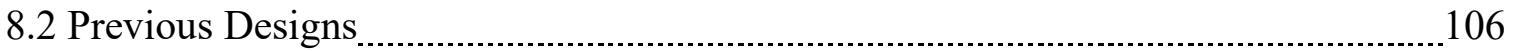

8.3 Final Design of Concrete Reaction Block Wall _.......................................................... 108

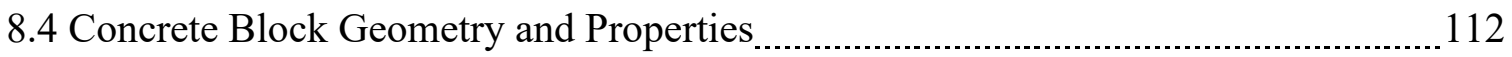

8.5 Carleton University Structural Lab Capacities _................................................... 115

9 Summary, Concluding Remarks and Recommendations ……………...............126

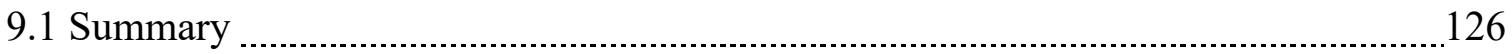

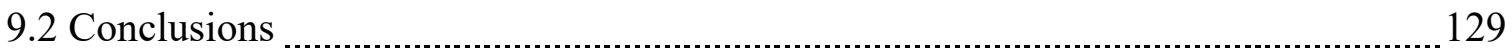

9.3 Recommendations for Future Work ……............................................................. 130

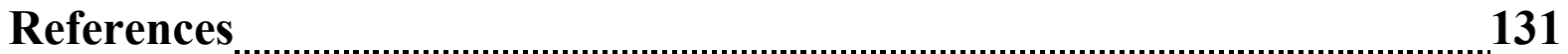




\section{List of Figures}

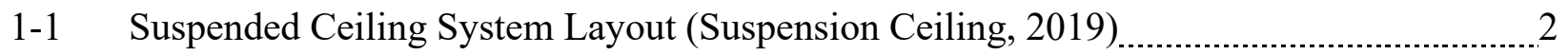

1-2 Suspended Ceiling Seismic Restraint (Soroushian et al., 2016a) _.................................... 3

1-3 Suspended Ceiling Seismic Perimeter Angle Attachment with Pop Rivet (ASTM, 2010)..3

1-4 Non-Structural Element Failure Inside Sony's Sensory Plant (Nakamura, 2017) ............... 5

1-5 Classroom of Hanshew Middle School (Anchorage Daily News, 2018) ............................. 6

1-6 Classroom of Houston Middle School (Anchorage Daily News, 2018) _........................... 7

1-7 Street in Mexico after the 2017 Earthquake (Blackwell, 2017)

1-8 Repair Cost of Building Components after Seismic Event (Takahashi et al., 2004)_..........9

3-1 Comparison of Fa Coefficient NBC vs IBC

3-2 Vp Difference Between a 2.5psf Ceiling (NBC) vs 4psf Ceiling (IBC) ............................ 41

3-3 Vp Difference With 4psf Ceiling Weight for Both NBC and IBC _ _ _............................ 42

3-4 Proposed NBC vs Proposed IBC Design Forces

4-1 3D ETABS Benchmark Model of Shanghai Tower (Lu et al., 2016) _.............................. 46

4-2 Category C Suspended Ceiling (600 mm x $600 \mathrm{~mm}$ Panels) _......................................... 48

4-3 Category D/E/F Suspended Ceiling (600 mm x $600 \mathrm{~mm}$ Panels) _................................... 48

4-4 Category D/E/F Suspended Ceiling with Seismic Bracing (1200 mm x 600 mm Panels) 49

5-1 Shake Table Schematic

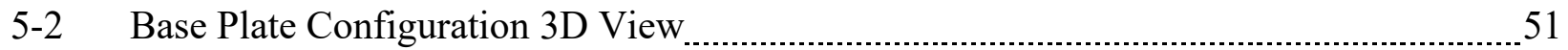

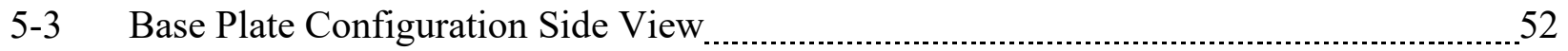

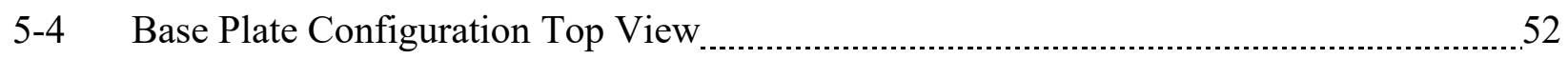

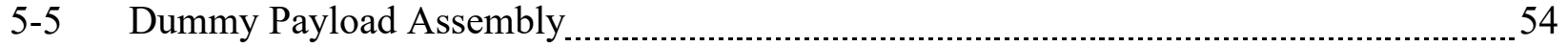

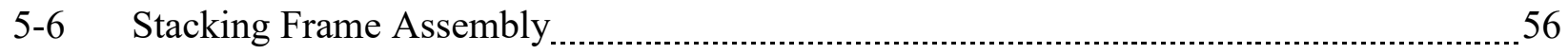

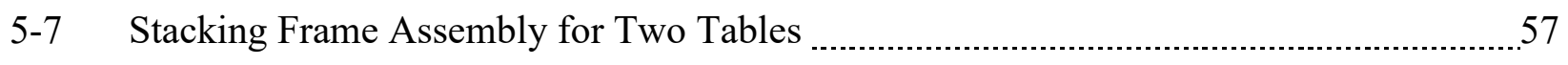

5-8 Stacking System 3D SAP2000 Model

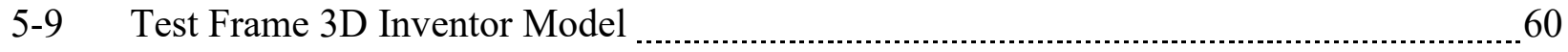




\section{List of Figures (CONT'D)}

5-10 Top View of Test Frame Roof $\quad 61$

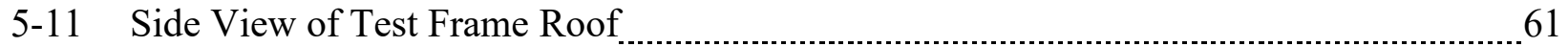

5-12 3D View of Test Frame Parts 66

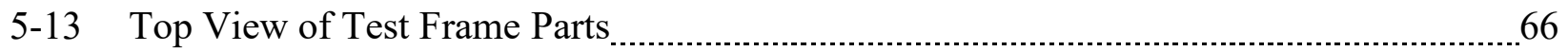

5-14 Side View of Test Frame with Adjustable Plenum Heights _........................................ 69

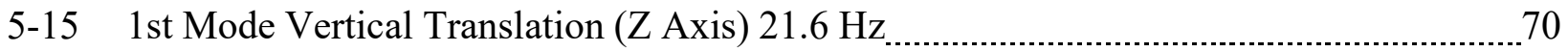

5-16 2nd Mode Horizontal Translation (X Axis) $22.9 \mathrm{~Hz} \ldots$

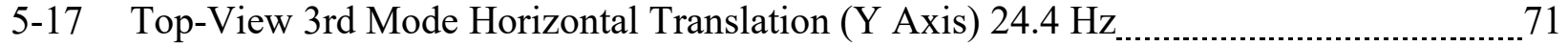

5-18 Amplification of Vertical Time History Record "64" ..................................................... 72

5-19 Amplification of Horizontal (X-Direction) Time History Record "64" _........................... 73

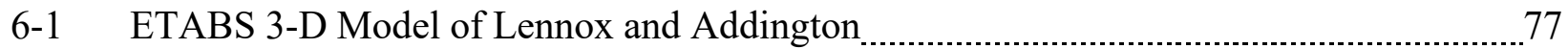

6-2 Typical Floor Layout of Building $\quad 77$

6-3 1st Mode Long Direction Translation (X Axis) 0.469s (2.13Hz) ………………............ 78

6-4 2nd Mode Short Direction Translation (Y Axis) 0.307s (3.26Hz) _ _ _........................... 79

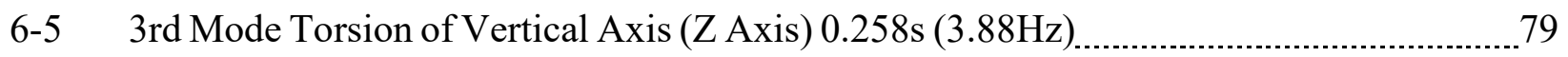

6-6 Record Locations of eastern Canada earthquake _ _ _ _ _ _ _ _ 81

6-7 Scaled Response Spectra (Ottawa)

6-8 Record locations of west coast North American earthquake records _............................ 83

6-9 Scaled Response Spectra (Victoria, BC) _ _

6-10 Carleton University Site Class C AC156 RRS

6-11 Victoria, BC Site Class C AC156 RRS

6-12 Top Floor Horizontal Response Spectra (Ottawa, ON) _ _ _ 89

6-13 Top Floor Horizontal Response Spectra (Victoria, BC) _

6-14 2nd Floor Horizontal Response Spectra (Ottawa, ON) $\quad 90$

6-15 2nd Floor Horizontal Response Spectra (Victoria, BC) $\quad 90$

6-16 Vertical Floor Response Spectra (Ottawa, ON)

6-17 Vertical Floor Response Spectra (Victoria, BC) 


\section{List of Figures (CONT'D)}

6-18 Floor Horizontal Response Spectra of 5-Storey Steel Moment Resisting Frame (Takhirov et al., 2010).

6-19 Recorded Floor Spectral Acceleration of Eight Storey Hospital, Los Angeles (Takhirov et al., 2010)

7-1 ZeroLengthImpact3D Hysteresis 97

7-2 Schematic of OpenSees Model 3D View. 98

7-3 Section A-A from Figure 7-2

7-4 $\quad 5^{\text {th }}$ (Mid Height) Floor Response Record X-Direction (Earthquake 235) _.......................99

7-5 $\quad 5^{\text {th }}$ (Mid Height) Floor Response Record Y-Direction (Earthquake 235) ........................ 100

7-6 $\quad 5^{\text {th }}$ (Mid Height) Floor Response Record Z-Direction (Earthquake 235) ......................... 100

7-7 $\quad 5^{\text {th }}$ (Mid Height) Floor Response Records Combined (Earthquake 235) ........................ 101

7-8 $\quad 5^{\text {th }}$ Floor Response Spectra Earthquake Record 235

7-9 Horizontal Displacement of Panel

7-10 Vertical Displacement of Assembly

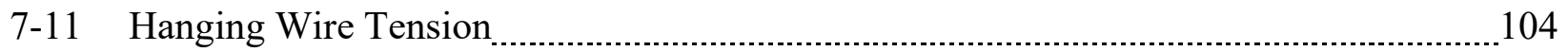

7-12 Increase in Displacement due to Hold-Down Clips $\ldots \ldots \ldots$

8-1 Fiszman's Concrete Block Design (Fiszman, 2014)

8-2 Miller's Concrete Block Design (Miller, 2015)

8-3 Final Concrete Block Design 3D Model $\ldots$

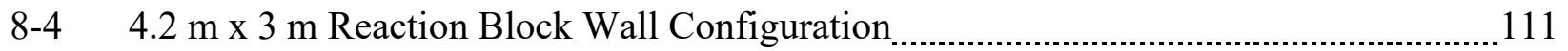

8-5 Construction of Concrete Block

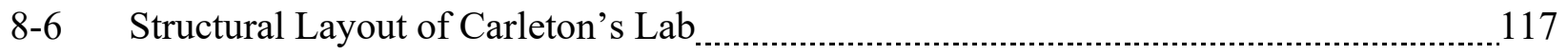

8-7 Pile Capacity and Tributary Area (Fiszman, 2014) $\ldots 117$

8-8 Locations for Placement of 4-3 System on Strong Floor $\ldots$

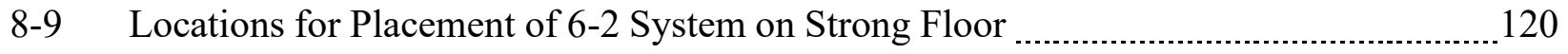

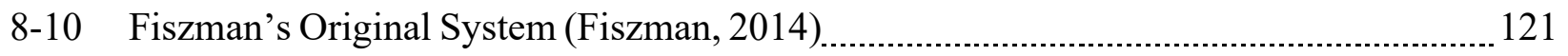

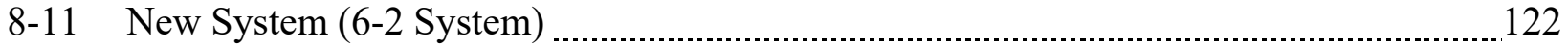




\section{List of Figures (CONT'D)}

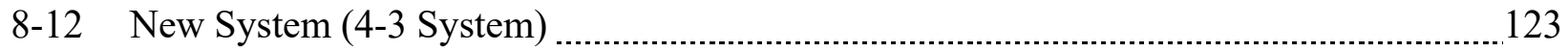

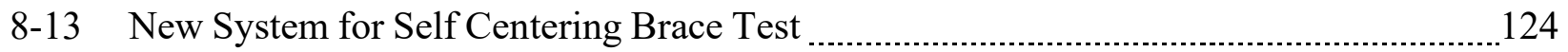

8-14 Setup of Blocks for Self Centering Brace Test (Ahmed Hassan) _................................... 125 


\section{List of Tables}

2-1 Summary of Previous Shake Table Experiments _ _ _ $\quad 26$

3-1 Summary of Installation Standards _ _ _

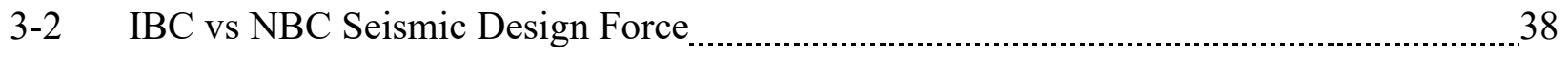

3-3 IBC vs NBC Importance Factor ………. 40

5-1 Capacity of Frame Members (1.76 kPa Ceiling Load/ $6.3 \mathrm{~m} / \mathrm{s}^{2}$ Horizontal and $8.93 \mathrm{~m} / \mathrm{s}^{2}$ Vertical)

5-2 Safety Factor of Frame Members (1.76 kPa Ceiling Load/ $6.3 \mathrm{~m} / \mathrm{s}^{2}$ Horizontal and

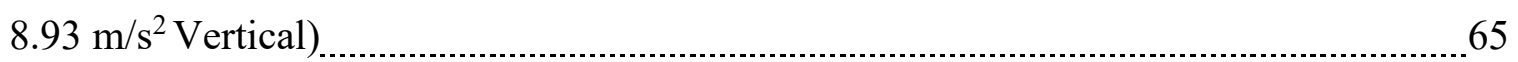

5-3 SAP2000 Test Frame Modal Frequencies _ _ _ _ _

6-1 Summary of Earthquake Records near Ottawa, ON $\quad 81$

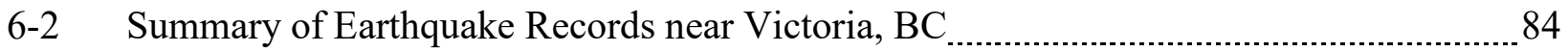




\section{Chapter 1: Introduction}

\subsection{Suspended Ceiling Systems}

A suspended ceiling is classified as any ceiling that is hung from the structural ceiling above. Suspended ceilings are often found in commercial buildings as part of the building contents. Suspended ceilings allow for mechanical and electrical equipment to be located in the ceiling space between the structure and the suspended ceiling below. Suspended ceilings are often used due to their inherent easier installation compared to a drywall ceiling, and their easy accessibility to service mechanical and electrical equipment above. Suspended ceilings are classified as nonstructural, or operational and functional components in a building that provide important services to the building occupants. Suspended Ceilings are made up of four main components: hanger wires, main-tee beams, cross-tee beams, and ceiling panels. The wires, hung from the floor slab above, hold up the main and cross-tee beams of the suspended ceiling. The ceiling panels are simply placed on top of the beams. Although in some installations, the ceiling panels may be held down using hold-down clips to the grid members. Figure 1-1 illustrates a typical ceiling assembly showing the common ceiling system components. 


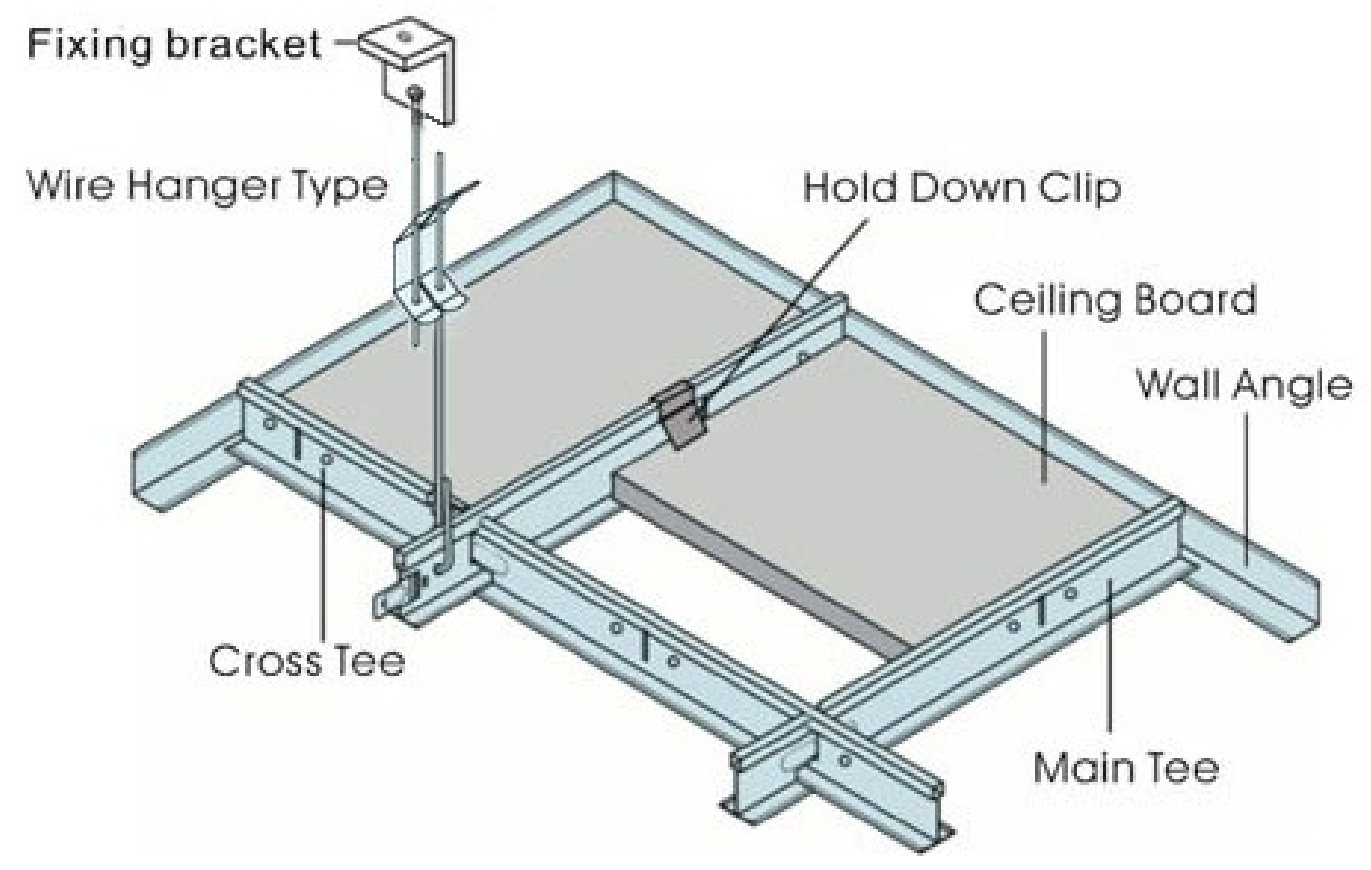

Figure 1-1: Suspended Ceiling System Layout (Suspension Ceiling, 2019)

Suspended ceilings may have additional components depending on the seismic design category that will be described in Chapter 3 of this report. This includes seismic restraint in the form of a compression post connecting the grid members to the structure above with the compression post restrained by four diagonal splay wires that extend from the bottom of the compression post to the structure at an angle less than 45-degrees, as shown in Figure 1-2. Another component that is sometimes used are pop rivets. These pop rivets connect the grid members to the supporting ceiling perimeter angle sections, which are typically fastened on two adjacent sides, as shown in Figure 1-3, in accordance with the requirements based on the seismic design category. 


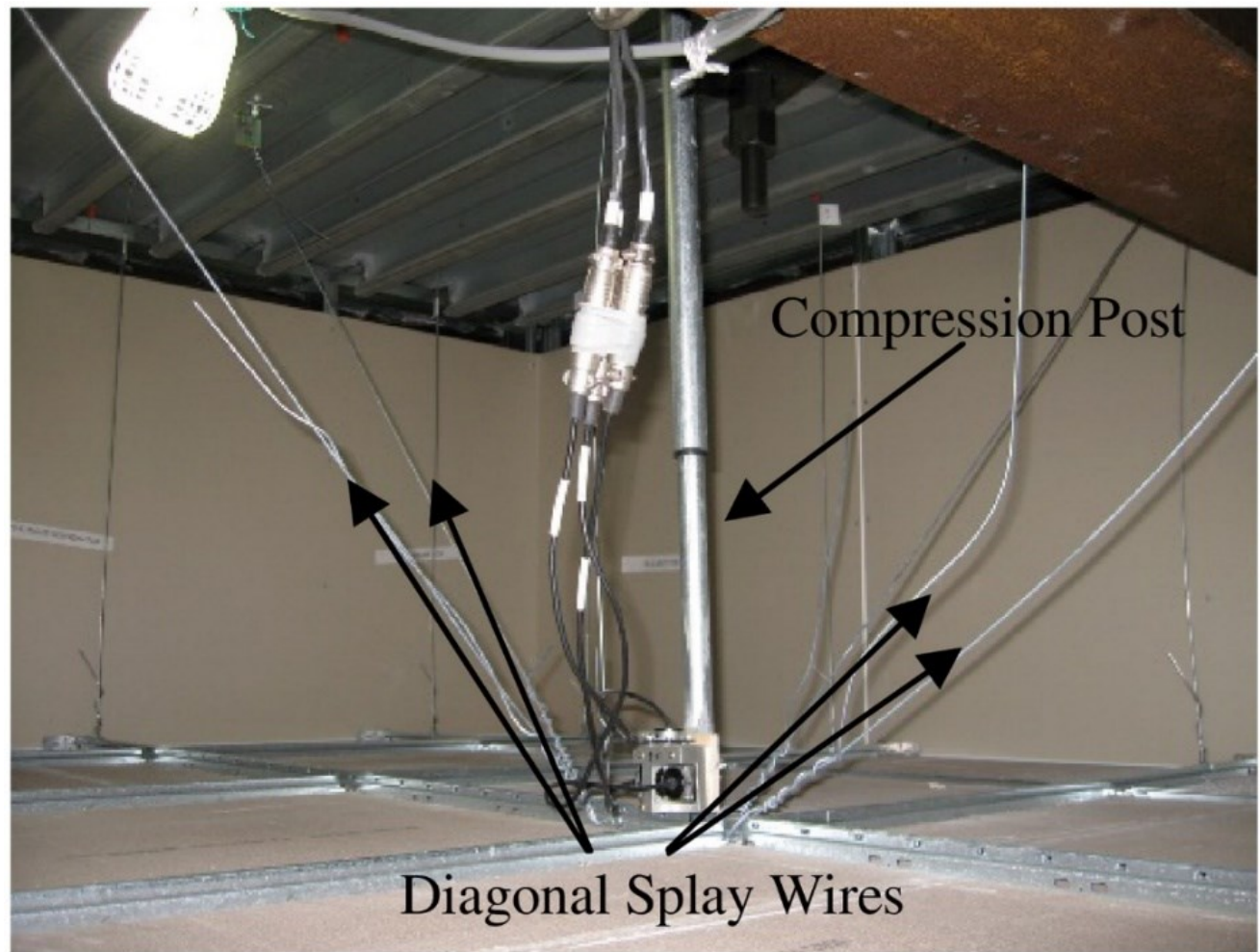

Figure 1-2: Suspended Ceiling Seismic Restraint (Soroushian et al., 2016a)
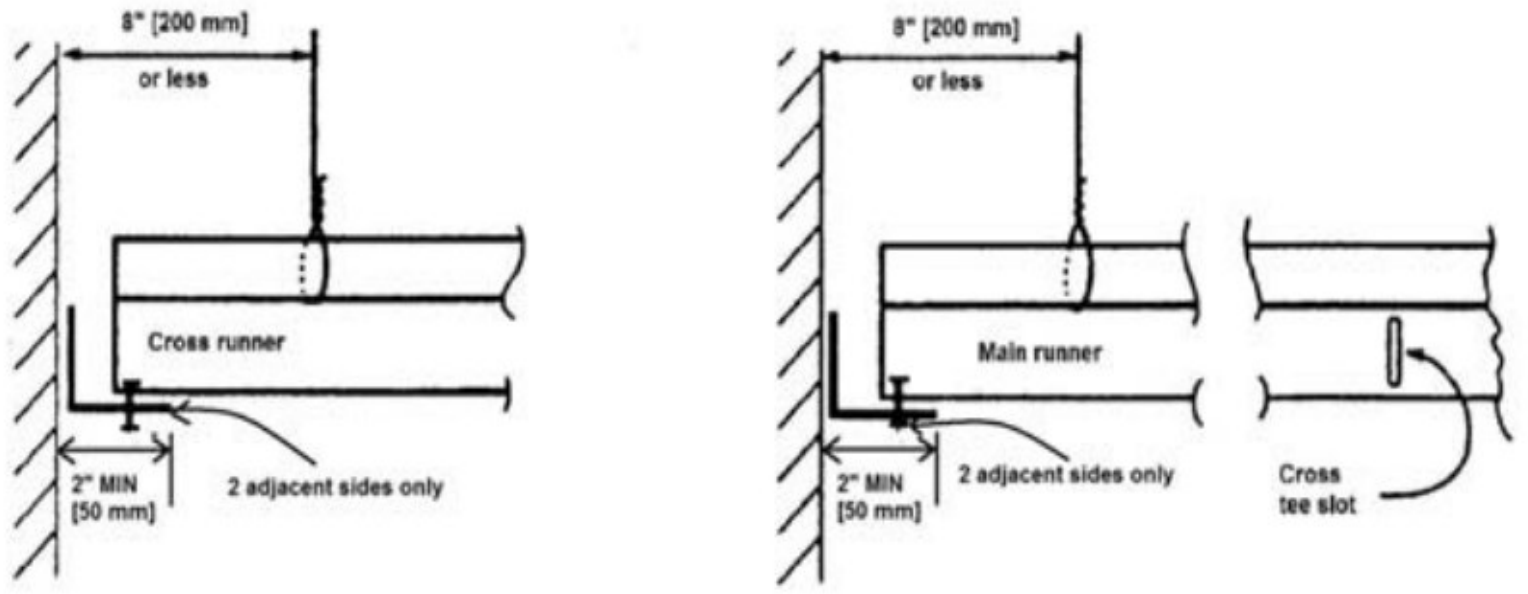

Figure 1-3: Suspended Ceiling Perimeter Angle Attachment with Pop Rivet (ASTM, 2010) 
Non-structural components are typically not designed as part of the primary seismic resistant system; however, these components could have an impact on the seismic response of the building through their contributions to the mass and stiffness properties, and interaction of the nonstructural components with the main structural system. In collaboration with Tokyo Institute of Technology (Japan) and Tongji University (China), Carleton University has initiated an experimental research program on suspended ceilings that utilizes a new multiple-unit mobile shake table system. In this report, the new testing facilities that include a multiple-unit mobile shake table system specially developed for testing of non-structural components are described.

\subsection{Failure of Suspended Ceiling Systems}

During a seismic event, structures are subjected to high level of ground acceleration. Although modern structures are designed to withstand major seismic events, experiences have shown that many buildings still suffer damage to the structural and non-structural systems as a result of the poor performance of the non-structural components during earthquakes. A study conducted in 2011 by Dhakal et al. (2011) described the damage caused by the 6.2 magnitude earthquake in Christchurch, New Zealand (2011). The findings have shown that some tall buildings built according to older design codes suffered both structural and non-structural damage whereas, even in shorter buildings where the structures remained intact, the non-structural components such as suspended ceilings were severely damaged (Dhakal et al., 2011).

Japan has witnessed many earthquakes in the past, including the Tohoku earthquake which took place on March 11, 2011. This earthquake was a magnitude 9.0 with many foreshocks and aftershocks reaching above M7.0 and caused a devastating tsunami. The main event and aftershock events of the Tohoku earthquake caused heavy casualty of 22056 that includes 6157 injuries. 
Along with the impact on human life, these events also caused billions of dollars in economic losses. Some buildings not designed to current codes collapsed during the earthquake but many buildings that were designed to modern standards still suffered damage to their dampening systems and non-structural elements (Norio et al., 2011). Another more recent earthquake in Japan took place in 2016. With a magnitude of 7.0, the Kumamoto Earthquake caused some but not severely high number of deaths due to collapse of structures. However, of particular interest though, the failure of non-structural elements in structures caused huge social-economic losses and the resulting number of injuries placed a heavy burden on emergency response and resources for recovery. As a result of the earthquake, many factories had to be shut down until repairs could be made and the structures deemed to be safe again. Most of these repairs concerned only failed nonstructural elements. The damage to a major sensor factory and the impact on production due to repair downtime cost the owner of the factory an estimated $\$ 1$ Billion (Nakamura, 2017). Figure 1-4 shows the failure of non-structural elements in the plant.

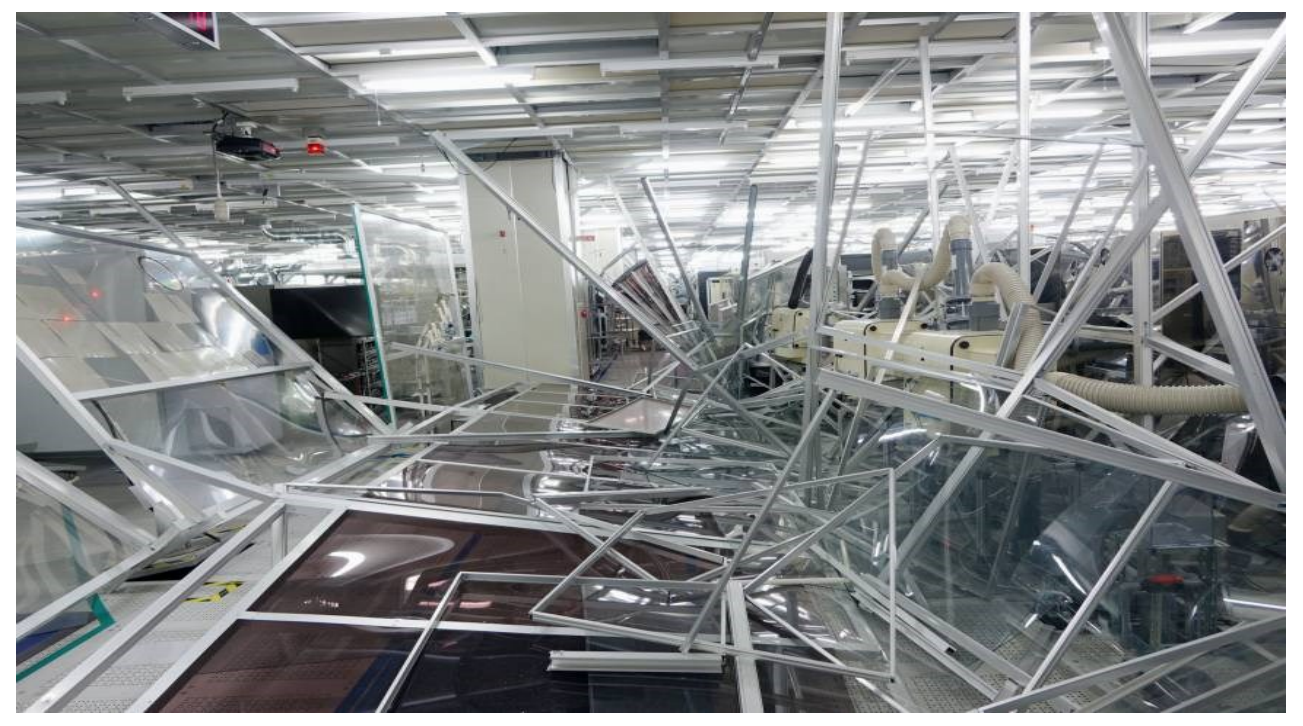

Figure 1-4: Non-Structural Element Failure Inside Sony's Sensory Plant (Nakamura, 2017) 
On November 30, 2018, a 7.0 magnitude earthquake hit South Central Alaska. There were multiple aftershocks following the main shock event, with some reported magnitudes above 5.0. This recent seismic event has further shown the importance of the performance of non-structural elements in buildings to seismic safety of communities. Schools in South Central Alaska suffered significant damage, mostly due to the failure of their suspended ceilings. Although there were no reported injuries, many of the schools had to be closed for a week. Two schools were damaged so severely that the schools had to be closed for the rest of the school year and the next. Figures 1-5 and 1-6 show the collapse of the suspended ceilings located in the classrooms of Hanshew and Houston Middle School, respectively (Anchorage Daily News, 2018).

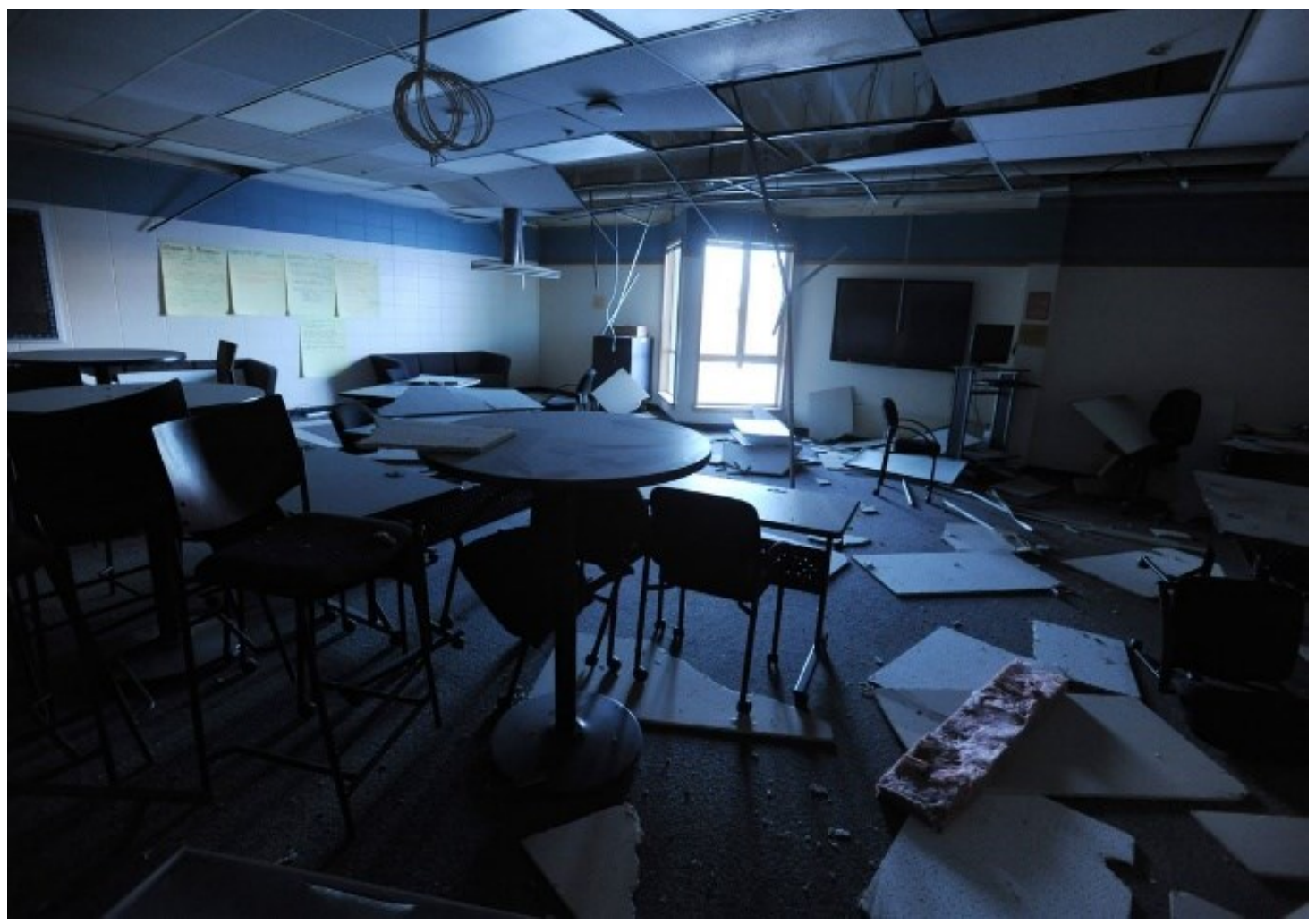

Figure 1-5: Classroom of Hanshew Middle School (Anchorage Daily News, 2018) 


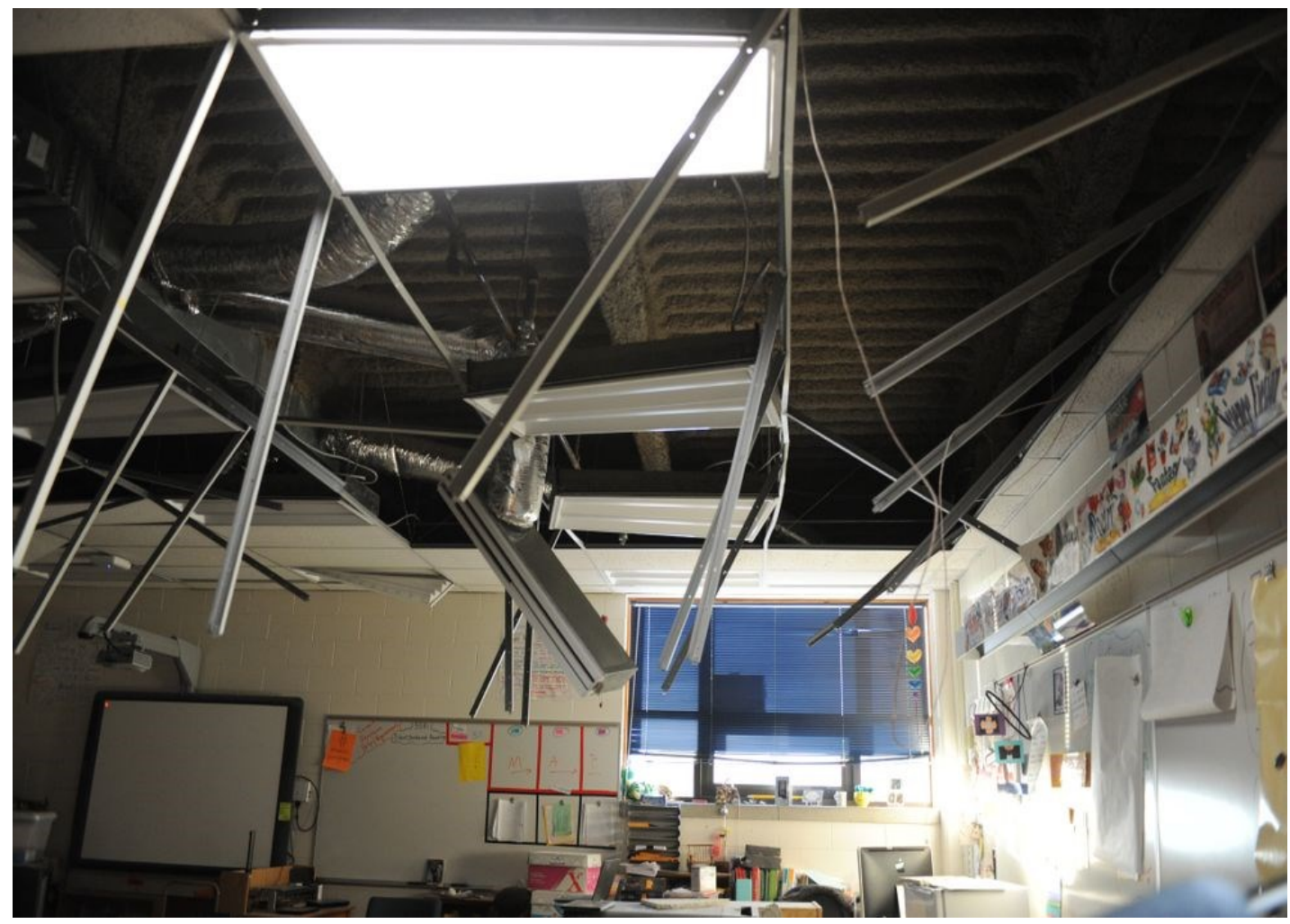

Figure 1-6: Classroom of Houston Middle School (Anchorage Daily News, 2018)

During a seismic event, the failure of non-structural elements can pose a significant threat to the health and safety of occupants in a building. In terms of the non-structural elements focused in this study, failure of suspended ceiling components pose a high risk to human life because these elements are positioned above head height and therefore become dangerous when dropped. Fallen components of suspended ceilings can also create a tripping hazard during evacuation and, in some cases, may completely block evacuation exits during emergency situations. Failure of these elements can also lead to an occupant's perception that the building is unsafe and may collapse. Then the occupant's instinct is to evacuate the building which can cause mass congestion and panic in the streets, reducing the ability of first responders to respond to emergencies in the area. It may lead to better outcomes if the occupants can feel safe to stay inside of buildings, if the non- 
structural components in the buildings perform adequately without causing alarm during earthquakes. An example of this behaviour can be seen in Figure 1-7, which shows the panic and congestion in the streets of Mexico City after an earthquake that occurred in 2017.

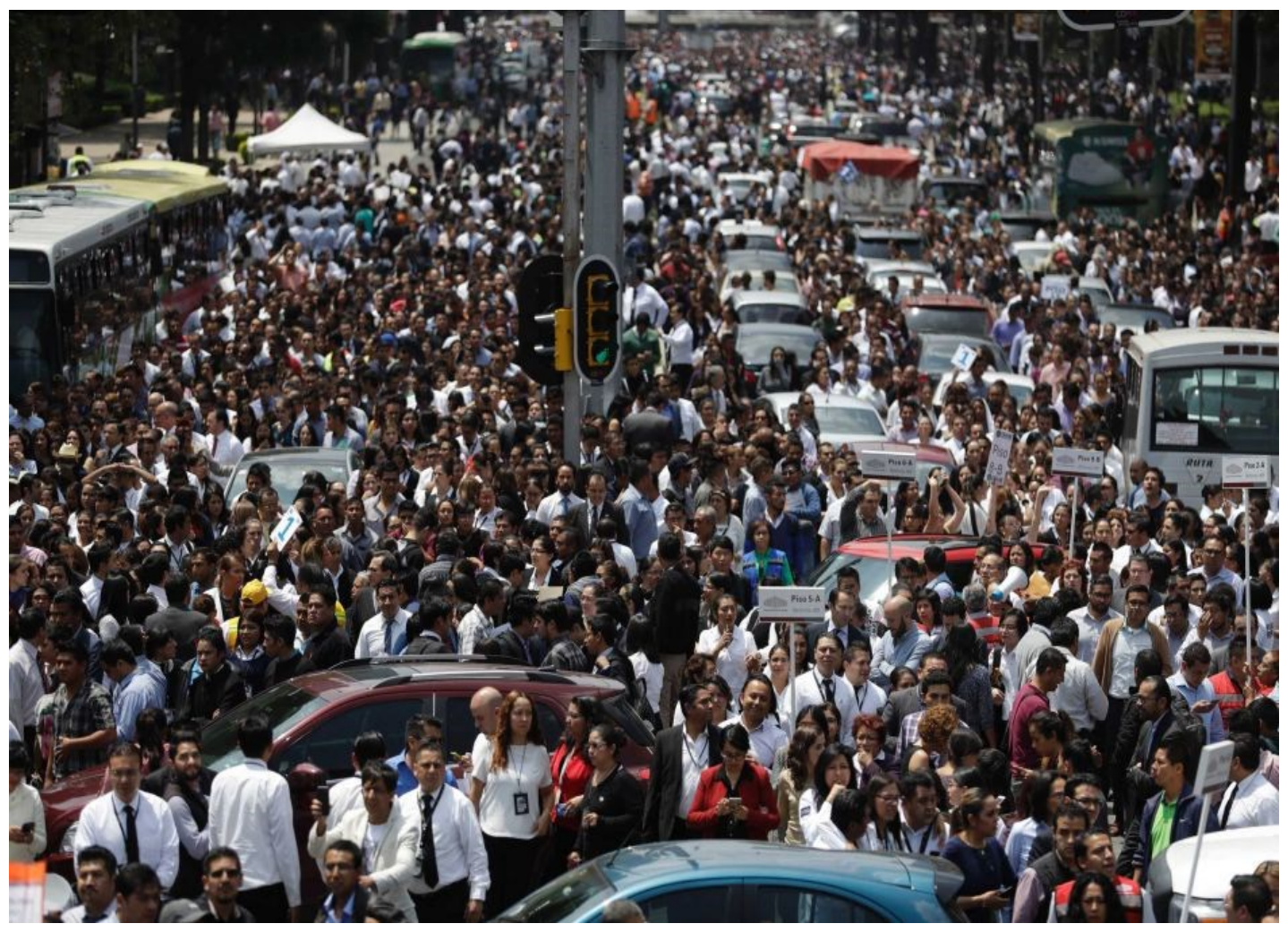

Figure 1-7: Street in Mexico after the 2017 Earthquake (Blackwell, 2017)

\subsection{Economic Impact from Failure of Suspended Ceilings}

Failure or poor performance of non-structural elements in earthquakes can lead to huge socio-economic losses after an earthquake. Non-structural elements make up approximately $60 \%$ of the costs of construction of a building, dependent on the type of structure (e.g., hospitals contain a much higher percentage of non-structural elements, which include medical equipment). 
Depending on the type and extent of failure of non-structural elements, the damage to nonstructural elements and their repair could significantly increase the recovery time of a building to become functional again after an earthquake, resulting in large additional losses for the owner. It is observed in a previous study that non-structural systems account for an estimated $78 \%$ of the total annual earthquake loss in the United States (Soroushian et al., 2016a). Figure 1-8 illustrates the comparison of the repair costs to a building and all its components after an earthquake. As shown, the majority of the repair costs is associated with non-structural elements (Takahashi \& Shiohara, 2004).

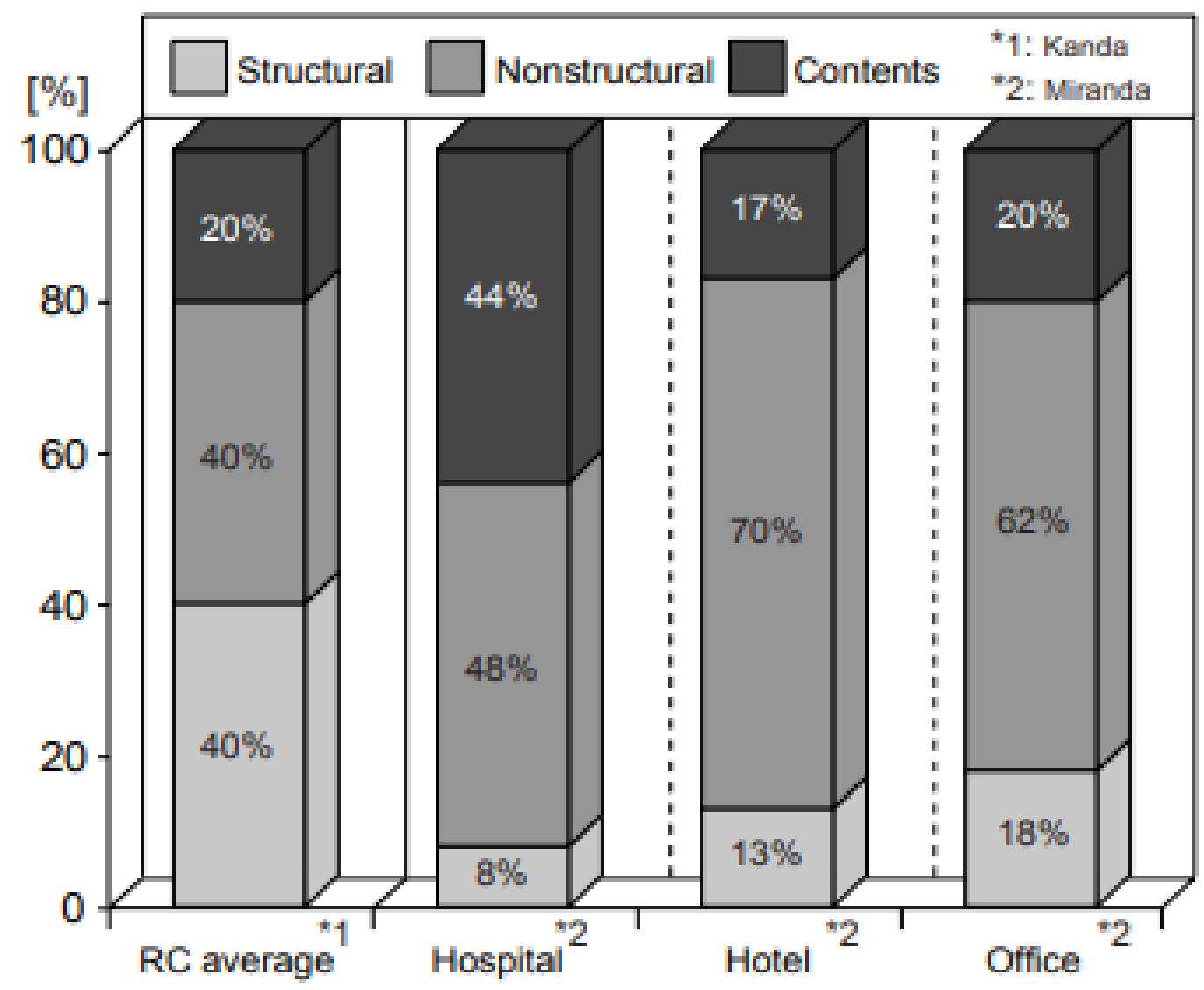

Figure 1-8: Repair Cost of Building Components after Seismic Event

(Takahashi et al., 2004) 


\subsection{Objectives of Research}

The first goal of this study is to gain insight into existing design procedures for suspended ceilings through review of existing literature and numerical modelling. The second goal is to prepare and design the research infrastructure required to test the seismic performance of suspended ceilings designed according to those procedures. These goals are accomplished through:

- State-of-the-art review of previous research on experimental testing and numerical modelling of suspended ceilings;

- Comparison of National Building Code of Canada versus International Building Code with respect to the seismic design force of suspended ceiling systems;

- Design of a test frame and other required assemblies for an experimental research program on the seismic behaviour and performance of suspended non-structural components (including suspended ceilings) using a new multi-unit mobile shake table system;

- Evaluation of the ICC-AC156 seismic test procedure for non-structural components;

- Nonlinear dynamic analysis of a sample ceiling frame test assembly to be able to predict the behaviour of future shake table test of suspended ceilings;

- Design a reconfigurable concrete block reaction wall for future testing of non-structural components. 


\section{Chapter 2: Literature Review}

\subsection{Progress of Experimental Testing}

A survey of literature shows that there have been very few reported studies on experimental testing on the seismic performance of suspended ceilings. Experimental research on suspended ceiling systems and ceiling components has slowly progressed since the 1980s. There have been studies investigating the failure mechanisms of suspended ceilings, the effects of size and boundary conditions and the capacities of the individual components. However, due to the nature of suspended ceilings and the high possible variability in the system configurations (Grid member type, perimeter attachment, panel size, etc.), there is still a lack of information on the performance of suspended ceilings during earthquakes. This chapter presents a summary of some of the experimental and numerical reported studies and their conclusions.

\subsection{Previous Experimental Studies}

\subsubsection{Shake Table Tests}

In 1983, ANCO Engineers Inc. conducted a shake table test on a suspended ceiling (Yao et al., 2000). The size of their tested system was $3.6 \mathrm{~m} \mathrm{x} 8.5 \mathrm{~m}$ which was made up of the typical $600 \mathrm{~mm} \times 1200 \mathrm{~mm}$ ceiling panels. The researchers tried to examine the effects of various restraints used in ceiling systems. They also examined the interaction of the suspended ceiling system with light fixtures. The strong ground motion record from the 1952 Taft earthquake (Yao et al., 2000) was used for the input excitation. The results from the test indicated that the use of splay wires and compression struts did not improve the dynamic response of the ceiling. The use of pop rivets was found to be more effective in improving seismic performance compared to splay 
wires. They also concluded that safety lines were an easy and feasible method to support drop-in light fixtures (Yao et al., 2000).

In 1984, Granneman et al. performed shake table tests to investigate the impact of partitions attached to suspended ceilings (Yao et al., 2000). The system was $3.66 \mathrm{~m} \mathrm{x} 4.88 \mathrm{~m}$ with typical $600 \mathrm{mmm}$ x $1200 \mathrm{~mm}$ ceiling panels. They used a uniaxial sinusoidal excitation input with a peak acceleration of $2.2 \mathrm{~g}$. The three main types of damage observed in the system were separation of cross-tees from main-tees, splice damage in the main-tees, and stretching of splay wires. The use of vertical struts was found to improve the uplift behaviour of the ceiling. These tests also demonstrated the effectiveness of splay wires with partial height partitions (Yao et al., 2000).

In 2000, Yao et al. (2000) performed a shake table analysis on a $1.2 \mathrm{~m} \mathrm{x} 4 \mathrm{~m}$ system using $600 \mathrm{~mm}$ x $600 \mathrm{~mm}$ ceiling panels. The ceiling had a suspension length of $1 \mathrm{~m}$. The results of the test were used to develop a numerical model that demonstrated the natural frequency of a suspended ceiling could be approximated as a pendulum with a frequency given by Equation 2.1.

$$
f=\frac{1}{2} \sqrt{(g / l)}
$$

This test used an incremental shock spectrum excitation specified in the Taiwanese Design Code for a hard rock site. This was input into the shake table as a uniaxial input motion in the long direction of the ceiling. In this study, the researchers followed up with previous studies to further investigate the effect of the 45-degree splay wires as prescribed by Ceilings \& Interior Systems Construction Association (CISCA) and the new installation standard of using hanging wires within $200 \mathrm{~mm}(8$ ") from the perimeter angle. The researchers also investigated the effect of transverse supports to prevent the main runners from spreading. Three conclusions were made from the results. Firstly, splay wires did not improve seismic performance as was also observed in previous 
studies. Secondly, adequate edge connectivity can increase the capacity of the system during an earthquake. Finally, transverse supports had a major influence on the seismic capacity of the ceiling by increasing the fragility acceleration from $0.91 \mathrm{~g}$ to $2.7 \mathrm{~g}$ (Yao et al., 2000).

In 2005, Ishioka et al. (2005) conducted shake table tests on Japanese suspended ceilings. They tested a metal furring ceiling using a $5.5 \mathrm{~m}$ x $5.5 \mathrm{~m}$ steel frame. The tested ceiling had a footprint of $2.7 \mathrm{~m} \times 5.0 \mathrm{~m}$. Input waveforms were scaled roof acceleration-response $(4 \%, 8 \%$, $12 \%, 16 \%, 20 \%, 32 \%$ of $g$ ) simulated using ground motions of the M6.7 Geiyo Earthquake in Japan. The tests were performed to observe the seismic performance of the Seismically Engineered Ceiling Clip (SECC) developed by the researcher. There are a couple of differences of the ceiling components used in Japanese ceilings as compared to ceilings commonly found in Canada. One of the differences is the use of a steel angle as a lateral brace instead of the compression post and splay wires used in Canadian ceilings. The findings of the study were that the proposed design performs much better than the conventional design (Ishioka et a., 2005).

In 2006, studies had been conducted at the University of Buffalo by Badillo-Almaraz et al. (2006). Badillo-Almaraz et al. performed shake table tests of ceiling assemblies at the University of Buffalo. The test frame used was $4.9 \mathrm{~m}$ x $4.9 \mathrm{~m}$ with fundamental frequencies of 17.5 Hz and $9.5 \mathrm{~Hz}$ in the horizontal and vertical directions, respectively. These tests investigated a variety of perimeter and panel configurations. The ceiling configurations considered in the tests include variations in the ceiling panel size. Normal-sized panels have plan dimensions within 6.35 $\mathrm{mm}(1 / 4 \mathrm{in})$ of the nominal dimensions, whereas undersized panels have dimensions that are smaller than the nominal panel dimensions in excess of the $6.35 \mathrm{~mm}$ tolerance. Badillo-Almaraz et al. (2006) tested the influence of retainer clips (panel hold down clips) on suspended ceiling performance. As noted in previous studies, retainer clips are often removed during maintenance 
and not properly replaced (Badillo-Almaraz et al., 2007). One issue with this testing is they used ICC-ES AC156 protocols to develop a Required Response Spectrum (RRS). Thus, the input motions used in the tests were floor response motions not ground motions. The test frame amplified these motions further by its dynamic deformations during tests due to its low stiffness in both the vertical and horizontal directions. The vertical frequency of the frame was $9.5 \mathrm{~Hz}(7.5 \mathrm{~Hz}$ with the ceiling) and a horizontal frequency of $19.5 \mathrm{~Hz}$ (Takhirov, 2009). Earthquake excitations were generated by using the spectrum matching procedure of the shake table control software STEX and scaled to match the target spectra over the frequency range of 1.3-33 Hz. The results showed that connections between members were more flexible than the member themselves. This characteristic led to the dislodging of panels. When hold down clips were implemented on the system to keep panels from dislodging, a failure in the grid members had a greater chance of developing at lower levels of shaking. Undersized tiles caused more damage to the ceiling system when subjected to vertical excitations compared to horizontal excitations with the extent of fallen panels observed during the tests. The failure of rivets at the supporting angle around the ceiling perimeter had a large impact on the seismic performance of the entire system. Removal of compression posts did not have a substantial effect on the observed seismic performance of the ceilings. Another conclusion was that the size of the panel greatly influenced how many panels were dislodged during tests (Badillo-Almaraz et al., 2007).

The other study at the University of Buffalo was performed by Gilani et al., (2010). The purpose of these tests was to observe the common failure mechanisms of the system along with their influence on the structure. For the test setup, the ceiling had a negligible effect on the fundamental frequency of the test frame in the horizontal direction. However, it was different in the vertical direction where it had a significant effect due to the added mass of the ceiling to the 
vertical dynamic mass of the test frame. It was observed in the tests that only panels near the middle of the system were dislodged during the tests. This result was not consistent with the damage observed in past earthquakes where ceiling damage occurred along the perimeter. As mentioned by the researchers, this variance could be due to the size effect of the ceiling in that the ceiling systems found in the field are typically larger than the tested systems. Further, based on the previous findings, it is recognized that further investigation is needed on the ceiling performance due to influences of the vertical flexibility of the supporting structural slab and the consideration of the ceiling location with respect to the building height in the generation of the RRS as input excitations to the ceilings. In the tests conducted by Gilani et al. (2010) the flexibility of the test frame caused vertical accelerations in the middle of the frame to reach $24 \mathrm{~g}$ for a $3 \mathrm{~g}$ input excitation. The tests were conducted with multi-directional input excitations, with a maximum spectral acceleration starting at $0.25 \mathrm{~g}$ and increasing to $3 \mathrm{~g}$ in increments of $0.25 \mathrm{~g}$. Simulated acceleration time histories were synthesized to match the ICC-ES AC156 RRS (Gilani et al., 2010).

In 2007, McCormick et al. (2007) performed full-scale shake table tests on suspended ceilings to investigate their interaction with partition walls. The test frame had a footprint of $4 \mathrm{~m}$ $\mathrm{x} 2 \mathrm{~m}$ with a height of $3.5 \mathrm{~m}$ and was tested using uniaxial input motions only. The results indicated that the seismically designed ceiling had $80 \%$ higher response accelerations compared to the traditional ceiling at high drift levels. This test was a preparation study for future tests at the EDefense shake table in Japan (Mccormick et al., 2008).

In 2010, Pentangelo et al. (2010) performed shake table tests on continuous plasterboard suspended ceilings. The test frame for these tests had a layout of $2.42 \mathrm{~m} \mathrm{x} 2.71 \mathrm{~m}$ with a height of $2.72 \mathrm{~m}$ above the shake table. This test frame was subjected to uniaxial horizontal accelerations. The test frame had a fundamental frequency of $30 \mathrm{~Hz}$. The input motions were scaled to the RRS 
of the ICC-ES AC156 with an $S_{D S}$ of $1.5 \mathrm{~g}$. Where $S_{D S}$ is the short period spectral acceleration as determined in Section 11.4.5 of the ASCE 7-16. The results from the tests indicated low fragility of the tested ceiling system as the ceiling suffered no damage at all input intensities (Pentangelo et al., 2010).

In 2011, Soroushian et al. (2011) performed testing on a suspended ceiling at the University of Nevada, Reno. A two-story steel braced frame with a footprint of $18.3 \mathrm{~m}$ x $3.66 \mathrm{~m}$ was used for seismic testing. The test frame was placed upon three biaxial shake tables. The frame had a fundamental frequency of $4.5 \mathrm{~Hz}$. Artificial ground motions that matched ICC-AC156 RRS were used as excitations for the tests with compensation procedures to achieve the target motion in the frame. The test results were correlated with the test results from E-Defense and the University of Buffalo. The conclusions from these tests indicated that the component amplification factor $A_{p}$ of 2.5 was unconservative in both the horizontal and vertical directions. The test results showed a median amplification of 3.8 in the ceiling members with respect to the test frame columns. The tests indicated that for ceilings with a $22 \mathrm{~mm}(7 / 8$ ") wall moulding, very low shake intensities could cause unseating failure (Soroushian et al., 2016).

In 2012, Ryu et al. (2012) conducted shake table testing on two different test frames. The first test frame had a footprint of $6.3 \mathrm{~m}$ x $6.3 \mathrm{~m}$. The second frame used two $6.3 \mathrm{~m} \times 6.3 \mathrm{~m}$ frames with a link of $6.3 \mathrm{~m} \times 3.9 \mathrm{~m}$ creating a total footprint of $16.5 \mathrm{~m}$ x $6.3 \mathrm{~m}$. The $6.3 \mathrm{~m} \times 6.3 \mathrm{~m}$ smaller test frame had modal frequencies of $11.3 \mathrm{~Hz}$ horizontally and $22.0 \mathrm{~Hz}$ vertically. The goal of this research was to identify failure mechanisms and investigate the effects of various systems. The shake table control software STEX was used to generate time histories that matched the ICC-ES AC156 RRS with an open-loop compensation to adjust for amplification due to the frame's flexibility. The results from the test concluded that ceiling systems were more vulnerable to three- 
directional inputs compared to one or two-directional input excitations. Also, the weight and size of the system directly impacted the probability of system failure (Ryu et al., 2012).

In 2012, another study performed by Soroushian et al. (2012) used two and threedirectional excitations on a five-storey steel frame with both base-isolated and base-fixed configurations. The input excitations were from recorded earthquake ground motion (e.g., Northridge 1994). This research aimed to investigate more into the seismic performance of sprinkler systems, however, suspended ceilings were also considered in this experiment. The results of this experiment followed that of previous tests. The findings showed that lateral bracing did not improve seismic performance and sprinkler heads caused considerable damage to ceiling panels (Soroushian et al., 2012).

In 2016, Lu et al. (2016) performed shake table tests on typical Chinese ceilings. The differences between Chinese ceilings and North American ceilings are, Chinese ceilings use $8 \mathrm{~mm}$ hanger rods and metal $\mathrm{U}$ bars as main runners (Main $\mathrm{T}$ in Figure 1-1) whereas, North American ceilings use hanging wires and T-Beams. A three-storey test frame was used with a storey height of $1.5 \mathrm{~m}$ and a footprint of $4 \mathrm{~m} \times 4 \mathrm{~m}$. The frame had a horizontal fundamental frequency of 25.1 $\mathrm{Hz}$ and a vertical frequency of $25.0 \mathrm{~Hz}, 7.4 \mathrm{~Hz}$, and $8.4 \mathrm{~Hz}$ for stories 1,2,3, respectively. As per the Building Seismic Design Code in China, two strong-motion records and one artificial acceleration time history were used as input accelerations. Conclusions from the results indicated that the $A_{p}$ factor of 2.5 is low for the vertical direction. The ceilings supported by the $8.4 \mathrm{~Hz}$ and 7.4 Hz floor had $8 \%$ and $33 \%$ amplification above the design factor of 2.5 (Lu et al., 2018).

In 2016, another study was also performed in China by Wang et al. (2016) to investigate the damage observed during the Lushan Earthquake with shake table testing. The setup consisted of a single storey reinforced concrete frame $(3.9 \mathrm{~m} \times 3.9 \mathrm{~m})$ with a $3.1 \mathrm{~m} \times 3.7 \mathrm{~m}$ suspended 
ceiling. The input to the shake table was a three-dimensional ground motion record of the 2008 Wenchuan earthquake with a peak ground acceleration horizontally of $1.10 \mathrm{~g}$. The response spectra of the shake table motions differed significantly from the ICC-ES AC156 RRS in terms of frequency content and the ratio of vertical and horizontal motions. These tests did produce similar damage to that observed from the Lushan Earthquake; however, there were some discrepancies with previous shake table studies that resulted in lower fragility curves. The reasons behind the discrepancy are due to the scale of the specimen and the measured roof spectrum significantly varying from the required roof spectrum outlined in ICC-ES AC156 (Wang et al., 2016).

In 2017, Pourali et al. (2017) performed full-scale experimental testing on a fully floating suspended ceiling system. The test frame allowed for a $2.15 \mathrm{~m} \times 4.55 \mathrm{~m}$ floating ceiling. The ceiling was composed of $600 \mathrm{~mm} \times 1200 \mathrm{~mm}$ ceiling panels. The typical ceiling space located in between the suspended ceiling and the structural ceiling above, known as the plenum depth, was found to range between $200 \mathrm{~mm}$ to $500 \mathrm{~mm}$. Uniaxial excitations were used as input motions for the shake table. The test frame used had a natural frequency of $12.5 \mathrm{~Hz}$ with a size of $2.6 \mathrm{~m}$ high and a footprint of $5.2 \mathrm{~m} \times 2.65 \mathrm{~m}$. The test results demonstrated that the response of the ceiling behaved like a simple pendulum. Results also showed that adding mass to the ceiling did not have a significant impact on the peak displacement. The added mass, however, did result in smaller grid accelerations due to less sliding and vibrations in the tiles (Pourali et al., 2017).

\subsubsection{Testing of Individual Components}

Dhakel et al. (2016) performed both tension, compression, and shear tests on the main components of a ceiling system and their connections. These tests were used to investigate the ultimate strength of the components and generate fragility curves. The tests results showed that in 
both tension and compression, cross-tee connections were the weakest part of the ceiling system.

The tests also showed that all components except for main runner splices were weaker in compression than in tension. The tests concluded that connections would fail before the member reached its capacity causing failure of the system before reaching the design load of the ceilings. A limitation as mentioned in the study was that the design standard in New Zealand had no specific provisions for testing of suspended ceiling components and connections (Dhakal et al., 2016).

Soroushian et al. (2016a) performed monotonic and cyclic tests on cross-tee joints to investigate the axial stiffness and strength. These tests were used to generate fragility curves and the test data were used to define a nonlinear element using OpenSees software to model the crosstee connection joint. Another study was done on the perimeter attachments of a ceiling system. Three types of attachments were tested using monotonic and cyclic loading which included pop rivets, seismic clips and seismic clips attached to the partition with a screw. The tests concluded that a perimeter seismic clip without a screw in the partition had the least capacity with respect to tension and compression. The seismic clip with the screw in the partition had the highest capacity. The pop rivet had comparable tension capacity with the screw attached seismic clip; however, it only had about half of the capacity in compression (Soroushian et al., 2016b).

\subsection{Numerical Models}

There have been very few reported studies on numerical modelling of suspended ceiling systems. Because of the variations of suspended ceiling systems, it is difficult to model all the separate components and their influences on the collapse behaviour of the system. 
Yao et al. (2000) developed a numerical model using SAP2000. This model only included elastic elements using frame elements for the runners, cable elements for the hanging wires, roller supports for the perimeter angle and the panels were represented as a lumped mass. This model was verified with experimental testing and it was concluded that a ceiling with no sway bracing would have a fundamental frequency similar to that of a pendulum's frequency with equivalent mass and length. Using the numerical model, it was found the analytical results in peak frequencies of the suspended ceiling system without sway wires were very similar to the observed experimental results. The peak responses in the tests were found to be lower than the analytical predictions. This was attributed to the damping ratio of $5 \%$ assumed in the analytical model, which after further study appeared to be less than that of the experimental system (Yao et al., 2000).

Ryu et al. (2012) developed a linear numerical model of suspended ceiling to verify their experimental results. The suspended ceiling was modelled as a unidirectional simplified system and the equation of motion was solved using MATLAB. The researcher developed a model for the vibration responses of a main-tee ceiling component in both the longitudinal and transverse directions. For the longitudinal direction, the model was constructed as multiple pendulums in series with springs representing splices and pop rivets. They used an equivalent damping ratio of $30 \%$. The model in the longitudinal direction produced similar results to the experimental tests until the pop-rivet in the numerical model of the test ceiling failed causing the frequency of the system to change. Upon failure of the pop-rivets, the numerical model experienced larger displacements in the system than the observed test results. In the transverse direction, the main-tee was modelled as a beam pinned at both ends with additional support springs representing the horizontal restraints. The results of the analytical model correlated well with the experimental test results in maximum displacement and vibration responses of the system (Ryu et al., 2012). 
Badillo-Almaraz et al. (2007) developed a numerical model also using SAP2000. This model used elastic beam elements to represent the main-tees and cross-tees. Main-tee beams were modelled as continuous whereas cross-tee beams were pinned at both ends. The panels were modelled using very stiff beams to create an $\mathrm{x}$-shape with a lumped translational-rotational mass at the center using $5.1 \mathrm{~kg} / \mathrm{m}^{2}$ to match that used in experimental testing at the University of Buffalo (Badillo-Almaraz et al., 2007). The 12-gauge wire hanger and splay wires were modelled using a hook-link element with a determined stiffness of $33.7 \mathrm{~N} / \mathrm{mm}$ and $26.7 \mathrm{~N} / \mathrm{mm}$ respectively in two directions to only resist tensile loads. The compression posts were represented by channel frames with the appropriate cross-sectional properties. The splices in the members were modelled by Linear Links. For the main-tees, the degrees-of-freedom of the splice links were fully fixed in all directions with the exception of using a stiffness of $6.2 \mathrm{~N}-\mathrm{m} / \mathrm{rad}$ for the vertical and lateral rotations. The same modelling parameters and assumptions were also applied to the modelling of the cross-tee links. The boundary conditions of the ceiling panels and the gaps between the panels and the supporting tees were represented by horizontal T/C (Tension and Compression) Friction Isolator Links with a calculated $3.2 \mathrm{~mm}$ gap between the panel and the tee beams with a horizontal coefficient of friction of 0.5 . The T/C link allows the researcher to model a gap in either tension or compression direction to allow for bilinear stiffness behaviour before and after the gap closes. In the case of a panel sliding there is friction of the panel on the grid member represented by a stiffness value and the gap is set to the distance between the edge of the panel and the center of the grid member. Therefore, when the panel slides and contacts the grid member, the stiffness becomes higher to represent the impact of the panel on the member. To capture the effect when a panel lifts off the tee and comes in contact with the wider portion of the tee beam located at the top of the web, the vertical coefficient of friction between the panel and the tee beam was increased to 1.0. 
The boundary conditions on a free side were modelled as a T/C (Tension and Compression) Friction Isolator Link with a gap of $9.5 \mathrm{~mm}$ and $19.1 \mathrm{~mm}$ for unbraced and braced systems, respectively. The perimeter sides of the ceiling fixed by rivets were modelled by fixing the vertical degree-of-freedom but allowed to move relative with the support tees in the horizontal direction with a coefficient of friction of 0.5 . The numerical model also included a supporting floor deck constructed of a composite steel deck supported on a steel beam. A sensitivity analysis was conducted to determine the influences of the friction coefficient values, tile weight and supporting deck frequency on the behaviour of the ceiling system. Natural floor frequencies ranging from 2.6 $\mathrm{Hz}$ to $18.4 \mathrm{~Hz}$ were considered (Ryu et al., 2009). It was demonstrated that the fragility curves generated by using the model were good representation of the dynamic response behaviour of the suspended ceiling system. Input motions consisted of twenty-four artificial horizontal and vertical records generated using the earthquake ground motion program SIMQKE. The acceleration spectra were generated using ICC-ES AC156 with a height ratio factor of 0.5 to represent floor accelerations at mid-height of a structure. Chapter 23 of ASCE 7-05 was used to convert horizontal to vertical motions with the vertical coefficient $C_{v}$. The records were then filtered using the $4^{\text {th }}$ order Low Pass Butterworth filter and a baseline correction was applied. The horizontal acceleration records that were used as input motions for the model had peak floor accelerations (PFA) ranging from $0.5 \mathrm{~g}$ to $2.8 \mathrm{~g}$. Rayleigh damping of $2 \%$ was applied to the vibration modes of $6 \mathrm{~Hz}$ and $15 \mathrm{~Hz}$. The model was used to develop fragility curves of two differently sized systems under both braced and unbraced conditions. The conclusion from this study was that unbraced ceilings had a higher probability of damage due to unseating of the t-beams at the perimeter angle. Also, braced systems induced tiles to uplift at lower acceleration excitations. Finally, a larger system was found to be less likely to experience panel dislodgement compared to a smaller system; 
however, the larger system is more likely to experience unseating of the grid members on the perimeter angle. The model did not include the non-linear characteristics of the ceiling components. The other limitation as mentioned in the study was the inability of the model to capture the progressive collapse behaviour of the system (Badillo-Almaraz et al., 2007).

Soroushian et al. (2016) performed testing to evaluate the non-linear axial behaviour of cross-tee joints to develop a detailed numerical model to represent this behaviour. The joints were tested in both monotonic and reverse cyclic tests to generate fragility curves and to verify the numerical results. The researcher discussed the limitations of the experiment which might have affected the results. Such limitations included the absence of ceiling panels, the boundary conditions, and the member alignments. Opensees was the analysis software used to model the hysteretic behaviour of the joints. This was done by assigning a uniaxial material "Pinching4" to a zero-length element. A sensitivity analysis was performed to determine all 39 parameters. This analysis was limited to keeping the maximum cumulative hysteresis energy within $10 \%$ of the experimental results. During the study, it was found that 23 parameters were independent and could be set to a constant value. For the simplicity of adding this element into future system models, a generic model was produced to avoid accounting for all the small discrepancies in each test (Soroushian et al., 2016a).

An OpenSees model of suspended ceiling was developed by Zaghi et al. (2016). The method of modelling the ceiling system consisted of the following elements. To model the acoustic ceiling tile the researcher tried two methods, one of which was a shell element (ShellMITC4) and the other an X-shaped assembly made of twoNodeLink elements connecting corner joints to the center joint. The $\mathrm{X}$-shaped assembly was chosen for the model as it was less computationally expensive. The zeroLengthImpact3D element was developed and used to model the interaction of 
the tile on the tee beams. The authors use a coefficient of friction of 0.5 . The model was found to be very sensitive to the coefficient of friction and as such the value of 0.5 was chosen to validate their experimental results. Main runners and cross-tees were modelled using forceBeamColumn elements with zerolength elements used to model the joints. Hanging wires were also modelled by forceBeamColumn elements with the P-Delta effect using a $10 \%$ effective moment of inertia. Splay wires were modelled by truss elements with tension only ElasticPPGap material. Compression posts were modelled using truss element with a hollow section. The zeroLengthImpact3D was used to model the boundary conditions with their associated gap widths and the same friction coefficient as used previously. The fixed side was modelled using the ElasticPPGap to model the rivets. The analytical model was validated using the experimental results of a five storey structure (Soroushian et al., 2012). The analytical model was found to overestimate the failure of ceiling panels but was good at predicting the locations of panel failure (Zaghi et al., 2016).

Both Jiang et al. (2015) and Soroushian et al. (2010) have developed direct spectra-tospectra methods for estimating the response of non-structural components in nuclear power structures. These methods are very complex. Kasai et al. (2016) developed a more efficient simplified procedure for predicting the maximum response of non-structural components based on the vibration of the building structures excitation input. This model considers both the effects of the frequency content as well as the ground motion duration. This method does not require timehistory analysis, just mode shapes, modal frequencies, damping ratios and ground response spectra. 


\subsection{Summary of Previous Research}

Over the last 40 years, there has been a significant progression in evaluating the seismic performance of suspended ceilings. The majority of previous tests used acceleration time histories scaled to the RRS from the ICC-ES AC156. As will be discussed in chapter six, suspended ceilings do not meet the requirements of the AC156 test standard because the assumptions on testing conditions are different. It was observed that the approximate average maximum ceiling size in all previous shake table tests was found to be $27.1 \mathrm{~m}^{2}\left(291.7 \mathrm{ft}^{2}\right)$. A summary of all previous shake table tests discussed in this chapter is presented in Table 2-1.

In terms of numerical modelling, three full system models have been developed by previous researchers. Two models were developed with SAP2000, both only using elastic material properties. One non-linear model was developed using Opensees. All these models were incapable of modelling the progressive collapse of suspended ceilings during earthquakes. The model was accurate in modelling the load stage at which damage was initiated; however, it was much less accurate in predicting damage propagation.

Previous researchers have demonstrated that there are still many uncertainties with the seismic performance and in the provisions of design codes of suspended ceilings. This is due to the high degree of variations in these systems and accuracy and applicability issues with the current ICC-ES AC156 test standard that is discussed in Chapter 6. The suspended ceiling tests that will be conducted at Carleton University will allow further research into the seismic performance of suspended ceilings with a focus on the effect of variation of boundary conditions and input excitations including vertical and rotational input motions. The OpenSees model will be correlated with the experimental test results to produce a model that is computationally inexpensive which can be used by consulting and design engineers relatively easy to verify their design. 
Table 2-1 Summary of Previous Shake Table Experiments

\begin{tabular}{|c|c|c|c|c|c|c|}
\hline Year & Location & $\begin{array}{c}\text { Table } \\
\text { Size/Panel Size }\end{array}$ & Input & $\begin{array}{l}\text { Parameters } \\
\text { Tested }\end{array}$ & $\begin{array}{c}\text { Frame } \\
\text { Characteristics }\end{array}$ & Conclusions \\
\hline 1983 & $\begin{array}{c}\text { USA, } \\
\text { ANCO Seismic } \\
\text { Laboratory }\end{array}$ & $\begin{array}{c}3.6 \mathrm{~m} \mathrm{x} 8.5 \mathrm{~m} \\
(600 \mathrm{~mm} \\
\times 1200 \mathrm{~mm} \\
\text { panels })\end{array}$ & $\begin{array}{c}\text { Triaxial } \\
1952 \text { Taft Ground } \\
\text { Motions }\end{array}$ & $\begin{array}{c}\text { Splay Wires } \\
\text { Light Fixtures }\end{array}$ & $\begin{array}{l}\text { Matched Vertical } \\
\text { to represent floor } \\
\text { stiffness } \\
\text { Horizontal very } \\
\text { stiff }\end{array}$ & $\begin{array}{l}\text { Splay wires do not improve } \\
\text { seismic performance, }\end{array}$ \\
\hline 1984 & $\begin{array}{c}\text { USA } \\
\text { California } \\
\text { Polytechnic State } \\
\text { University }\end{array}$ & $\begin{array}{c}3.6 \mathrm{~m} \times 4.8 \mathrm{~m} \\
(600 \mathrm{~mm} \\
\times 1200 \mathrm{~mm} \\
\text { panels })\end{array}$ & $\begin{array}{c}\text { Uniaxial } \\
\underset{\text { pinusoidal }}{2.2 \mathrm{~g}}\end{array}$ & $\begin{array}{l}\text { Partial Height } \\
\text { Partitions } \\
\text { Vertical Struts }\end{array}$ & $\mathrm{N} / \mathrm{A}$ & Vertical Struts reduce uplift \\
\hline 2000 & Taiwan & $\begin{array}{c}1.2 \mathrm{~m} \mathrm{x} 4.0 \mathrm{~m} \\
(600 \mathrm{~mm} \times \\
600 \mathrm{~mm} \text { panels }) \\
\text { Hanging Length } \\
1 \mathrm{~m}\end{array}$ & $\begin{array}{c}\text { Uniaxial } \\
\text { Time history } \\
\text { generated from } \\
\text { Taiwanese } \\
\text { Response } \\
\text { Spectrum }\end{array}$ & $\begin{array}{l}\text { Splay Wires, } \\
\text { Lateral } \\
\text { Restraints }\end{array}$ & $\begin{array}{c}\text { Frequency of } \\
24.8 \mathrm{~Hz} \\
\text { horizontal }\end{array}$ & $\begin{array}{l}\text { Splay wires do not improve } \\
\text { seismic performance; } \\
\text { Fragility acceleration } \\
\text { increased from } 0.9 \mathrm{~g} \text { to } 2.7 \mathrm{~g} \\
\text { with the use of lateral } \\
\text { restraints. }\end{array}$ \\
\hline 2005 & Japan & $\begin{array}{c}5.5 \mathrm{~m} \times 5.5 \mathrm{~m} \\
\text { Frame } \\
5.0 \mathrm{~m} \times 2.7 \mathrm{~m} \\
\text { Ceiling Size }\end{array}$ & $\begin{array}{c}\text { Triaxial Input } \\
\text { Scaled time } \\
\text { histories from } \\
\text { Geyio Earthquake }\end{array}$ & $\begin{array}{l}\text { Proposed } \\
\text { Seismically } \\
\text { Engineered } \\
\text { Ceiling Clip }\end{array}$ & $\mathrm{N} / \mathrm{A}$ & $\begin{array}{l}\text { Proposed solution } \\
\text { significantly improves } \\
\text { seismic performance }\end{array}$ \\
\hline
\end{tabular}




\begin{tabular}{|c|c|c|c|c|c|c|}
\hline 2006 & $\begin{array}{l}\text { USA } \\
\text { University of } \\
\text { Buffalo }\end{array}$ & $4.88 \mathrm{~m} \mathrm{x} 4.88 \mathrm{~m}$ & $\begin{array}{c}\text { Triaxial } \\
\text { Time histories } \\
\text { synthesized to } \\
\text { match the RRS of } \\
\text { the AC156. }\end{array}$ & $\begin{array}{c}\text { Panel Size } \\
\text { Compression } \\
\text { Posts } \\
\text { Retainer Clips }\end{array}$ & $\begin{array}{l}17 \mathrm{~Hz} \text { Horizontal } \\
9.5 \mathrm{~Hz} \text { Vertical }\end{array}$ & $\begin{array}{c}\text { Compression posts have } \\
\text { minor effect on seismic } \\
\text { performance }\end{array}$ \\
\hline 2007 & Japan & $4 \mathrm{~m} \times 2 \mathrm{~m}$ & Uniaxial & Japanese Ceiling & $\mathrm{N} / \mathrm{A}$ & $\begin{array}{l}\text { Preliminary Results for E- } \\
\text { Defense Tests }\end{array}$ \\
\hline 2010 & $\begin{array}{l}\text { Italy } \\
\text { University of } \\
\text { Naples }\end{array}$ & $2.71 \mathrm{~m} \mathrm{x} 2.42 \mathrm{~m}$ & Uniaxial & $\begin{array}{l}\text { Continuous } \\
\text { Plasterboard } \\
\text { Ceiling }\end{array}$ & $30 \mathrm{~Hz}$ Horizontal & $\begin{array}{l}\text { Continuous ceiling performs } \\
\text { significantly better than } \\
\text { typical panel ceiling }\end{array}$ \\
\hline 2011 & $\begin{array}{l}\text { USA } \\
\text { University of } \\
\text { Nevada }\end{array}$ & $18.3 \mathrm{~m} \mathrm{x} 3.66 \mathrm{~m}$ & $\begin{array}{l}\text { Uniaxial } \\
\text { Simulated Time } \\
\text { History Scaled to } \\
\text { RRS of ICC- } \\
\text { AC156 }\end{array}$ & $\begin{array}{c}\text { Seismic } \\
\text { Performance }\end{array}$ & 4.5 Hz Horizontal & $\begin{array}{c}\text { Ap component factor of } 2.5 \text { is } \\
\text { un-conservative }\end{array}$ \\
\hline 2012 & $\begin{array}{l}\text { USA } \\
\text { University of } \\
\text { Buffalo }\end{array}$ & $\begin{array}{l}6.3 \mathrm{~m} \times 6.3 \mathrm{~m} \\
16.5 \mathrm{~m} \times 6.3 \mathrm{~m}\end{array}$ & $\begin{array}{c}\text { Triaxial } \\
\text { Simulated Time } \\
\text { History Scaled to } \\
\text { RRS of ICC- } \\
\text { AC156 }\end{array}$ & $\begin{array}{c}\text { Various System } \\
\text { Configurations } \\
\& \\
\text { Failure } \\
\text { Mechanisms }\end{array}$ & $\begin{array}{c}11.3 \mathrm{~Hz} \\
\text { Horizontal } \\
22 \mathrm{~Hz} \text { Vertical }\end{array}$ & $\begin{array}{l}\text { Ceilings more vulnerable to } \\
\text { three-directional input } \\
\text { Mass and size of the ceiling } \\
\text { directly affected probability } \\
\text { of failure }\end{array}$ \\
\hline 2012 & $\begin{array}{c}\text { Japan } \\
\text { E-Defense }\end{array}$ & $\begin{array}{l}5 \text { Storey } \\
\text { moment } \\
\text { resisting steel } \\
\text { frame building }\end{array}$ & $\begin{array}{l}\text { Triaxial Ground } \\
\text { Motions from } \\
1994 \text { Northridge } \\
\text { Earthquake }\end{array}$ & $\begin{array}{l}\text { Ceiling } \\
\text { interaction with } \\
\text { Sprinkler } \\
\text { Systems }\end{array}$ & $\mathrm{N} / \mathrm{A}$ & $\begin{array}{l}\text { Lateral Bracing does not } \\
\text { improve seismic performance } \\
\text { Sprinkler heads caused major } \\
\text { damage to ceiling panels. }\end{array}$ \\
\hline
\end{tabular}




\begin{tabular}{|c|c|c|c|c|c|c|}
\hline 2016 & $\begin{array}{c}\text { China } \\
\text { IEM Laboratory }\end{array}$ & $\begin{array}{c}4.0 \mathrm{~m} \text { x } 4.0 \mathrm{~m} . \\
3 \text { Storey Steel } \\
\text { Frame }\end{array}$ & $\begin{array}{c}\text { Two Strong } \\
\text { Ground Motion } \\
\text { Records and one } \\
\text { simulated time } \\
\text { history }\end{array}$ & $\begin{array}{l}\text { Chinese Ceiling } \\
\text { performance } \\
\text { when attached } \\
\text { to rigid and } \\
\text { flexible } \\
\text { structures. }\end{array}$ & $\begin{array}{c}25.1 \mathrm{~Hz} \\
\text { Horizontal } \\
\text { Vertical } \\
1^{\text {st }} \text { Storey: } 25 \mathrm{~Hz} \\
2^{\text {nd }} \text { Storey: } 7.4 \mathrm{~Hz} \\
3^{\text {rd }} \text { Storey: } 8.4 \mathrm{~Hz}\end{array}$ & $\begin{array}{c}\text { Ap component factor of } 2.5 \text { is } \\
\text { un-conservative }\end{array}$ \\
\hline 2016 & $\begin{array}{c}\text { China } \\
\text { China Earthquake } \\
\text { Administration } \\
\text { Laboratory of } \\
\text { Earthquake } \\
\text { Engineering }\end{array}$ & $\begin{array}{c}3.9 \mathrm{~m} \times 3.9 \mathrm{~m} \\
\text { Reinforced } \\
\text { Concrete Frame } \\
3.1 \mathrm{~m} \times 3.7 \mathrm{~m} \\
\text { Ceiling }\end{array}$ & $\begin{array}{l}\text { Triaxial } 2008 \\
\text { Wenchuan } \\
\text { Earthquake } \\
\text { Records }\end{array}$ & $\begin{array}{l}\text { Chinese Ceiling } \\
\text { subjected to } \\
\text { Wenchuan } \\
\text { Earthquake }\end{array}$ & N/A & $\begin{array}{c}\text { Ceiling damage replicated } \\
\text { that seen after the Lushan } \\
\text { Earthquake }\end{array}$ \\
\hline 2017 & $\begin{array}{l}\text { New Zealand } \\
\text { University of } \\
\text { Canterbury }\end{array}$ & $\begin{array}{c}5.2 \mathrm{~m} \times 2.65 \mathrm{~m} \\
\text { Steel Frame } \\
4.55 \mathrm{~m} \times 2.15 \mathrm{~m} \\
\text { Ceiling }\end{array}$ & $\begin{array}{c}\text { Uniaxial } \\
\text { Simulated Time } \\
\text { History Scaled to } \\
\text { RRS of ICC- } \\
\text { AC156 }\end{array}$ & $\begin{array}{l}\text { Performance of } \\
\text { a fully floating } \\
\text { ceiling }\end{array}$ & $\begin{array}{c}12.5 \mathrm{~Hz} \\
\text { Horizontal }\end{array}$ & $\begin{array}{l}\text { Added mass reduced grid } \\
\text { accelerations } \\
\text { Results consistent with } \\
\text { simple pendulum theory }\end{array}$ \\
\hline
\end{tabular}




\section{Chapter 3: Design Standards and Current Practices}

\subsection{Current Installation and Design Standards}

This chapter summarizes the key installation and design standards for suspended ceiling systems used in North America. The chapter also investigates the difference between the National Building Code of Canada and the International Building Code. A proposed design force is presented to compare with the experimental results from the future suspended ceiling shake table testing at Carleton University.

\subsection{Standards of Installation}

Suspended ceilings in North America are installed in accordance to the "Standard Practice for Installation of Metal Ceiling Suspension Systems of Acoustical Tile and Lay-in Panels" under the designation ASTM C636 design standard (ASTM, 1996). In these standards, suspended ceilings are classified into three categories based upon the seismic risk. Category A and B are ceilings located in areas where seismic design is not required and therefore are designed only for gravity forces. Category $\mathrm{C}$ is the lowest category of seismic design which is applicable to ceilings with a maximum weight of $120 \mathrm{~N} / \mathrm{m}^{2}\left(2.5 \mathrm{lbs} / \mathrm{ft}^{2}\right)$ and based on the seismic risk of target building. Finally, Category D, E, F are for heavy ceilings in areas of high seismic risk. For all categories except category A and B, installation requirements are outlined within the "Standard Practice for Installation of Metal Ceiling Suspension Systems of Acoustical Tile and Lay-in Panels in Areas Subject to Ground Motions" issued under the designation ASTM E580 (ASTM, 2010). The standard ASTM C636 provides the basic requirements required for the installation of all ceiling 
categories whereas, ASTM E580 provides additional guidelines and requirements for ceiling systems to withstand seismic forces.

Table 3-1 Summary of Installation Standards

\begin{tabular}{|l|c|c|}
\hline & $\begin{array}{c}\text { Category C } \\
\text { (Average Ceiling } \\
\text { Weight } \leq 2.5 \mathrm{psf})\end{array}$ & $\begin{array}{c}\text { Category D/E/F } \\
\text { Category C } \\
\text { (Average Ceiling } \\
\text { Weight } \geq 2.5 \mathrm{psf})\end{array}$ \\
\hline $\begin{array}{l}\text { Minimum Ultimate Load of Main } \\
\text { and Cross Runners and splices }\end{array}$ & $60 \mathrm{lb}$ & $180 \mathrm{lb}$ \\
\hline Perimeter Angle & & \\
\hline Perimeter Attachment & None & 2 in \\
\hline $\begin{array}{l}\text { Hanger Wire } \\
\text { (within } 200 \text { mm (8 in) from wall) }\end{array}$ & $\begin{array}{c}\text { Angle is less than } \\
7 / 8 \text { in }\end{array}$ & $\begin{array}{c}\text { Pop rivets two adjacent } \\
\text { sides }\end{array}$ \\
\hline (within 200 mm (8 in) from wall) & $3 / 8$ in & 3/4 in \\
\hline Clearance on unattached sides & All sides & Unattached Sides \\
\hline
\end{tabular}

\subsubsection{ASTM C636 Standard}

The ASTM C636 standard provides installation guidelines for all suspended ceilings. This standard requires the following:

- Hanging wires to be minimum 12-gauge and to be located on main runners at a maximum spacing of $1200 \mathrm{~mm}(4 \mathrm{ft})$ on center. 
- The main runners are required to be level within a tolerance limit of $6.4 \mathrm{~mm}$ in a distance of $3050 \mathrm{~mm}(1 / 4$ in over $10 \mathrm{ft})$.

- Cross runners are required to be located within $0.79 \mathrm{~mm}(1 / 32 \mathrm{in})$ of the center distance.

\subsubsection{ASTM E580 Standard (Section 1.4 and Section 1.6)}

Ceilings of size equal to or less than $13.4 \mathrm{~m}^{2}\left(144 \mathrm{ft}^{2}\right)$ and surrounded by walls connected to the structure above are exempt from requirements of this practice outlined below. Ceiling systems equal to or less than $92.9 \mathrm{~m}^{2}\left(1000 \mathrm{ft}^{2}\right)$ are exempt from lateral force bracing requirements as specified in section 5.2.8 of ASTM E580, which include providing a compression post and four diagonal splay wires to resist seismic forces.

\subsubsection{Free Floating Suspended Ceilings (Section 1.8)}

A ceiling that is not connected to any walls is designed to resist a seismic force equal to 1.4 times its vertical weight. The connection of a free-floating suspended ceiling is designed to accommodate full 360-degree range of movement in the horizontal direction with consideration of any potential interaction with other non-structural components nearby.

\subsubsection{Category $C$}

As summarized in Figure 3-1 above, Category $\mathrm{C}$ ceilings includes ceiling systems with an average maximum weight of $120 \mathrm{~N} / \mathrm{m}^{2}\left(2.5 \mathrm{lbs} / \mathrm{ft}^{2}\right)$. Ceilings with average weight above $120 \mathrm{~N} / \mathrm{m}^{2}$ $\left(2.5 \mathrm{lbs} / \mathrm{ft}^{2}\right)$ are to be installed as per Section 5 of the standard ASTM E580 while still adhering to 
the design force requirement for Category $\mathrm{C}$ ceilings. The main and cross runners along with their splices and connectors must be able to resist a minimum ultimate load of $27 \mathrm{~kg}(60 \mathrm{lb})$ in both tension and compression. This includes a 5-degree misalignment of a connection in both directions. The support ledge of the ceiling is required to have a minimum seating width of $22 \mathrm{~mm}(7 / 8 \mathrm{in})$. For ledges less than the minimum required width, it is required to have a hanging wire within $200 \mathrm{~mm}$ (8 in) from the wall. Terminated ends of ceiling runner members are required to have a minimum clearance of $9 \mathrm{~mm} \mathrm{(3/8} \mathrm{in)} \mathrm{from} \mathrm{the} \mathrm{wall,} \mathrm{with} \mathrm{a} \mathrm{spreader} \mathrm{bar} \mathrm{located} \mathrm{within} 200 \mathrm{~mm}$ ( 8 in) from the wall. Pop rivets are not permitted as per section 4.2.6 of ASTM E580 standard. Connection of the hanging wires to the structure are required to support a minimum load of $45 \mathrm{~kg}$ (100 lbs). In suspended ceiling setup, hanging wires are to be installed to be no more than one in six out of plumb vertically.

\subsubsection{Category $\mathrm{D} / \mathrm{E} / \mathrm{F}$}

For design of Category D/E/F ceilings as summarized in Fig 3-1, only heavy-duty maintees as specified in ASTM C636 can be used. The main and cross runners along with their splices and connectors must be able to resist a minimum ultimate load of $82 \mathrm{~kg}(180 \mathrm{lb})$ in both tension and compression. This includes a 5-degree misalignment of a connection in both directions. Both splices and intersection connectors are to be mechanically interlocked. Support ledge of the ceiling should have a minimum width of $50 \mathrm{~mm}$ ( 2 in). A ceiling classified as Category $\mathrm{D} / \mathrm{E} / \mathrm{F}$ is required to be attached to the perimeter angle on two adjacent supporting walls of the ceiling while allowing the other two perimeter sides of the ceiling to be free to move by a distance of $18 \mathrm{~mm}(3 / 4 \mathrm{in})$ movement relative to these other two supporting walls. A spreader bar is to be used on the unattached sides within $200 \mathrm{~mm}$ ( 8 in) from the wall. A hanging wire is to be located within 200 
$\mathrm{mm}(8 \mathrm{in})$ from the wall on all sides of the ceiling. Connection of the hanging wires to the structure are to support a minimum allowable load of $45 \mathrm{~kg}(100 \mathrm{lbs})$. Hanging wires are required to be no more than one in six out of plumb.

\subsubsection{Typical Standards for all Ceiling Categories in ASTM E580}

Ceilings greater than $92.9 \mathrm{~m}^{2}\left(1000 \mathrm{ft}^{2}\right)$ are required to have lateral force bracing comprised of four 12-gauge wires and a compression post within $50 \mathrm{~mm}$ ( 2 in) of a cross runner intersection. These wires should be installed in a V-shape arrangement at a maximum inclined angle of 45 degree with the horizontal. The four wires are required to be rotated 90-degree from one another. Lateral braces are required to start within $1800 \mathrm{~mm}(6 \mathrm{ft})$ from each wall and are placed at a maximum spacing of $3600 \mathrm{~mm}(12 \mathrm{ft})$ in both directions.

Ceilings should not exceed an area of $232.3 \mathrm{~m}^{2}\left(2500 \mathrm{ft}^{2}\right)$ without the installation of a seismic separation joint or a full height partition that breaks the ceiling into an area smaller than $232.3 \mathrm{~m}^{2}\left(2500 \mathrm{ft}^{2}\right)$

\subsection{Current Canadian Design Codes (NBC 2015)}

Currently, the guidance on design of non-structural components in Canadian design standards is very limited. In comparison to seismic design of buildings, there has only been a limited amount of research on non-structural components in buildings in the past. New Zealand follows a similar design approach to that of the National Building Code of Canada (NBC, 2015). However, as mentioned in the study by Pourali et al. (2017) New Zealand's design code mainly requires the design of non-structural components for serviceability limit states. There are other 
similar standards for the design and installation of suspended ceilings such as FEMA, CISCA, and ASTM C635. Manufacturers of ceilings provide their own guidelines on design and installation that meet at least the minimum requirements as specified in the design standards of ASTM C636 and ASTM E580 (Pourali et al., 2017). The design equations of NBC 2015 for non-structural components are the same as the 2012 Ontario Building Code (OBC, 2019).

The seismic design force acting at the center of mass of a suspended ceiling is calculated as per section 4.1.8.18.1 in the $\mathrm{OBC} 2012$ (OBC, 2019) as follows:

$$
V_{p}=0.3 I_{e} F_{a} S_{a}(0.2) S_{p} W_{p}
$$

where $S_{a}(0.2)$ represents the $5 \%$ damped spectral response acceleration at a period of 0.2 seconds, $I_{e}$ is the importance factor of the structure subjected to an earthquake, $F_{a}$ is the site coefficient factor, $S_{p}$ is the component response factor which represents the dynamic interaction of the suspended ceiling with the support building structure when subjected to the design earthquake based on its natural dynamic properties, and $W_{p}$ is the weight of a component or system. For calculating the design force on a suspended ceiling, the system's weight would be used as $W_{p}$.

The factor $S_{p}$ is calculated using Eq 3.2:

$$
\begin{gathered}
S_{p}=C_{p} A_{r} A_{x} / R_{p} \\
\text { with } 0.7 \leq S_{p} \leq 4.0
\end{gathered}
$$

where $C_{p}$ is risk consequence factor which reflects the associated risk with failure of the component. For a suspended ceiling system, the factor is taken as 1.0. The parameter $A_{r}$ is the component force dynamic amplification factor, based on the ratio of the natural vibration period of the component and the fundamental period of the building, which is taken as 1.0 for suspended 
ceilings. The factor $A_{x}$ is the height factor which accounts for the amplification of the base acceleration at the height of the building where the component is attached. It is given by Eq 3.3:

$$
A_{x}=\left(1+2 \frac{h_{x}}{h_{n}}\right)
$$

where $h_{x}$ is the height where the non-structural component is attached to the structure and $h_{n}$ is the total average roof height of the structure. Finally, $R_{p}$ is the component response modification factor which accounts for the energy dissipation capacity of the non-structural component and its connection to the structure, which for the case of suspended ceiling is taken as 2.5 . The values of $C_{p}, A_{r}$, and $R_{p}$ for other non-structural components are presented in Table 4.1.8.18 of NBC 2015 (NBC, 2015).

In addition to the seismic design force for non-structural components, there are seismic design requirements to prevent impact between the structure and hanging components. The Canadian building code NBC states that if the components can swing 45-degree without impacting a structure then they can be designed as a pendulum system; otherwise sway braces can be used and designed to the required loads to restrain the sway movement of the components (NBC, 2015)

\subsection{International Building Code (IBC/ASCE 2015)}

According to the international building code (IBC, 2012) Section 1613, non-structural elements subjected to seismic forces are to be designed in accordance with ASCE 7 (2016). As per ASCE 7-16, section 13.3, the horizontal seismic force $F_{p}$ of a non-structural component is calculated by Eq 3.4 as shown below: 


$$
\begin{gathered}
F_{p}=0.4 A_{P} S_{D S} W_{P}\left(1+2 \frac{z}{h}\right) /\left(\frac{R_{P}}{I_{P}}\right) \\
\text { Limits: } F_{p \max }=1.6 S_{D S} I_{P} W_{P} \\
\text { Limits: } F_{p \min }=0.3 S_{D S} I_{P} W_{P}
\end{gathered}
$$

where $A_{p}$ is the component amplification factor, $I_{p}$ is the component importance factor, $W_{p}$ is the component operating weight, $R_{p}$ is the component response modification factor, $Z$ represents the height of the connection of the non-structural component to the structure relative to the base of the structure, $H$ represents the average roof height of the structure, and $S_{D S}$ is the short period spectral acceleration as determined in Section 11.4.5 of the ASCE 7-16. Table 13.5-1 in ASCE 7-16 provides the values $A_{p}=1.0, R_{p}=2.5$ for suspended ceilings.

The seismic force for design of suspended ceilings is specified in section 13.5.6 of ASCE 7-16. Suspended ceilings with an area less that $13.4 \mathrm{~m}^{2}\left(144 \mathrm{ft}^{2}\right)$ and ceilings that are constructed using screw or nail attached gypsum board and are surrounded by walls laterally braced to structure above are exempt from the seismic design standard of the ASCE 7-16. The ceiling must use a minimum ceiling weight (13.5.6.1) $W_{p}$ not less than $192 \mathrm{~N} / \mathrm{m}^{2}$ (4 psf). The seismic design category for the ceiling is determined in section 11.6 of the ACSE 7-16 and based on $S_{D S}$ and $S_{M S}$ with the associated risk category using Tables $11.6-1$ and $11.6-2 . S_{D S}$ is the $5 \%$ damped spectral response acceleration at short periods and $S_{M S}$ is the $5 \%$ damped spectral response acceleration at short periods adjusted for site class effects. Design Category C use ASTM C635, C636 and E580. Category D, E and F are required to be designed in accordance with the requirements of ASTM E580 section 5 with the following additional requirements as per section 13.5.6.2.2 "perimeter angle $\mathrm{min}$ is 2.0 in $(50 \mathrm{~mm})$ unless qualified clips are used". If clips are to be used, they must be 
attached to the perimeter angle with minimum two screws and the clips must be installed around the entire ceiling perimeter. Two adjacent walls are to be attached to the angle or clip and the two other ends are to have a minimum $19 \mathrm{~mm}$ (3/4 in) clearance from the wall. They must also be allowed to slide and rest on the clip/angle. All ceilings must not exceed $232 \mathrm{~m}^{2}\left(2500 \mathrm{ft}^{2}\right)$ without the use of a separation joint or full eight partition. The areas that are separated must have a ratio of long to short dimensions of $4: 1$.

While these simplified equations provide an estimate of the load on a suspended ceiling system, they do not account for many common conditions including the effects of overall size, layout of attachment points, different boundary conditions, or changing stiffness due to dislodgment of ceiling tiles.

\subsubsection{Comparison of Design Codes (NBC vs IBC)}

Comparing the design load requirements of the current National Building Code of Canada (NBC, 2015) with those in the ASCE/IBC (ASCE, 2016) the similarities on the seismic design requirements between these two design standards are first outlined as follows. For both codes, the coefficient of $R_{p}$ is 2.5. The $A_{p}$ component factor in the ASCE is 1 and therefore can be removed from the comparison. Both $C_{p}$ and $A_{r}$ in the NBC are also equal to 1 and therefore do not need to be considered in the comparison. Both codes use the $A_{x}$ factor to represent the amplification of the base acceleration in relation to the component's attachment location along the height of the building. To compare the remaining factors between the two design standards, Eq 3.1 of the NBC formula for seismic force for non-structural components is calculated for the two limiting values of $S_{p}$ as shown in Eq 3.2. Similarly, the ASCE formula for the seismic force of non-structural components is also determined with respect to $S_{D S}$ using Eq 3.5 and 3.6 in order to have a better 
understanding of the difference between the two codes. As shown in Table 3-2, it can be seen that if $F_{a}, I_{e}$, and $W_{p}$ have the same values between the two codes, the NBC gives a higher seismic design force making it a more conservative approach to the design. However, it is recognized that the comparison between the seismic design force values from the two codes are influenced by the site class, seismic design category and weight of the ceiling which are different between the two codes.

$$
\begin{aligned}
& S_{S}=S_{a}(0.2) \\
& S_{D S}=\frac{2}{3} F_{a} S_{S}
\end{aligned}
$$

Table 3-2 IBC vs NBC Seismic Design Force

\begin{tabular}{|l|c|c|}
\hline & $\begin{array}{c}\mathrm{IBC}(\mathrm{NBC} \\
\text { coefficients })\end{array}$ & \\
& & $\mathrm{NBC}$ \\
\hline Seismic Design Force & $0.27 \mathrm{~F}_{\mathrm{a}} \mathrm{S}_{\mathrm{a}}(0.2) \mathrm{I}_{\mathrm{e}} \mathrm{W}_{\mathrm{p}} \mathrm{S}_{\mathrm{p}}$ & $0.3 \mathrm{~F}_{\mathrm{a}} \mathrm{S}_{\mathrm{a}}(0.2) \mathrm{I}_{\mathrm{e}} \mathrm{W}_{\mathrm{p}} \mathrm{S}_{\mathrm{p}}$ \\
\hline Minimum Design Force & $0.2 \mathrm{~F}_{\mathrm{a}} \mathrm{S}_{\mathrm{a}}(0.2) \mathrm{I}_{\mathrm{e}} \mathrm{W}_{\mathrm{p}}$ & $0.21 \mathrm{~F}_{\mathrm{a}} \mathrm{S}_{\mathrm{a}}(0.2) \mathrm{I}_{\mathrm{e}} \mathrm{W}_{\mathrm{p}}$ \\
\hline Maximum Design Force & $1.07 \mathrm{~F}_{\mathrm{a}} \mathrm{S}_{\mathrm{a}}(0.2) \mathrm{I}_{\mathrm{e}} \mathrm{W}_{\mathrm{p}}$ & $1.2 \mathrm{~F}_{\mathrm{a}} \mathrm{S}_{\mathrm{a}}(0.2) \mathrm{I}_{\mathrm{e}} \mathrm{W}_{\mathrm{p}}$ \\
\hline
\end{tabular}

As shown in Figure 3-1 the chart outlines the effect of varying the factor $F_{a}$ values between the two codes. Due to NBC (2015) using $F_{a}$ values in relation to the PGA (Peak ground acceleration), in order for a simpler comparison of the influence of the $F_{a}$ factor, the $2006 \mathrm{OBC}$ $(\mathrm{OBC}, 2006)$ was used for the $F_{a}$ values which are based on the spectral acceleration with the same 
ranges as the IBC (IBC, 2012). Also, Site Class F was excluded from this comparison, as for both codes site specific evaluation is required to determine the $F_{a}$ value.

As can be seen in Figure 3-1, the $F_{a}$ values are equivalent for $S_{a}(0.2)$ greater than 1 for all site classes and for $S_{a}(0.2)$ less than 0.5 the NBC is on average $16.2 \%$ lower than the IBC for all the site classes excluding site class F.

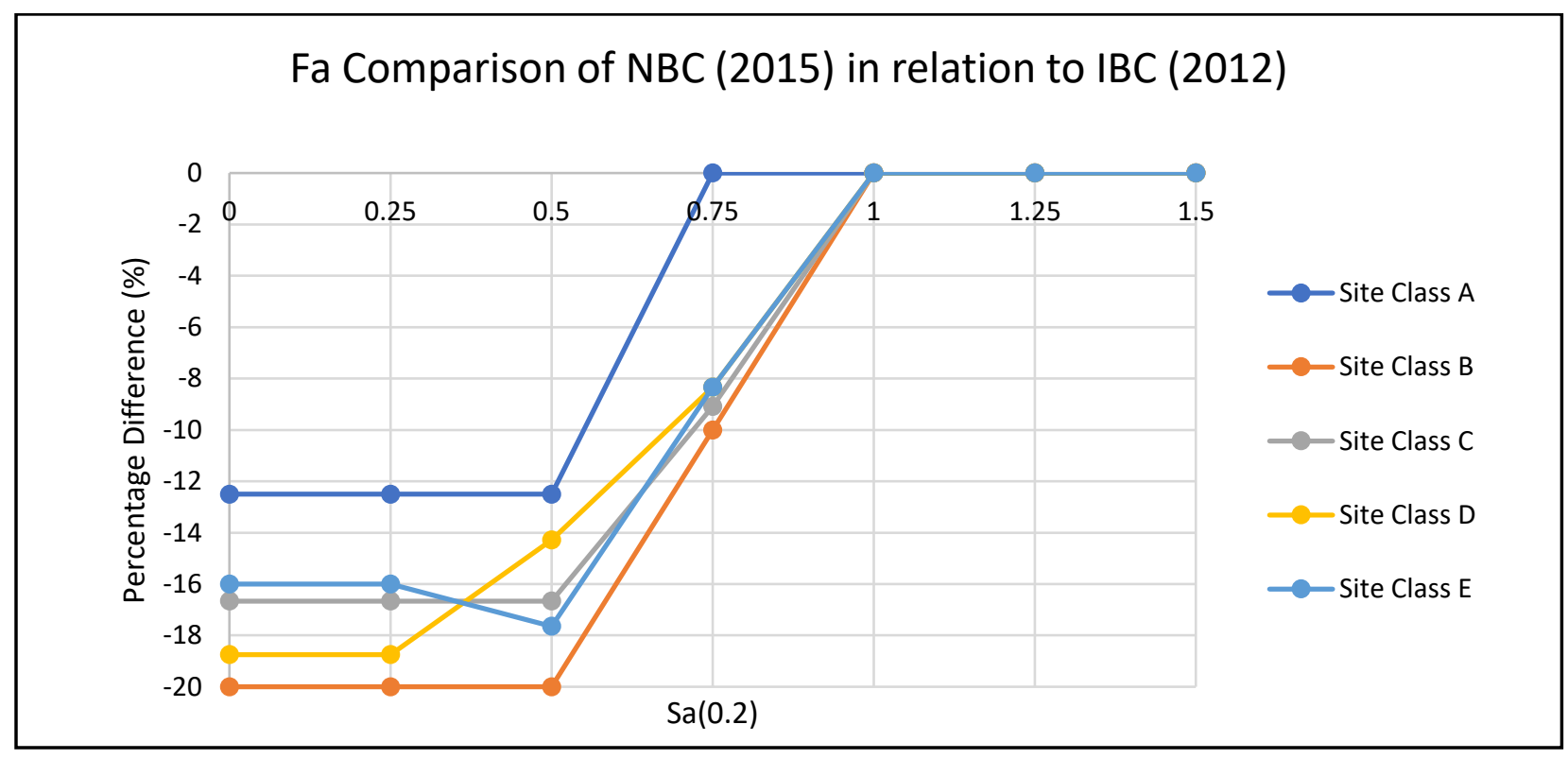

Figure 3-1: Comparison of Fa Coefficient NBC vs IBC

The next parameter to consider that may have an impact on the comparison of the seismic design force of non-structural components between the two codes is the importance factor. The NBC uses the same $I_{e}$ for the suspended ceiling as the importance factor used for the entire building which ranges from 0.8 for low importance to 1.5 for post disaster buildings. The IBC outlines an importance factor for the components themselves, for a suspended ceiling as per section 13.1.3. $I_{p}$ is taken as 1.0 except for Risk Category 4 buildings. For Category 4 buildings which is equivalent to the NBC "post disaster" building, the importance factor is the same between the two codes as 
equal to 1.5 . This shows that for a high importance building (Category 3 ) the NBC is $30 \%$ greater than the IBC. This also means that for low importance buildings the NBC is $20 \%$ less than the IBC. However, this can be excluded in the majority of buildings as most buildings are not classified as low importance and the majority of those that are classified as low importance are not likely to have suspended ceilings.

Table 3-3 IBC vs NBC Importance Factor

\begin{tabular}{|l|c|c|}
\hline \multicolumn{3}{|c|}{ Importance Factor } \\
\hline Seismic Risk Category & IBC & NBC \\
\hline Category 1 (Low) & 1.0 & 0.8 \\
\hline Category 2 (Normal) & 1.0 & 1.0 \\
\hline Category 3 (High) & 1.0 & 1.3 \\
\hline Category 4 (Post-Disaster) & 1.5 & 1.5 \\
\hline
\end{tabular}

The next factor to consider is the weight of the ceiling system. As per the NBC, the designer determines the weight $\left(W_{p}\right)$ based on the components used in the ceiling system which is usually around $120 \mathrm{~N} / \mathrm{m}^{2}(2.5 \mathrm{psf})$ as per the seismic design category C limit (ASTM E580) whereas, in the ASCE the designer is required to use a minimum of $192 \mathrm{~N} / \mathrm{m}^{2}(4 \mathrm{psf})$. The two graphs shown below demonstrate the difference in the seismic design force along the height of the building for a suspended ceiling inside a structure located in Ottawa (City Hall), Ontario. Using Equations 3.1 and 3.4 above, Figure 3-2 uses a calculated weight of 2.5 psf for the NBC Design Force and 4 psf ceiling weight as per the minimum for the ASCE. Figure 3-3 uses the same design weight of 4 psf as per ASCE given the scenario that the calculated weight of the ceiling for the NBC is 4 psf. Together with the following values found in the climatic data of the NBC with $S a(0.2)$ equal to 
0.439 and PGA equal to 0.281 for Ottawa; a comparison of the seismic force for suspended ceiling system between the two design standards are shown below in Fig 3-2 and 3-3.

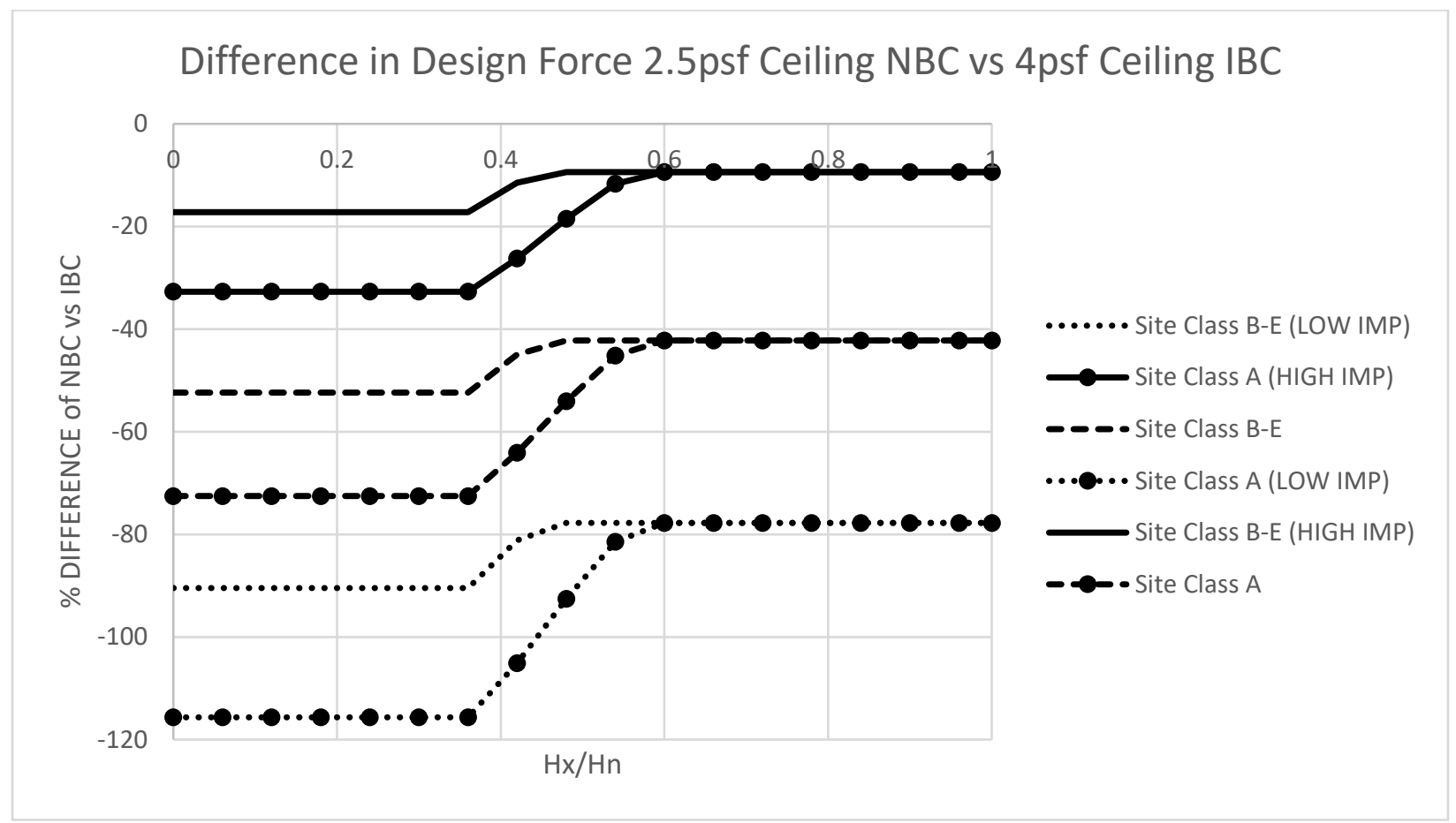

Figure 3-2: $V_{p}$ Difference Between a 2.5psf Ceiling (NBC) vs 4psf Ceiling (IBC)

As shown by the plots in Fig 3-2, if the designer choses to use the NBC Design Equation, they will end up using the actual suspended ceiling weight as $W_{p}$. Whereas, for the IBC the designer is required to use a minimum weight of $4 \mathrm{psf}\left(192 \mathrm{~N} / \mathrm{m}^{2}\right)$. Assuming the weight of the ceiling system is equal to or below $2.5 \mathrm{psf}\left(120 \mathrm{~N} / \mathrm{m}^{2}\right)$ the NBC design force is significantly lower than the IBC design force for all site classes, for all floors of the building and for all building types. 


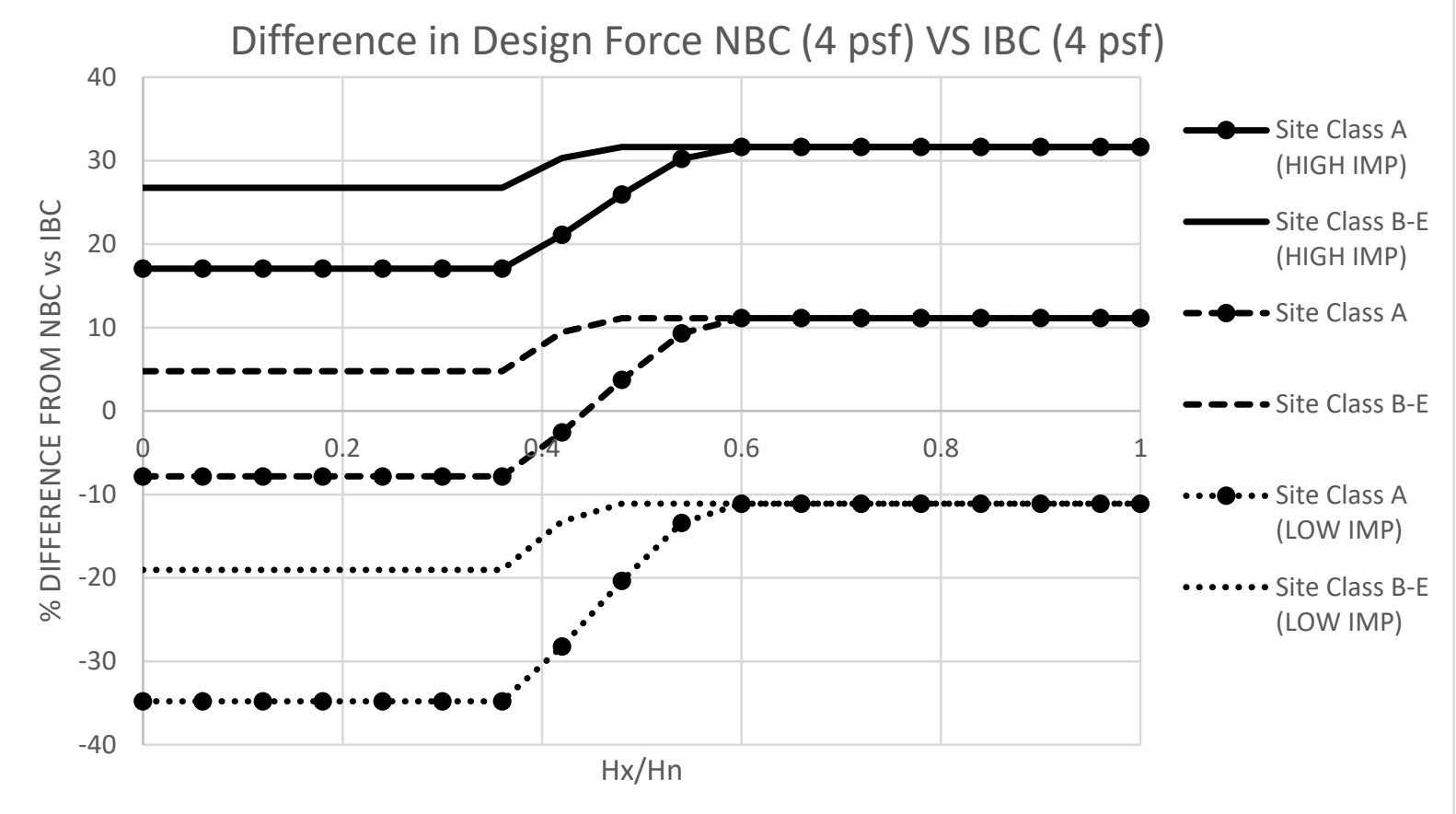

Figure 3-3: V Difference With 4psf Ceiling Weight for Both NBC and IBC

Figure 3-3 shows the comparison of design forces when the weight of the system $\left(W_{P}\right)$ used in both equations are the same. The majority of buildings that contain suspended ceilings are at minimum classified as normal importance. Another factor to consider is the ceilings will experience maximum acceleration at the upper stories of a building and therefore the comparison can be observed between a $h_{x} / h_{n}$ of 0.6 to1.0. If the low importance design forces and the lower half of buildings are excluded in the comparison, the NBC is $10 \%$ higher for a normal importance and post disaster buildings and $30 \%$ higher for high importance buildings when compared to the IBC.

Canadian design engineers are required to follow the IBC to classify the ceiling to determine what seismic category it lies within. In the process, they will have calculated two design forces, one for IBC and one for NBC. Some engineers may choose to select the higher of the two 
for design since this should be a conservative approach; however, this approach may be overconservative, which demonstrates the need for more research into the seismic performance of suspended ceilings. This conservative (perhaps over-conservative approach) to design using the worst case of the NBC and IBC forces is compared in Figure 3-4 for normal and high importance buildings. This modified design force along with the original design forces from the IBC and NBC, may be compared to the future experimental shake table results to verify if the current codes are adequate or whether more research is required into the development of future design forces related to suspended ceilings.

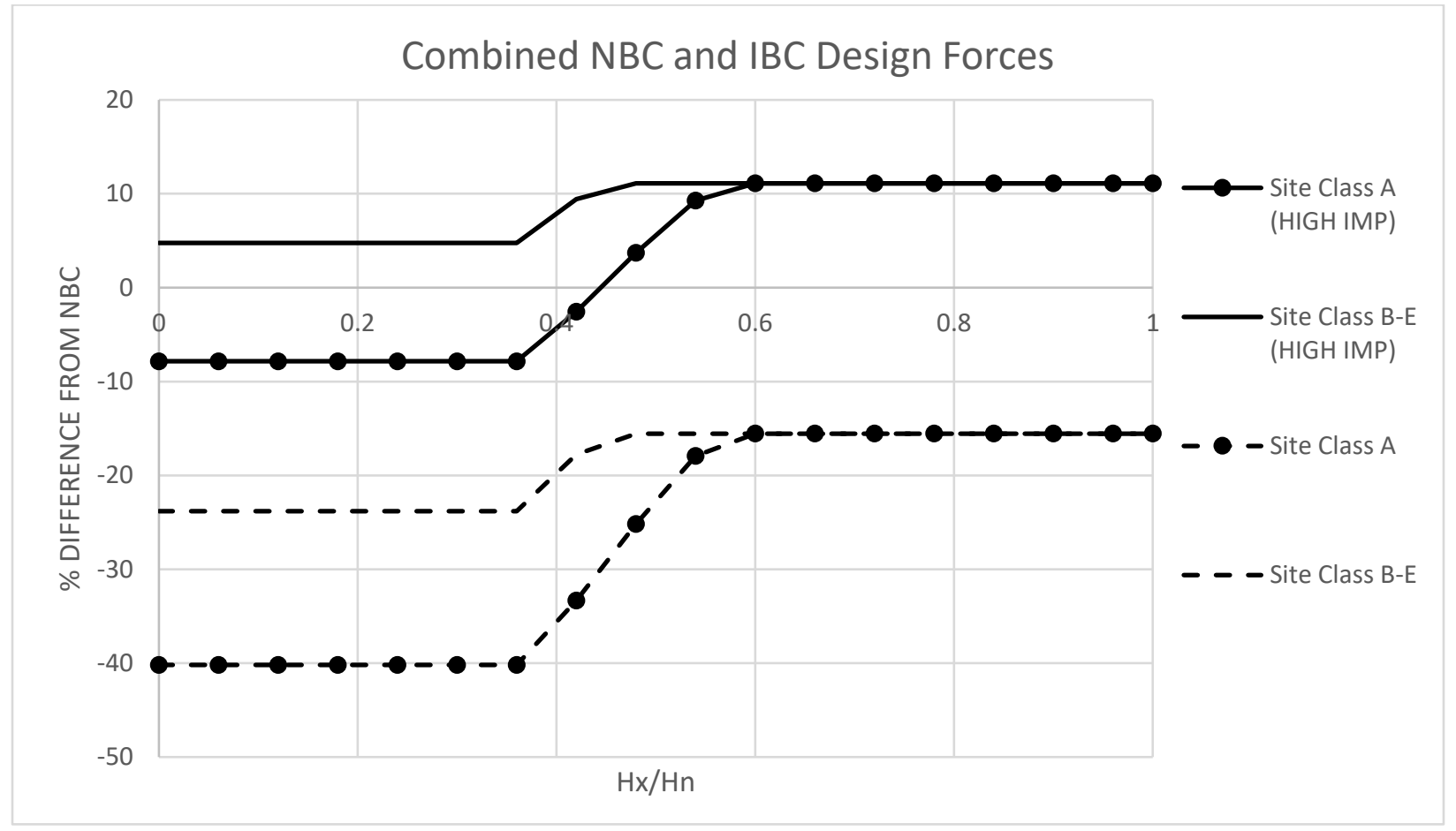

Figure 3-4: Combined NBC and IBC Design Forces

The combined method with the 1.3 coefficient added to the IBC and the minimum design weight of $4 \mathrm{psf}\left(192 \mathrm{~N} / \mathrm{m}^{2}\right)$ to the NBC creates a difference between the codes of $+/-15 \%$ for the 
upper half of normal, high and post disaster buildings. The other variation between the two codes is related to the site coefficient and importance factor. 


\section{Chapter 4: Current International Joint Research Project}

Carleton University is collaborating with Tongji University and Tokyo Institute of Technology on an ILEE (International Joint Research Project of Earthquake Engineering) research project on seismic performance of suspended ceilings. The overall research program is being led jointly by Prof. Kazuhiko Kasai of Tokyo Institute of Technology, Prof. Huanjun Jiang of Tongji University and Carleton University researchers. In the research program, Tongji University conducted full size shake table tests of suspended ceiling systems using two 30 ton shake tables. These tests include consideration of different boundary conditions and evaluation of the effect of seismic clips and dampeners. Ground motions recorded from the 2011 Tohoku earthquake in Japan and the 2008 Wenchuan earthquakes in China were used for the tests. The input excitations were scaled to the seismic hazard level corresponding to a probability of exceedance of 50,10 and $2 \%$ in 50 years. Researchers in Tokyo Institute of technology conducted time-history response analysis correlation studies of the suspended ceiling systems by using the detailed finite element models developed by Motoyui $(2014,2017)$.

The aim of the joint international research project is to evaluate the seismic performance of suspended ceiling systems in mega-tall buildings. The researchers at Tongji University modelled the Shanghai Tower, the second tallest building in the world, as the prototype building for their investigation. A 3D ETABS model of the Shanghai Tower was created by Lu et al. (2016) in Figure 4-1. 


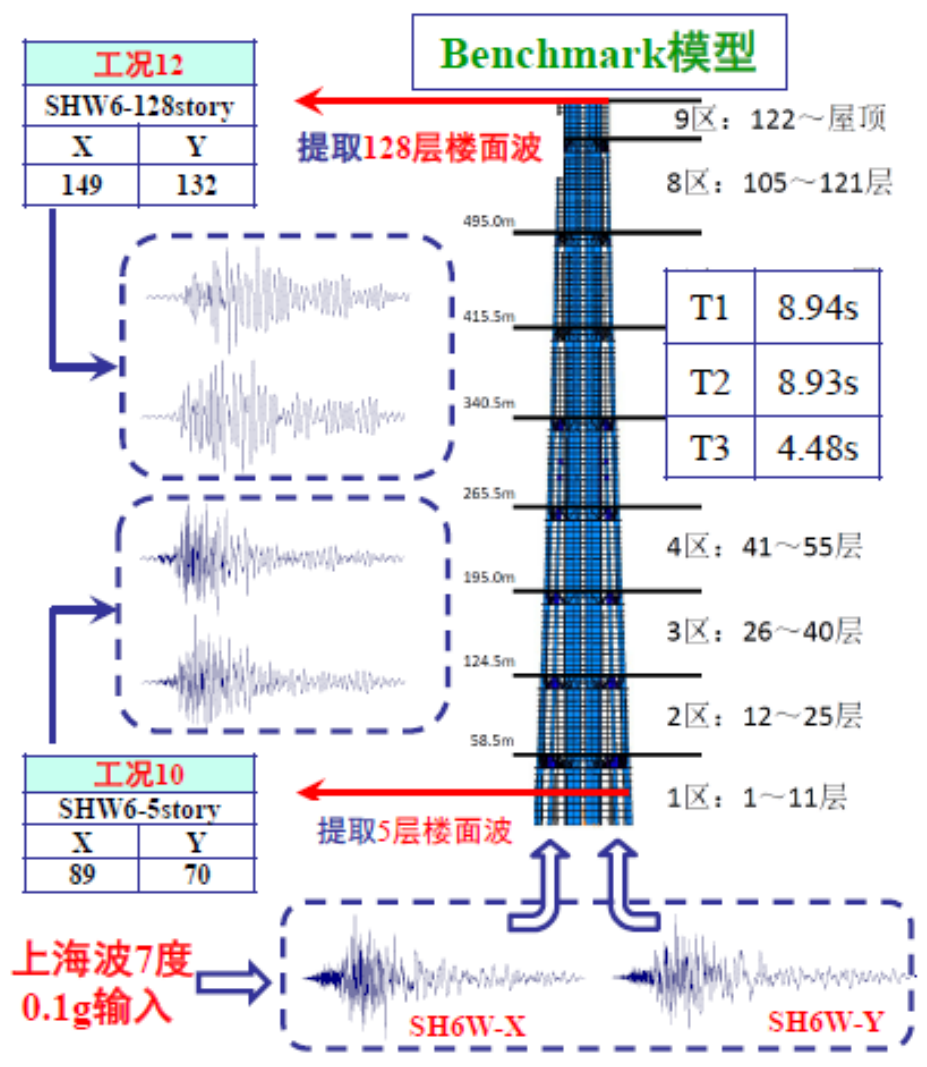

Figure 4-1: 3D ETABS Benchmark Model of Shanghai Tower (Lu et al., 2016)

Shanghai Tower at $606.1 \mathrm{~m}$ high was chosen as the prototype structure in the research as it is classified as a Mega-Tall Building. The building was designed as a steel-concrete composite lateral resisting system using a concrete core with steel outrigger trusses connecting the core to the perimeter steel truss frame. The building model was used to generate input excitations floor response motions at the $5^{\text {th }}, 30^{\text {th }}$ and $128^{\text {th }}$ Floor.

The participation of Carleton University in the international joint research project is testing of suspended ceiling systems using a new multi-unit mobile shake table system of four shake tables to simulate the floor response motions of the super-tall buildings. The testing program at Carleton is designed to provide additional insights to the seismic performance of suspended ceilings in tall buildings that are complementary to the large-scale shake table test results by Tongji University. 
The Carleton test program will consider the influence of vertical and rotational floor response motions in addition to the horizontal excitations to the seismic performance of suspended ceiling systems. In addition to suspended ceilings in the super-tall 128-Storey Shanghai Tower, performance in mid-rise buildings will also be investigated. The 11-Storey Residence Building at Carleton University (Lennox and Addington) is used as the prototype building in this investigation. The differences in the two prototype buildings will allow for comparison of the seismic performance of suspended ceilings when subjected to excitations with distinct differences in motion intensity and frequency contents because of the vast differences in floor response motions between a super-tall building and a more common mid-rise building in Canada.

The future testing program at Carleton University will consist of testing ceilings installed to the standards of both Category $\mathrm{C}$ and Category $\mathrm{D} / \mathrm{E} / \mathrm{F}$. Multiple ceiling configurations are considered to investigate the seismic performance with varying lateral restraints, panel sizes, ceiling size, and multidirectional input motions. Schematics of possible ceiling configurations for future experimental testing are shown in Figures 4-2 to 4-4. 


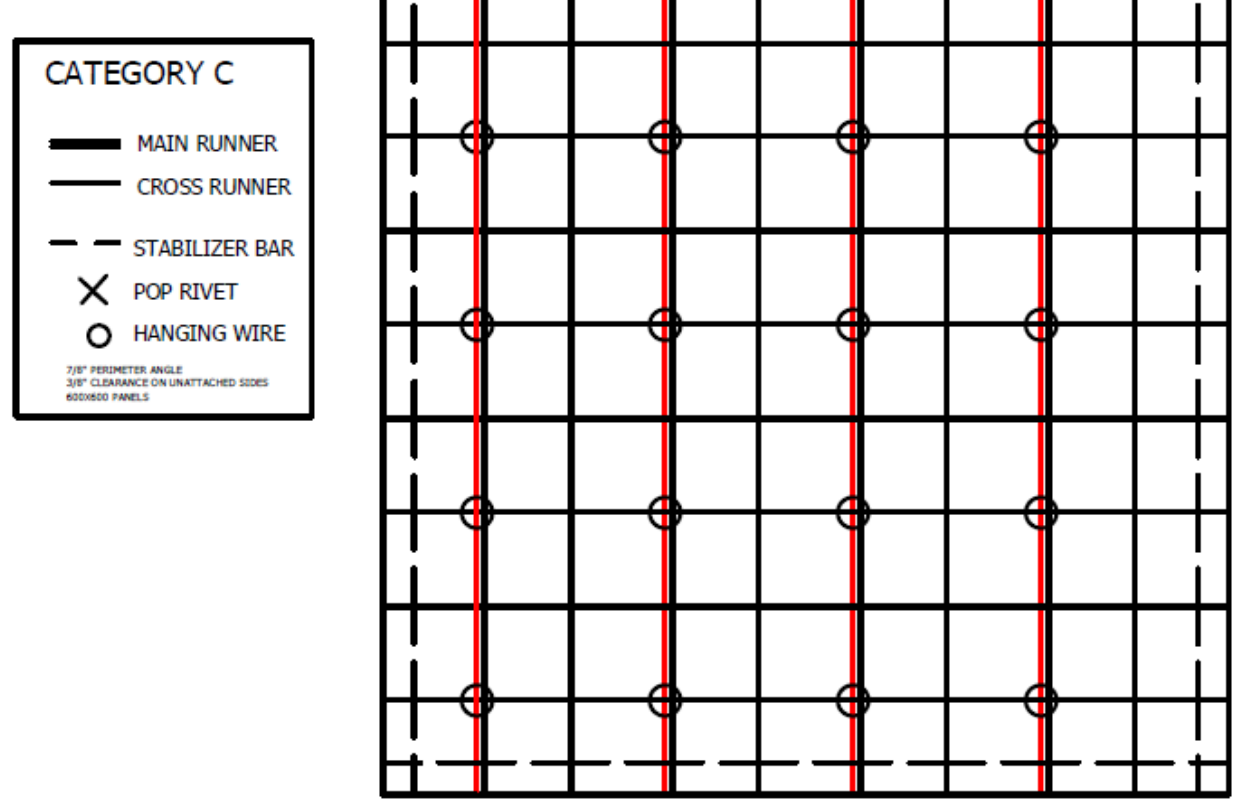

Figure 4-2: Category C Suspended Ceiling (600 mm x $600 \mathrm{~mm}$ Panels)
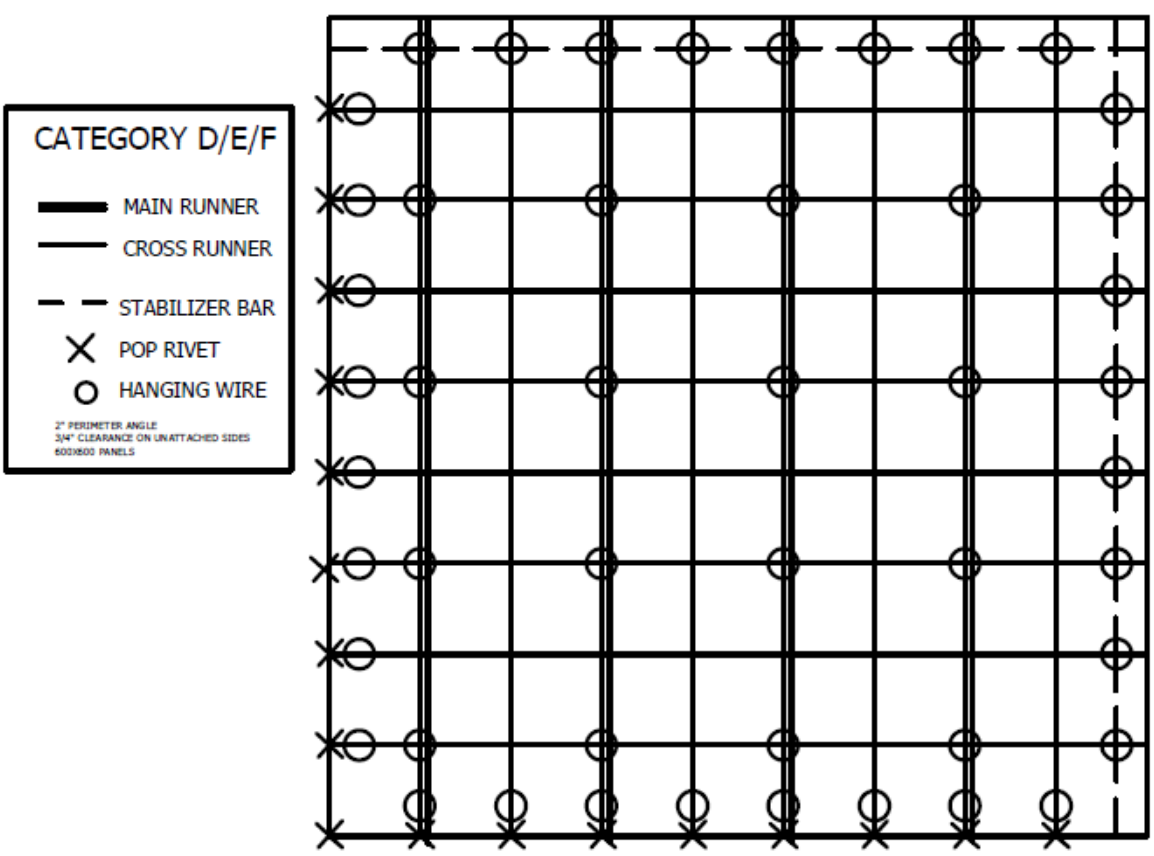

Figure 4-3: Category D/E/F Suspended Ceiling (600 mm x $600 \mathrm{~mm}$ Panels) 


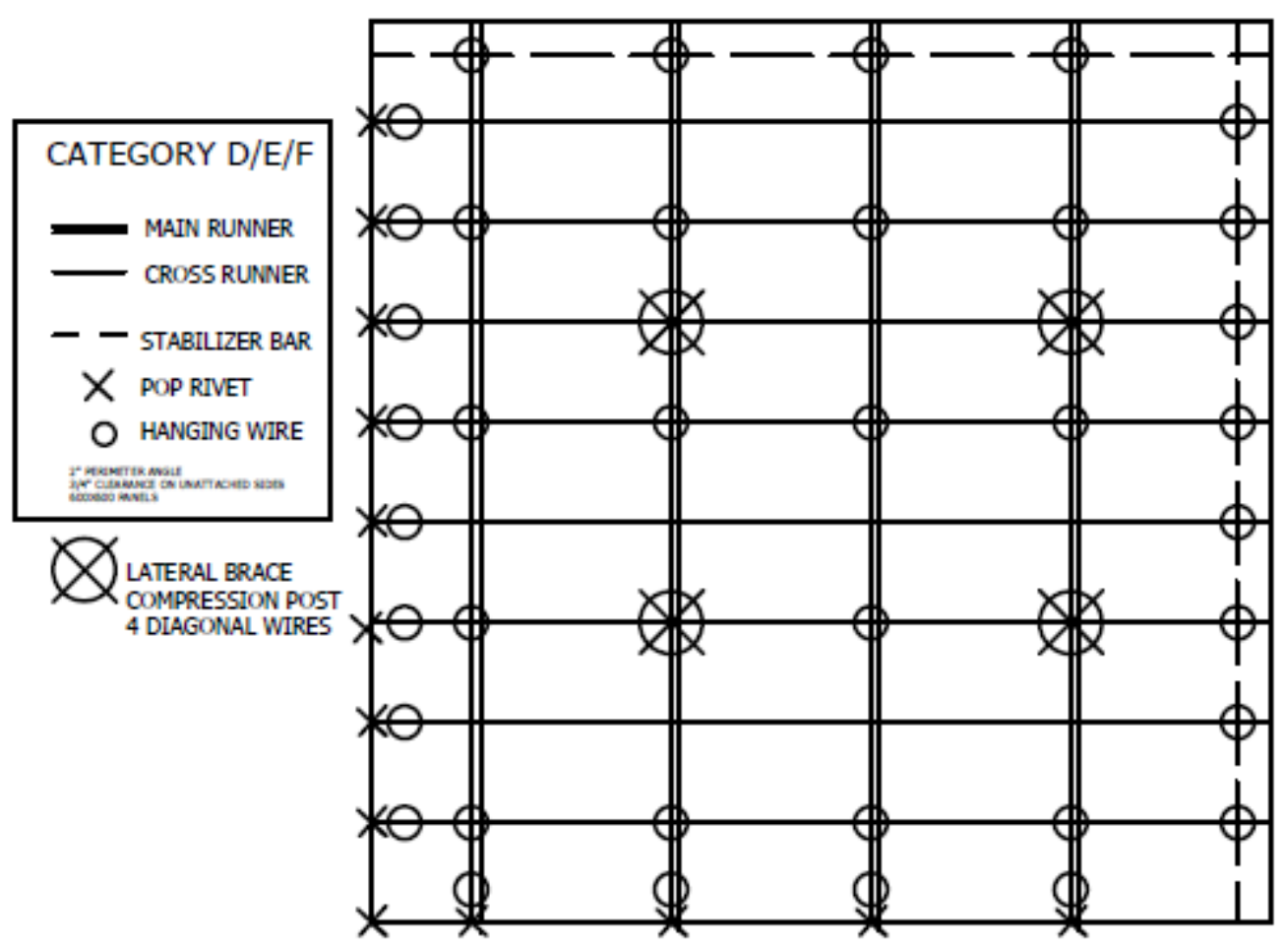

Figure 4-4: Category D/E/F Suspended Ceiling with Seismic Bracing (1200 mm x $600 \mathrm{~mm}$

\section{Panels)}

Using the mobile shake tables, the goals of the Carleton test program are to observe the performance of non-structural elements of different layouts and configurations, including boundary conditions, varying support configurations, effects of partitions, and varying input excitements. The future tests will provide insights on the adequacy of current design standards. 


\section{Chapter 5: Design of Test Frame for Non-Structural Components}

\subsection{Layout of Shake Tables}

The new MTS multi-unit shake table systems at Carleton University consist of four independent shake tables each with 6 independent degrees-of-freedom controlled by six actuators attached to an upper and lower frame as shown in Figure 5-1. The lower frame is a thin steel plate with holes at each corner to be bolted into concrete. The tables are to be used at Carleton University as mobile units that can be placed in any configuration within the lab.

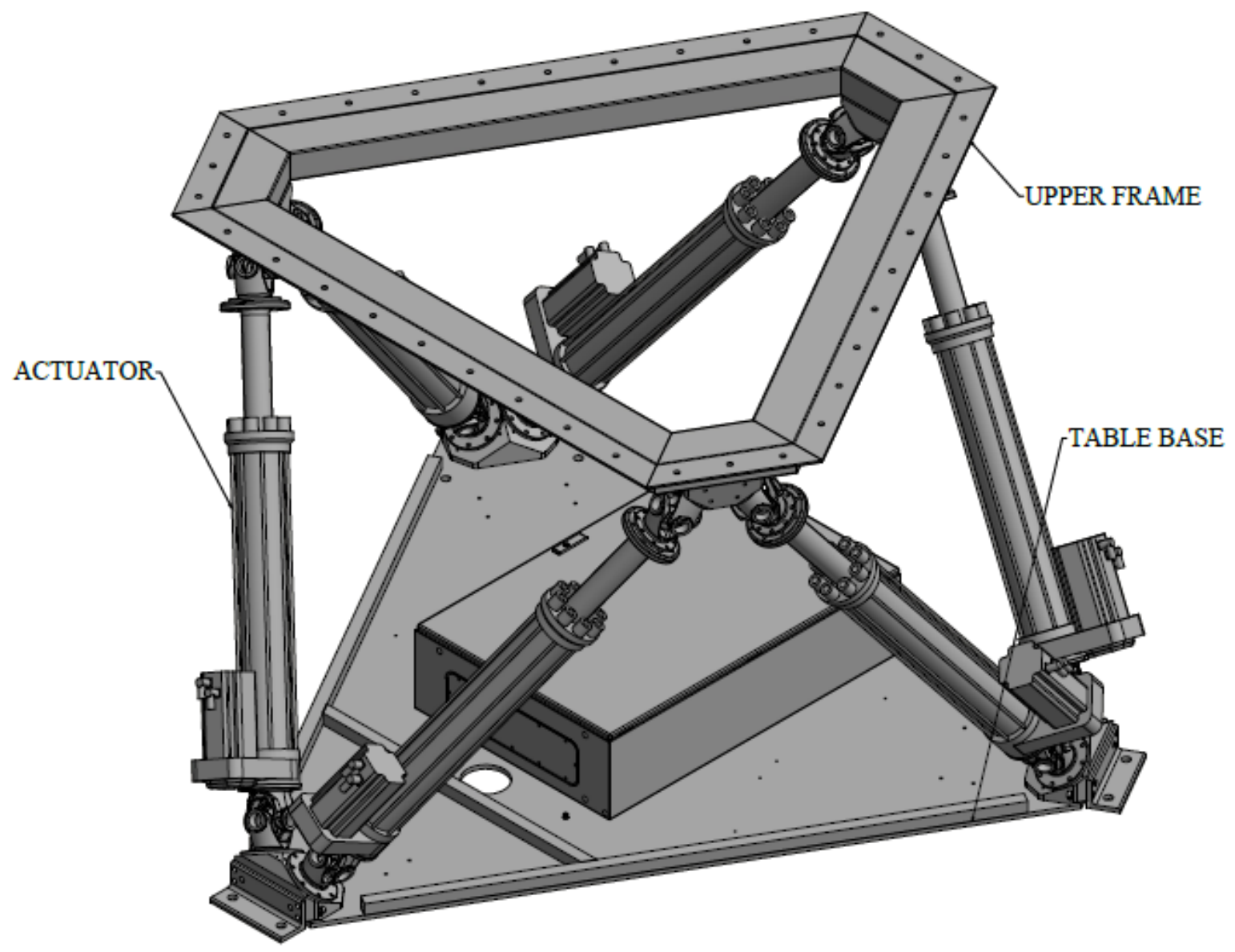

Figure 5-1: Shake Table Schematic 


\subsubsection{Installation of Tables}

A steel plate (BP1) was designed to be post tensioned to the lab's strong floor. A smaller plate (BP2) is to be placed on top of the large plate for alignment positioning and adjustment of the tables as shown in Figures 5-2 to 5-4. To install the tables, BP1 is placed on the strong floor and then aligned with the plates of other table units in the $\mathrm{X}$ and $\mathrm{Y}$ axis. The plate BP1 is then post tensioned to the floor. Next, the plate BP2 and the shake table are placed on the plate BP1. Jacking bolts will be used in conjunction with a laser tracker to level the tables in the vertical axis and rotation about the horizontal axis. Once the tables are aligned and level with respect to each other, grout will be pumped in to fill the 2 in to 4 in gap between BP1 and BP2 for final positioning of the table unit as shown in Figure 5- 3.

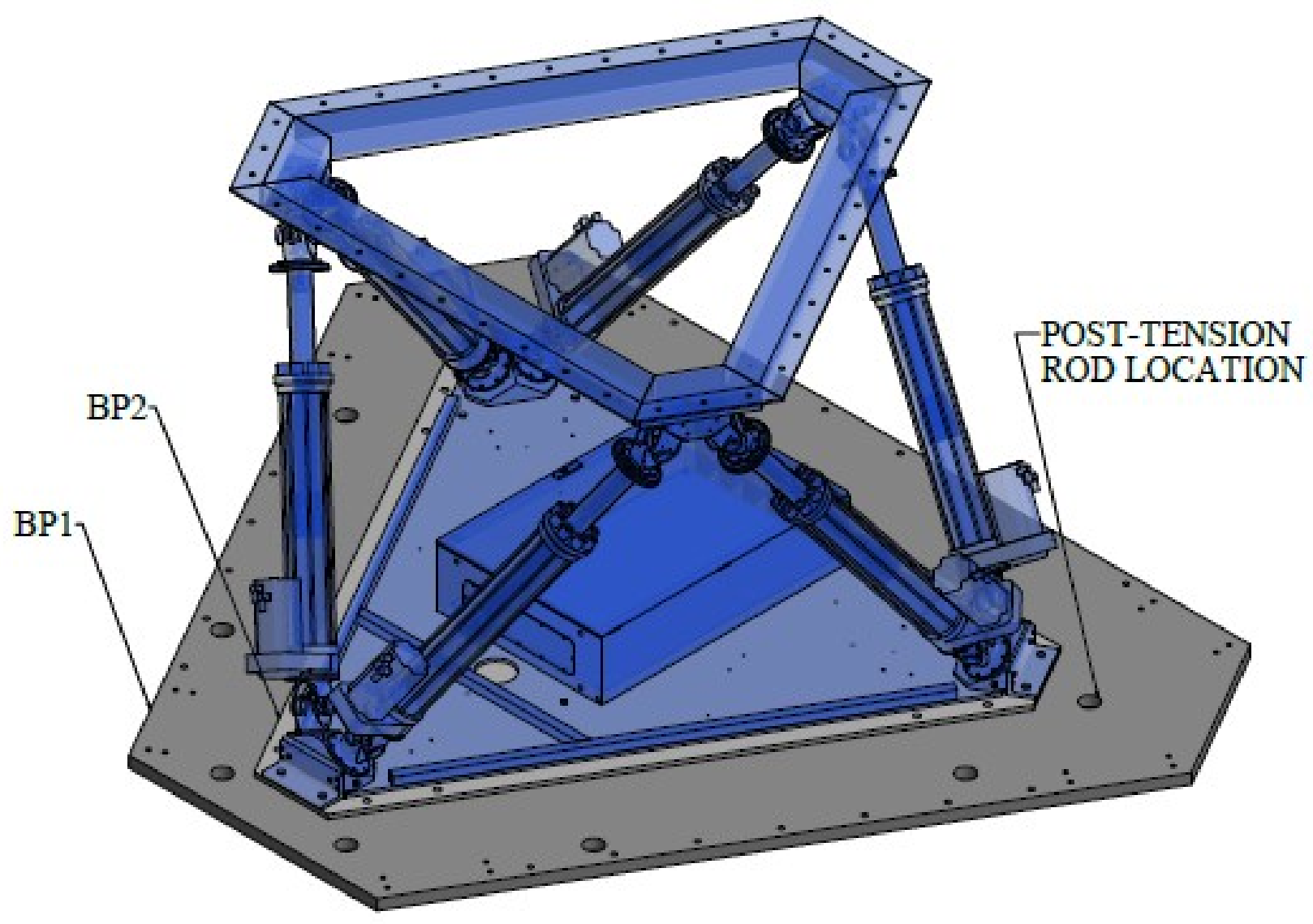

Figure 5-2: Base Plate Configuration 3D View 


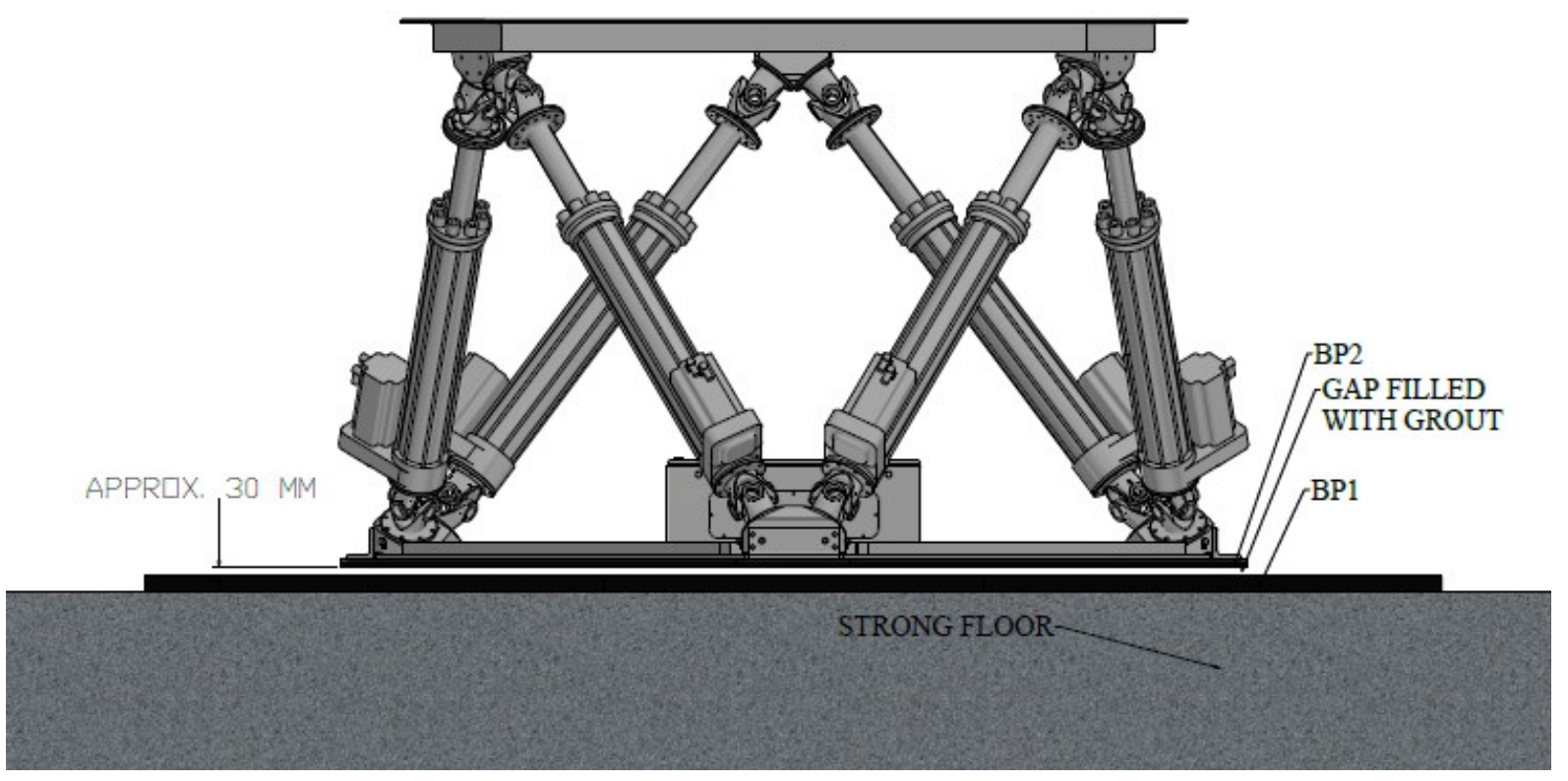

Figure 5-3: Base Plate Configuration Side View

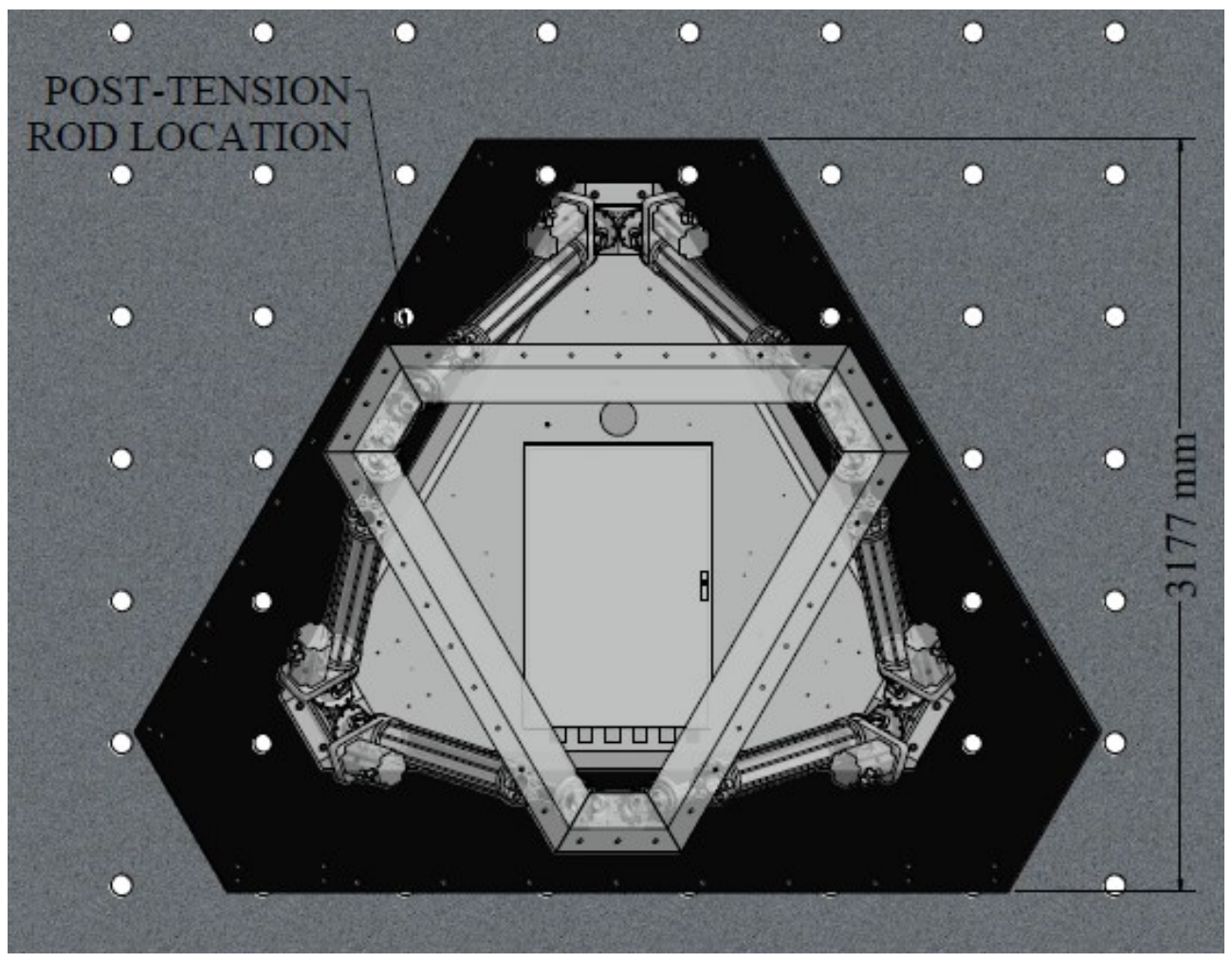

Figure 5-4: Base Plate Configuration Top View 


\subsubsection{Design Criteria}

The bottom plate (BP1) was designed to allow for post tensioning rods to hold down the system to the strong floor with anchor holes at $600 \mathrm{~mm}$ x $600 \mathrm{~mm}$ grid spacing. To resist overturning of the system a minimum of one rod is required at each corner of the table base. The tables thickness was designed to resist plate bending and provide full embedment of the bolts connecting the table to the plates at the base of the actuators. BP1 was required to have a big enough footprint to allow for a stacking frame to enclose the table as discussed in Chapter 5. Both plates were designed to resist bending from lifting during installation of these systems. The purpose of BP2 is to ensure minimal deflection during jacking which will in turn increase the accuracy of the laser tracker points at the base of the table. The plate BP2 also prevents the requirement to clean the grout off the underside of the tables for safety and accessibility reasons. To ensure the threaded holes in the BP1 would have an equivalent strength to a common nut, the plate was required to be $50 \mathrm{~mm}$ ( 2 in) thick. The size and thickness of the steel plates were designed to have an overall weight within the crane payload capacity.

\subsection{Dummy Payload}

A dummy payload design (MTS, 2020) was adapted for performance calibration of the shake tables. The dummy payload of $3000 \mathrm{~kg}$ located with a center of gravity (COG) of $1000 \mathrm{~mm}$ above the center of table was adapted to test the maximum controlled motion capacity of the table. The dummy payload consists of two I-beams per side with a steel plate at mid height in the corners connecting all three sides. The beams are bolted to the top triangular frame of the shake table and then beams are connected on top using the corner plates. Finally, the additional weight is added to the top of the assembly via steel plates bolted at the corner of the beams. The dummy payload can be assembled in different configurations to examine the performance change in the shake table 
with different specimens. This can be accomplished either by only using the lower set of I-beams and placing the steel corner plates for different variations in mass at a COG of approximately $500 \mathrm{~mm}$. The other option is to use less plates in the assembly to examine a lower mass at a high COG. The dummy payload assembly is illustrated in Figure 5-5.

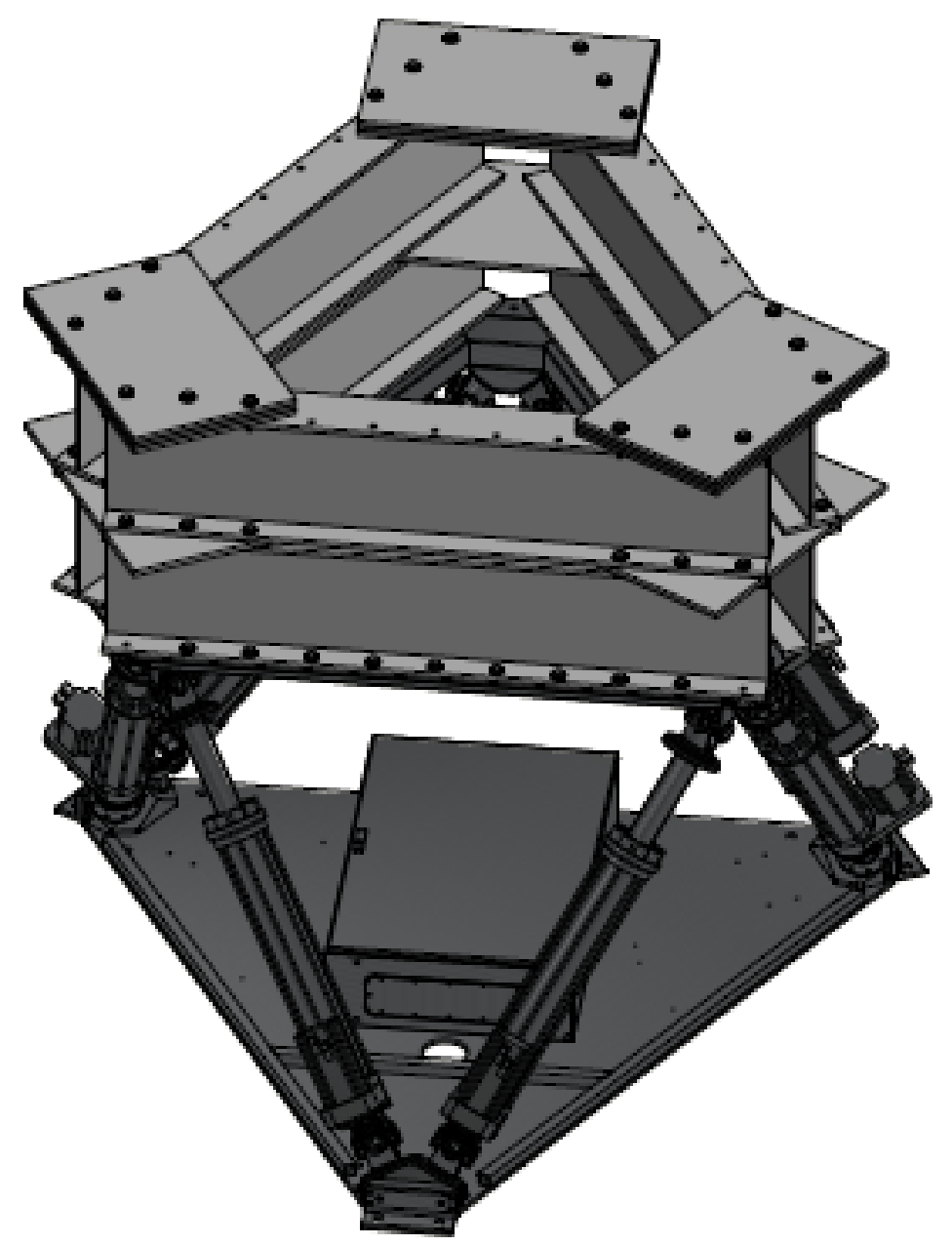

Figure 5-5: Dummy Payload Assembly 


\subsection{Stacking System}

A stacking system was designed to store the tables by stacking them one on top of another in the structures lab while they are not in active use. Due to the significant footprint of the tables, it is required that they be able to be stacked upon one another. The design criteria of the stacking system are as follows:

- Each shake table is completely enclosed within the stacking frame

- Stacking frame can support a maximum of three shake tables

- Stacking frame can resist seismic forces compatible with the seismic hazard of Ottawa

- $\quad$ Stacking frame can be assembled/disassembled easily

The storage system was designed with the intent to minimize the floor spaced used by the tables while not in use. The stacking frame was designed with the capacity to store a maximum of three tables on top of one another. This provides the option of storing all the tables in two stacks of two tables high or, one stack of three tables if only a single table is being used for testing. For assembling the stacking system and considering the heavy weight of the baseplates as mentioned in Chapter 4, the stacking frame was designed so that it can be easily lifted in separate assemblies. The total weight of each assembled shake table unit was calculated to be approximately $7200 \mathrm{~kg}$. The stacking frame was designed with bolted connections for easy assembly and disassembly. This led to the design of a brace frame instead of a moment resisting frame.

\subsubsection{Geometry Layout}

The stacking frame consists of two base plates, three brace frames and three moment resisting frames. The plate $\mathrm{BP} 1$ is used to act as a diaphragm for the beams at the top of the frame when the systems are stacked. The three long sides consist of angles as diagonal braces bolted to 
the columns below and the beam above. As the columns on the short sides are at an angle with respect to one another (not perpendicular or parallel) which prevents an easy bolted connection design. The solution is to use an HSS beam as this will allow for the beam to be cut to fit tight to the columns and allow for a fillet weld. The beams at the top of the frame are to be bolted into the BP1 from the system above in order to transfer the lateral loads into the diagonal braces. Figure 56 and Figure 5-7 show the layout of a single stacking frame and a complete assembly with two tables stacked on top of one another.

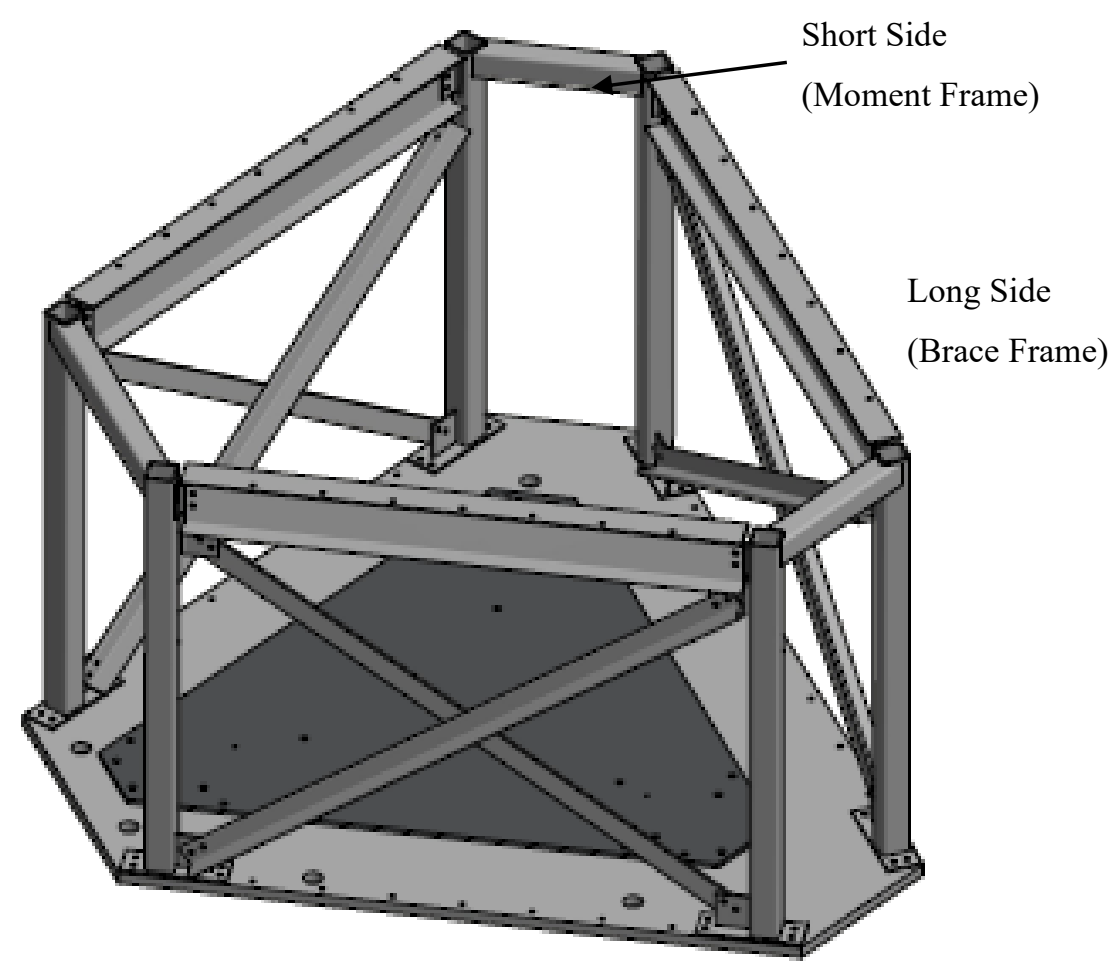

Figure 5-6: Stacking Frame Assembly 


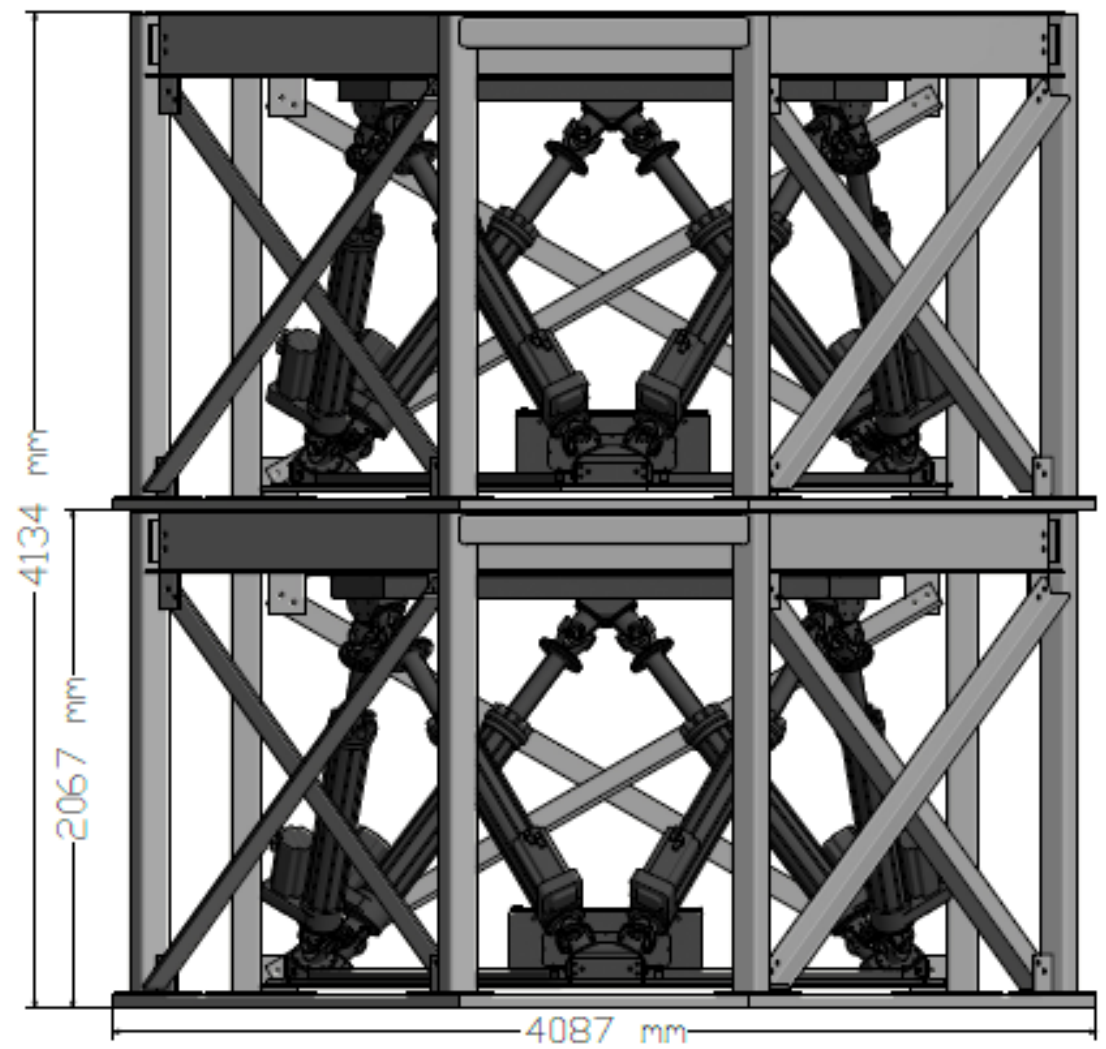

Figure 5-7: Stacking Frame Assembly for Two Tables

\subsubsection{Computer Modelling}

SAP2000 was used to model the stacking system and to optimize the size of the members. The results from the SAP analysis were verified with hand calculations. During the design stage, it was expected that the dimensions of the frame would have to be constantly adjusted due to examining the most feasible solution for the connections based on constructability. Therefore, the SAP model used approximate dimensions to produce conservative design forces which were then verified using hand calculations. A stiff column was placed in the middle of the plates with a nodal mass at the top of it to represent the COG (Center of Gravity) of the table. The bottom shake table was not included in the analysis as it would not have an impact on the design of the stacking frame members and connections. From the modal analysis of the system, it was observed that adding a 
plate to act as a diaphragm at the top of the assembled system would greatly increase the stiffness and fundamental frequency of the staking frame. The first mode was vertical deformation of the top plate at $6.12 \mathrm{~Hz}$. The second and third modes were translation in the horizontal directions of 11.79 Hz and $12.1 \mathrm{~Hz}$ respectively. The modelled weight of the entire system is $175.4 \mathrm{kN}$ and the base shear was calculated to be $40.1 \mathrm{kN}$ using $R_{d}$ of 1.5 and $R_{o}$ of 1.3 . The Ottawa response spectrum was scaled by a factor of two as input excitation for the seismic design of the stacking frame. The 3D SAP2000 model of the stacking frame is shown in Figure 5-8.

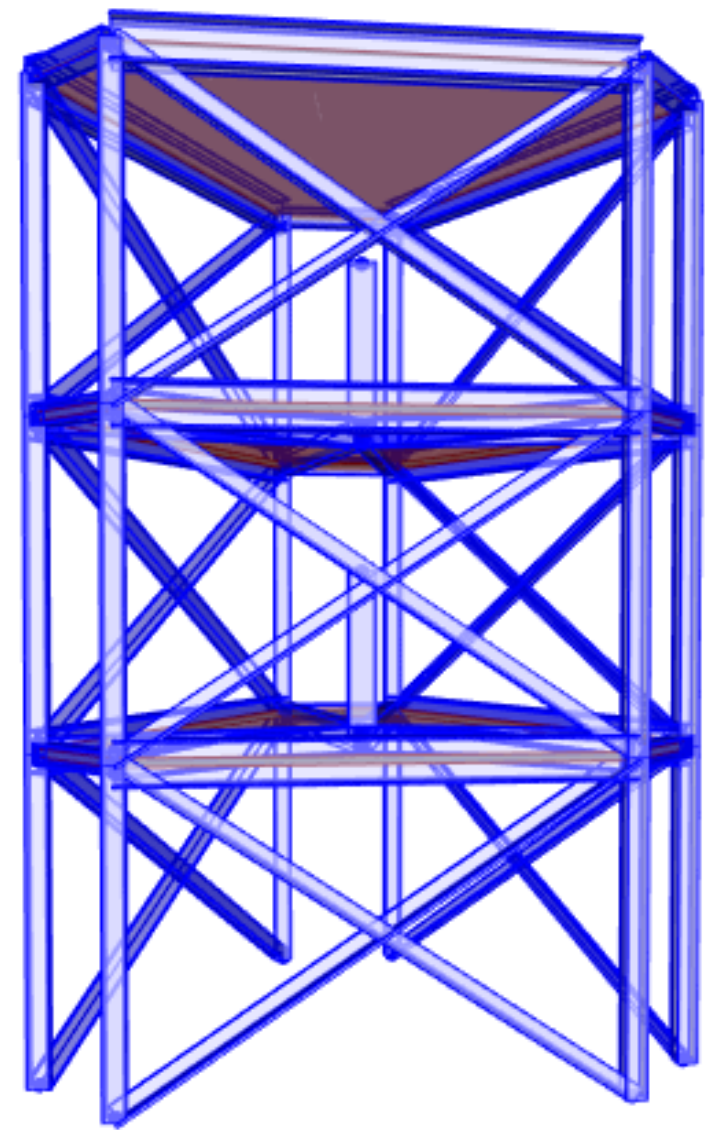

Figure 5-8: Stacking System 3D SAP2000 Model 


\subsection{Test Frame}

\subsubsection{Design Criteria}

The test frame was designed to evaluate the seismic performance of a variety of nonstructural components. This includes suspended ceiling systems, cable tray systems, other hanging systems, and floor components. The test frame had to meet the following requirements:

- Maximize use of four mobile shake tables with a Capacity of 3-Ton per table

- Test frame footprint must fit within structural lab

- $\quad$ Test frame must be able to resist maximum forces produced by Shake Table

- Test frame must be able to be assembled/disassembled easily

- Test frame must be stiff to reduce amplification of input motions

\subsubsection{Geometry and Layout}

The initial design of the test frame was designed around the limitations of the structural lab where it will be operated. The Structural Lab at Carleton University contains a "strong floor" with holes for post-tensioning lockdown of testing equipment to the floor. The strong floor measures $26450 \mathrm{~mm} \times 11200 \mathrm{~mm}$ with a hole pattern for post tensioning of 41 x 16 holes at $600 \mathrm{~mm} \mathrm{O} / \mathrm{C}$ spacing. With the baseplates designed to have two post tensioned rods at each of the three corners, the max width of the table could be $6600 \mathrm{~mm}$. Using this as the initial design dimension, multiple models were developed to test the optimum dimension of the test frame with the table capacity and specimen capacity. As this frame will be used with both testing of suspended ceilings and other non-structural components in the future the size was reduced to minimize the weight of the test frame in order to maximize the specimen capacity. The footprint of the test frame was designed to be $5.4 \mathrm{~m} \times 5.4 \mathrm{~m}$. The height of the test frame was initially set to $1000 \mathrm{~mm}$ to fall within the 
shake table capacity of three tonnes located at $1 \mathrm{~m}$ above the center of gravity of the table. During the various design stages of the frame, the height was adjusted to $1725 \mathrm{~mm}$ so that the suspended ceiling would have a max pendulum height from the bottom chord of the open web steel joist (OWSJ) of $1200 \mathrm{~mm}$ to match the tests performed at the Tongji University. Autodesk Inventor Professional 2020 was the software used to develop a 3D model of the test frame. Figures 5-9, 510, and 5-11 show the 3D layout of the test frame placed on four shake tables. The Test Frame with all bolts for the connections included has a weight of $55.83 \mathrm{kN}(5690.75 \mathrm{~kg})$. When the weight of the shake table's top frame is included with this load, the shake tables are loaded to $57.42 \%$ of their available capacity. This allows for a maximum specimen load of $51.30 \mathrm{kN}$ which is equivalent to an area load of $1.76 \mathrm{kPa}$.

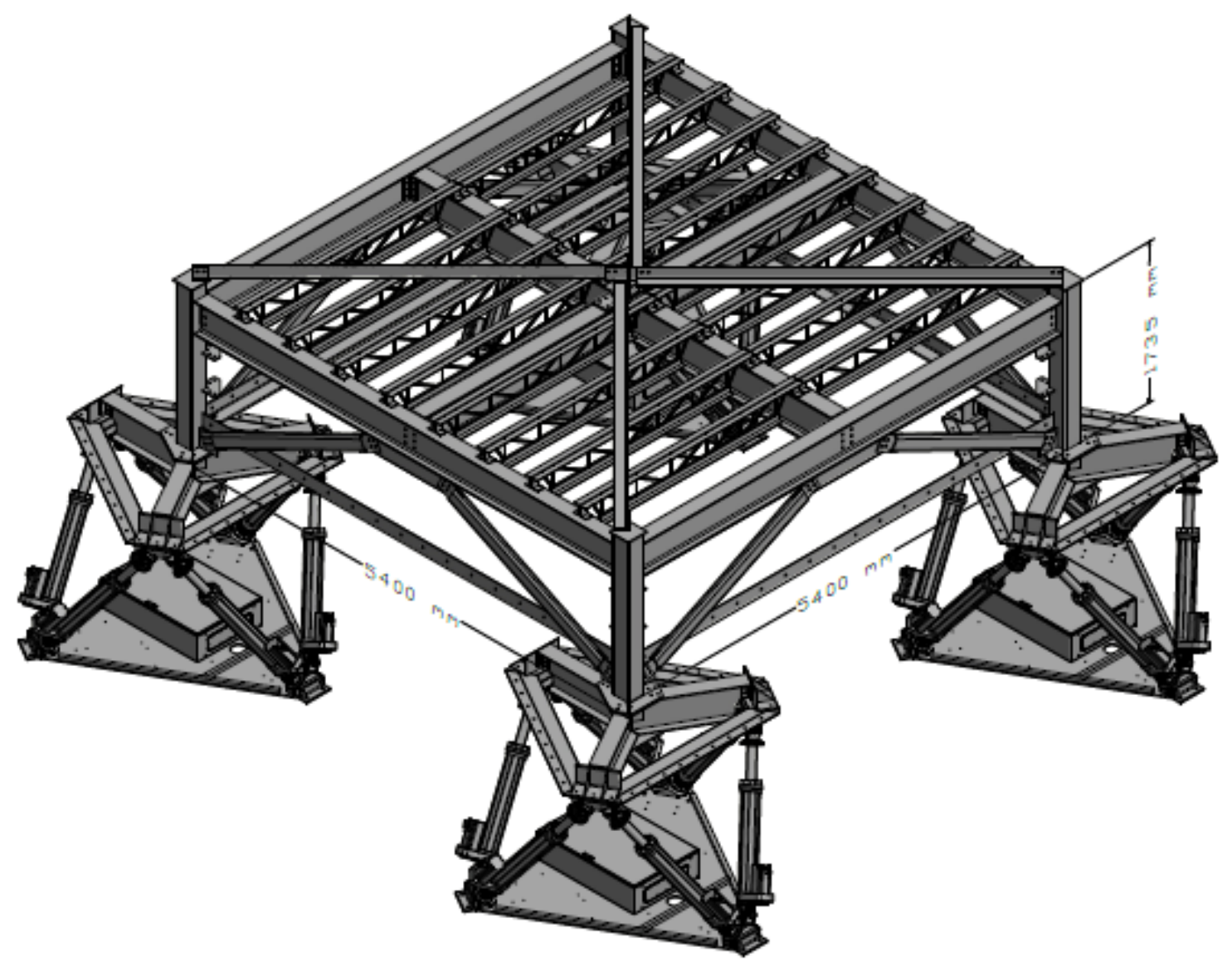

Figure 5-9: Test Frame 3D Inventor Model 


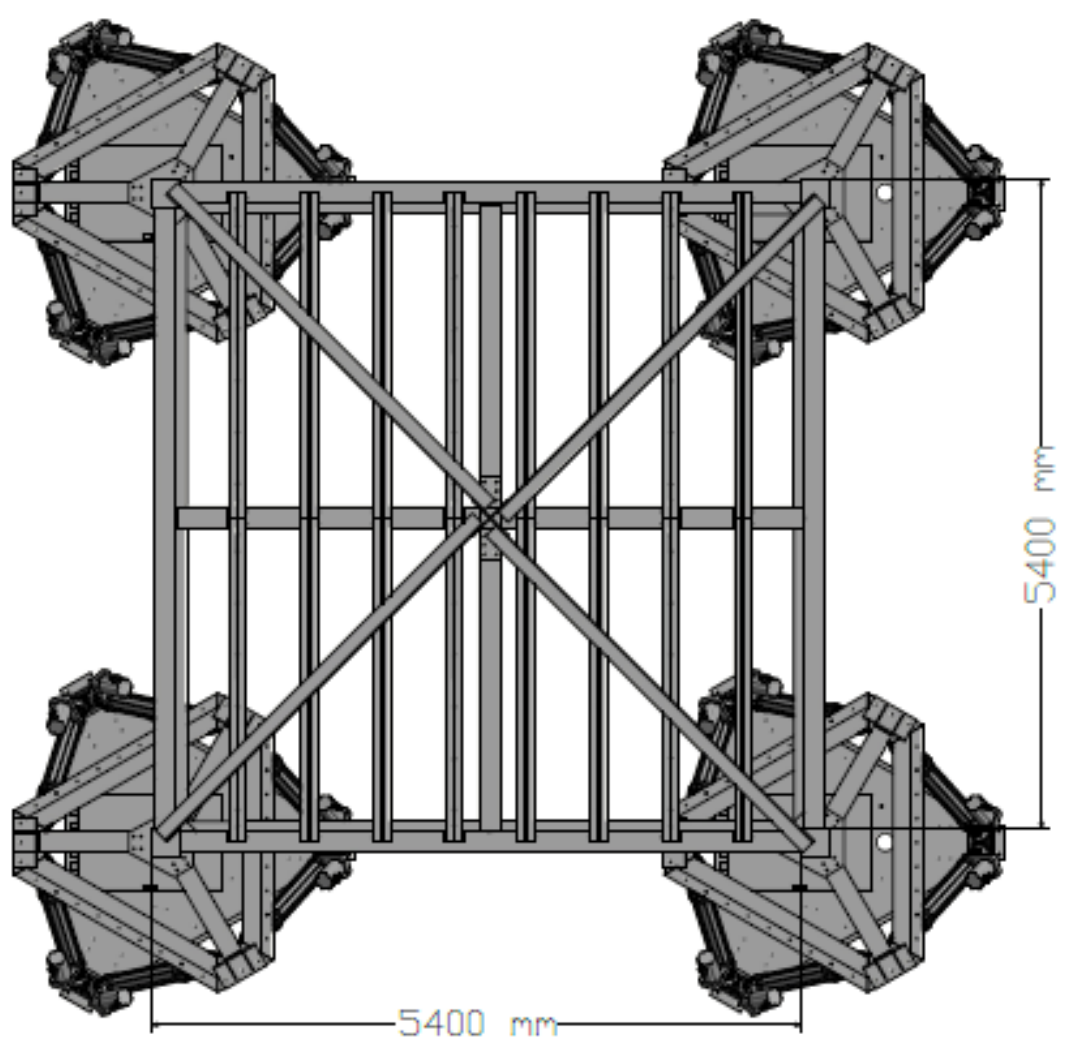

Figure 5-10: Top View of Test Frame Roof

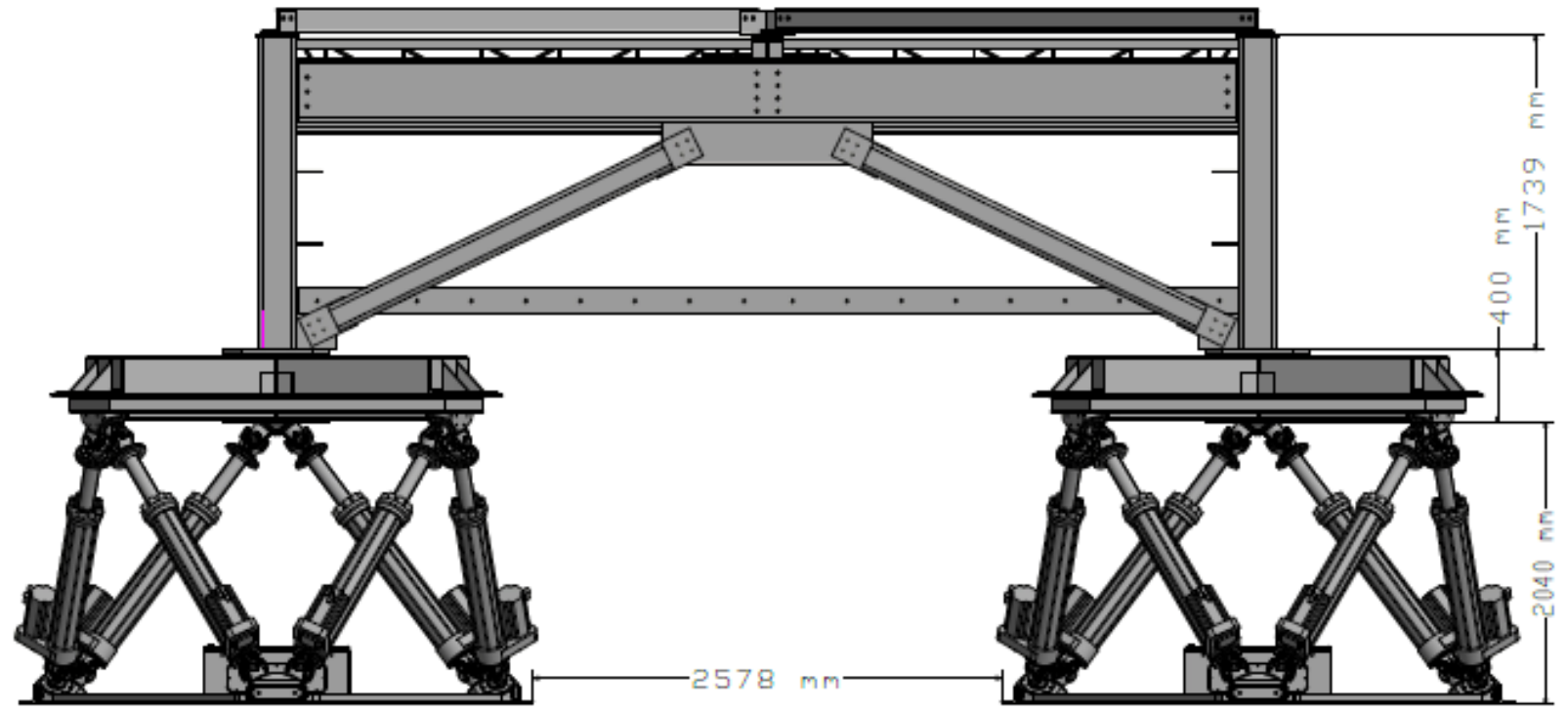

Figure 5-11: Side View of Test Frame

CHAPTER 5: DESIGN OF TEST FRAME FOR NONSTRUCTURAL COMPONENTS

G. DAVIDSON 


\subsubsection{Structural Members}

In order to resist the seismic horizontal forces, three options for the frame design have been considered which range from a braced frame, a moment resisting frame with fixed columns and pin connected beams, and a moment resisting frame with fixed beam and pinned columns. One design criterion of the test frame was to be able to assemble and disassemble with ease to minimize storage space of the lab when not in use. In order to accomplish this, it was determined that the most feasible method would be a braced frame as all the connections would be pin connected with bolts. For the operating mode of the multi-unit shake table systems working together as a single large shake table platform with the test frame placed on top, the shake tables are controlled independently to provide synchronized motion of the test frame platform to reproduce the specified time history motions of the test frame platform. However, due to the possibility of the tables not perfectly moving in sync with one another, this can cause additional forces in the frame. These forces can be minimized by employing force fighting compensation techniques in the control of the shake table motions by adjusting the tables motions to reduce these external forces. Alternatively, the tables can be operated by ignoring these additional shake table interaction forces by simply following the input excitations of the time history without compensation for out-of-sync motion. In this case in order to absorb the interaction forces that may arise due to out-of-sync table motion, the bolted connections in the test frame are designed to allow some minor movement in the frame to minimize the forces caused by table force fighting. The columns were designed as HSS members as this allowed for easier connections on adjacent sides to the W-Shape beams. The braces were also designed to be HSS members for their strength properties and for the torsional resistance of the member. The roof system was comprised of W-Shape beams with open web steel joists (OWSJ) spanning between the interior and perimeter beams. The OWSJ were chosen for 
their inherent property of high stiffness with minimal weight. Another benefit that was key for the primary testing of suspended ceilings was the connection of ceiling to structure. The OWSJ allowed for multiple attachment points without any permanent features needed within the structural members. Open web steel joists are also very common in practice for the majority of steel buildings that have suspended ceilings.

\subsubsection{Capacity of Structural Members}

Tables 5-1 and 5-2 below summarize the capacity of the Test Frame Members. The maximum required strength was found by using a specimen load of $1.76 \mathrm{kPa}$ to provide a conservative design as the additional load was added to the frame members as uniformly distributed loads therefore, simplifying the possible arrangements of non-structural systems. The frame model was subjected to sine wave input excitations at a frequency of $4 \mathrm{~Hz}$ with an amplitude of $6.3 \mathrm{~m} / \mathrm{s}^{2}$ in both horizontal directions simultaneously with an $8.93 \mathrm{~m} / \mathrm{s}^{2}$ vertical excitation. The amplitude in the horizontal and vertical directions were set to the maximum capacity of the shake table. The input frequency was selected by using increments of $2 \mathrm{~Hz}$ starting at $0 \mathrm{~Hz}$ and increasing to the maximum frequency of $15 \mathrm{~Hz}$. The frequency did not have a significant impact on the capacity of the frame members as they were all overdesigned due to a stiffness-based design vs a strength-based design. Therefore, $4 \mathrm{~Hz}$ was chosen to represent an average response as $15 \mathrm{~Hz}$ would be the maximum capacity of the table and would also start to approach resonance frequency of the frame. 
Table 5-1 Capacity of Frame Members

(1.76 kPa Ceiling Load/ $6.3 \mathrm{~m} / \mathrm{s}^{2}$ Horizontal and $8.93 \mathrm{~m} / \mathrm{s}^{2}$ Vertical)

\begin{tabular}{|c|c|c|c|c|c|c|c|}
\hline \multicolumn{2}{|c|}{ Frame Component } & \multicolumn{3}{|c|}{ Available Strength (Design Capacity) } & \multicolumn{3}{|c|}{$\begin{array}{l}\text { Maximum Required } \\
\text { Strength }\end{array}$} \\
\hline Part \# & Member & $\begin{array}{c}\text { Moment } \mathrm{M}_{\mathrm{r}} \\
(\mathrm{kNm})\end{array}$ & $\begin{array}{c}\text { Shear } V_{r} \\
(\mathrm{kN})\end{array}$ & $\begin{array}{c}\text { Axial } A_{r} \\
(\mathrm{kN})\end{array}$ & $\begin{array}{c}\mathrm{M} \\
(\mathrm{kNm})\end{array}$ & $\begin{array}{c}\mathrm{V} \\
(\mathrm{kN})\end{array}$ & $\begin{array}{c}\mathrm{A} \\
(\mathrm{kN})\end{array}$ \\
\hline B1 & W360X51 & 277.0 & 489.0 & 1194.0 & 56.2 & 42.1 & 28.5 \\
\hline $\mathrm{B} 2$ & W360X51 & 277.0 & 489.0 & 1056.0 & 56.2 & 42.1 & 28.5 \\
\hline B3 & W360X45 & 189.0 & 469.0 & 412.0 & 3.0 & 2.0 & 58.8 \\
\hline B4 & W360X45 & 189.0 & 469.0 & 412.0 & 7.8 & 17.2 & 58.8 \\
\hline B5 & W410X85 & 462.0 & 851.0 & 952.0 & 65.5 & 51.4 & 20.5 \\
\hline B6 & W410X85 & 534.0 & 851.0 & 2284.8 & 82.7 & 29.9 & 11.6 \\
\hline BR1 & L127X127X9.5 & 11.0 & 496.0 & 723.0 & 0.5 & 1.0 & 30.5 \\
\hline $\mathrm{BR} 2$ & HSS $152 \times 76 \times 9.5$ & 36.0 & 595.0 & 851.0 & 0.6 & 1.0 & 89.8 \\
\hline $\mathrm{C} 1$ & HSS203X203X9.5 & 145.0 & 793.0 & 1962.0 & 3.3 & 1.9 & 19.3 \\
\hline $\mathrm{C} 2$ & HSS152X152X9.5 & 86.6 & 667.0 & 1640 & 7.6 & 45.1 & 10.1 \\
\hline OWSJ & OWSJ & 25.3 & & & 2.0 & & \\
\hline
\end{tabular}

As shown in Table 5-2, the minimum overdesign factor of the test frame members is 4.9. The reason for the high overdesign of the members is due to the members being designed based on stiffness and not capacity. These results were produced using a load case of 1.0 Dead +1.0 Earthquake with no ductility and overstrength factors used. The resistance factor of the structural steel was set to 0.9 as commonly adopted in steel structure design. As the frame will be subjected to multiple input excitations over its life span it is important to have overdesigned members to 
ensure no fatigue induced failures in the members. Figures 5-12 and 5-13 show a 3D view and a top view of the test frame with the parts labelled for reference.

Table 5-2 Safety Factor of Frame Members

(1.76 kPa Ceiling Load/ $6.3 \mathrm{~m} / \mathrm{s}^{2}$ Horizontal and $8.93 \mathrm{~m} / \mathrm{s}^{2}$ Vertical)

\begin{tabular}{|c|c|c|c|c|c|}
\hline \multicolumn{2}{|c|}{ Frame Component } & \multicolumn{3}{|c|}{ Overdesign Factor } & \multirow{2}{*}{$\begin{array}{c}\text { Limiting } \\
\text { Overdesign Factor }\end{array}$} \\
\hline Part \# & Member & M & V & A & \\
\hline B1 & W360X51 & 4.9 & 11.6 & 41.9 & 4.9 \\
\hline $\mathrm{B} 2$ & W360X51 & 4.9 & 11.6 & 37.1 & 4.9 \\
\hline B3 & W360X45 & 63.0 & 234.5 & 7.0 & 7.0 \\
\hline B4 & W360X45 & 24.2 & 27.3 & 7.0 & 7.0 \\
\hline B5 & W410X85 & 7.1 & 16.6 & 46.4 & 7.1 \\
\hline B6 & W410X85 & 6.5 & 28.5 & 197.0 & 6.5 \\
\hline BR1 & L127X127X9.5 & 22.0 & 496.0 & 23.7 & 22.0 \\
\hline BR2 & HSS $152 \times 76 \times 9.5$ & 60.0 & 595.0 & 9.5 & 9.5 \\
\hline $\mathrm{C} 1$ & HSS203X203X9.5 & 43.9 & 417.4 & 101.7 & 43.9 \\
\hline $\mathrm{C} 2$ & HSS152X152X9.5 & 11.3 & 14.8 & 162 & 6.8 \\
\hline OWSJ & OWSJ & 12.91 & & & 12.9 \\
\hline
\end{tabular}




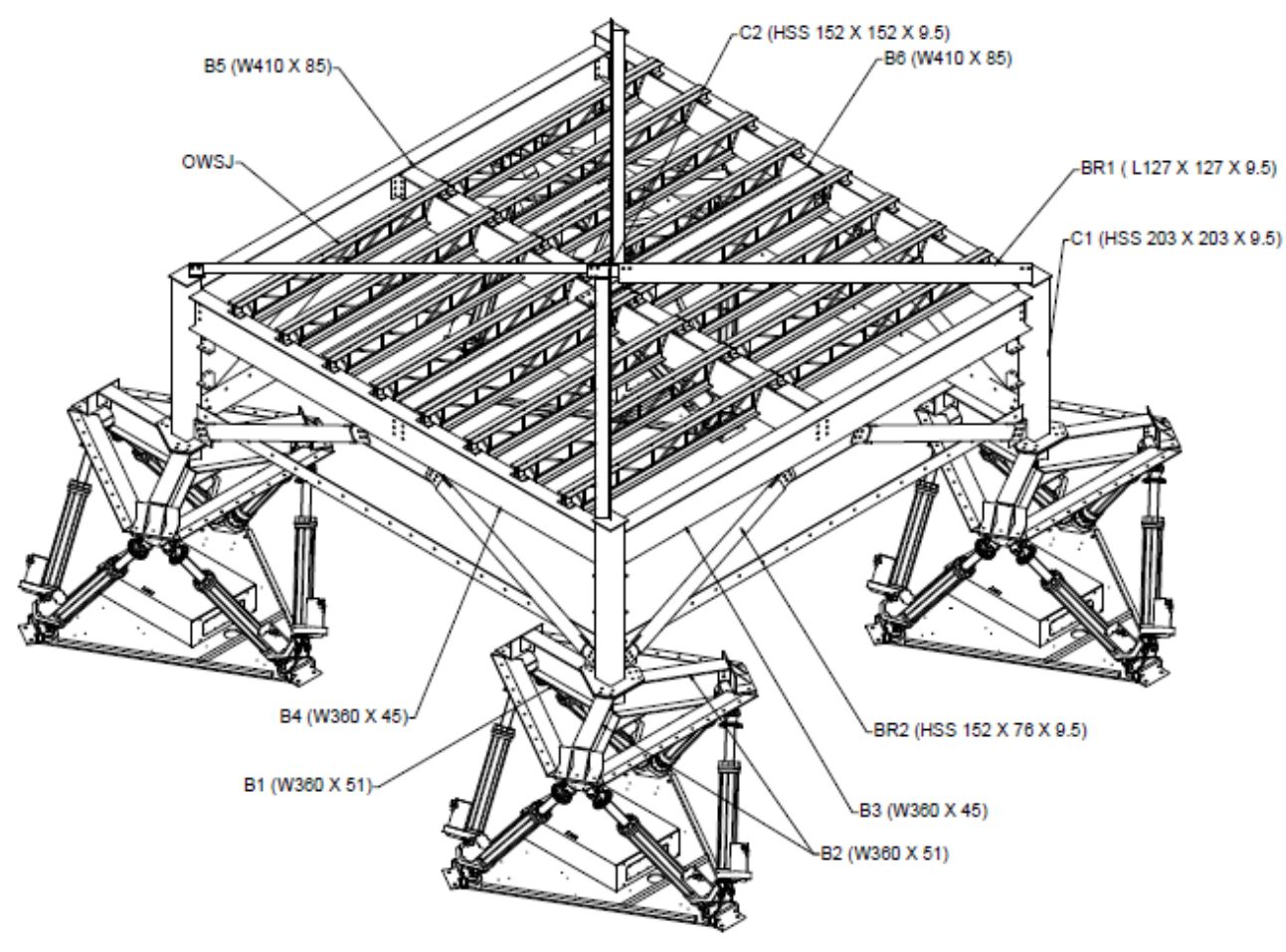

Figure 5-12: 3D View of Test Frame Parts

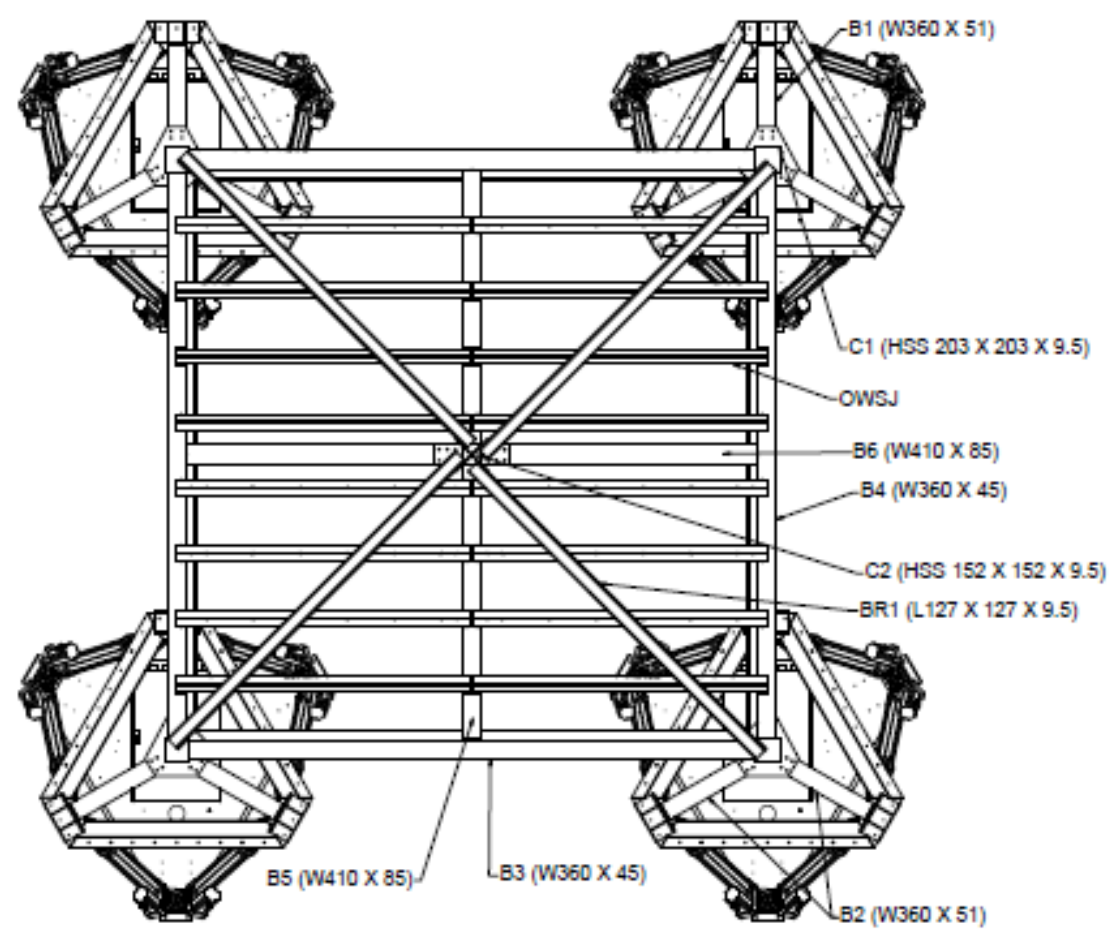

Figure 5-13: Top View of Test Frame Parts 


\subsubsection{Stiffness Design}

The majority of previous researchers used frames with vertical frequencies designed to replicate typical floor frequencies in the range of $8-10 \mathrm{~Hz}$ (Ryu, 2009). Previous researchers observed vertical amplifications in the frames that were not representative of that in the field due to the vertical frame stiffness (Takhirov, 2009). In order to prevent this issue, the desired vertical frequency of the frame was designed to be greater than $20 \mathrm{~Hz}$. This would reduce amplification of input excitations and therefore, floor motion responses can be used as direct input excitations of a typical floor in a building. If the amplification of the frame is significant, then compensation procedures would be required to compensate for the vibration of the test frame in reproducing the required input excitation for testing. Weight can be added to the roof of the frame to decrease the vertical vibration frequency of the test frame if desired for future testing. As mentioned above typical floor frequencies range between $8-10 \mathrm{~Hz}$ and therefore the vertical frequency of the test frame can be reduced to represent different floor frequencies observed in practice which will allow investigation of the influence of floor vibration on the seismic performance of suspended ceilings. The bare frame's horizontal modes were also designed to be greater than $20 \mathrm{~Hz}$ to minimize the amplification of horizontal input motions. As the fundamental frequency of the test frame loaded with test specimens will be reduced due to the additional specimen weight on the test frame, the frequency can be calculated using Equation 6.1.

$$
f_{i}=\frac{1}{2 \pi} * \sqrt{\frac{k_{i}}{m_{i}}}
$$

As specimens are added to the frame, the stiffness remains the same however, the mass increases which therefore decreases the modal frequency as shown below. 
Type equation here.

$$
\frac{\sqrt{\mathrm{m}_{\mathrm{i}}}}{\sqrt{\mathrm{m}_{\mathrm{i}+\mathrm{s}}}}=\left(\frac{1}{2 \pi} * \sqrt{\frac{k_{i}}{m_{i+s}}}\right) /\left(\frac{1}{2 \pi} * \sqrt{\frac{k_{i}}{m_{i}}}\right)
$$

\subsubsection{Unique Features of Test Frame Design}

As the test frame will be used for future testing of other non-structural components other than suspended ceiling systems, the test frame needs to have a versatile design. The plenum space above a ceiling system varies significantly depending on architectural and mechanical requirements, as a result the test frame was designed with adjustable plenum heights. For a floating ceiling with no perimeter angle required, the test frame can accommodate a plenum height of $1600 \mathrm{~mm}$ for a $5400 \mathrm{~mm}$ x $5400 \mathrm{~mm}$ ceiling. The maximum length from underside of open web steel joist to strong floor is $3300 \mathrm{~mm}$, however the ceiling would need to have a reduced area to avoid interaction with the shake tables. Suspended Ceiling systems with perimeter angles required can be tested with varying plenum heights of $400 \mathrm{~mm}, 800 \mathrm{~mm}$ and $1200 \mathrm{~mm}$ as shown in Figure 5-14. Another feature of the test frame is the ability to remove the angle bracing at the roof for future testing of non-structural floor components and equipment. For testing of floor components, plywood or steel deck can be fastened to the top chord of the open web steel joists to create a floor assembly. The final unique feature of the test frame is the ability to reuse the triangular base attachment to the shake table for direct placement of test specimens on the shake tables, such as a three-dimensional structure with four supports with each support on a separate shake table. 


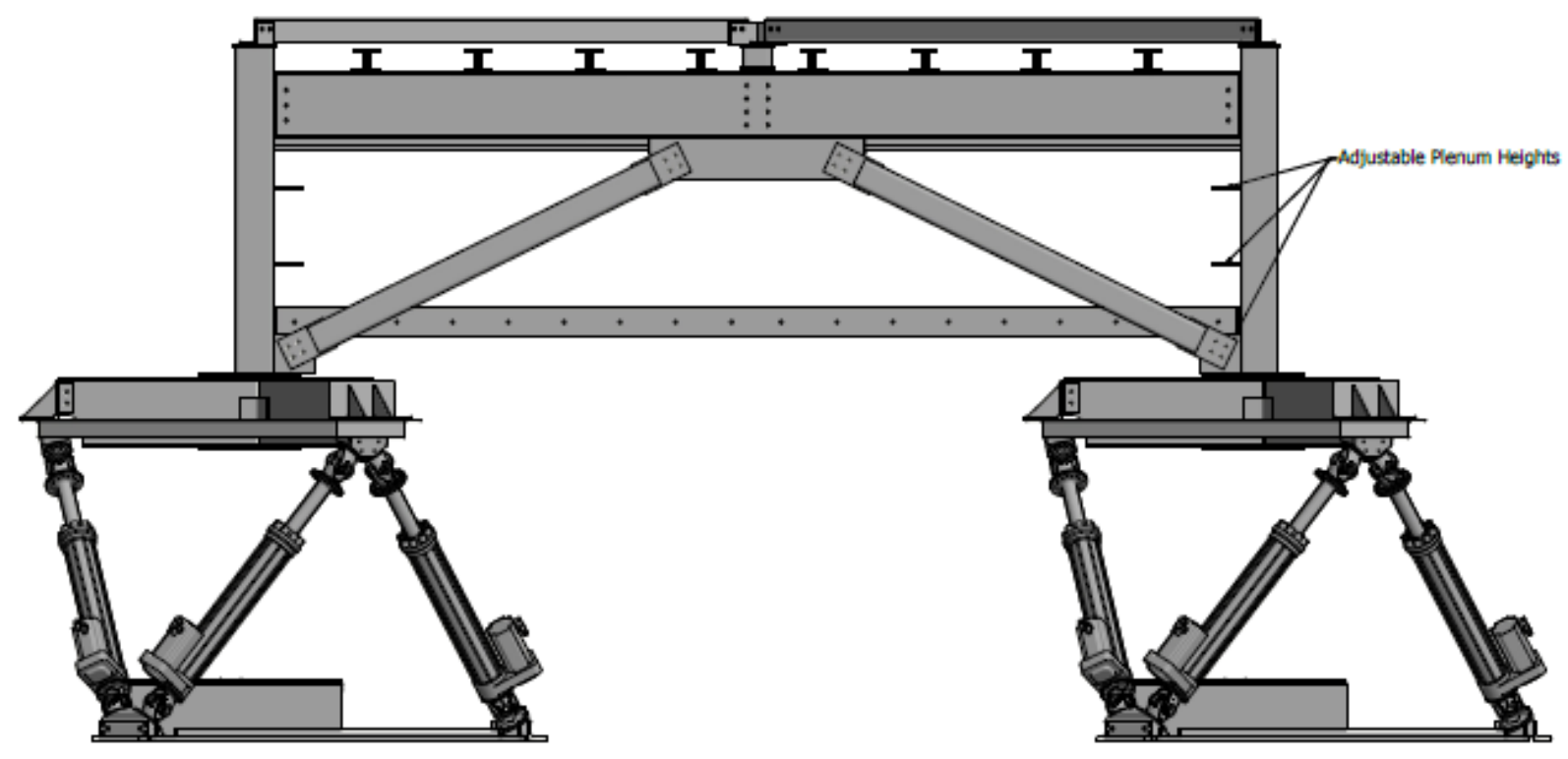

Figure 5-14: Side View of Test Frame with Adjustable Plenum Heights

\subsubsection{Numerical Model (SAP2000)}

Using SAP2000, the test frame was modelled to optimize the design and evaluate the dynamic properties. Using the built-in design optimization tool, the frame members were selected to be light and stiff to increase the fundamental frequencies. All members were modelled using pin ends connections with the exception of the I-Shape Beams in the center of the roof of the frame and underneath the columns. It is expected that the experimental frame will have fundamental frequencies slightly higher than the numerical model as the designed bolted connections will not be "perfectly pinned" as they do provide some rotational resistance. The test frame assembly was modelled by linear elements which included the test frame and the assemblies that attached the test frame to the shake tables. . 


\subsubsection{Modal Analysis}

The results from the model produced using SAP2000 indicate that the frame has the desired fundamental frequencies. The fundamental frequencies of the test frame are shown below for the frame with maximum specimen weight and with no specimen.

Table 5-3: SAP2000 Test Frame Modal Frequencies

\begin{tabular}{|c|c|c|}
\hline & No Specimen (0kPa) & Max Specimen (1.76kPa) \\
\hline Vertical (Z Direction) & $21.6 \mathrm{~Hz}$ & $15.5 \mathrm{~Hz}$ \\
\hline Longitudinal (X Direction) & $22.9 \mathrm{~Hz}$ & $15.6 \mathrm{~Hz}$ \\
\hline Transversely (Y Direction) & $24.4 \mathrm{~Hz}$ & $17.1 \mathrm{~Hz}$ \\
\hline
\end{tabular}

The modal shapes and fundamental frequencies of the frame with no specimen can be seen below in Figures 5-15, 5-16 and 5-17.

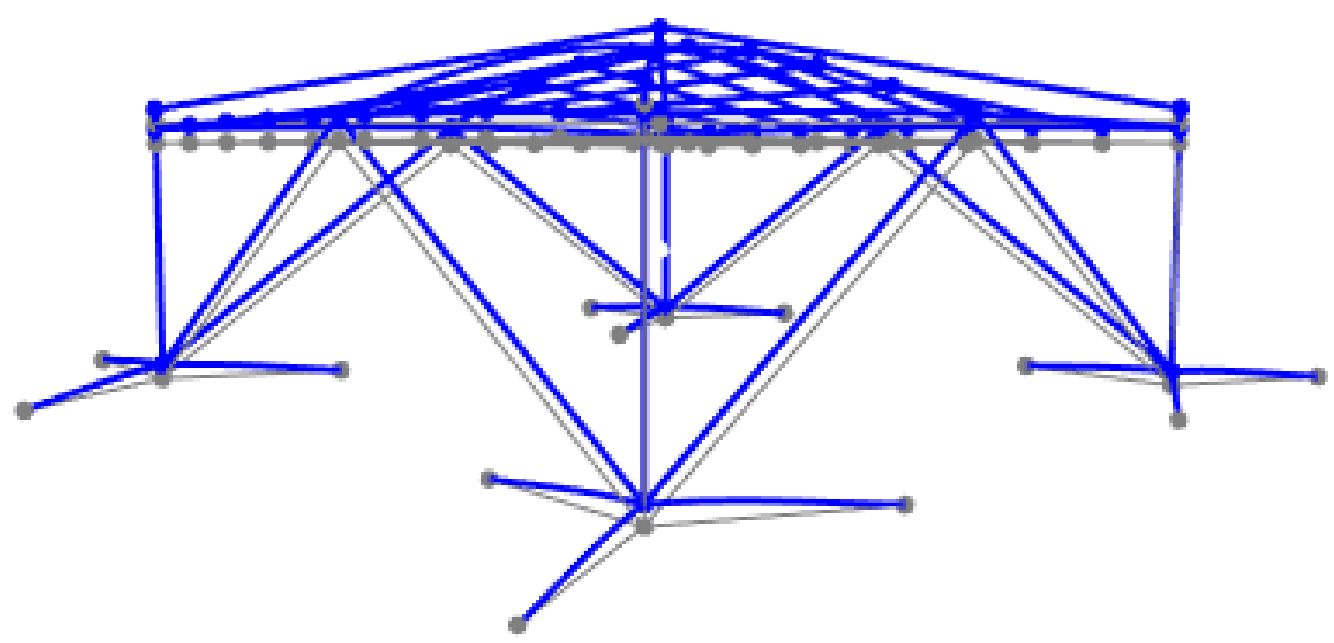

Figure 5-15: $1^{\text {st }}$ Mode Vertical Translation (Z Axis) $21.6 \mathrm{~Hz}$ 


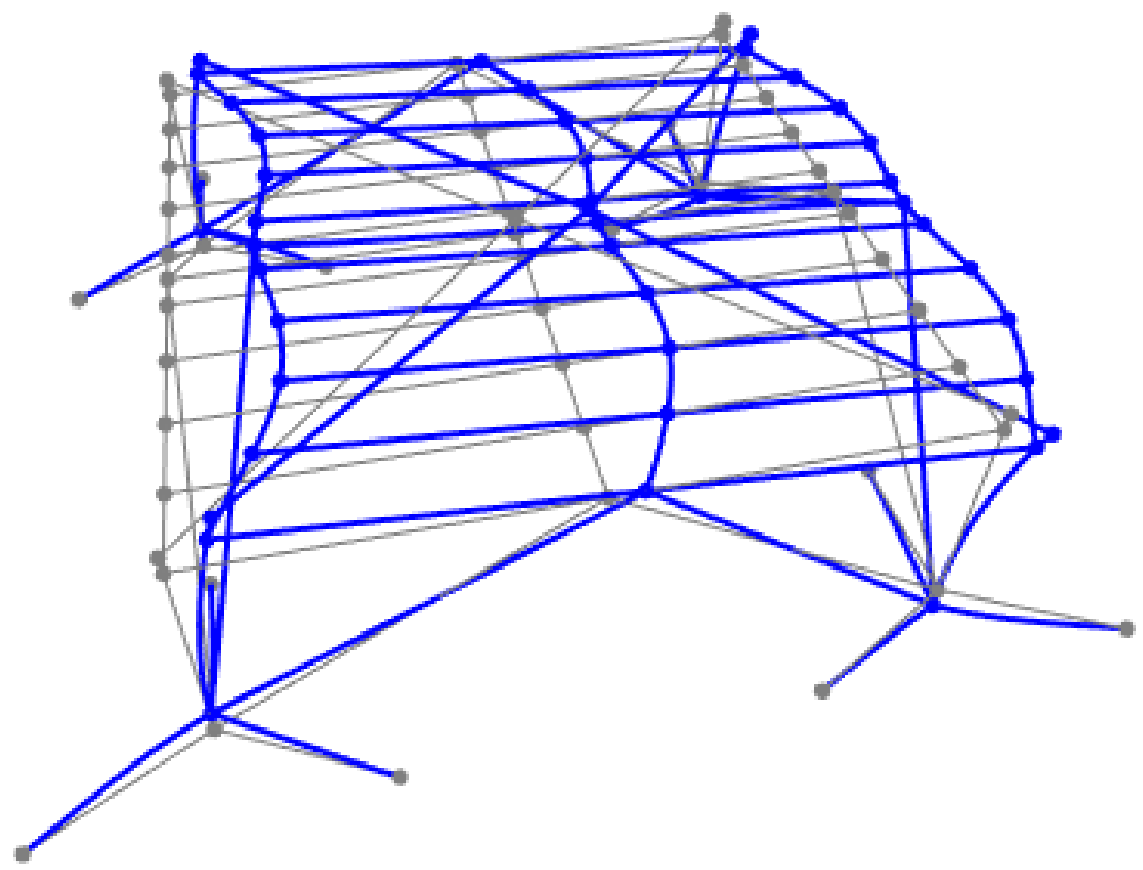

Figure 5-16: $2^{\text {nd }}$ Mode Horizontal Translation (X Axis) 22.9 Hz

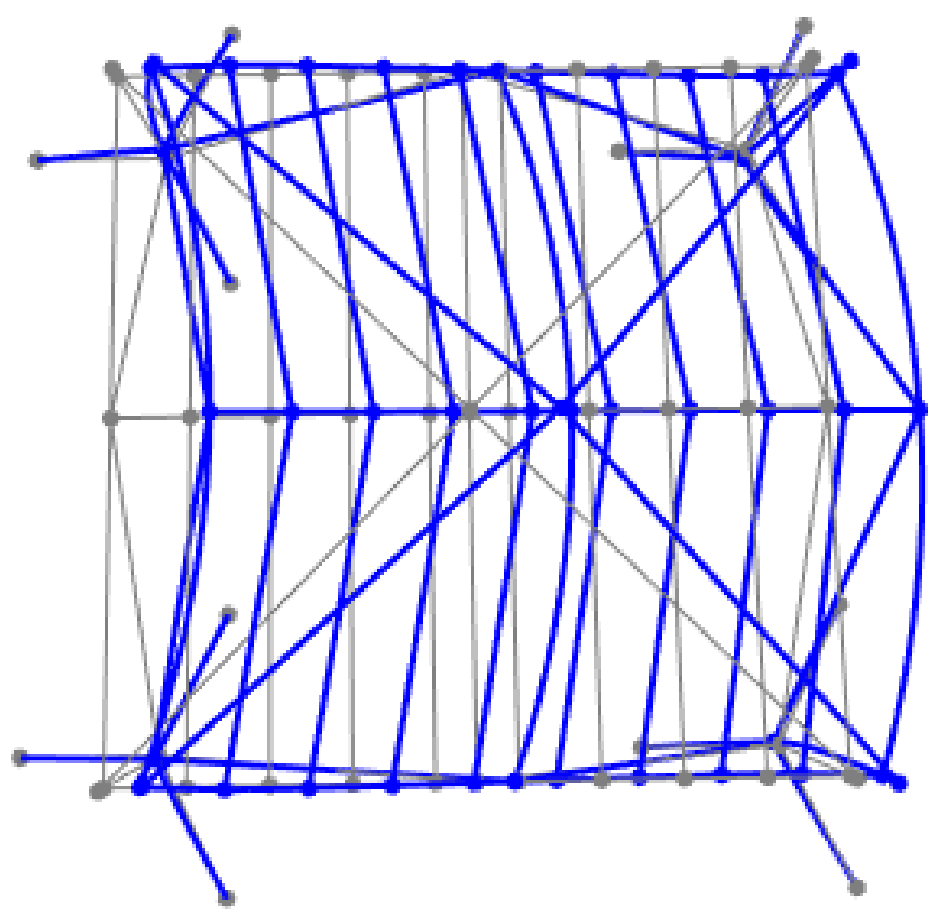

Figure 5-17: Top-View $3^{\text {rd }}$ Mode Horizontal Translation (Y Axis) $24.4 \mathrm{~Hz}$ 


\subsubsection{Amplification of Input Motions}

Time history analysis were performed on the computer model to predict the experimental variance between the input excitations on the shake tables versus the output motions at the middle of the test frame roof. As the tables were not included in the model the excitations were inputted as accelerations to the base of the test frame. The amplifications in the accelerations are produced by the flexibility in the frame. Although the motions will have slight amplification the control software for the tables should be able to compensate the motions during the experiment. Otherwise, an open loop compensation method can be developed during future testing as previous researchers have done in their experiments. As expected, based on the modal analysis of the frame, there is more amplification in the vertical direction in the middle of the test frame roof than the horizontal direction. Earthquake record "64" described in Chapter 6 was used as the input excitation for the test frame model with the output of the frame taken as the center of the roof as this point will experience the highest amplifications (Takhirov, 2009). Figure 5-18 and 19 demonstrate the amplification of the input excitations in the vertical and horizontal directions, respectively.

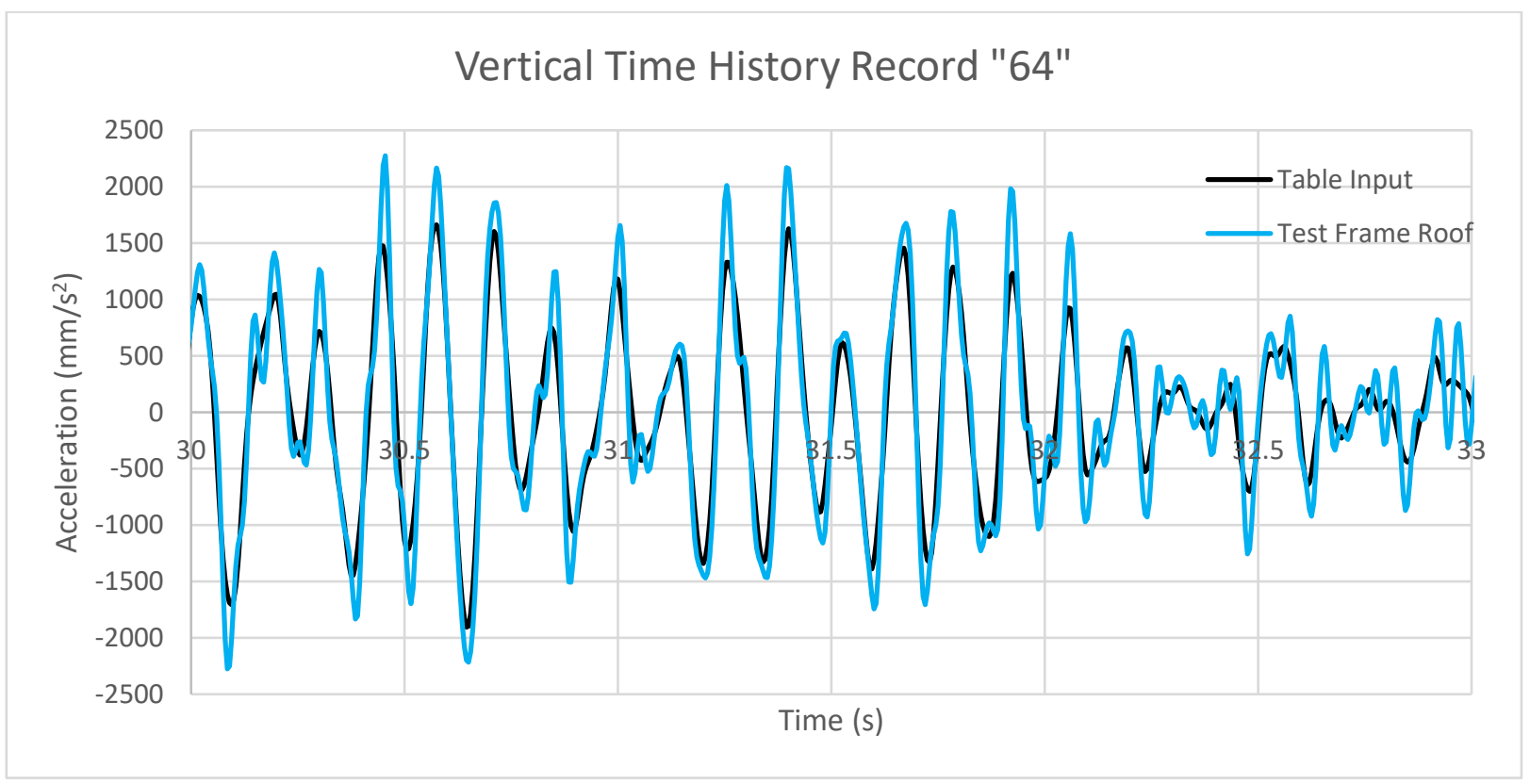

Figure 5-18: Amplification of Vertical Time History Record "64" 


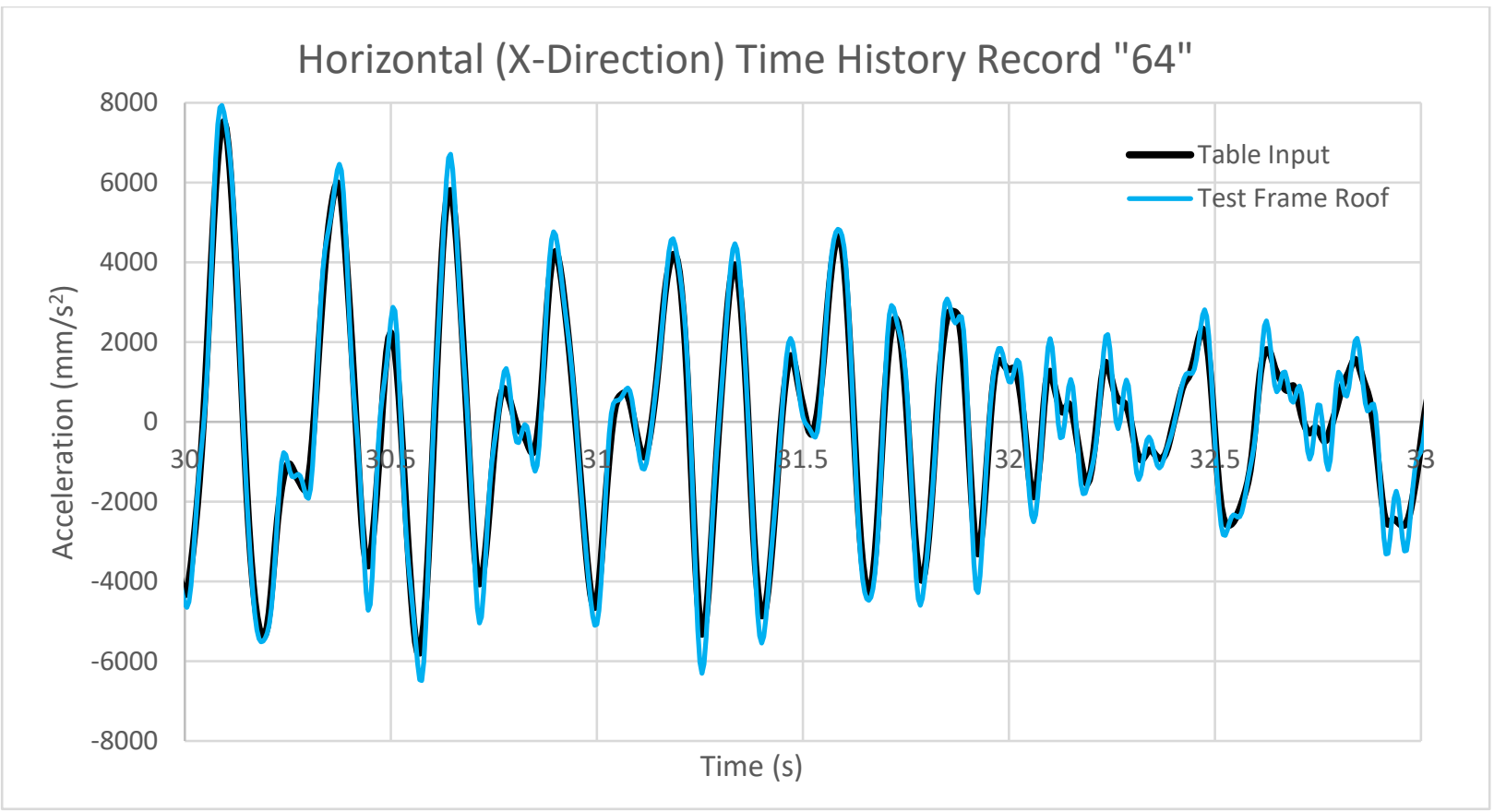

Figure 5-19: Amplification of Horizontal (X-Direction) Time History Record “64"

In conclusion, the amplification of the input excitations is significantly less than some previous experiments (Takhirov, 2009). The maximum amplification of output motion versus table input motions is a factor of 1.6. Although this is high, considering the required size and span of the test frame with the maximum payload capacity of the shake tables the design was optimized to produce the lowest feasible amplification. The actual amplification should be lower as the test frame is expected to be stiffer than the calculated fundamental frequencies. This amplification is significantly lower than that of the tests performed at the University of Buffalo (UB). The tests performed at UB experienced accelerations in the center of the roof of over $25.0 \mathrm{~g}$ causing failure of the suspended ceiling not typical to that observed in the field (Takhirov et al., 2010).

Three assemblies were designed to initiate the multiple-unit shake table testing program at Carleton University. The dummy payload was designed for commissioning of the shake tables for acceptance tests and for future calibration tests. The stacking frame was designed for storage of 
the shake tables while not in active use to reduce the overall space required for this testing program in the structural laboratory and allow for testing using the new concrete block reaction wall presented in chapter 8 . Finally, a test frame was designed and constructed to be used for future testing of non-structural components including both suspended and floor elements. The test frame model can be combined with the floor motion responses in Chapter 6 to develop a test frame response time history. This can be used for prediction of future experimental testing results by inputting the test frame excitations into the non-linear suspended ceiling model presented in Chapter 7. 


\section{Chapter 6: Evaluation of ICC AC-156 Testing Procedures}

\subsection{Etabs Model (Lennox \& Addington)}

This chapter provides an overview into the analysis of a mid-rise building subjected to earthquake records scaled with respect to the Ottawa and Victoria design response spectrum. The floor motion response records are then compared with the current required response spectrum. These records can be used for input excitations on the suspended ceiling model presented in Chapter 7 and the future experimental shake table testing as part of the testing program at Carleton University.

The structure that was analyzed as part of the research on seismic response behaviour and performance of suspended ceilings is the Lennox and Addington residence building at Carleton University's campus in Ottawa. The building was opened in 2011 and holds a population of 717 students.

The Lennox and Addington residence building is a ten-storey concrete structure with shear walls as the lateral force resisting system. This structure sits on a raft foundation with the basement floor as a slab on grade. This building has an approximate footprint of $1580 \mathrm{~m}^{2}\left(17,000 \mathrm{ft}^{2}\right)$. All structural components of the building were constructed with concrete with a compressive strength of $35 \mathrm{MPa}$ with the exception of the raft foundation which had a concrete strength of $25 \mathrm{MPa}$. The buildings location has a seismic classification as Site Class $\mathrm{C}$ with $R_{d}$ and $R_{o}$ values of 1.5 and 1.3 respectively.

This building has a basement that provided access to the underground tunnel system of Carleton University. However, in the structural modelling, the basement floor is not included as a simplification so that the entire ground level is treated as fixed support of the building. The 
gridlines are setup as per the structural drawings. The first three storeys have a slight difference in structural layout compared to the rest of the building, which is included in the Etabs model. The upper stories have the same structural layouts as the third floor of the building, and they are modelled accordingly. The roof has a slightly thicker concrete slab due to the higher load resulting from the mechanical machinery and the snow loads. The loading of the structure only includes the self weight of the structural components. It is assumed no snow load, no live load due to occupancy, and no dead load due to non-structural elements for simplicity. In actual design of the structure the load combination would include 1.0 Dead Load + 0.5 Live Load + 0.25 Snow Load.

In the model, the shear walls and floor slabs are represented as solid, uncracked concrete sections, without modelling the reinforcing. The floor slabs are effectively rigid diaphragms and will not affect the linear behaviour of the structure. The uncracked shear wall stiffness is too high; however, this is balanced by the omission of the transformed stiffness contribution of the steel reinforcing. Overall, the stiffness and resulting period are in a reasonable range for this type of structure. Figure 6-1 and Figure 6-2 illustrates the Etabs model of the analyzed building. 


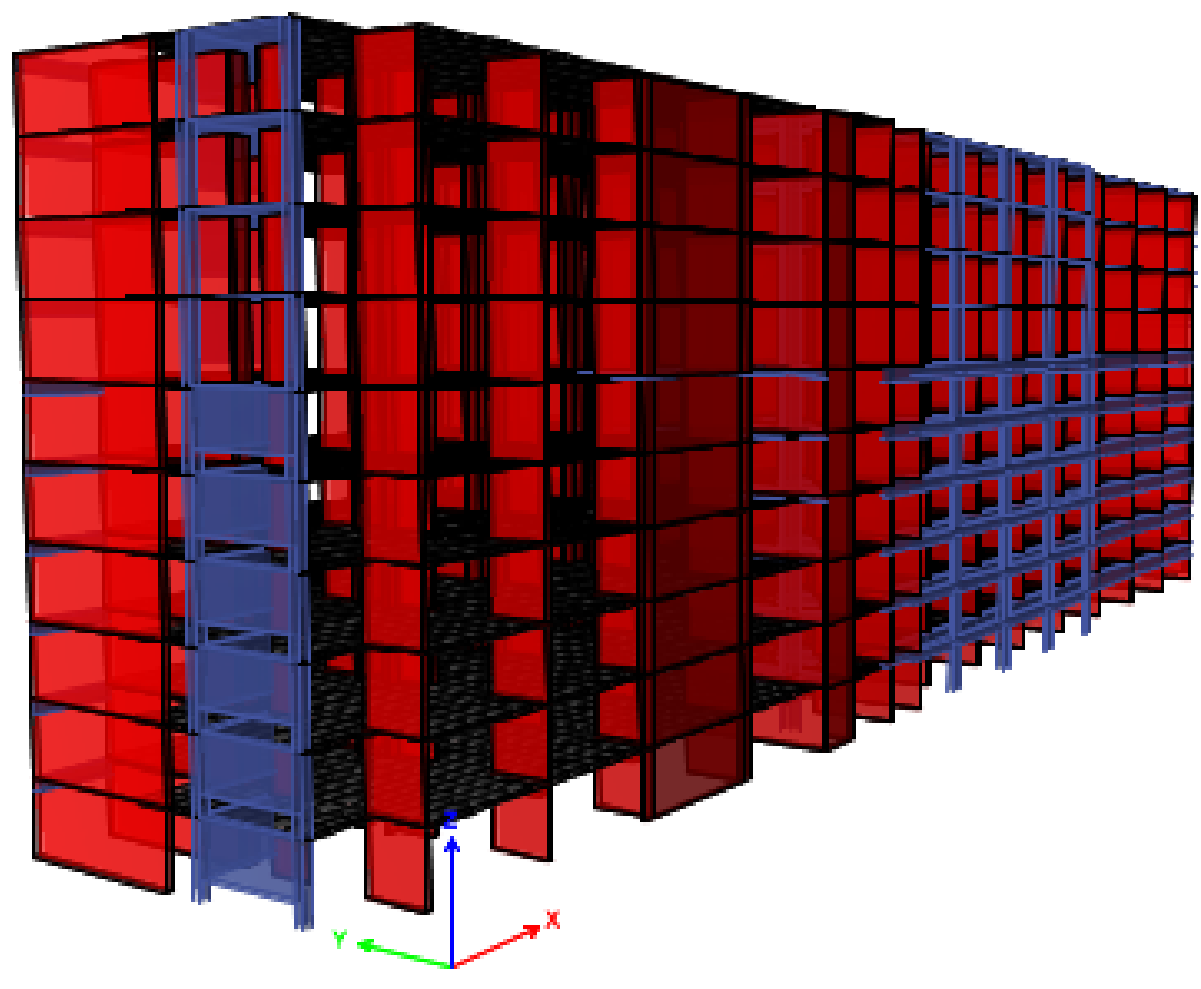

Figure 6-1: ETABS 3-D Model of Lennox and Addington

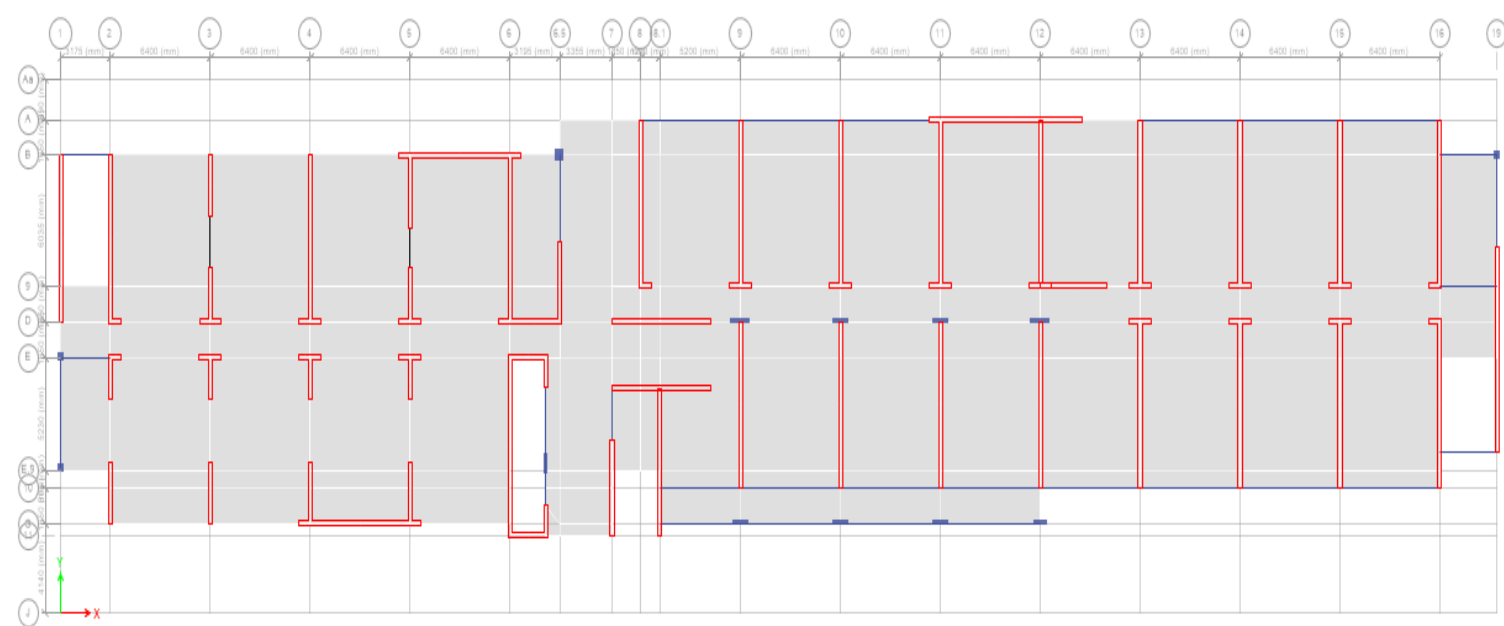

Figure 6-2: Typical Floor Layout of Building 


\subsection{Modal Analysis}

The results from the model generated using Etabs indicate that the structure has realistic fundamental frequencies of a concrete structure. The first mode is a translation in the long direction of the structure of $0.469 \mathrm{~s}(2.13 \mathrm{~Hz})$ which was expected due to the majority of shear walls being located in the short direction of the building. The second mode is found to be a translation mode in the short direction of $0.307 \mathrm{~s}(3.26 \mathrm{~Hz})$. The third mode of the structure is torsion about the vertical axis of $0.258 \mathrm{~s}(3.88 \mathrm{~Hz})$. The first three modes of the structure are shown in Figures 6-3 to 6-5:

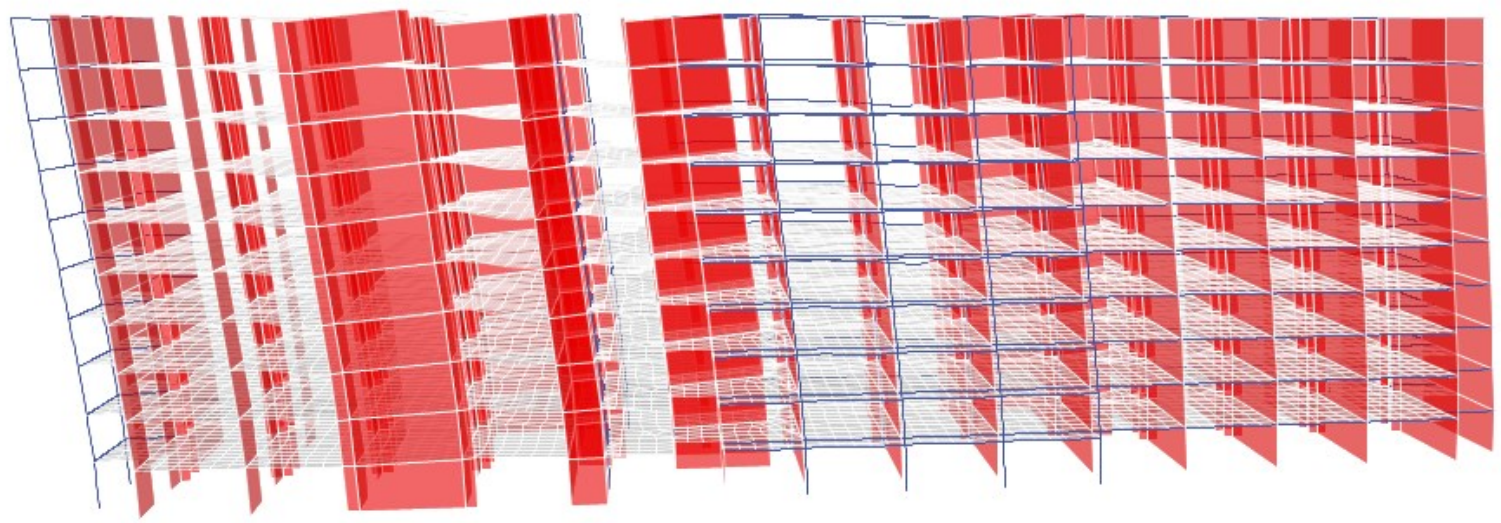

Figure 6-3: $1^{\text {st }}$ Mode Long Direction Translation (X Axis) $0.469 \mathrm{~s}(2.13 \mathrm{~Hz})$ 


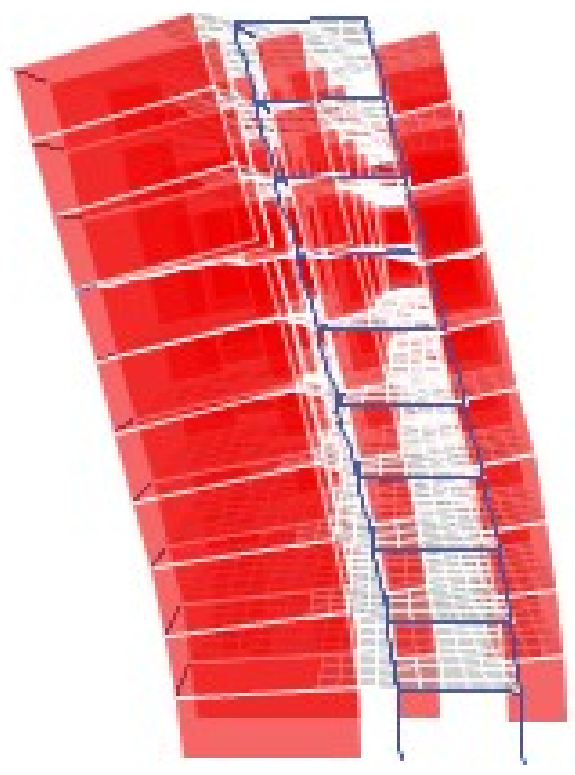

Figure 6-4: $2^{\text {nd }}$ Mode Short Direction Translation (Y Axis) 0.307 s (3.26 Hz)

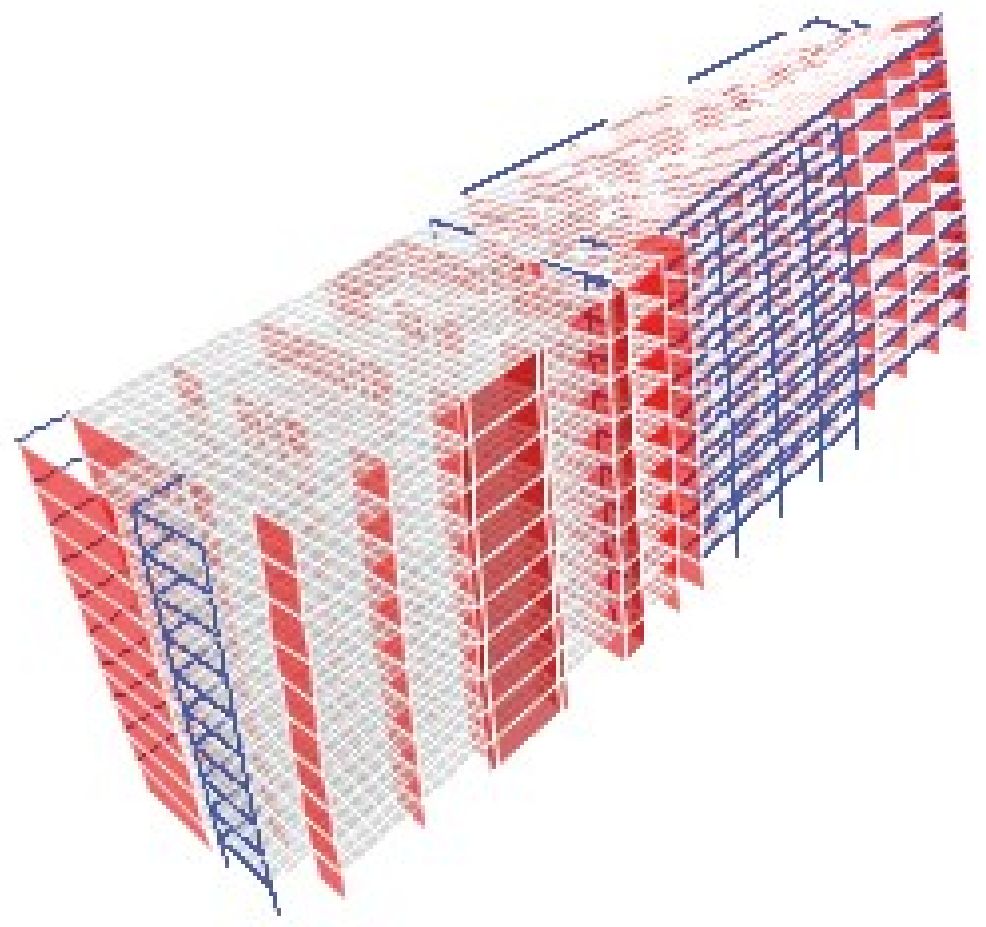

Figure 6-5: $3^{\text {rd }}$ Mode Torsion of Vertical Axis (Z Axis) 0.258 s (3.88 Hz) 


\subsection{Input Ground Motions}

In a computer simulation study, the responses of suspended ceilings in the Lennox and Addington building are evaluated by following the same testing protocol as used in the Tongji shake table test on the Japanese and Chinese ceilings. In addition, ten ground motions are chosen and scaled appropriately to meet the minimum required five ground motions per site. Five ground motion records around eastern Canada are selected. Five additional records from the west coast of North America are chosen and scaled to Site Class C located in Victoria, BC. The two sites, one in eastern and another in western Canada are subjected to seismic hazards with different characteristics including different frequency contents. The records are scaled in accordance to the scaling procedure described in Commentary $\mathrm{J}$ of the National Building Code of Canada "Selection and Scaling of Ground Motion Time Histories" (NBC, 2015). These records are used as input excitations in Etabs analysis to generate floor response motions of the building. The floor response motions are compared with the required response spectrum outlined in "Acceptance Criteria for

Seismic Certification by Shake-table Testing of Non-Structural Components" designated as the ICC-ES AC156 (ICC, 2010). 


\subsection{Ottawa, ON Time History Records}

The five records located near Carleton University are shown in Figure 6-6:

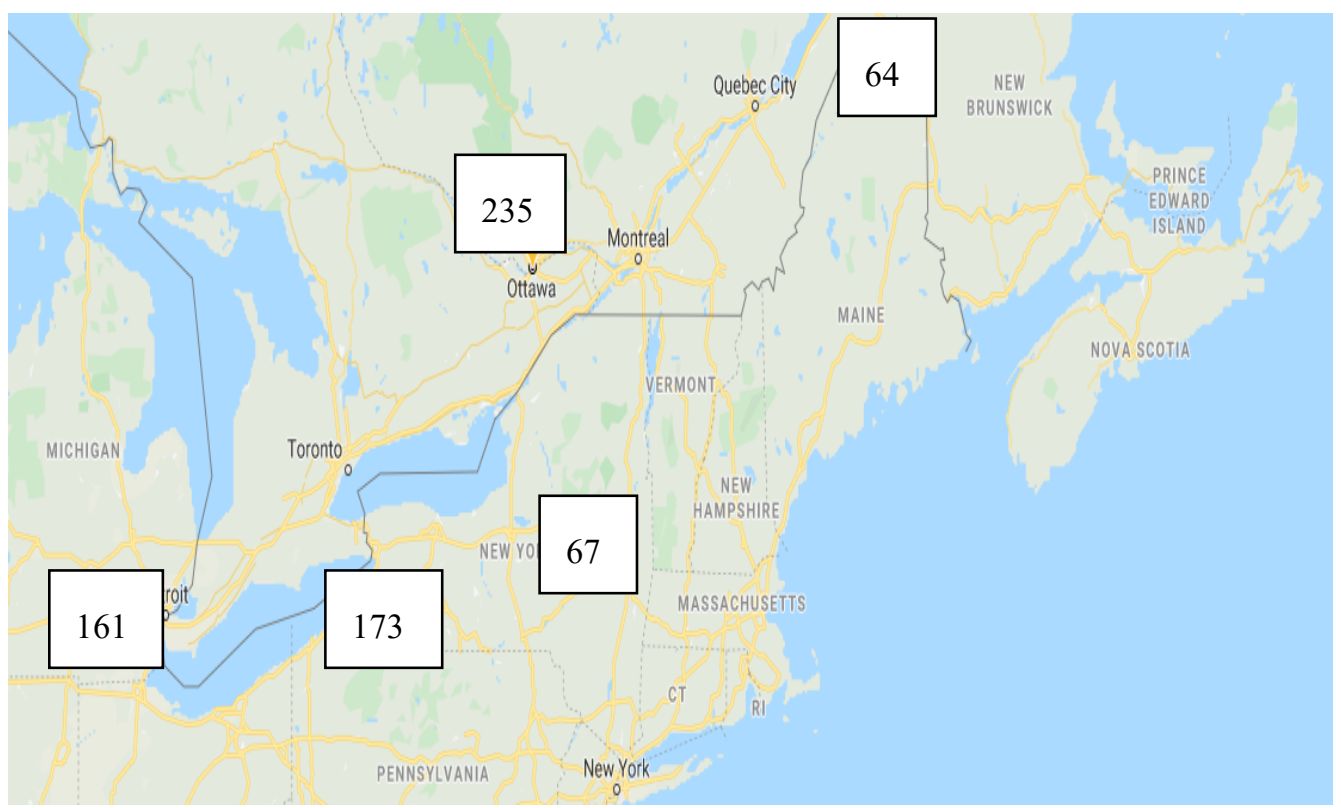

Figure 6-6: Record Locations of eastern Canada earthquake records

Table 6-1 describes the location of the five ground motion records selected from the PEER Database (PEER, 2013). All records excluding record \#235 contain three directional time history records.

Table 6-1 Summary of Earthquake Records near Ottawa, ON

\begin{tabular}{|c|c|c|c|c|c|}
\hline $\begin{array}{c}\text { Earthquake } \\
\text { Record }\end{array}$ & Earthquake & Year & Magnitude & $\begin{array}{c}\text { Distance to } \\
\text { Rupture Plane } \\
(\mathrm{km})\end{array}$ & Vs30 (m/s) \\
\hline 64 & Saguenay & 1988 & 5.85 & 192 & 822.1 \\
\hline 67 & Saguenay & 1988 & 5.85 & 488 & 900.7 \\
\hline 161 & Cap Rouge & 1997 & 4.45 & 1088 & 437.1 \\
\hline 173 & Cap Rouge & 1997 & 4.45 & 738 & 684.9 \\
\hline 235 & Kipawa & 2000 & 4.62 & 292 & 2000 \\
\hline
\end{tabular}

The records were scaled with respect to the Lennox \& Addington Building site in Ottawa. The design spectrum of Site Class $\mathrm{C}$ was determined. A period range in which the records were 
scaled was based on the first modal period $\left(T_{1}\right)$ from the Etabs model. The defined period range was found to be $0.0711 \mathrm{~s}\left(0.15 \mathrm{~T}_{1}\right)$ to a maximum $1.5 \mathrm{~s}$. The scaled records spectral acceleration and target response spectrum are shown in Figure 6-7.

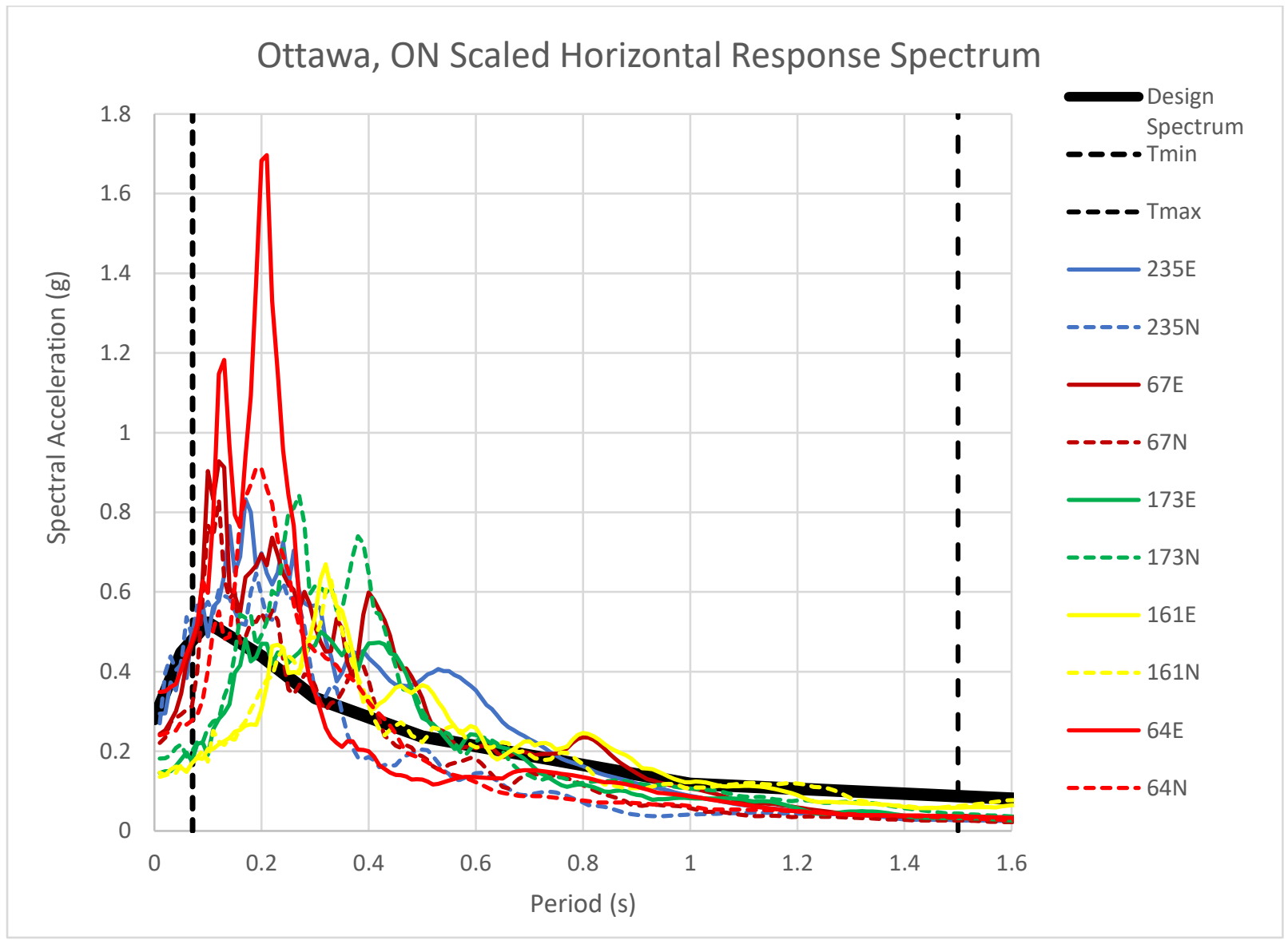

Figure 6-7: Scaled Response Spectra (Ottawa) 


\subsection{Victoria, BC Time History Records}

The five selected west coast North American earthquake records scaled to Site Class C in Victoria, BC are shown in Figure 6-8 and 6-9.

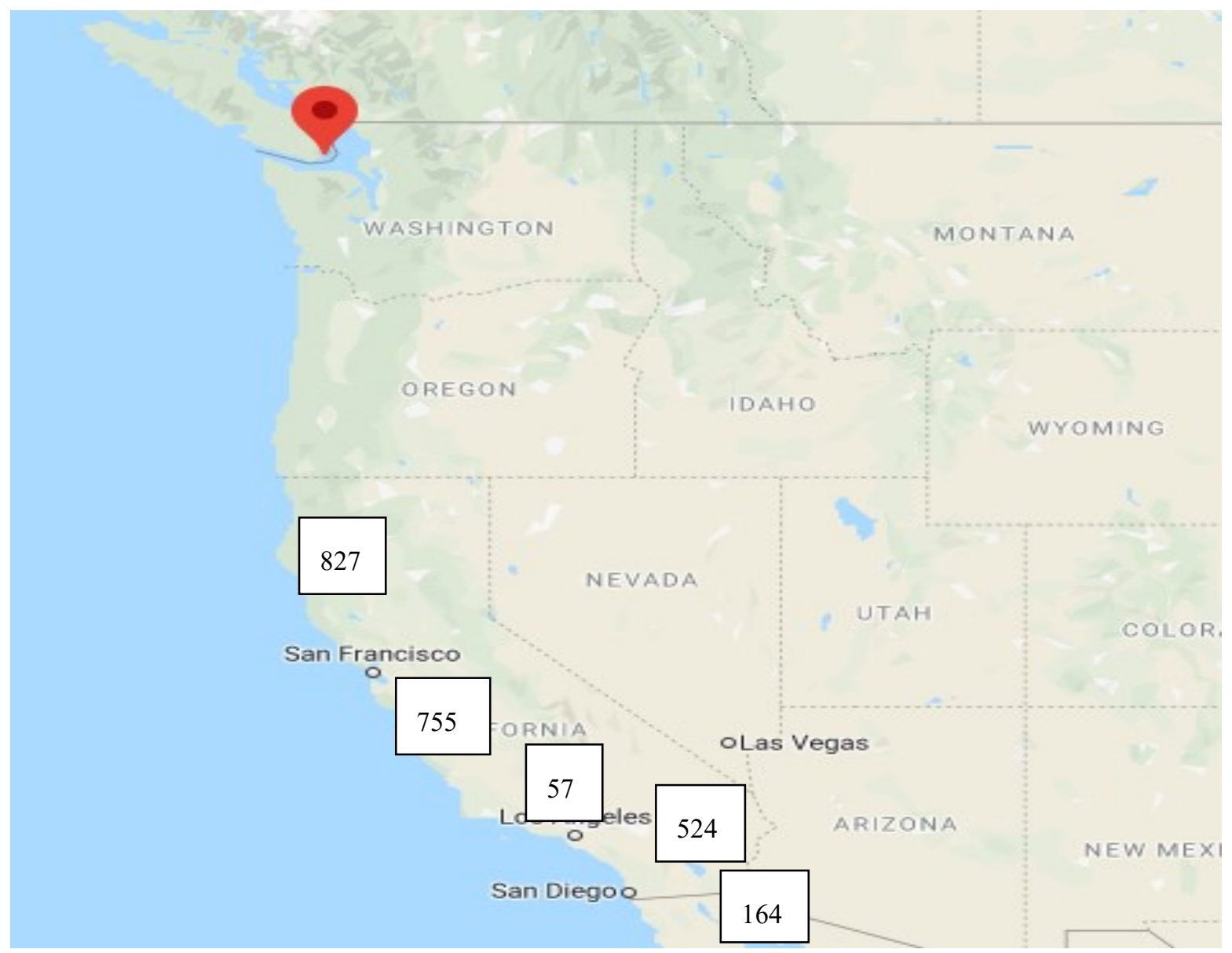

Figure 6-8: Record locations of west coast North American earthquake records

Table 6-2 describes the location of the five ground motion records selected from the PEER

Database. All the selected west coast earthquake records were recorded in California, USA with shear wave velocity of the top $30 \mathrm{~m}$ of foundation soil in the range of Site Class C. 
Table 6-2 Summary of Earthquake Records near Victoria, BC

\begin{tabular}{|c|c|c|c|c|c|}
\hline $\begin{array}{c}\text { Earthquake } \\
\text { Record }\end{array}$ & Earthquake & Year & Magnitude & $\begin{array}{c}\text { Distance to } \\
\text { Rupture Plane } \\
(\mathrm{km})\end{array}$ & Vs30 (m/s) \\
\hline 57 & San Fernando & 1971 & 6.61 & 23 & 450.3 \\
\hline 164 & Imperial Valley-06 & 1979 & 6.53 & 15 & 471.5 \\
\hline 524 & N. Palm Springs & 1986 & 6.06 & 27 & 379.3 \\
\hline 755 & Loma Prieta & 1989 & 6.93 & 20 & 561.4 \\
\hline 827 & Cape Mendocino & 1992 & 7.01 & 20 & 457.1 \\
\hline
\end{tabular}

For purposes of this study, the records were scaled with respect to the Lennox \& Addington Building located on a site in Victoria, BC discussed in Section 6.2 above. This allowed for one building to be used for two different cities instead of creating two separate models. As the building was only analyzed linearly and the design of the structure itself was not part of this study this simplification seemed appropriate. The scaled records spectral acceleration and target response spectrum are shown in Figure 6-9.

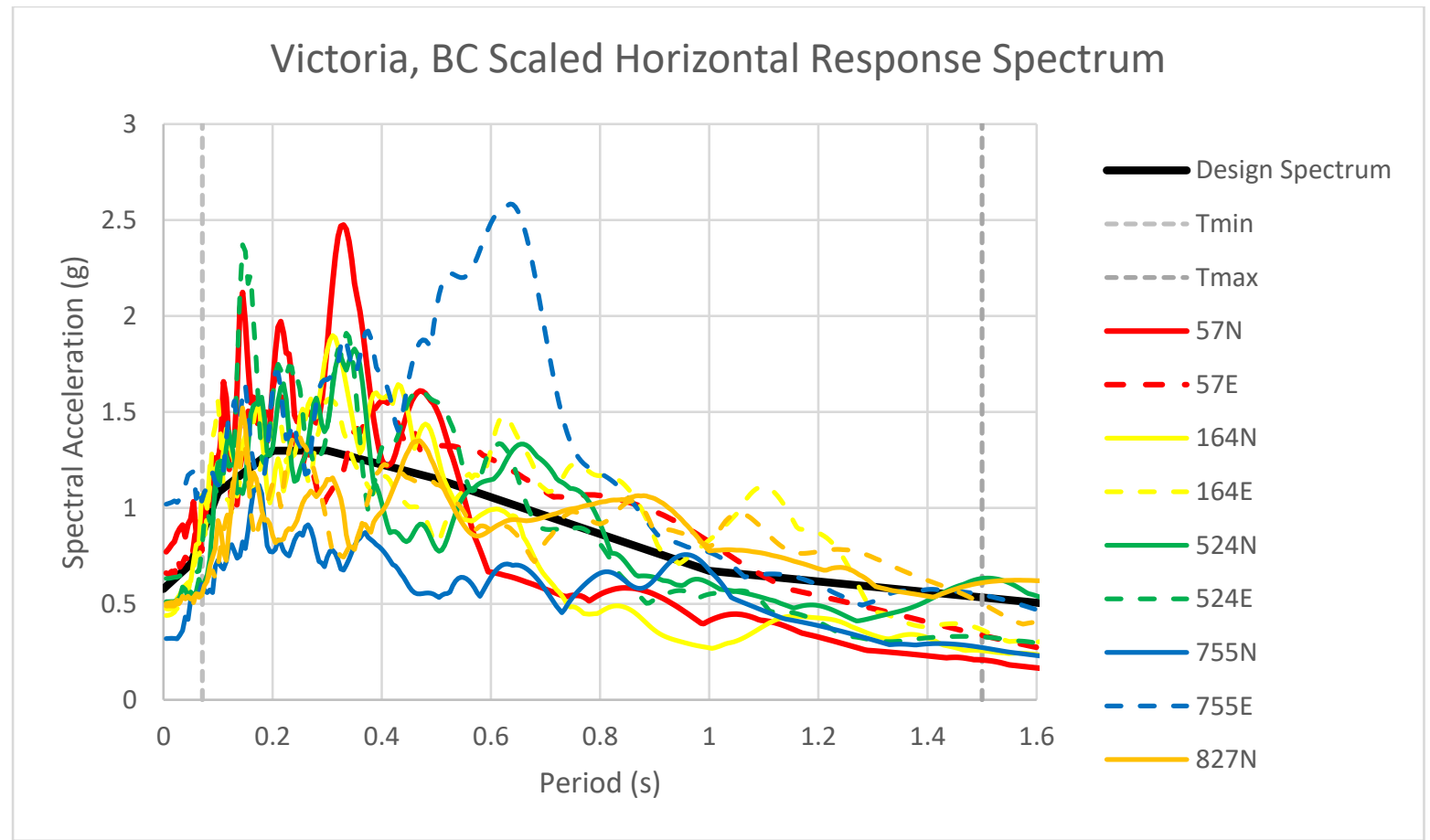

Figure 6-9: Scaled Response Spectra (Victoria, BC) 


\subsection{AC-156 Required Response Spectrum (RRS)}

The majority of previous shake table experiments on suspended ceiling systems used generated excitations matching the required response spectrum outlined in "Acceptance Criteria for Seismic Certification by Shake-table Testing of Non-Structural Components" designated as the ICC-ES AC156 (ICC, 2010).

Takhirov et al. (2010) investigated the validity and short comings of the AC156 and possible alternative testing procedures to evaluate the seismic performance of suspended ceilings. The AC156 was developed for components that have a limited number of attachment locations to the structure. As suspended ceilings are large systems with multiple attachment points, there is the need to assess the applicability of the AC156 procedure for testing of suspended ceilings. In addition to the question of multiple attachment points, the $\mathrm{AC} 156$ procedure assumes the test components are fastened directly to the shake tables. In comparison, suspended ceilings are hung from test frames attached to the shake tables which causes additional amplification of the input excitations due to dynamic response of the test frame. Takhirov et al. (2010) concluded that following the AC156 test procedure for testing of suspended ceiling at frequency of the test frame caused failure modes different than those observed in actual buildings during earthquakes.

The required response spectrum is a function of the short-period spectral acceleration. The required response spectrum is used in previous experimental testing to scale simulated excitations in order to test non-structural components such as suspended ceiling systems. As per section 6.5 of $\mathrm{AC} 156$, components with fundamental frequencies greater than $16.7 \mathrm{~Hz}$ are considered to be rigid. Therefore, a suspended ceiling system is considered as a flexible component. The shortperiod design acceleration $S_{D S}$ is a function of the site soil coefficient $F_{a}$, and $S_{S}$ the short-period spectral acceleration of the building site, as shown in Equation 6.1. 


$$
S_{D S}=\frac{2}{3} F_{a} S_{S}
$$

The horizontal required response spectrum $A_{\text {Flex }}$ and $A_{\text {Rigid }}$ for a flexible and rigid component, respectively, are calculated using the following equations:

$$
\begin{gathered}
A_{\text {Flex }}=S_{D S}\left(1+2 \frac{z}{h}\right) \\
A_{\text {Rigid }}=0.4 S_{D S}\left(1+2 \frac{z}{h}\right)
\end{gathered}
$$

where $z$ is the height above the ground level where the component is attached to the structure, and $h$ is the total height of the building above the ground. The RRS is constructed starting at $0 \mathrm{~Hz}$ and $10 \%$ of $A_{\text {Flex, }}$ increasing linearly up to $A_{\text {Flex }}$ at $1.3 \mathrm{~Hz}$. The response spectrum is constant from 1.3 $\mathrm{Hz}$ to $8.3 \mathrm{~Hz}$ and then decreases linearly to $A_{\text {Rigid }}$ at $33.3 \mathrm{~Hz}$. The maximum acceleration of a flexible component is limited to 1.6 times $S_{D S}$. For the vertical response spectrum, $z$ is assumed to be 0.0 for all locations in the building. Therefore, with $F_{a}=1.0$, the vertical RRS is determined as follows:

$$
\begin{gathered}
A_{\text {Flex }}=0.67 S_{D S} \\
A_{\text {Rigid }}=0.27 S_{D S}
\end{gathered}
$$

Two site locations were chosen to gain insight on the procedure of AC-156 RRS for evaluation of the seismic performance of suspended ceilings. The site at Carleton University in Ottawa, Ontario is the first chosen site location for this investigation. Carleton university is located 
in eastern Ontario and is the site location of the Lennox and Addington building as mentioned in Section 6.2 above. The second location is Victoria, British Columbia which is exposed to larger west coast earthquakes. This western Canada site is selected to investigate the impact of different earthquakes with different characteristics on the required response spectrum. The RRS generated by AC156 is shown in Figures 6-10 and 6-11 for Ottawa and Victoria respectively.

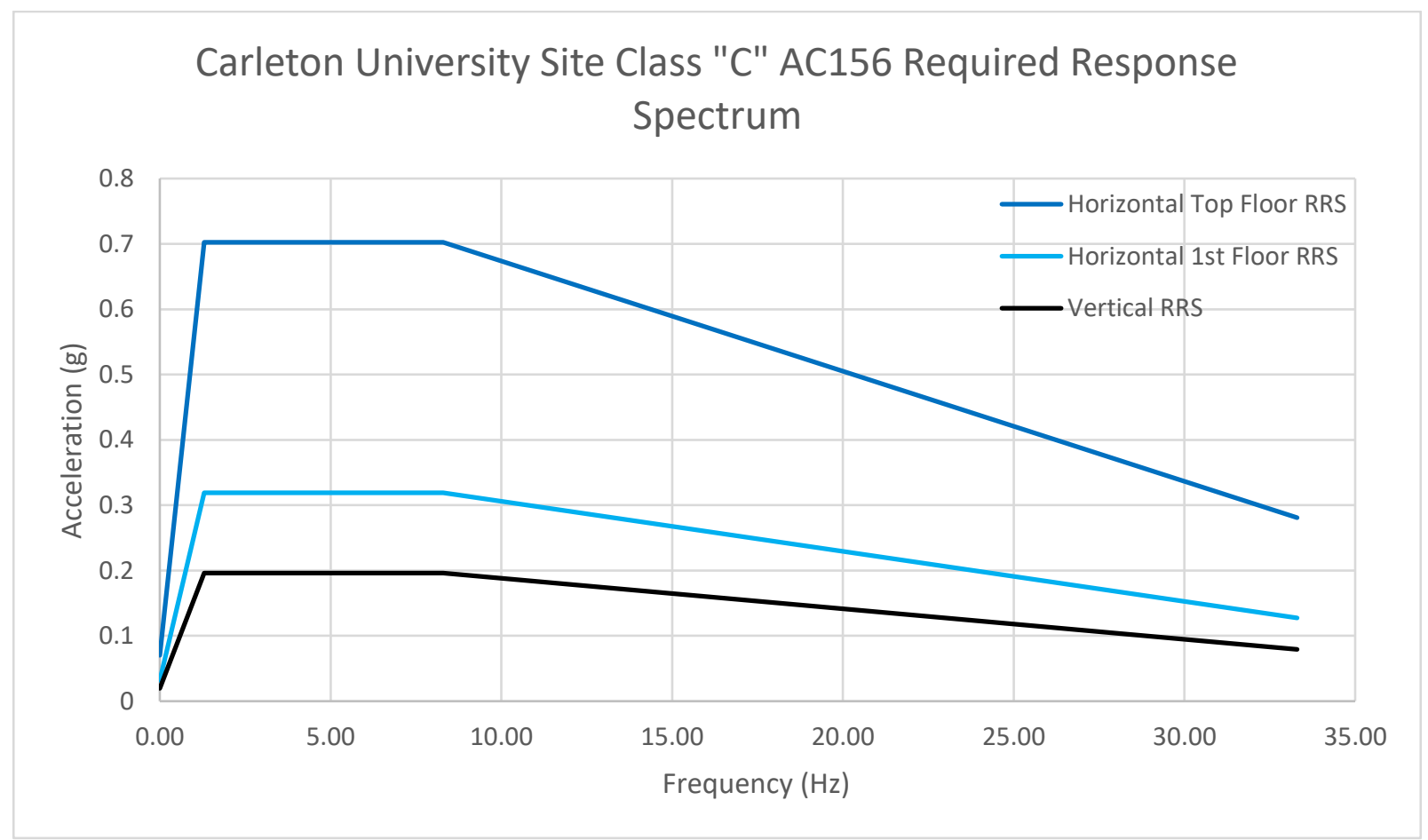

Figure 6-10: Carleton University Site Class C AC156 RRS 


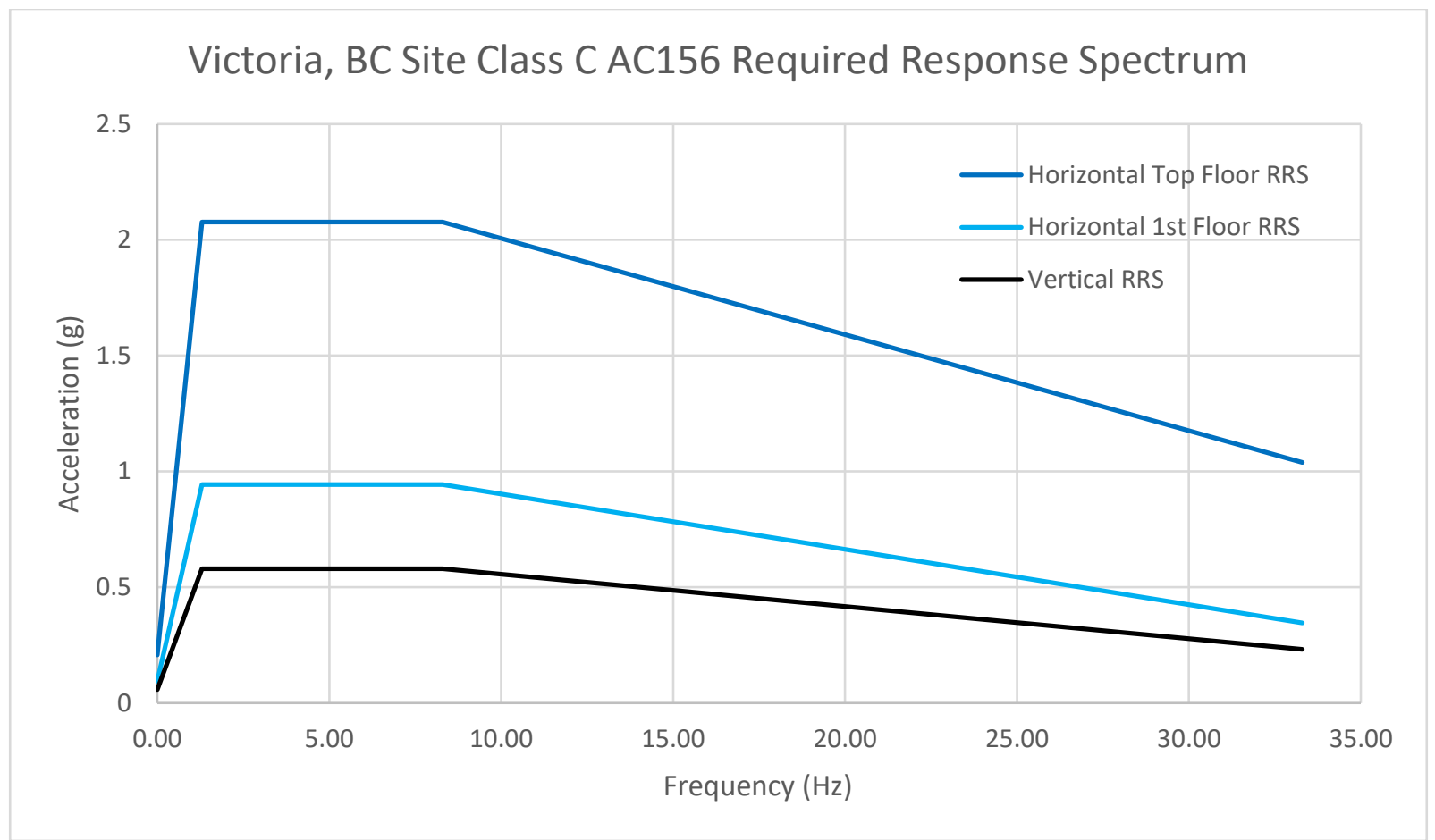

Figure 6-11: Victoria, BC Site Class C AC156 RRS

For the top floor of a building, $z / h$ is equal to 1.0 which amplifies $S_{D S}$ by a factor of 3 . However, the limit for the horizontal RRS is $1.6 * S_{D S}$ which will govern in this scenario.

\subsection{Floor Response Motions}

The time histories presented in section 6.4 and 6.5 were used as input excitations for the Etabs model and to simulate floor response motions. The building has 11 floors total above grade. The horizontal floor response motions at the top $\left(11^{\text {th }}\right.$ Floor $)$ and on the $2^{\text {nd }}$ Floor were used for a comparison with the ICC AC-156 required response spectrum. The comparison graphs for Ottawa and Victoria are shown in Figure 6-12 to 6-15. The Etabs model was simplified to evaluate the AC156 RRS to see the approximate differences in response spectrums. As such, the conclusions from this research are not definitive and further investigations with more detailed models are required to evaluate the accuracy of the AC156. 


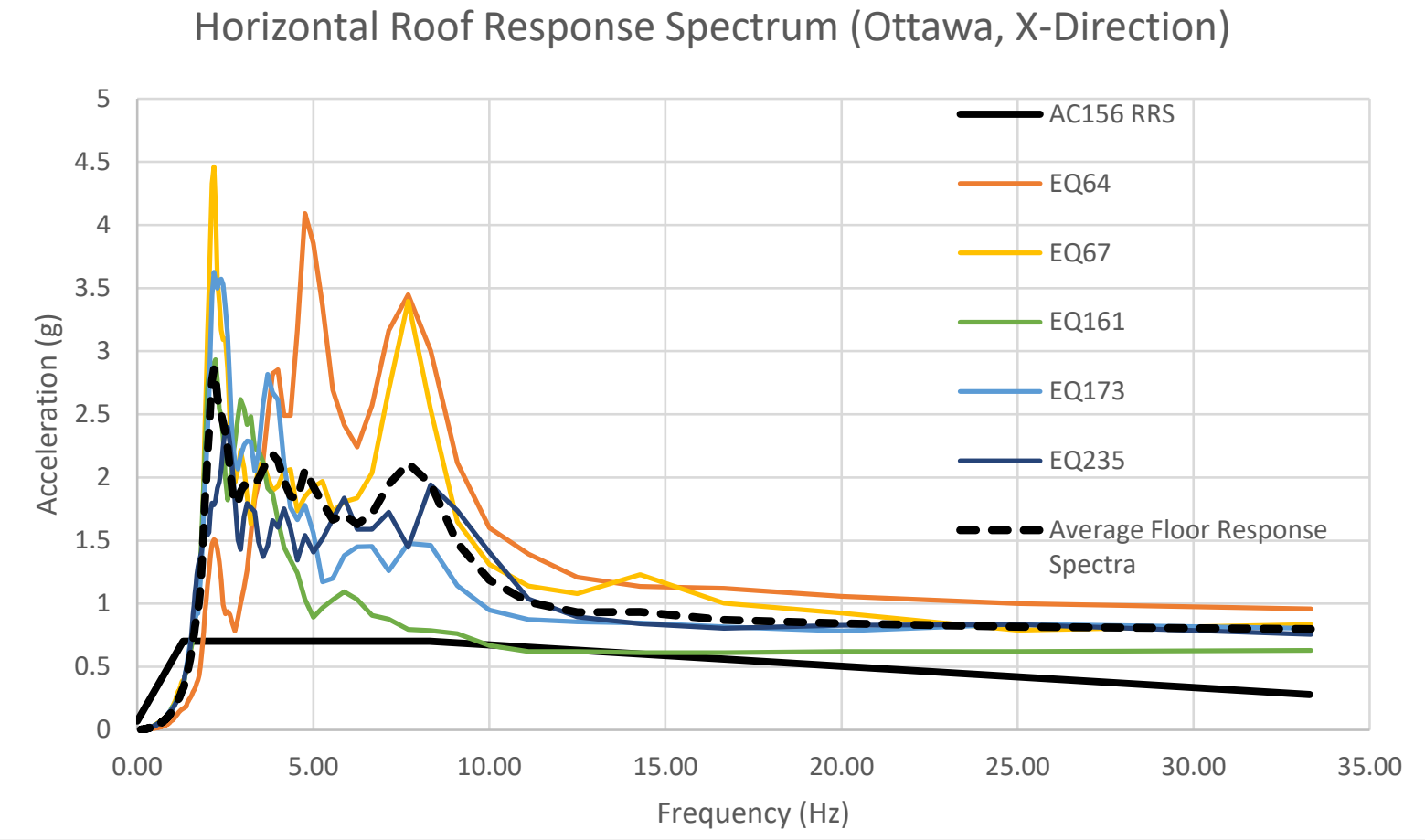

Figure 6-12: Top Floor Horizontal Response Spectra (Ottawa, ON)

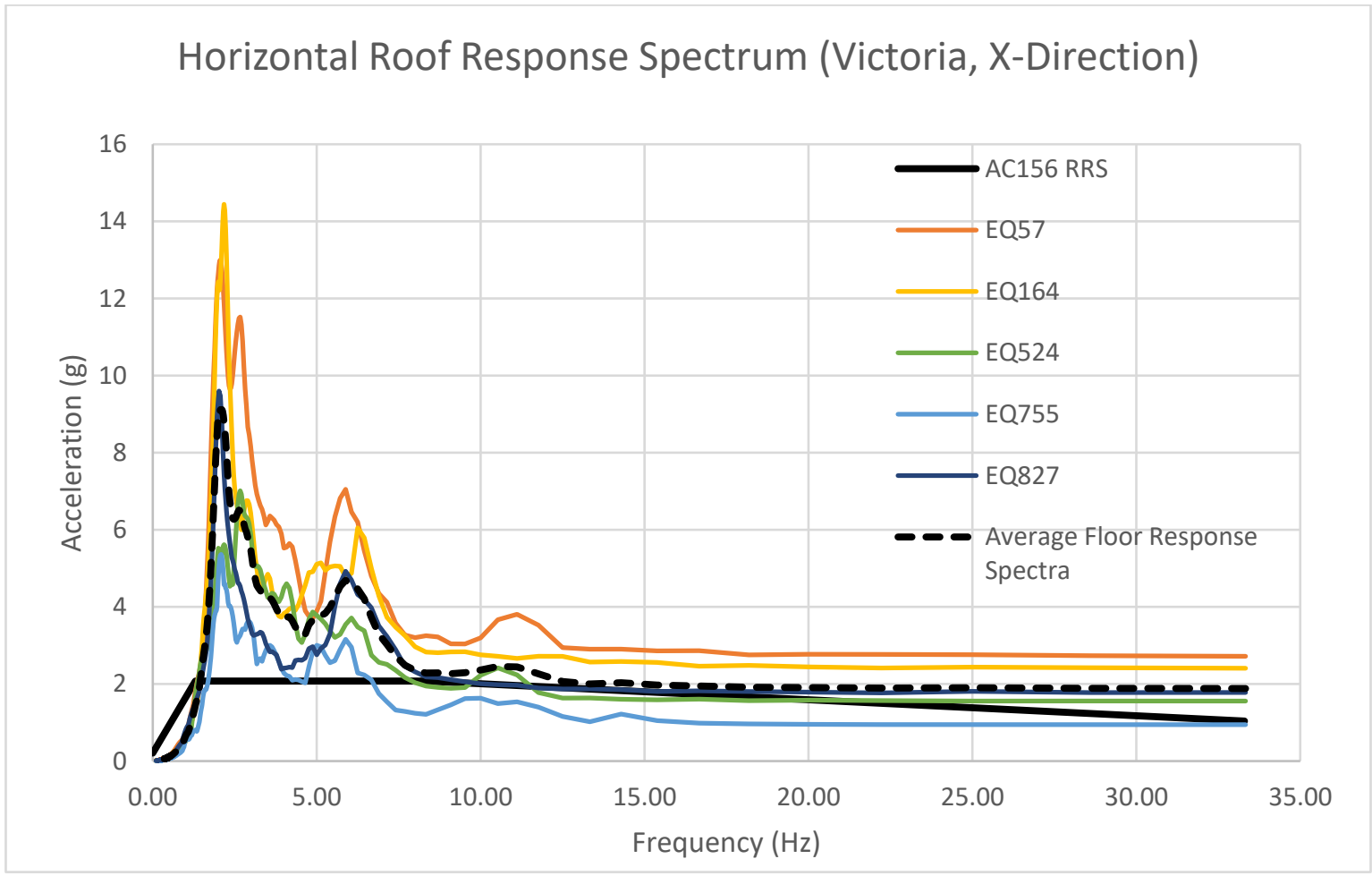

Figure 6-13: Top Floor Horizontal Response Spectra (Victoria, BC) 
Horizontal 2nd Floor Response Spectrum (Ottawa, X-Direction)

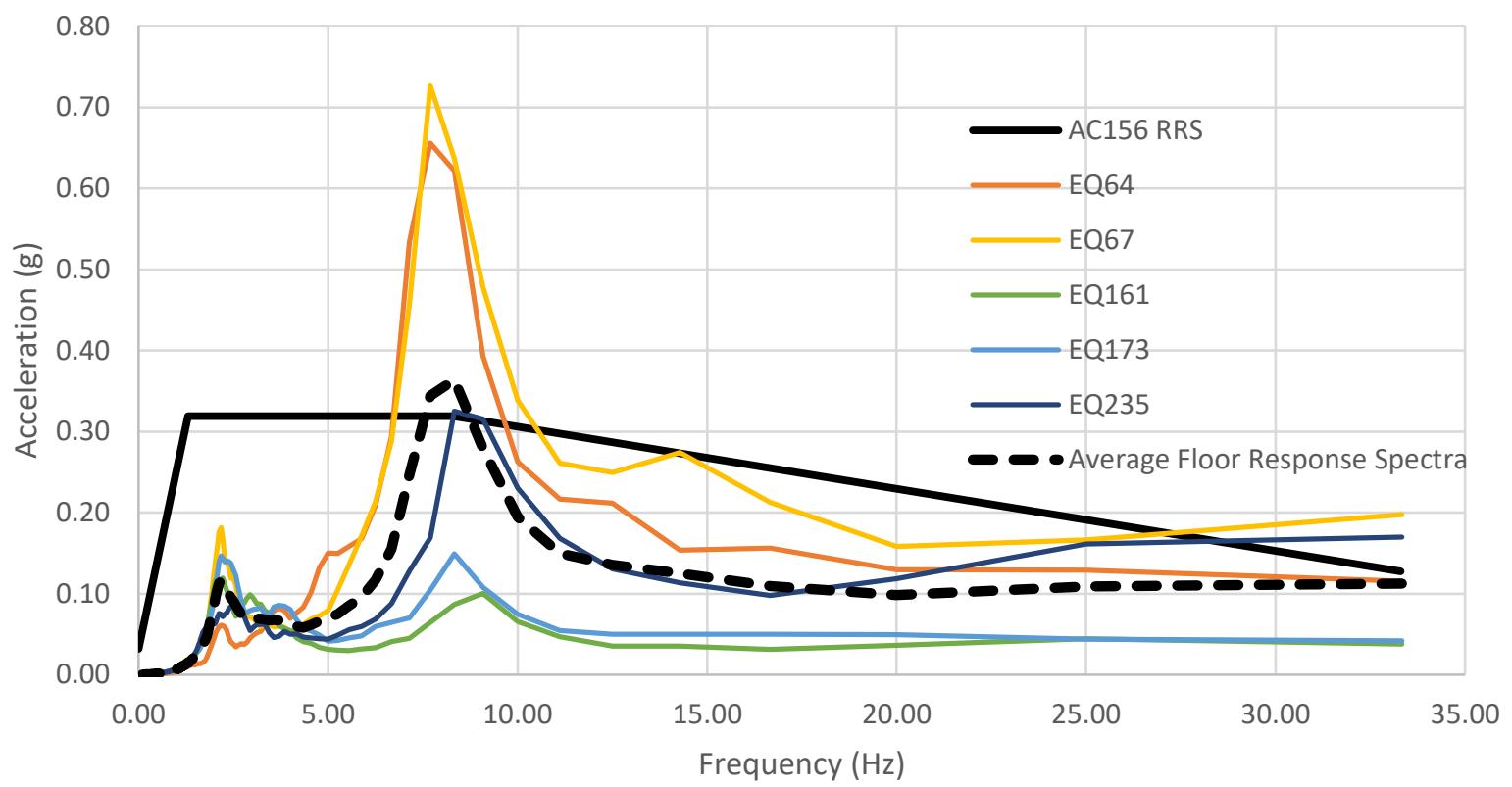

Figure 6-14: 2nd Floor Horizontal Response Spectra (Ottawa, ON)

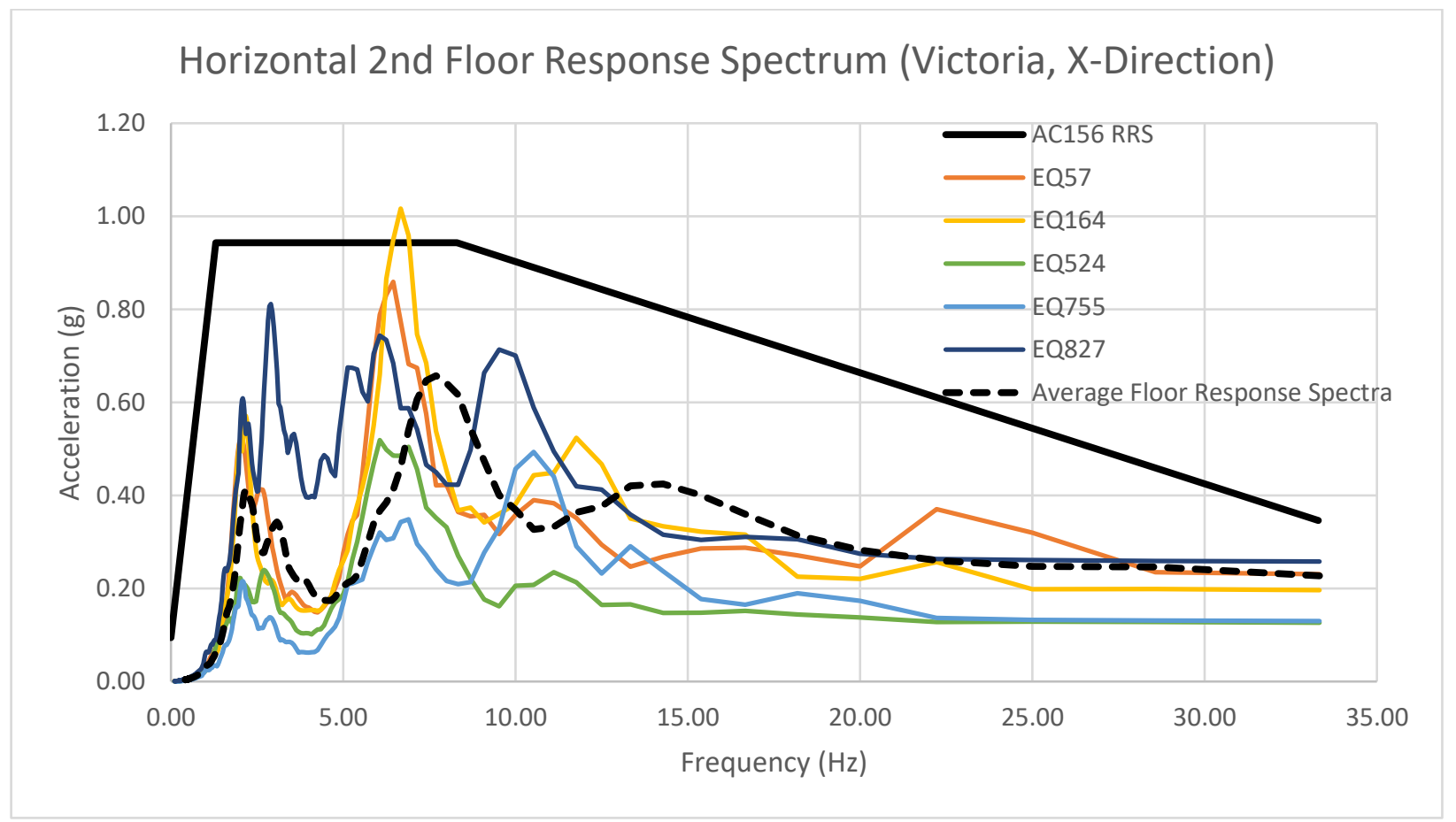

Figure 6-15: 2nd Floor Horizontal Response Spectra (Victoria, BC) 
As observed in Figures 6-12 to 6-15, the AC156 RRS provides a higher testing acceleration over most of the frequency range at lower floors in the building that experience lower amplification. However, at higher floors in the building the AC156 RRS is lower throughout the entire frequency range. The floor response spectra from the top floor of the building is approximately 2.9 times higher than the AC156 Response Spectra over the frequency range of 1.3 to $8.3 \mathrm{~Hz}$. The vertical floor response spectra of a typical storey are compared in Figure 6-16 and Figure 6-17.

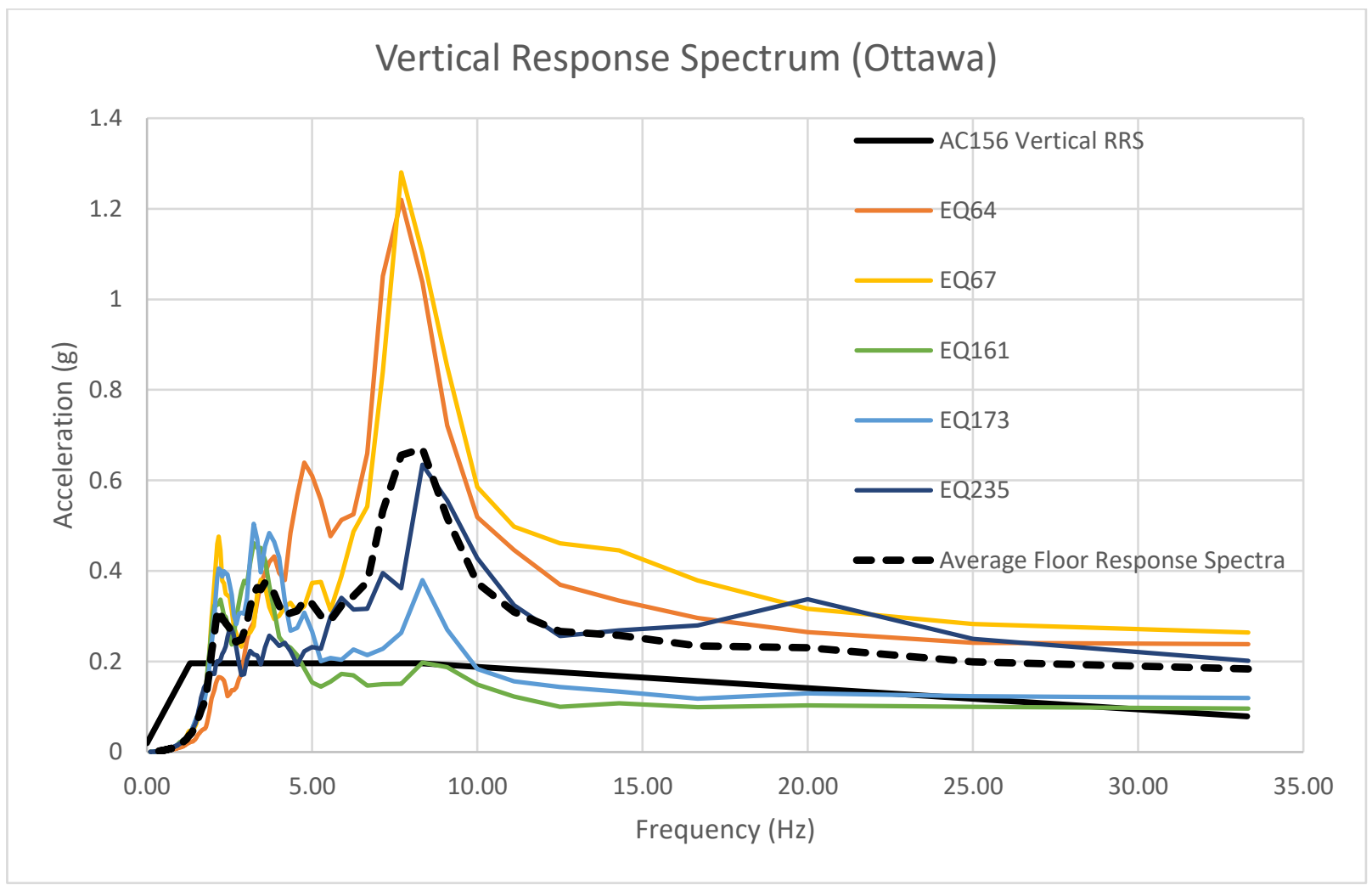

Figure 6-16: Vertical Floor Response Spectra (Ottawa, ON) 


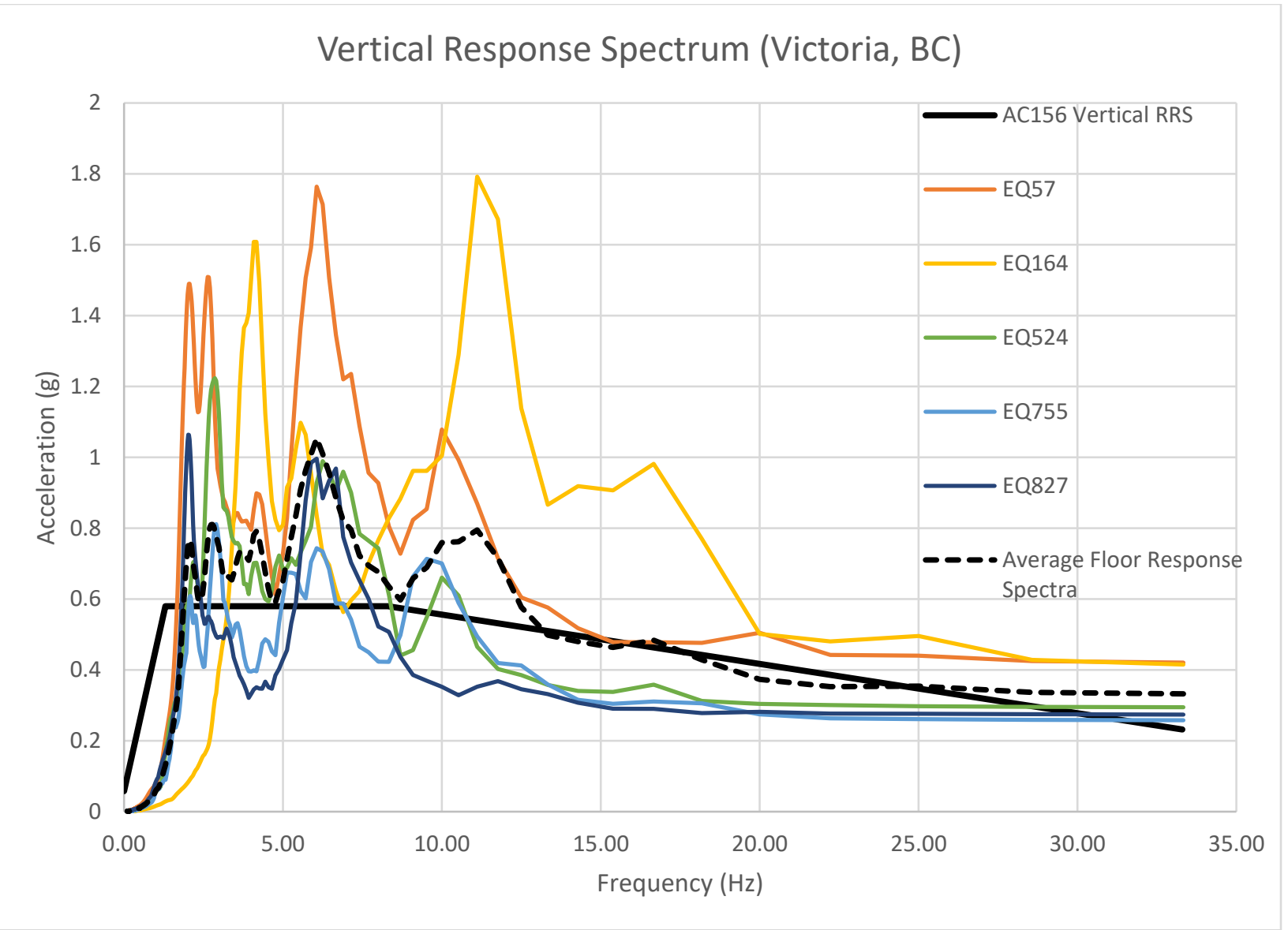

Figure 6-17: Vertical Floor Response Spectra (Victoria, BC)

The required vertical response spectrum as per the $\mathrm{AC} 156$ is lower than the average floor response spectrum for the campus building simplified model in Etabs.

To verify the results and Etabs model accuracy the floor response spectrum was compared to two sample buildings modelled in another study. The first sample building of a typical office building was modelled by Takhirov et al. (2010). The SAP model was a five-storey steel moment resisting frame. Figure 6-18 shows the floor response spectra of the building (Takhirov et al., 2010). 


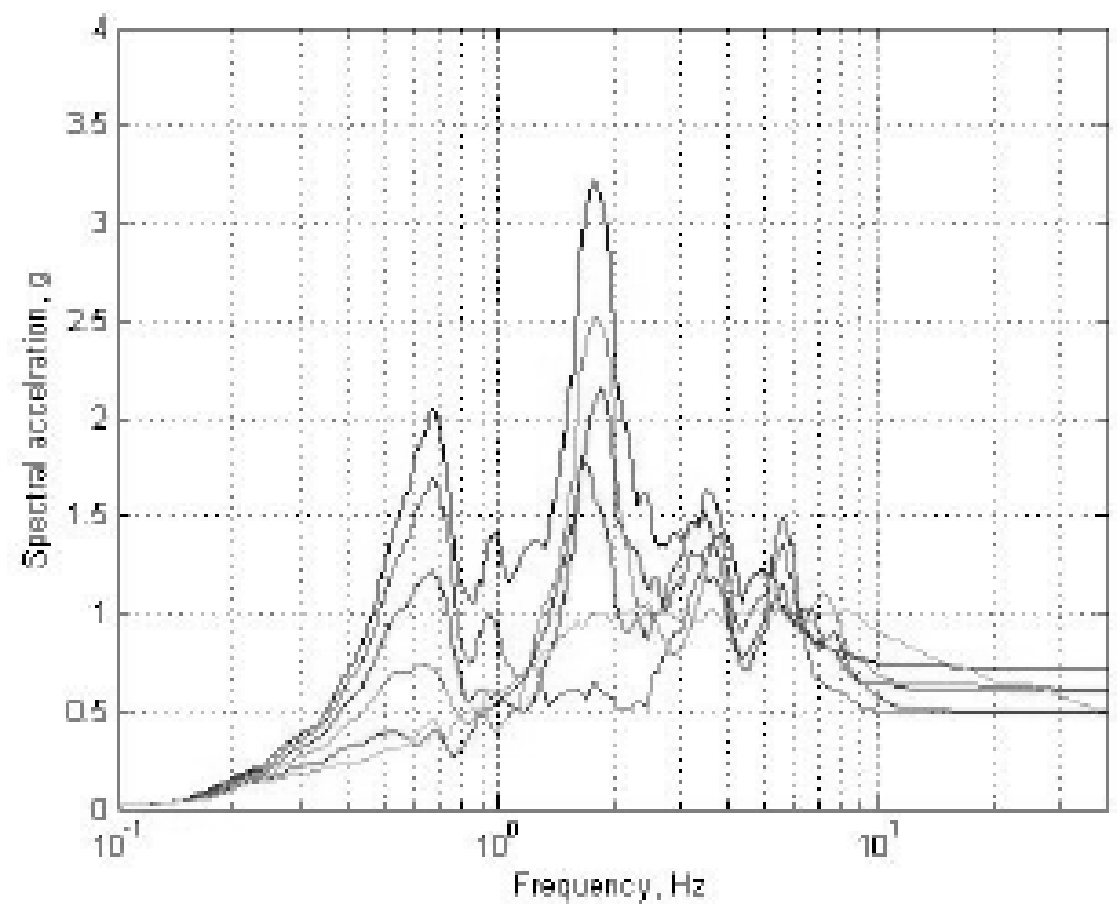

Figure 6-18: Floor Horizontal Response Spectra of 5-Storey Steel Moment Resisting Frame (Takhirov et al., 2010)

As shown in Figure 6-18, the building natural frequencies amplify the motions by a significant factor. This five-storey steel structure has a spectral acceleration amplification factor of over 3.0. The Etabs model of Lennox and Addington presented in this paper has an amplification factor of between 3.0 to 4.0, slightly higher than the five-storey model. Due to the differences between the two structures, the comparison is used as an approximation to indicate if the results are reasonable for the evaluation of the ICC-AC156 RRS. The higher amplification could be due to the fact that the height of Etabs structure is twice that of the referenced model. This height difference and heavier mass for the concrete structure led to a lower fundamental frequency which 
could have caused the higher amplifications due to the corresponding frequency content of the time history records. Along with the modelled structure the previous researchers also investigated an existing eight story hospital building in Los Angeles. This target building had accelerometers located on first, fourth and eight floors and recorded the 2008 Chino Hills earthquake in Southern California. As shown in Figure 6-19 the structure experienced amplifications of approximately 10 times that of the recorded ground motion.

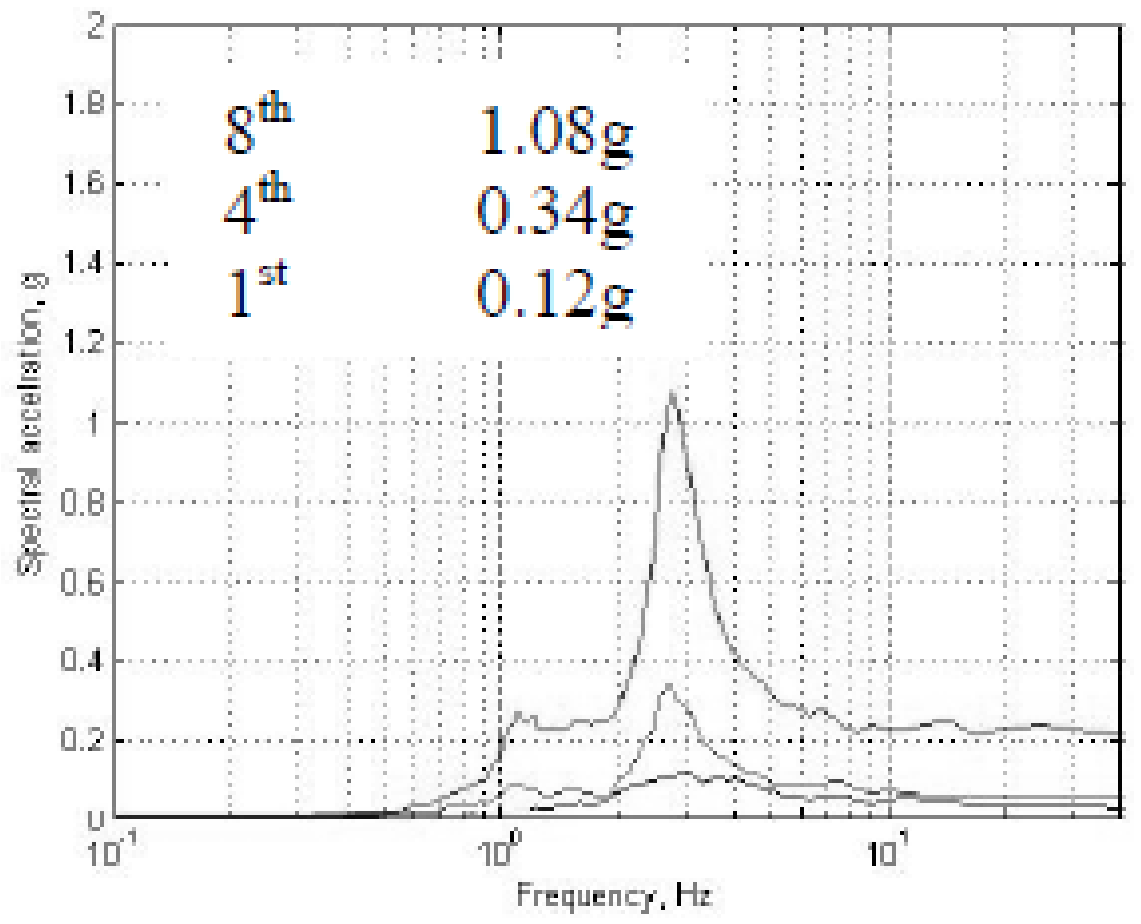

Figure 6-19: Recorded Floor Spectral Acceleration of Eight Storey Hospital, Los Angeles

(Takhirov et al., 2010)

The large amplification observed in the existing structure during an actual recorded earthquake reinforces that the Etabs model is reasonable for evaluation on the AC156 RRS. 


\subsection{Summary of the AC-156 Test Standard}

The recorded vertical floor response motions are for the whole storey and they do not account for additional amplification in the middle of floor spans due to the vertical response of the slabs. As such, the AC156 is found to be lower for both horizontal floor response motions for upper floors and for vertical floor response spectra in the entire building. Experimental tests of suspended ceilings should be carried out using floor response spectrum or time histories of the building where the ceiling is located. The test procedure of AC156 may need to be modified. The new multi-unit shake table system for conducting the experimental research program on seismic performance of suspended ceilings at Carleton University can duplicate the floor response motion records for ceiling tests. These tests can be compared with the test results obtained by following AC156 test procedure, and also results from Phase I tests conducted at Tongji University. 


\section{Chapter 7: OpenSees Model of Suspended Ceiling Panel}

\subsection{OpenSees Model}

A model was developed using OpenSees in order to investigate the dynamic behaviours of a suspended ceiling system. OpenSees is an open finite element framework software created from the National Science Foundation that uses scripts written in TCL language. The goal of the model was to create a simplified system for future researchers to expand on. A single suspended ceiling panel was modeled including the hanging wires, grid members and panel. This model once expanded to the layout of that to be used in the shake table tests will allow predictions of test results and eventually the experimental results will be used to validate the model. The OpenSees Model focused on two distinct characteristics in the system, which included the pendulum motion of the system and the sliding of panels on the grid members. The pendulum motion was observed in past models by previous researchers when sway wires and perimeter attachment were not used. The other characteristic is captured when the ceiling panel overcomes the friction on the grid members and begins to slide along the grid member. In the investigation here, the numerical model developed by Zaghi et al. (2016) which had been verified by experimental results was adopted here in the modelling of the suspended ceiling panel. The computer model of a single suspended ceiling panel subassembly can be extended to capture the non-linear behaviour of some ceiling elements and the boundary conditions of ceiling systems.

The hanging wires were modelled using elasticBeamColumn elements with properties of a 12-gauge wire that were fully fixed at the top (roof) and were pin connected at the bottom to the grid members (Main-Tee Beam). The grid members were developed using properties provided by Armstrong Ceilings and modelled as elasticBeamColumn elements with lumped masses at the ends of the members. The panel was modelled as X-Brace with very stiff elasticBeamColumn elements 
to create a diaphragm and represent the in-plane shear stiffness of the panel. The panels were connected at the ends with zeroLengthImpact3D elements in each horizontal direction with a 5 mm gap and a friction coefficient of 0.5 as validated by Zaghi et al. (2016). The hysteresis behaviour of the element is shown in Figure 7-1.

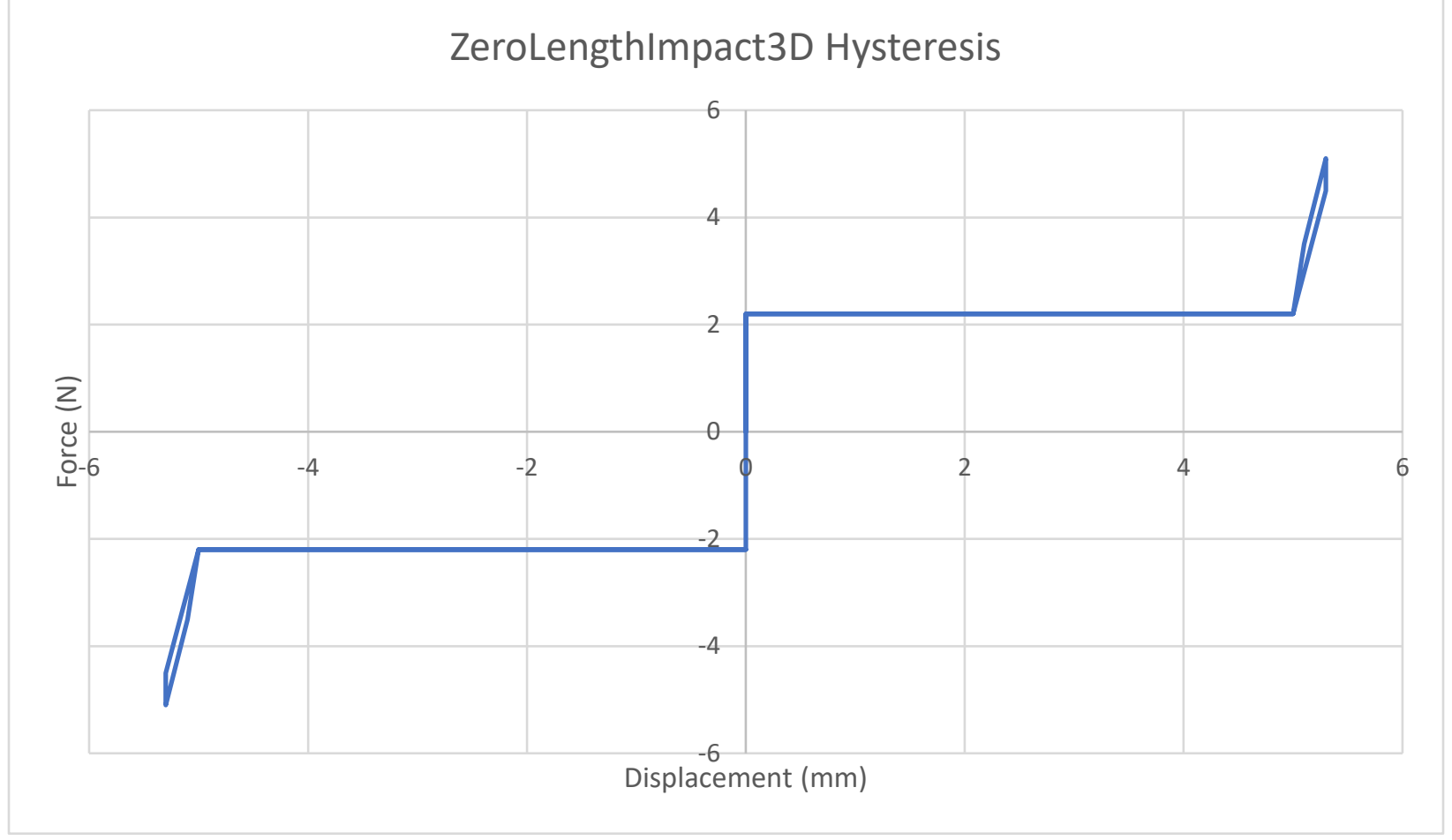

Figure 7-1: ZeroLengthImpact3D Hysteresis

This element was developed by Zaghi et al. (2016) by using zeroLengthContact3D element with the ImpactMaterial. This element allows the panel to slide along the grid members with the resistance of kinetic friction until it comes in contact with the vertical part of the grid member in which it impacts the member with a spring represented with a high stiffness value to act rigidly. ZeroLength elements and equalDOF commands were used to constrain the nodes located at the same locations. 
The schematic below in Figure 7-2 demonstrates the layout of the nodes and links used in the model. The zerolengthimpact3D element is represented as a spring in the figure below. Figure 7-3 illustrates the elements connecting the nodes in the OpenSees Model.

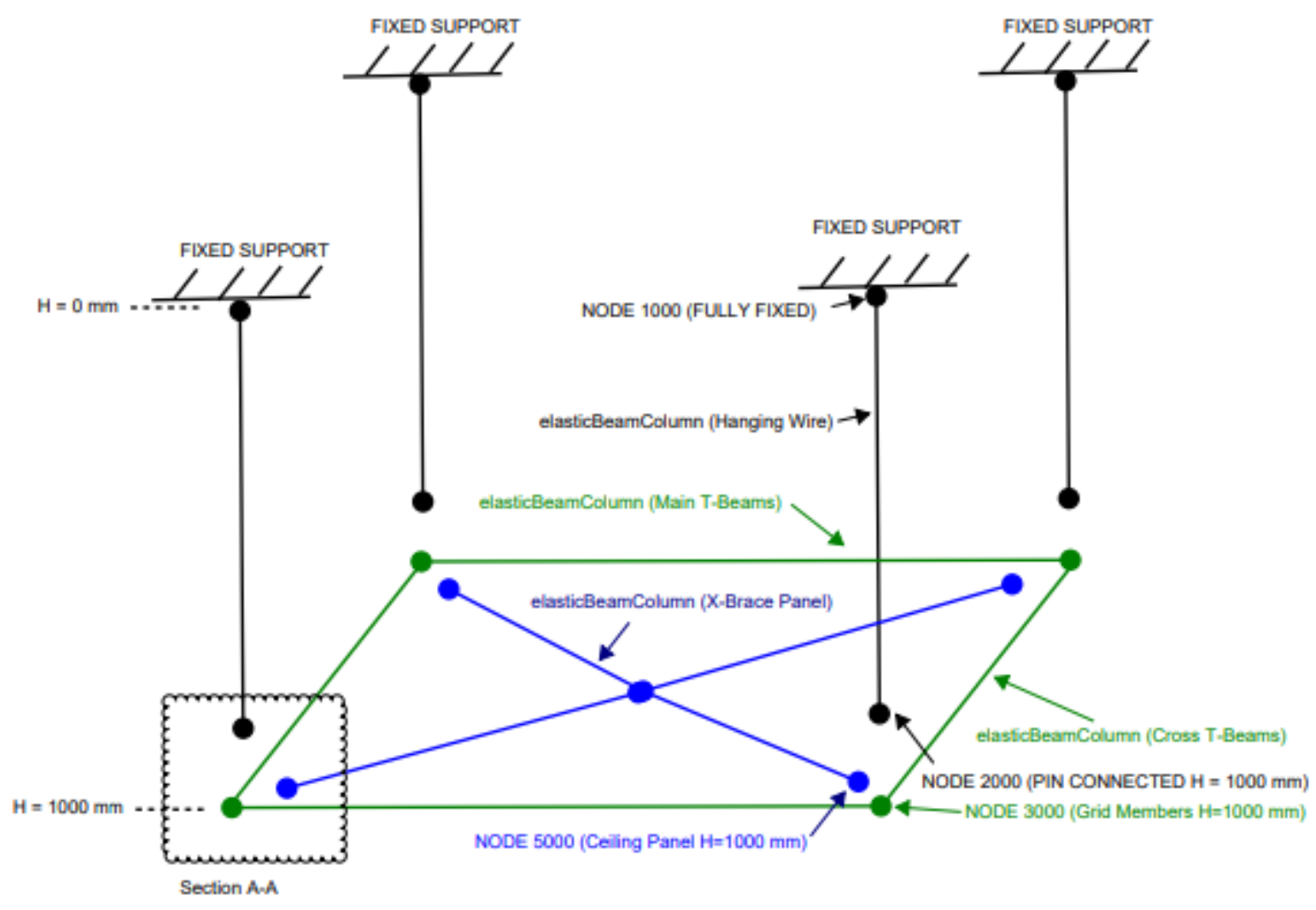

Figure 7-2: Schematic of OpenSees Model 3D View

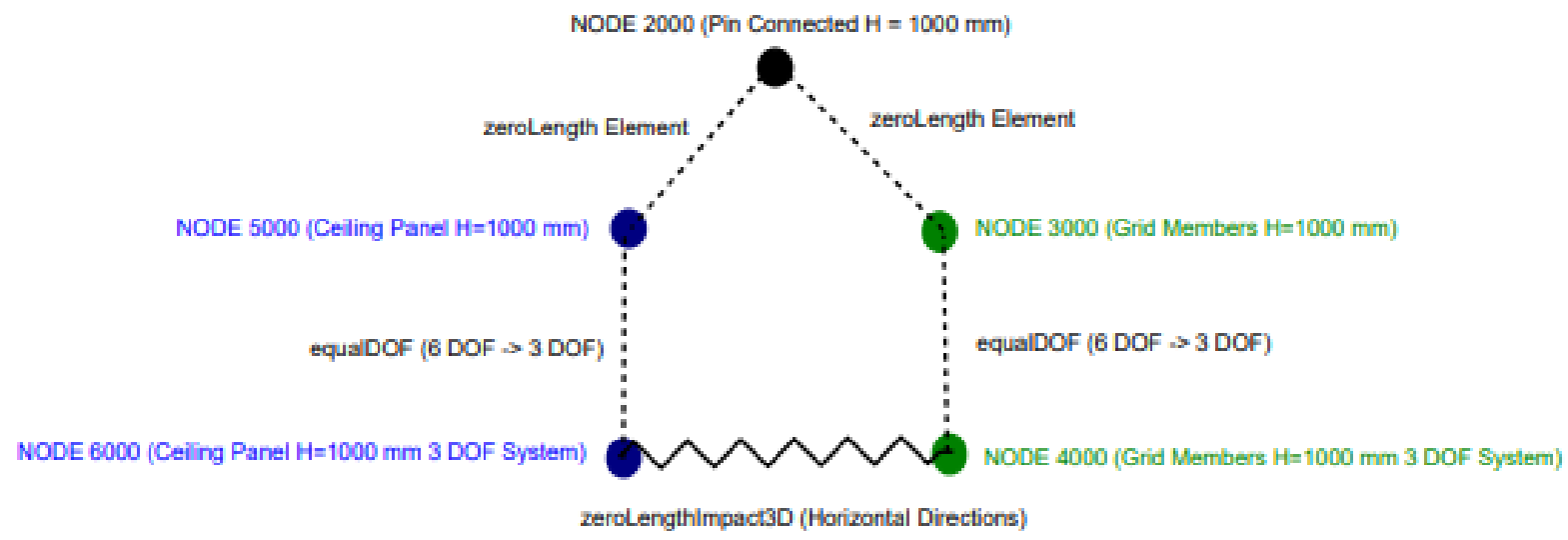

Figure 7-3: Section A-A from Figure 7-2 
The floor response motion from the scaled Earthquake record 235 was chosen to evaluate this model. To more closely examine the results, the time history response at time between 100s to $125 \mathrm{~s}$ which contained the peak response in the vertical and $\mathrm{x}$-direction of the model were examined in more detail. The floor response of storey five at mid-height of the building was chosen because the response spectra of Earthquake record 235 was closest to the average spectra from the five Ottawa records presented in Chapter 6 for both the $2^{\text {nd }}$ Floor and Top Floor Spectra. The acceleration time histories are shown below in Figures 7-4 to 7-7.

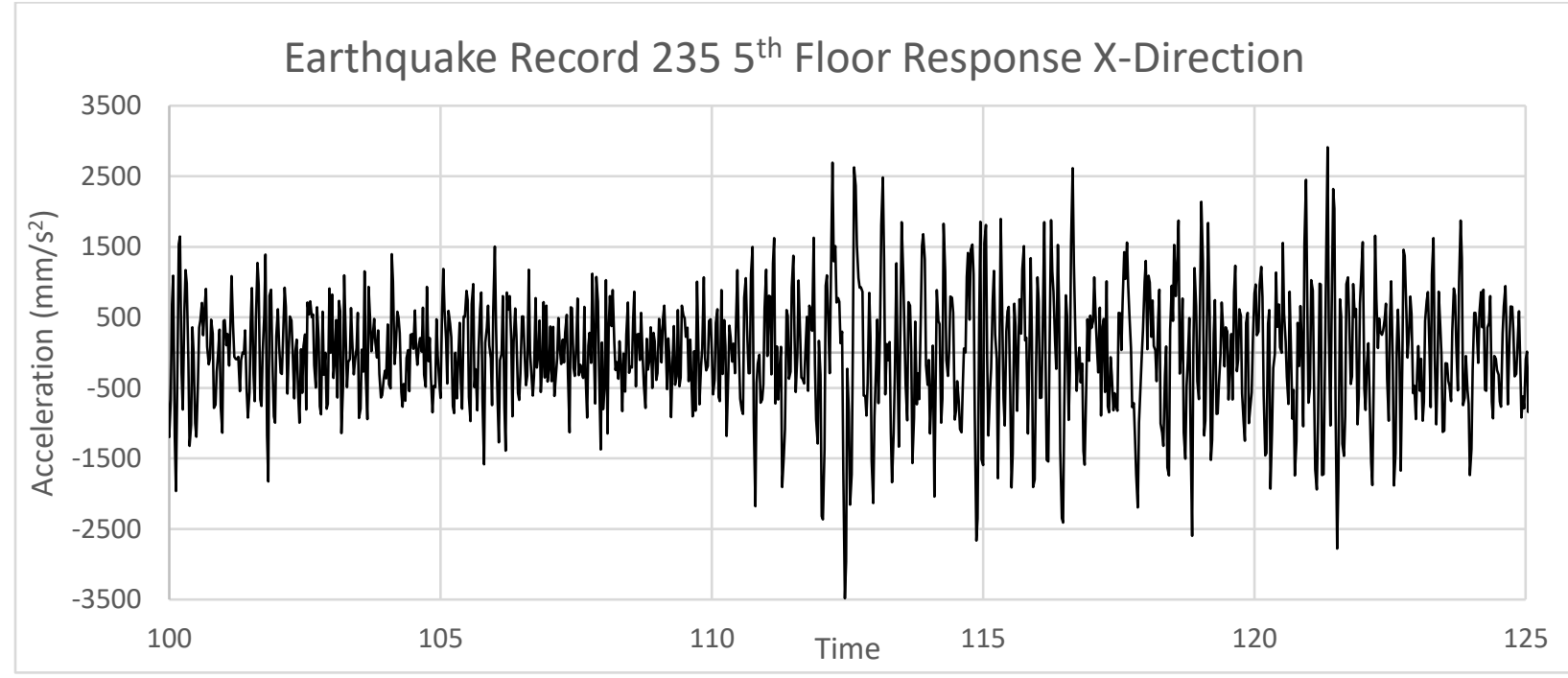

Figure 7-4: $5^{\text {th }}$ (Mid Height) Floor Response Record X-Direction (Earthquake 235) 


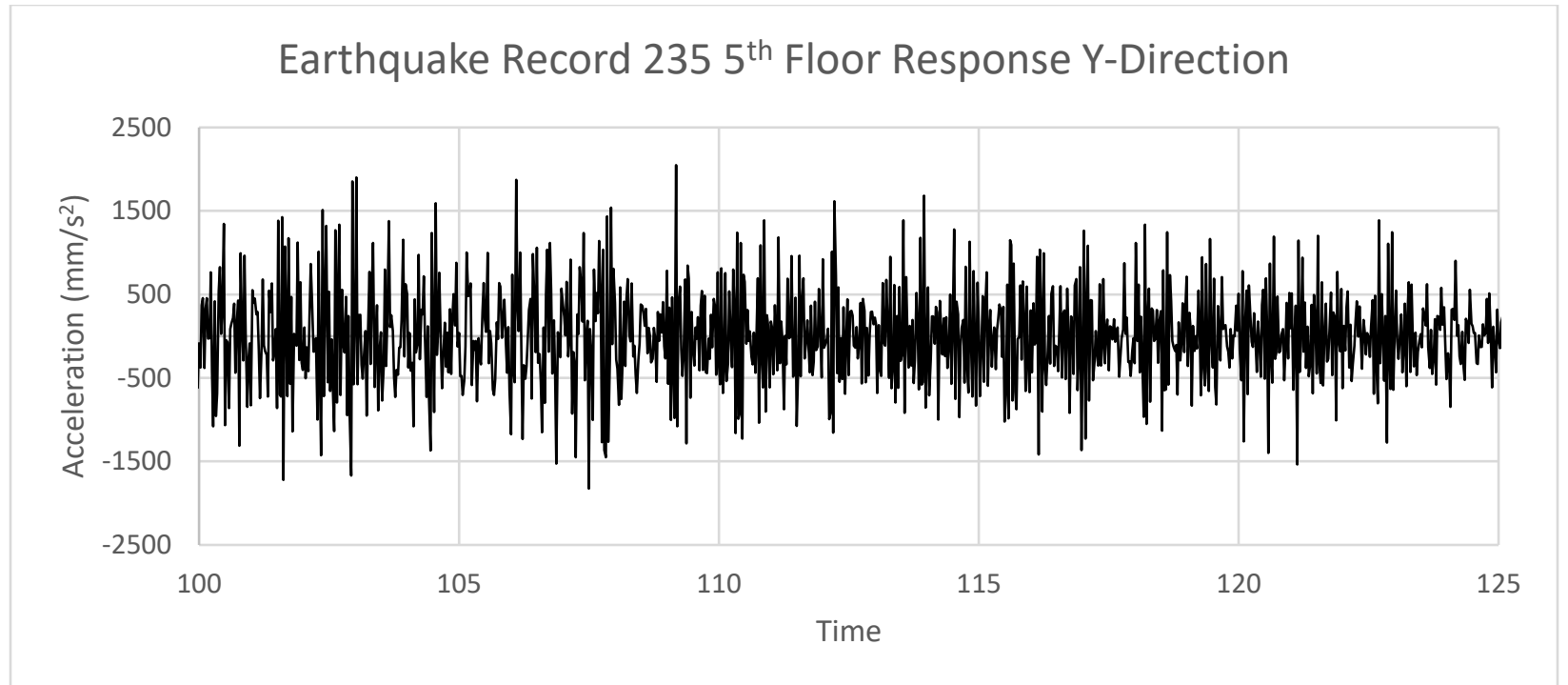

Figure 7-5: $5^{\text {th }}$ (Mid Height) Floor Response Record Y-Direction (Earthquake 235)

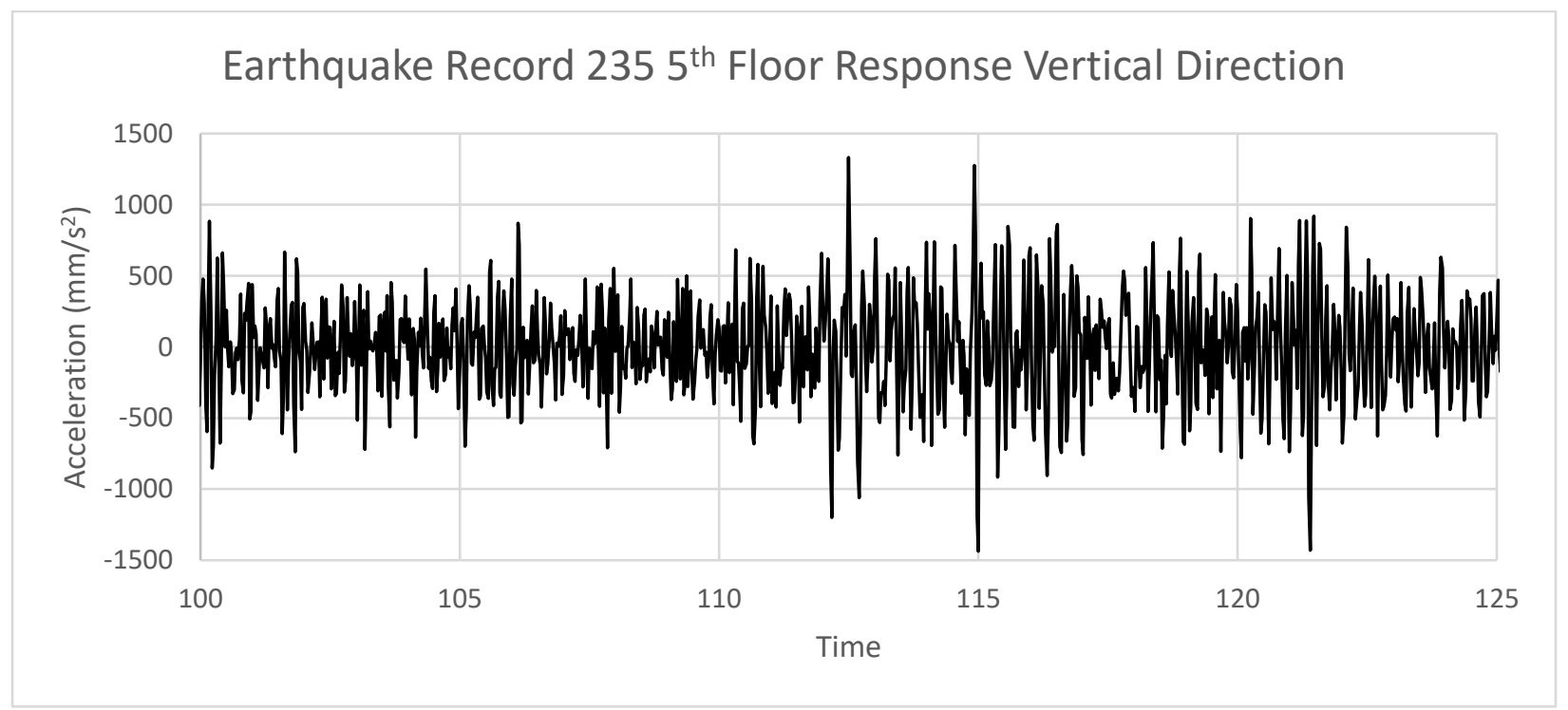

Figure 7-6: $5^{\text {th }}$ (Mid Height) Floor Response Record Z-Direction (Earthquake 235) 


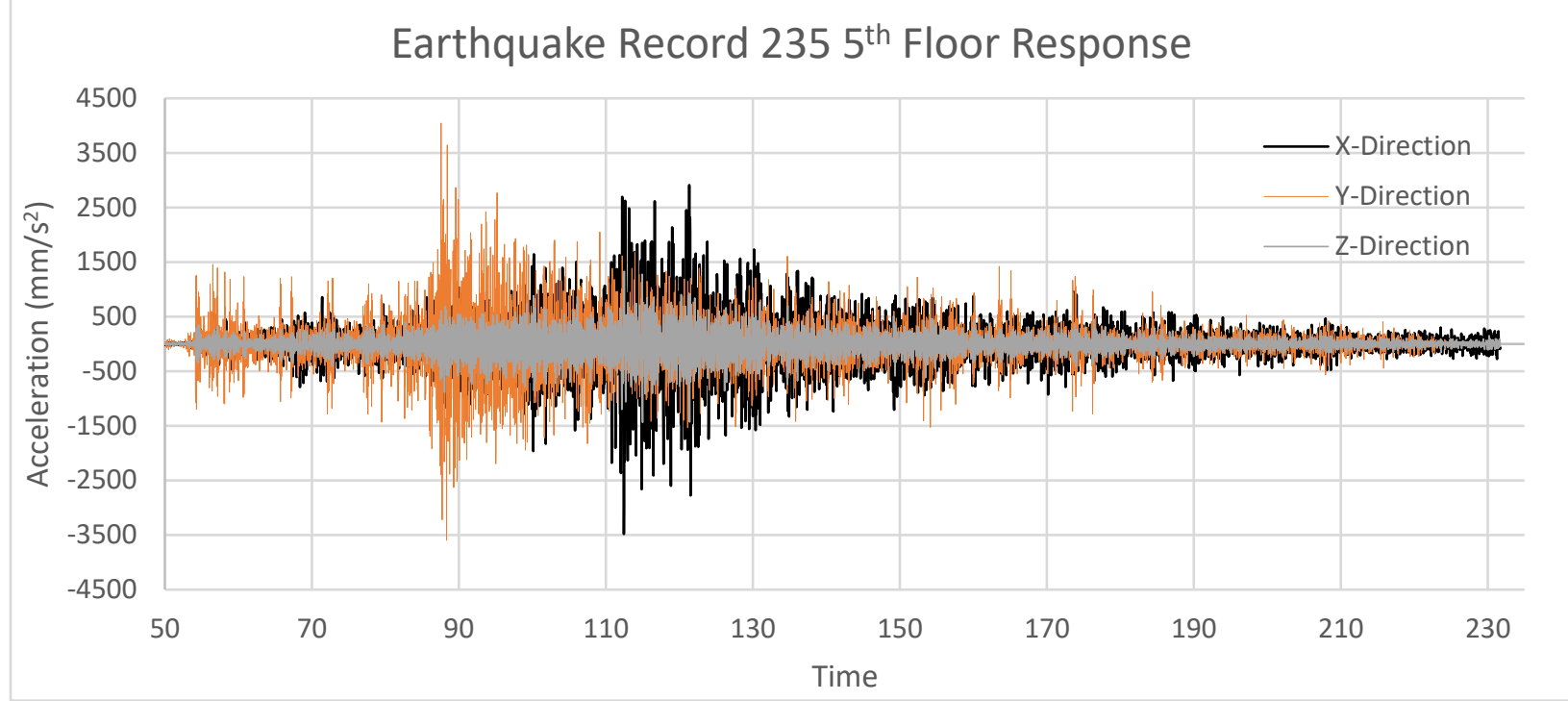

Figure 7-7: $5^{\text {th }}$ (Mid Height) Floor Response Records Combined (Earthquake 235)

As seen in the figures above, the maximum input acceleration was $3483 \mathrm{~mm} / \mathrm{s}^{2}, 4047$ $\mathrm{mm} / \mathrm{s}^{2}$, and $1437 \mathrm{~mm} / \mathrm{s}^{2}$ for the $\mathrm{X}, \mathrm{Y}$ and $\mathrm{Z}$ directions, respectively. As the maximum acceleration in the vertical direction was less than $1.0 \mathrm{~g}\left(9810 \mathrm{~mm} / \mathrm{s}^{2}\right)$, it was expected that there would be no uplift of the panel off the grid members. During development of the model, it was observed that the panel was able to lift off the grid members when subjected to high enough input excitations. As shown in Figure 7-8, the displacement in the X-Direction was three times larger than the YDirection even though the maximum acceleration was lower. This is most likely due to the frequency of the input motion and the geometry of panel. The natural period of a pendulum of equivalent length would be $1.55 \mathrm{~s}$. The approximate period of the modelled system taken from the peak amplitudes in Figure 7-8 is $1.2 \mathrm{~s}$. Therefore, as shown in Figure 7-8 below, the response spectra for the $5^{\text {th }}$ Floor at $1.2 \mathrm{~s}$ is $0.044 \mathrm{~g}$ in the $\mathrm{x}$-direction and $0.014 \mathrm{~g}$ in the $\mathrm{y}$-direction. This difference in the response spectrum with the $\mathrm{x}$-direction being larger by a factor of 3.14 explains the larger displacement response in the x-direction, as shown in Figure 7-9. The vertical 
displacement in Figure 7-10 is small as expected which is due to the swinging of the pendulum causing a change in vertical position.

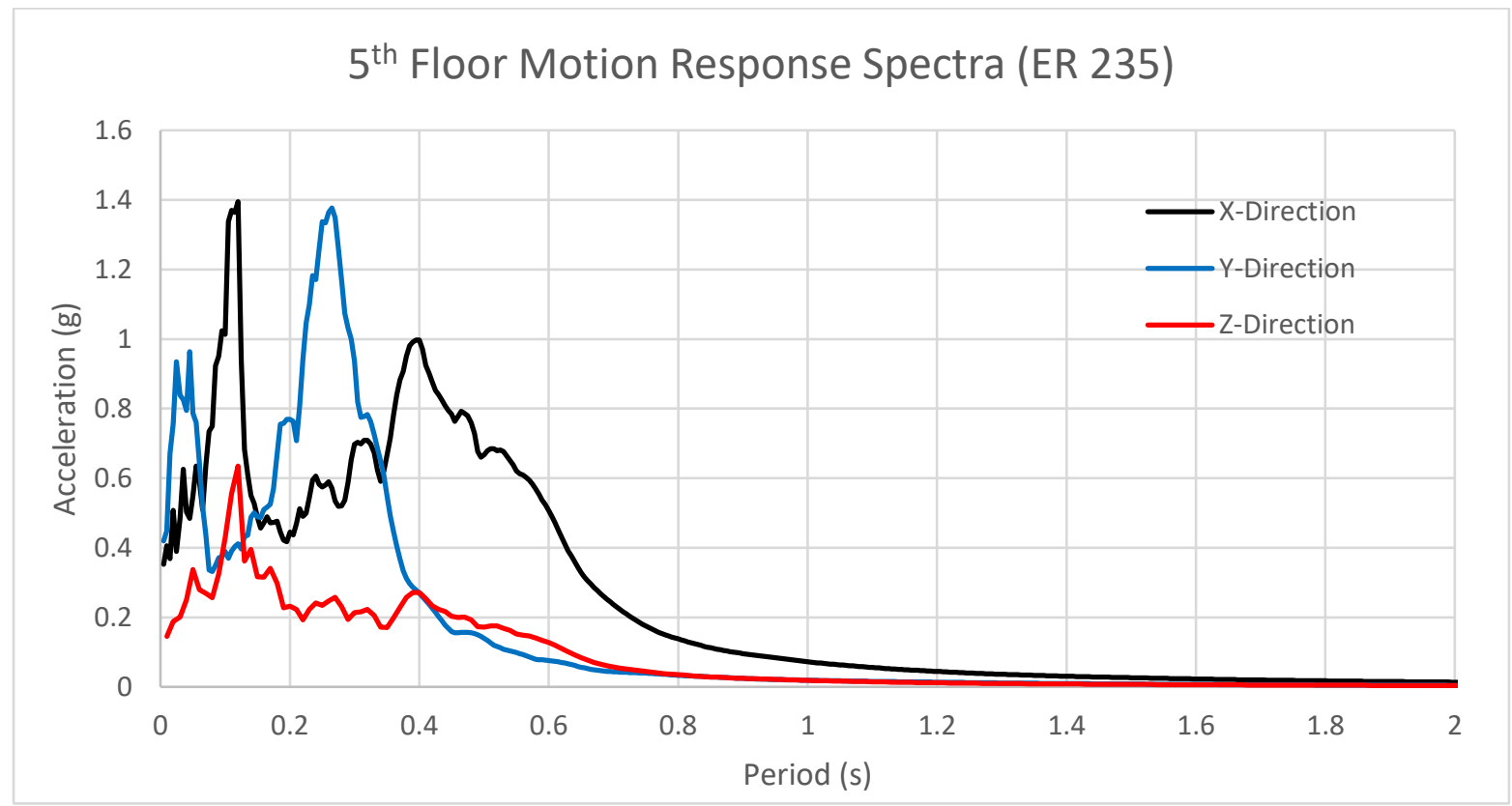

Figure 7-8: $5^{\text {th }}$ Floor Response Spectra Earthquake Record 235

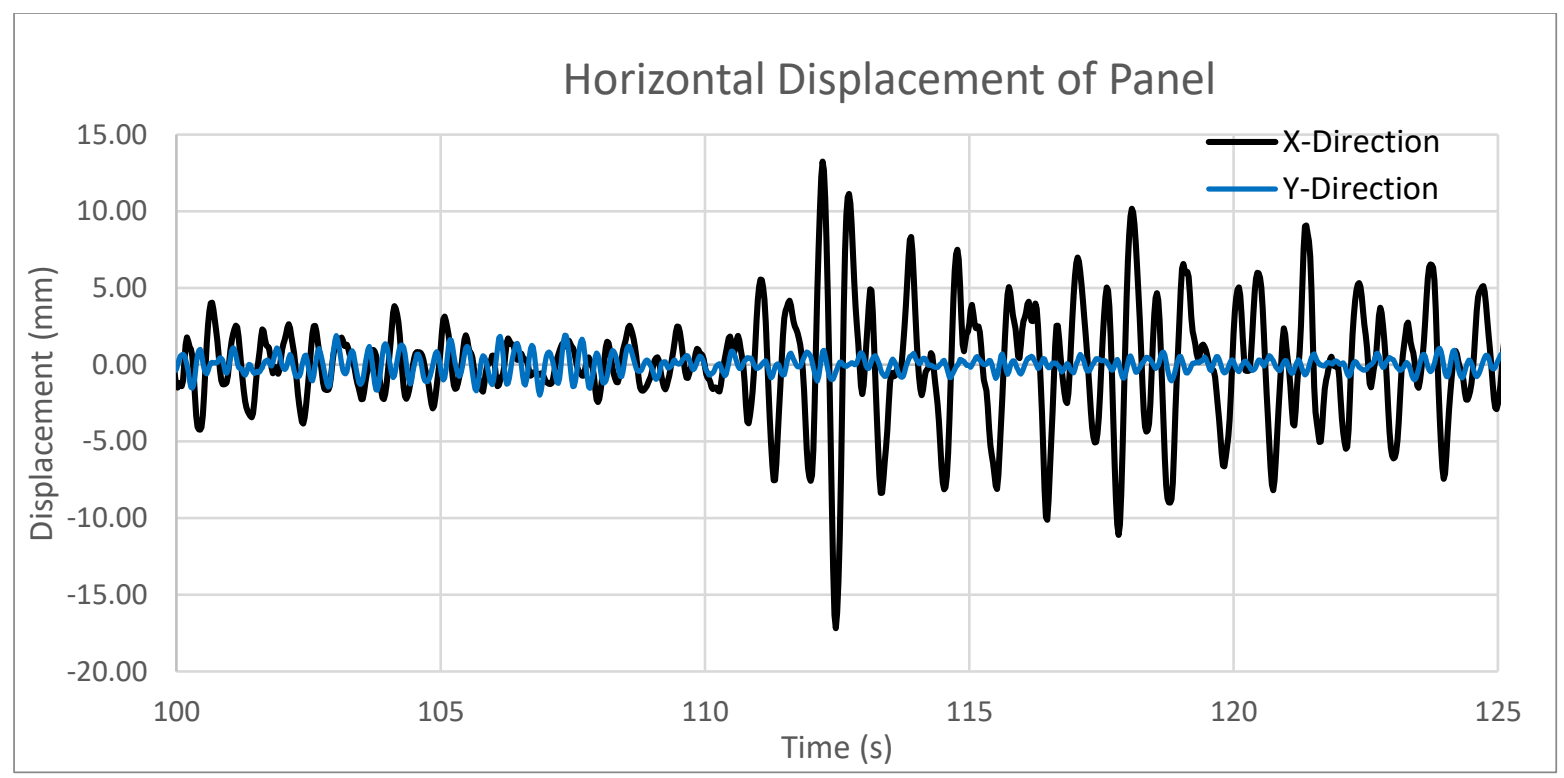

Figure 7-9: Horizontal Displacement of Panel 


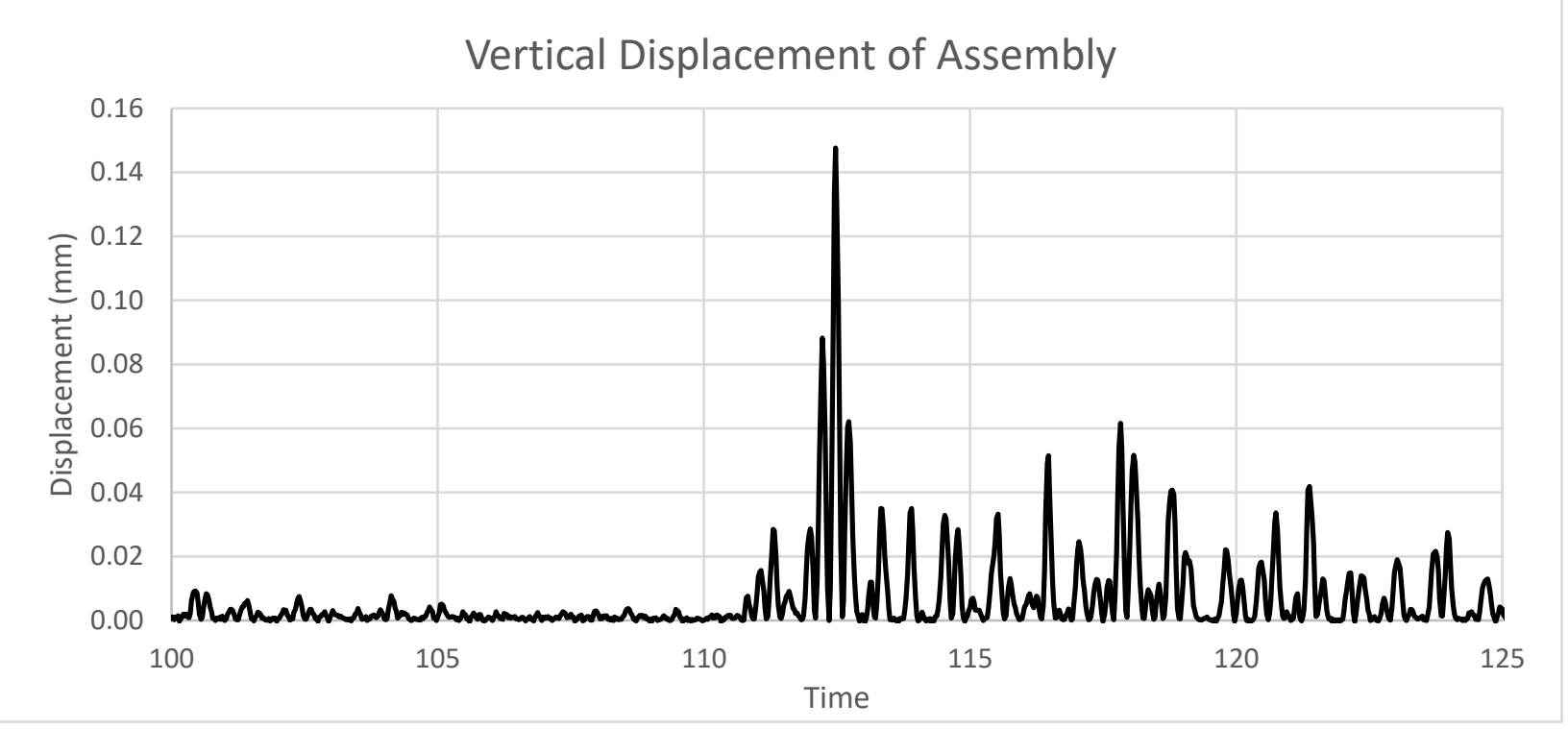

Figure 7-10: Vertical Displacement of Assembly

The force in the hanging wire was shown in Figure 7-11 to evaluate the difference in tension due to the swinging of the mass. As can be seen the force fluctuates by approximately $+/-$ $13 \%$ of the gravity load. This is mainly due to the vertical excitations and not the swinging of the panel. As the maximum acceleration in the vertical direction is $0.146 \mathrm{~g}$ which equates to $14.6 \%$ of the weight of the panel. Due to the swing having small horizontal displacements versus the length of the ceiling wires, the angle of movement is very small. This leads to small fluctuations in weight due to the reduced gravity load when the wires are not vertical. The minimum tensile strength of a 12-gauge hanging wire is $267 \mathrm{~N}(60 \mathrm{lbs})$ for a Category C ceiling system. If this were a full system, the hanging wire would be supporting four times the current load due to surrounding panels creating a total force of $45 \mathrm{~N}(10 \mathrm{lbs})$. This system used a $34.5 \mathrm{~Pa}(0.72 \mathrm{psf})$ panel and 3.79 $\mathrm{N} / \mathrm{m}(0.26 \mathrm{lb} / \mathrm{ft})$ grid members causing an approximate system weight of $57.5 \mathrm{~Pa}(1.2 \mathrm{psf})$, which is half of the Category limit of 114.9 $\mathrm{Pa}(2.4 \mathrm{psf})$. 


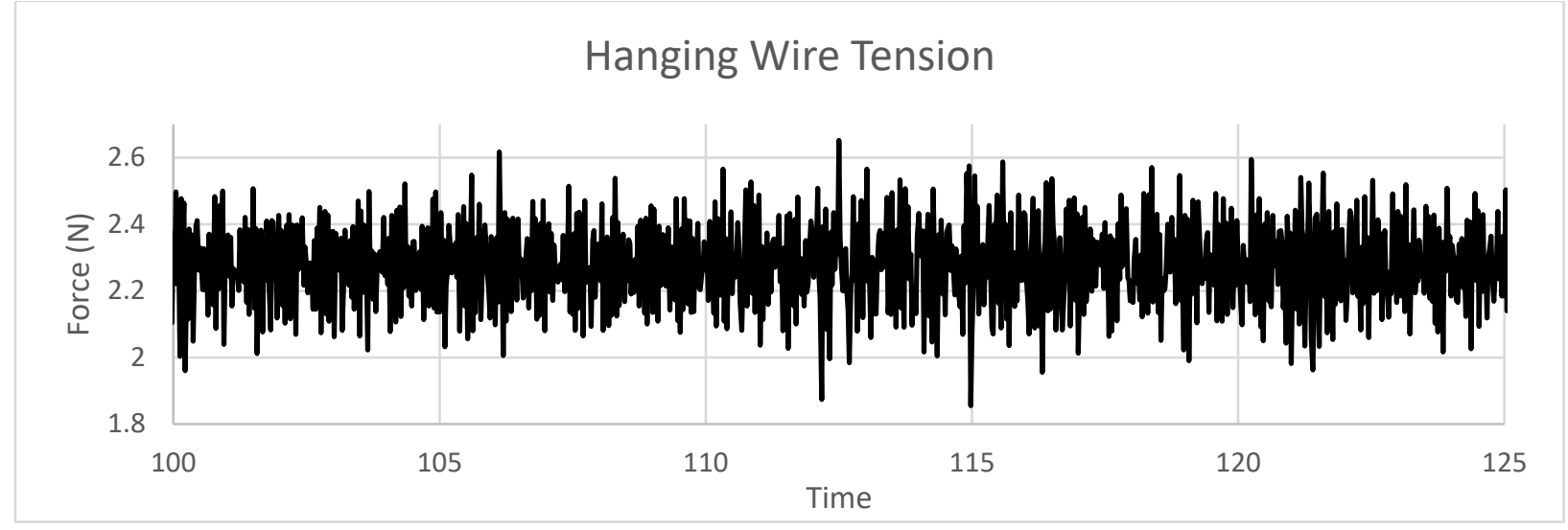

Figure 7-11: Hanging Wire Tension Force

As previous experiments have demonstrated, when hold down clips are used on the panels the grid members experienced failure at lower accelerations. To verify the model and the zeroImpact3D elements used, both a model with hold downs clips and without hold down clips were compared. As shown in the Figure 7-12 below, the system with the hold down clips experienced higher displacements which is a result of a higher horizontal force. This is due to the panel being unable to lift off the grid members and the higher friction resistance due to the hold down force not allowing the panel to slide. Therefore, all of the panels mass is transferred to the grid members resulting in a higher inertia and creating a larger horizontal force.

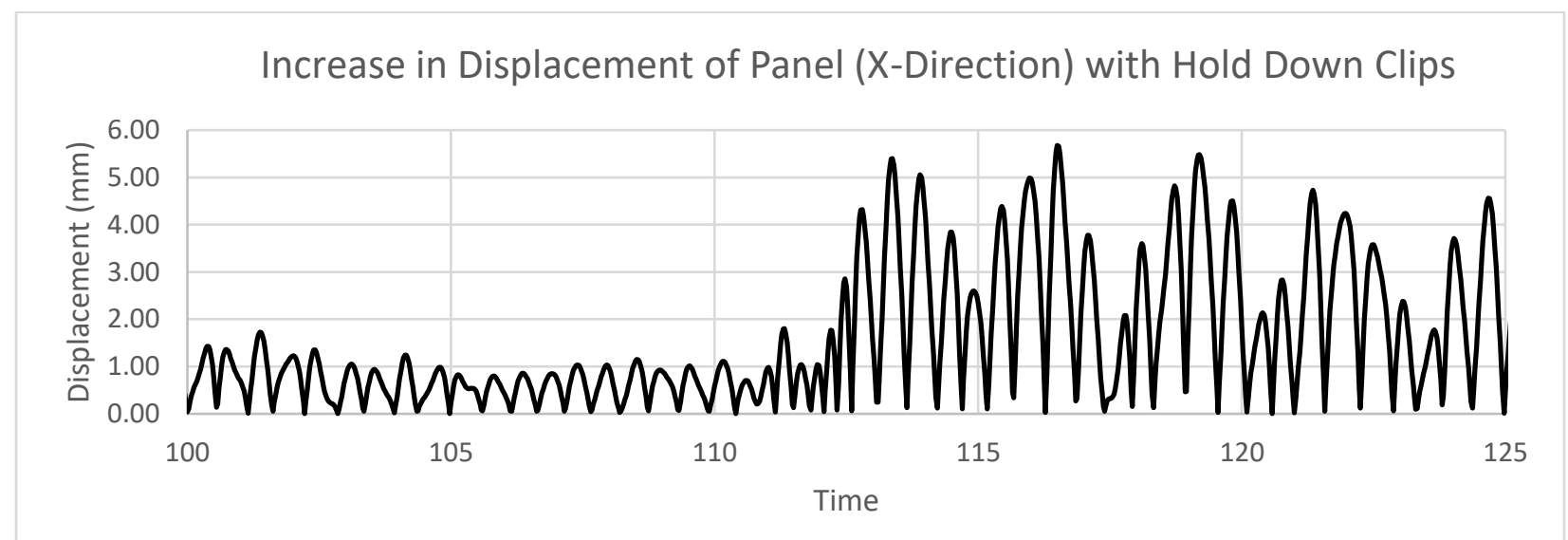

Figure 7-12: Increase in Displacement due to Hold Down Clips 
In conclusion, a non-linear finite element model of a single suspended ceiling panel was developed using OpenSees software. The majority of the components were modelled using linear element. Future researchers can adjust all these elements to be non-linear once the hysteresis of each component is determined. This model can evaluate the sliding and uplift of a ceiling panel and the impact of using hold-down clips on the ceiling panel. This model provides a framework for a larger system to be created in order to predict experimental shake table testing results at Carleton University. 


\section{Chapter 8: Concrete Block Reaction Wall}

\subsection{Overview}

A typical approach to experimental testing of structures is using hydraulic actuators supported by reaction steel frames. This approach of experimental setup of using steel frames to provide reaction for the hydraulic actuators is sometimes not efficient because of the inherent flexibility of steel frames. To overcome this disadvantage, the idea of concrete reaction walls is usually considered as an alternative to the steel reaction frame solution. For flexibility and versatility in experimental setup and applications, the concept of a unique reconfigurable concrete reaction block wall is presented. Concrete is the ideal material as the construction material for a reaction block wall because of its inherent high compressive stiffness while having approximately $1 / 3$ the density of steel.

\subsection{Previous Designs}

The design of the reconfigurable concrete reaction block wall at Carleton has gone through several design iterations. In the first design, Fiszman (2014) produced an initial design as shown in Figure 8-1. Fiszman investigated three design options for the concrete blocks that included a hollow block with $80 \mathrm{MPa}$ concrete, a solid $80 \mathrm{MPa}$ block and a solid block constructed with $40 \mathrm{MPa}$ lightweight concrete. A comparison of the blocks indicated that the solid lightweight block was the most feasible. The design criterion was the reaction block wall system should be able to withstand the reaction forces produced by two actuators: one at top (with a loading capacity of $1000 \mathrm{kN}$ ) and another at mid-height of the reaction wall (with a loading capacity of $500 \mathrm{kN}$ ) and test specimen. An investigation based on the strong floor capacity and the two overhead cranes lifting capacities in the structural laboratory indicated that the maximum system height could be 
$6000 \mathrm{~mm}$. The block size was determined based on the post tensioning holes in the strong floor which are laid out in a $600 \mathrm{~mm} \times 600 \mathrm{~mm}$ grid. This produced a design block size of $1200 \mathrm{~mm} \mathrm{x}$ 1800 mm x 1000 mm (W x L x H).

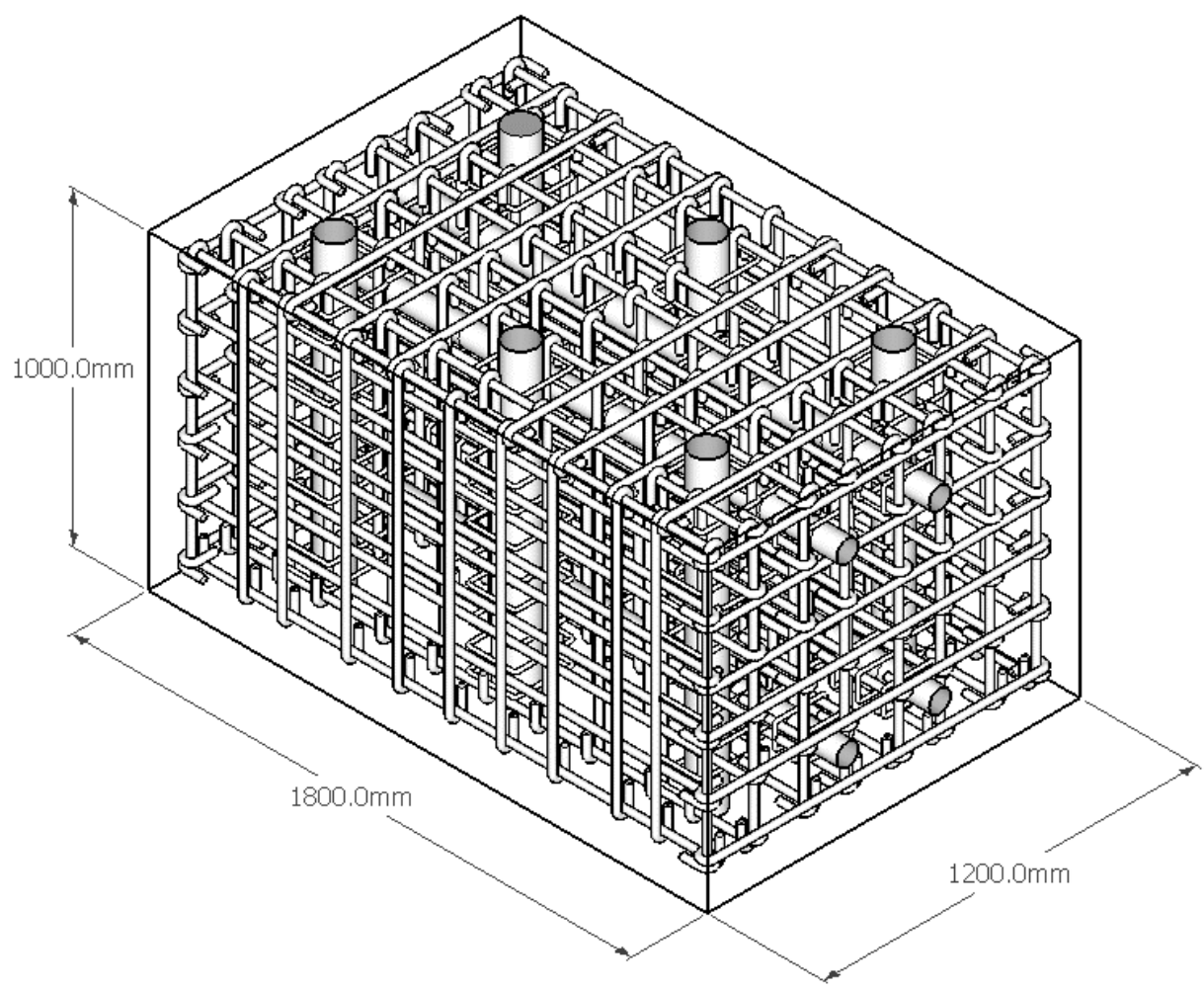

Figure 8-1: Fiszman's Concrete Block Design (Fiszman, 2014)

Miller (2015) optimized Fiszman's design of the concrete blocks as shown in Figure 8-2. The design block produced by Miller had the same dimensions as Fiszman's design. The main difference in the optimization was the addition of a concrete shear key at the top of the blocks to resist sliding between the blocks. 


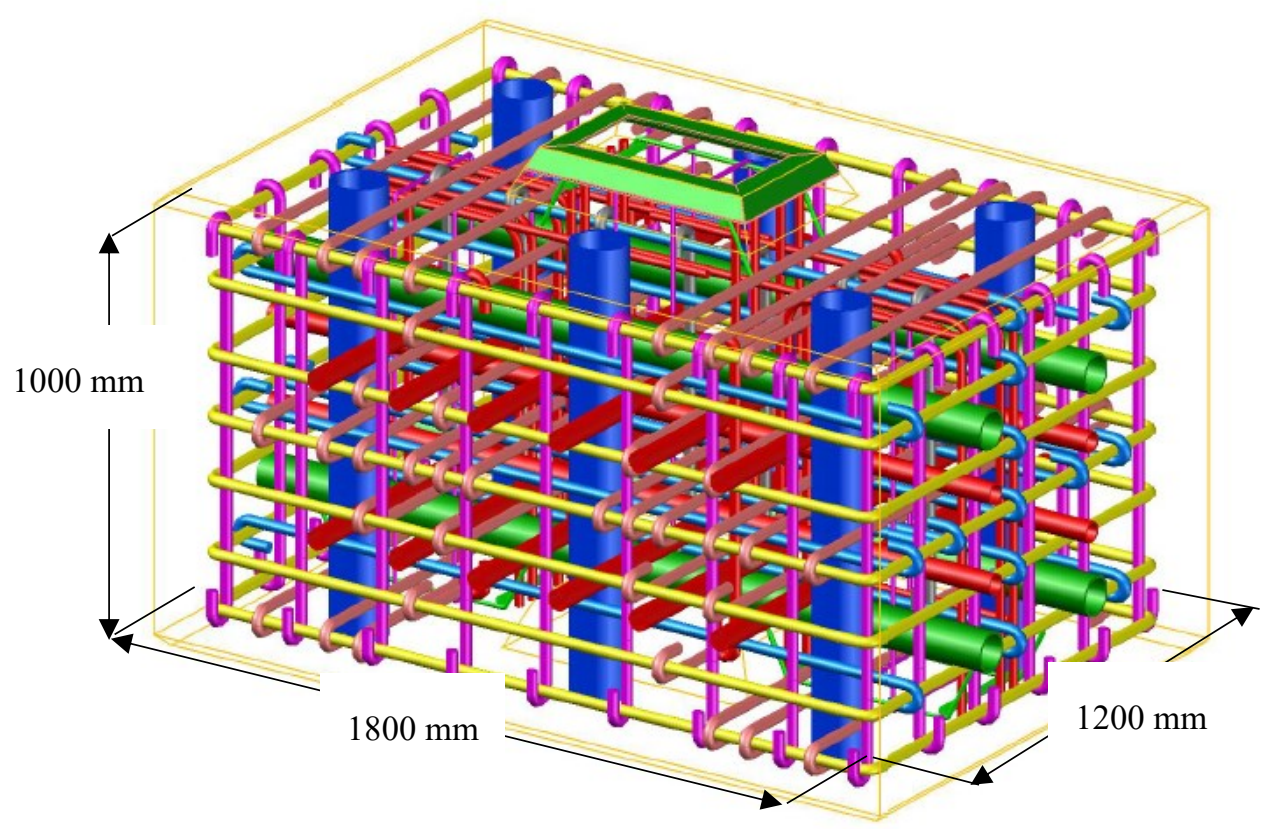

Figure 8-2: Miller's Concrete Block Design (Miller, 2015)

After review of the design and constructability of the concrete blocks the following observations were made. The revised design by Miller (Miller, 2015) assumed a concrete strength of $50 \mathrm{MPa}$ compared to the design by Fiszman of $40 \mathrm{MPa}$ of lightweight concrete, which could not be sourced from any local manufacturers and thus the design became unfeasible to produce. The reinforcing bends and hooks were not typical and therefore difficult to construct. It was determined that the design by Fiszman and Miller was difficult to construct to keep adequate bar spacing and provide sufficient concrete cover.

\subsection{Final Design of Concrete Reaction Block Wall}

A new concrete block was designed by optimizing the previous designs. Using the information from previous studies of the strong floor capacity (Fiszman, 2014) they were checked and verified with the new concrete reaction block wall system. 
In the final design, the design height of change to the block changed from the original $1000 \mathrm{~mm}$ to $600 \mathrm{~mm}$. The reason behind this change was due to the fact that lightweight concrete was not used in the blocks as the desired compressive strength could not be produced and each block was required to weigh less than 5 tons due to the capacity of the overhead cranes. The $600 \mathrm{~mm}$ height would also allow for more flexible placement positioning options for the actuators against the blocks. The new design block design allows for actuators to be placed in the center of the blocks or at the center between two blocks with a vertical spacing of $300 \mathrm{~mm}$ compared to the original design spacing of $1000 \mathrm{~mm}$. The second major change in the block designs is the addition of two steel shear keys compared to the concrete key in the design by Miller (Miller, 2015). The addition of the steel shear keys reduced the reinforcing required for the concrete key in the previous designs. The steel shear keys serve the same purpose as the concrete shear key in the previous design, to guide the blocks while stacking and to resist sliding by increasing the friction between two blocks. As the friction between blocks can be affected by multiple factors such as the levelness of the contact area and surface roughness of the blocks. The use of steel shear keys eliminates this uncertainty. Carleton University has two large capacity actuators, each with a max load of $1000 \mathrm{kN}$ and two small capacity actuators, each with a max load of $500 \mathrm{kN}$. Additional HSS ducts were placed in the concrete block to allow for a total of six vertical post tensioning rods, eight horizontal post tensioning rods or three large capacity actuator positions to go through a concrete block for anchoring purpose. The long horizontal side is capable of holding the small capacity actuators in five different positions. The new block design is shown in Figure 8-3. 


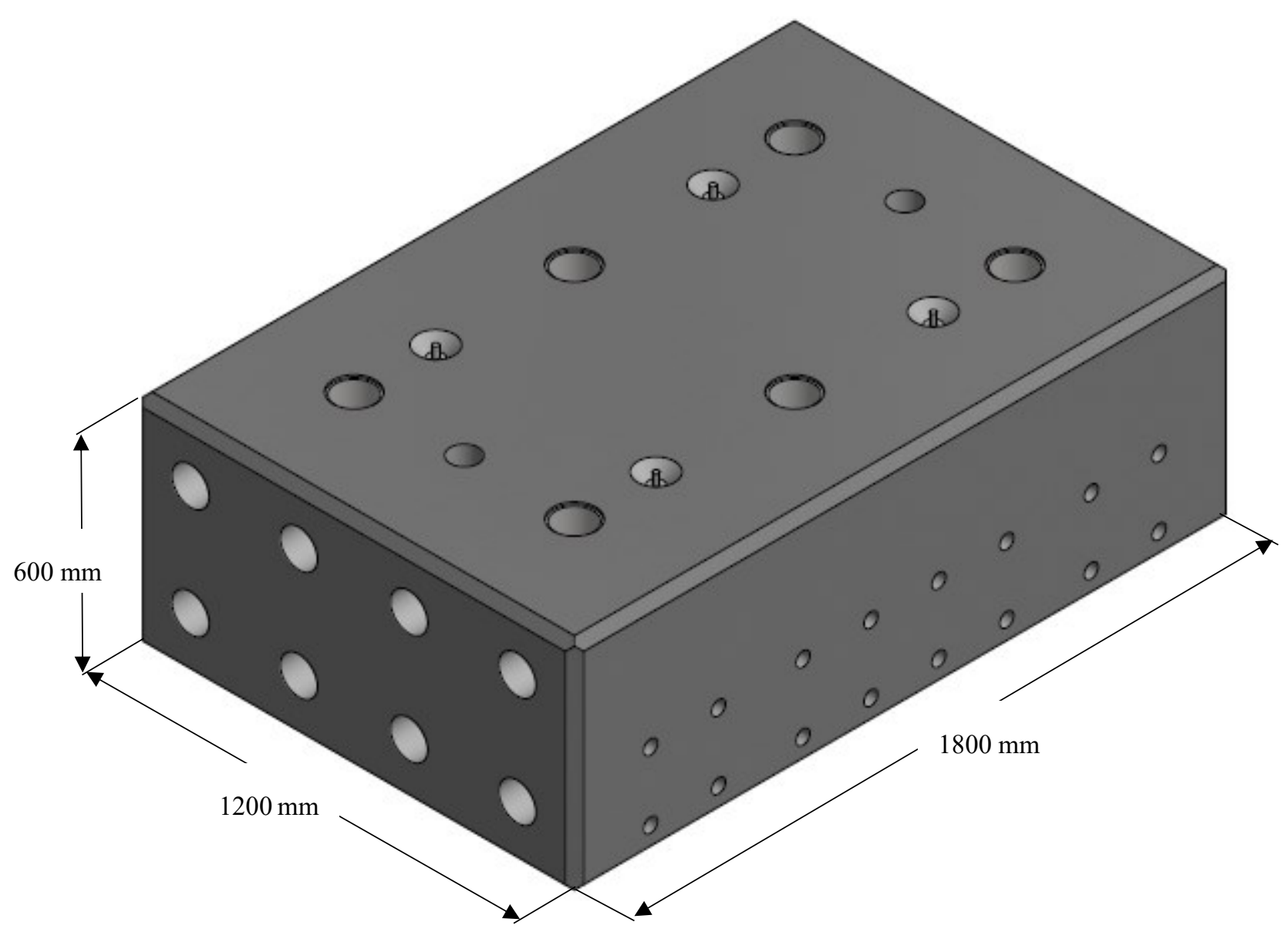

Figure 8-3: Final Concrete Block Design 3D Model

The reaction block wall was designed to withstand simultaneously the reaction forces of two actuators with varying loads at varying heights dependent on the configuration of the reaction block wall. The original design was capable of applying the load of $1000 \mathrm{kN}$ at the top of the wall setup and another load of $500 \mathrm{kN}$ at the middle of the reaction wall. After further investigation, the governing design criterion is the maximum actuator forces can be applied without causing any uplift (tensile forces) in the concrete blocks. Two different configurations of the concrete block reaction wall were analyzed; were the $4.2 \mathrm{~m}$ x $3 \mathrm{~m}$ system ( $1000 \mathrm{kN}$ and $500 \mathrm{kN}$ Forces) and the $6 \mathrm{~m}$ x $2.4 \mathrm{~m}$ system (400 kN and $200 \mathrm{kN}$ Forces) as described in this section 8.5 of this study. The systems will be referred to as the 4-3 system and the 6-2 system respectively. For the layout of 
the concrete blocks to form a reaction wall, a system consisting of two stacks of concrete blocks post tensioned together horizontally significantly increases the overturning and shear capacity of the concrete block wall. If testing involves any deviation from this setup, additional analysis should be performed to verify the load capacity of the setup. Figure 8-4 illustrates the $4.2 \mathrm{~m}$ x $3 \mathrm{~m}$ system configuration.

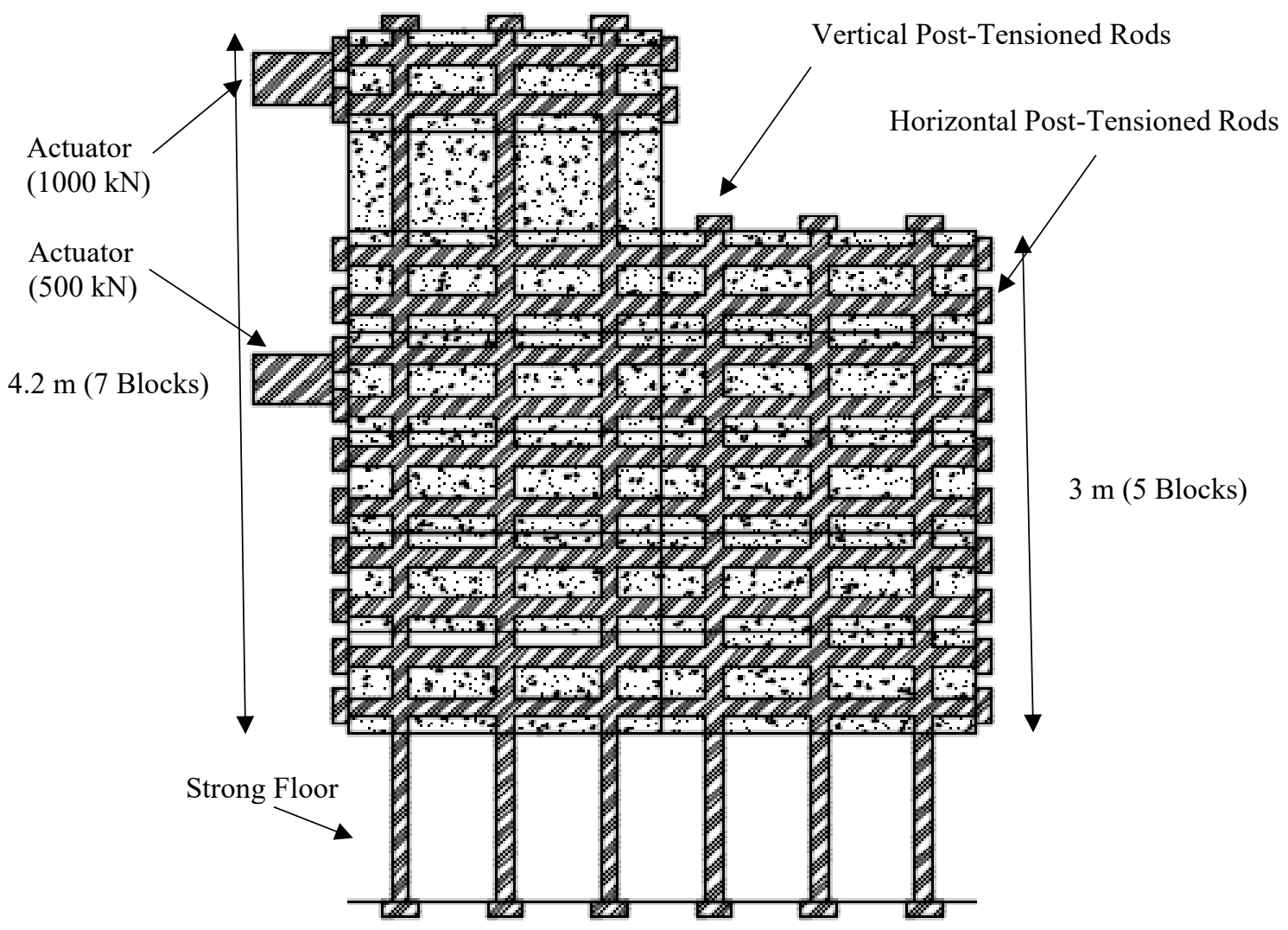

Figure 8-4: 4.2 m x 3 m Reaction Block Wall Configuration 


\subsection{Concrete Block Geometry and Properties}

\section{$\underline{\text { Post-Tensioning Rod Size and Location (Vertical) }}$}

For the reaction wall setup, the concrete blocks are to be post tensioned to the strong floor using $46 \mathrm{~mm}$ post-tensioning rods. The maximum service prestressing force is determined to be $1068 \mathrm{kN}$ which is equal to $0.6^{*} f_{p u}$. Six vertical rods per block spaced at $600 \mathrm{~mm}$ from each other to match the anchor holes of the strong floor are used for anchorage of the wall.

\section{Coupler}

For extending the reach or length of the post-tensioning rods, coupler can be used to join two post-tensioning rods together to reach the length required for the $6 \mathrm{~m} \mathrm{x} 2.4 \mathrm{~m}$ system. The coupler size is $79 \mathrm{~mm}$ which requires the duct to have a minimum diameter of $95 \mathrm{~mm}$.

\section{$\underline{\text { Vertical Ducts }}$}

Due to the size of the coupler the duct needed a minimum $95 \mathrm{~mm}$ interior diameter (ID). The selected duct size for the concrete block design has an interior diameter of $101.6 \mathrm{~mm}$ and an outer diameter of $114.3 \mathrm{~mm}$. This provides space for movement in the rods and allows for a larger tolerance in the fabrication of the blocks.

\section{Post-Tensioning Rod Size and Location (Horizontal) (1200 x 600 side)}

There are eight horizontal ducts the same size as those used in the vertical direction. The same bars and coupler are used in the horizontal ducts as those used in the vertical direction. The ducts however can support one $1000 \mathrm{kN}$ actuator per block. The design of the eight horizontal ducts included consideration of preventing differential movement between two stacks of blocks. Post-Tensioning Rod Size and Location (Horizontal) $(1800 \times 600$ side)

This side of the block has 16 HSS $48 \times 3.8$ ducts. These ducts have an ID of $40.7 \mathrm{~mm}$ in order to fit the rods for the small actuator $(500 \mathrm{kN})$ through. The rebar on this side has not been 
designed for prevention of spalling and bursting due to space limitations. Therefore, the force applied to the rods holding the actuator must be minimal in order to prevent damage to the blocks.

\section{$\underline{\text { Shear Keys }}$}

There is a total of four shear key locations per block. Two on the top and two on the bottom. The shear keys are $76.2 \mathrm{~mm}$ (diameter) solid cylinders with a total length between two blocks of $242 \mathrm{~mm}$. These rods are designed to a limited force of $287 \mathrm{kN}$ per rod, so for one block along the shear surface the two rods can resist $574 \mathrm{kN}$. If there are two stacks of blocks connected, then the total resistance is $1148 \mathrm{kN}$. The rest of the shear force will be resisted by the friction between the two concrete blocks. There is also the engineering judgement that with the shear keys taking 58\% of the max shear force that you can rely on static friction to provide the extra $42 \%$ needed to resist the shear force. Not accounted for is the vertical post tensioning rods that are possibly held tight against the edge of the ducts due to slight out of alignment. During testing if the blocks are found to slip the researcher can add smaller HSS Pipes inside the ducts at the joints or can apply hydrostone between the blocks to increase the friction.

\section{Concrete}

The concrete of the blocks has a minimum compressive strength of $40 \mathrm{MPa}$ with a density of $2200 \mathrm{~kg} / \mathrm{m} 3$. There are no added admixtures to the concrete.

\section{$\underline{\text { Reinforcing }}$}

The blocks reinforcing was designed to resist spalling and bursting of the concrete due to the post tensioning loads. There were some assumptions that had to be made before designing the reinforcing layout. The HSS pipes used as ducts for the thread bars were considered to take no load from the anchoring of the post-tensioning. This was due to the fact that even though the pipes axial compression resistance (HSS's Cr) was lower than the force to be applied and therefore the 
safer assumption was that the concrete would bear the load entirely. The next assumption was that the $1800 \mathrm{~mm}$ side with the small $48 \mathrm{~mm}$ HSS for the small actuator (500 kN MAX) would use a steel base plate to distribute the load along the face of the block, so no reinforcement was needed for bursting in this direction as there was limited space. A local rebar company was contacted in order to provide minimum hook diameters as some reinforcing had to hook around tight to the HSS $114 \mathrm{~mm}$ pipes. The rebar company provided a minimum ID of hook for a $25 \mathrm{M}$ bar to be $150 \mathrm{~mm}$ and a $20 \mathrm{M}$ to be $120 \mathrm{~mm}$. When detailing the blocks, a large amount of reinforcement was needed for the spalling due to the vertical post tensioning. The first draft was $35 \mathrm{M}$ rebar that needed to hook around the $114 \mathrm{~mm}$ HSS and therefore would not be able to be produced by any rebar manufacturer. In order to overcome this issue, it was decided that the blocks would utilise bundled bars. The code states, there can not be more than 4 bars in a bundle and spacing is provided based on the equivalent size of rebar (total rebar in bundle). Therefore, 2-25M rebar were bundled together to replace a single $35 \mathrm{M}$ rebar, this way the hooks could be created, and spacing requirements were satisfied. Figure 8-5 shows the reinforcing inside the concrete block during construction. 


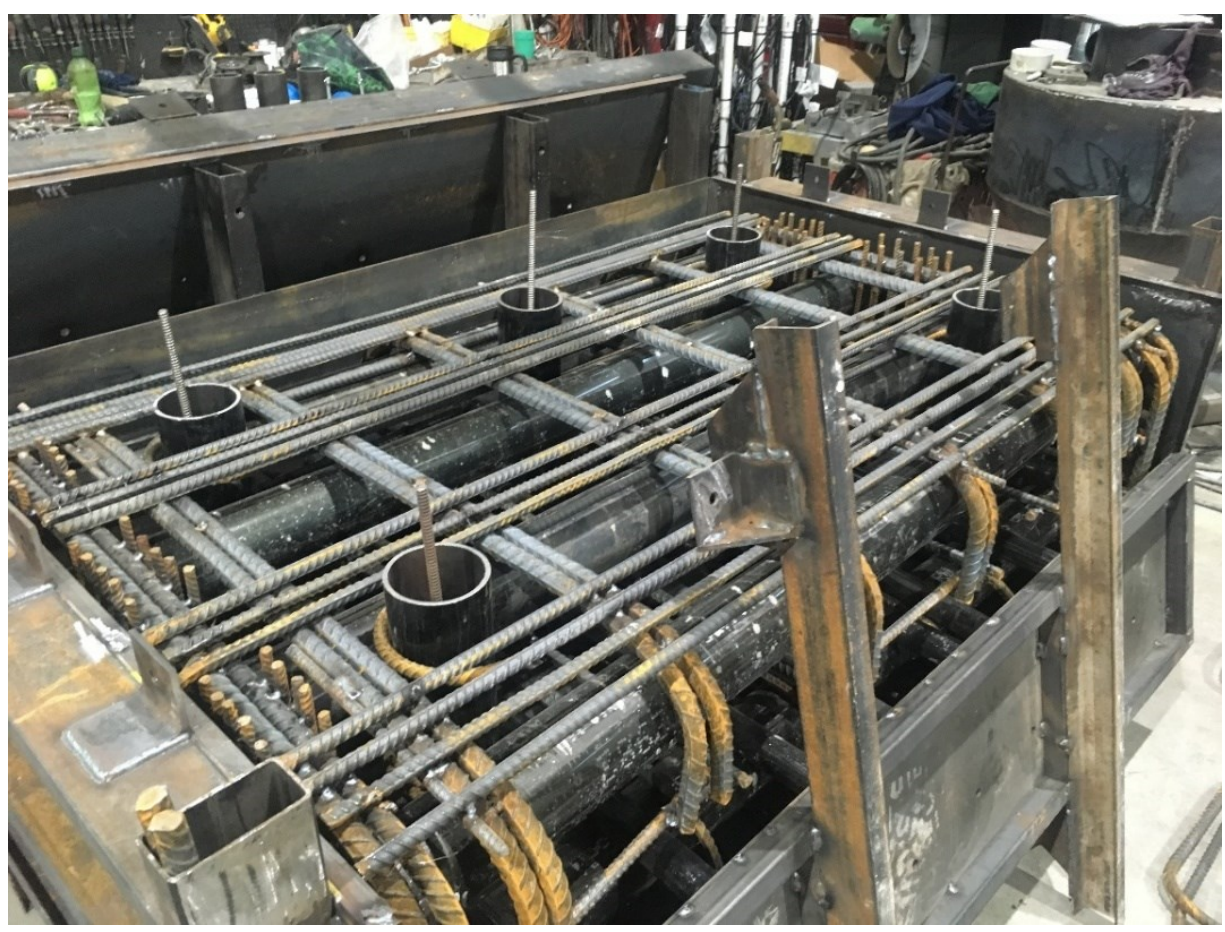

Figure 8-5: Construction of Concrete Block

\subsection{Carleton University Structural Lab Capacities}

The strong floor in the Minto building will be the future location for the strong wall. There are four structural aspects of the strong floor that needed to be analyzed in order to ensure the placement location of the concrete blocks on the strong floor can safely resist the loads from testing. These four components included: size and height of the system based on limitations of the cranes in the lab, moment and shear resistance of the strong floor, axial capacity of the columns, and finally, capacity of the foundation piles.

\section{Moment and shear resistance (Strong Floor)}

The strong floor is a $1 \mathrm{~m}$ deep concrete slab with provided reinforcement of $35 \mathrm{M}$ rebar at $150 \mathrm{~mm}$ spacing each way, top and bottom. According to the structural drawings of the strong 
floor, the maximum moment that can be resisted is $2000 \mathrm{kNm} / \mathrm{m}$. The maximum shear resistance is $1140 \mathrm{kN} / \mathrm{m}$.

The maximum point moment produced is $5600 \mathrm{kNm}$. This assumes that the stack needs to activate approximately $2.8 \mathrm{~m}$ width of slab to resist the moment. As the width of the block is $1.2 \mathrm{~m}$ long the assumption that $2.8 \mathrm{~m}$ of slab will activate is adequate.

Along with this simplified capacity check the previous researchers performed a floor analysis using a $6 \mathrm{~m} \times 2 \mathrm{~m}$ system with the $1000 \mathrm{kN}$ and $500 \mathrm{kN}$ forces and concluded that the floor was capable of resisting the dynamic forces.

\section{Axial Capacity of Columns}

In the strong floor analysis report (Fiszman, 2014) it was found that the columns supporting the strong floor could each withstand a pure axial load of $3900 \mathrm{kN}$. Due to this number being much higher than the pile capacity's, the columns were considered to not cause a limitation in design as the piles would fail first.

\section{Pile Capacity (Foundations)}

There are four different pile caps, each with a different capacity. The layout of the strong floor supports, and foundations are shown in Figure 8-6 referenced from the building's structural drawings. 


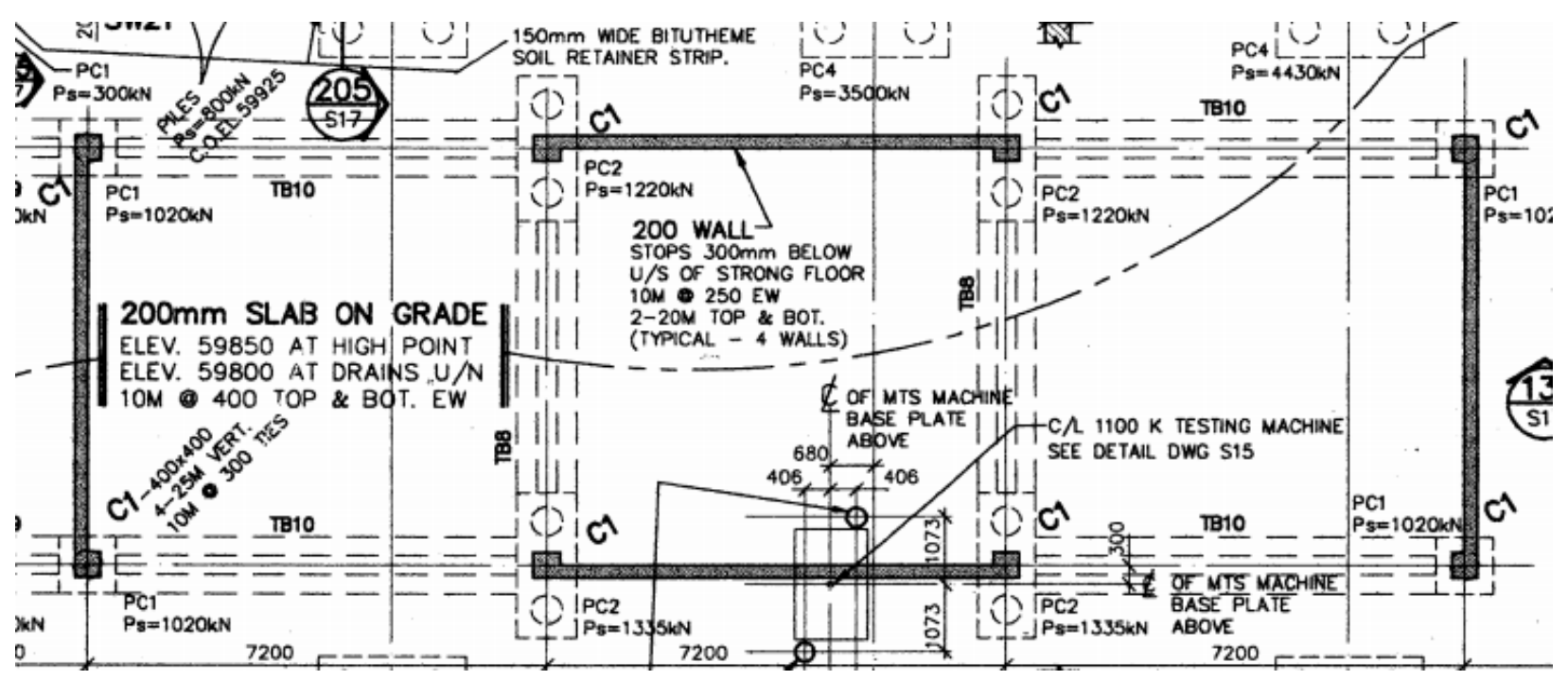

Figure 8-6: Structural Layout of Carleton's Lab

These piles have a service capacity range from $1020 \mathrm{kN}$ to $1335 \mathrm{kN}$. Fiszman produced Figure 8-7, indicating the pile capacity and the tributary floor area that the pile is supporting.

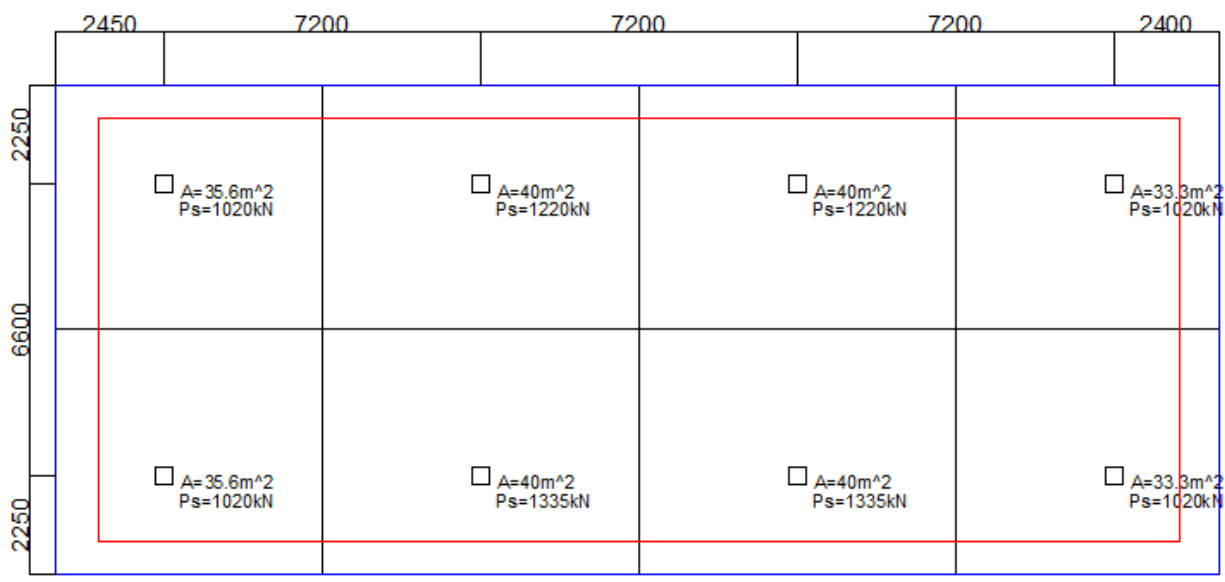

Figure 8-7: Pile Capacity and Tributary Area (Fiszman, 2014)

The pile capacity $P_{S}$ represents the total service capacity based on dead load which includes the weight of the strong floor and columns and the live load is any additional load on the floor. 
The max number of blocks that can be placed anywhere on the strong floor is limited by the capacity of the left most foundations located in Figure 8-7 above. Therefore, the maximum number of blocks is limited by $145 \mathrm{kN}$ which is equal to 5 Blocks. If the blocks are not placed over the right or left most foundations and moved to a minimum of $3.2 \mathrm{~m}$ away the maximum number of blocks is increased to 8 Blocks with a foundation limit of $239 \mathrm{kN}$.

\section{$\underline{\text { Height and Size (4-3 System) }}$}

The determined configuration using the original actuator forces of $1000 \mathrm{kN}$ and $500 \mathrm{kN}$ was found to be a $4.2 \mathrm{~m}$ and $3 \mathrm{~m}$ stack side by side. The limited height was due to the capacity of the post tensioning rods with applied actuator forces of $1000 \mathrm{kN}$ at a height of $3.96 \mathrm{~m}$ and $500 \mathrm{kN}$ at a height of $2.15 \mathrm{~m}$. The configuration was also limited by the capacities of the strong floor as the weight of the system can exceed the pile capacities.

\section{Height and Size (6-2 System)}

The determined configuration for the maximum height for actuator location was found to be a $6 \mathrm{~m}$ and $2.4 \mathrm{~m}$ stack side by side. The limited height was due to the ceiling height limitation with the post tensioning rods during the setup. The configuration was also limited by the capacities of the strong floor as the weight of the system can exceed the pile capacities.

\section{Locations for Strong Wall (4-3 System) (Blue dots represent Piles)}

The locations that the wall can not be placed on the strong floor is represented by the dots on the graph. These dots were found using only the dead weight of the system. The centroid of the two stacks were found as $1.65 \mathrm{~m}$ from the outside edge of the taller stack. Therefore, the centroid 
of the system must be placed within the region of no dots with the smaller stack extending towards the region of dots. The blue dots represent the supports of the strong floor and the red dots are locations that the pile capacity will be exceeded. An excel file will be provided so that exact locations of the wall can be found, and the weight of the object being tested can be added.

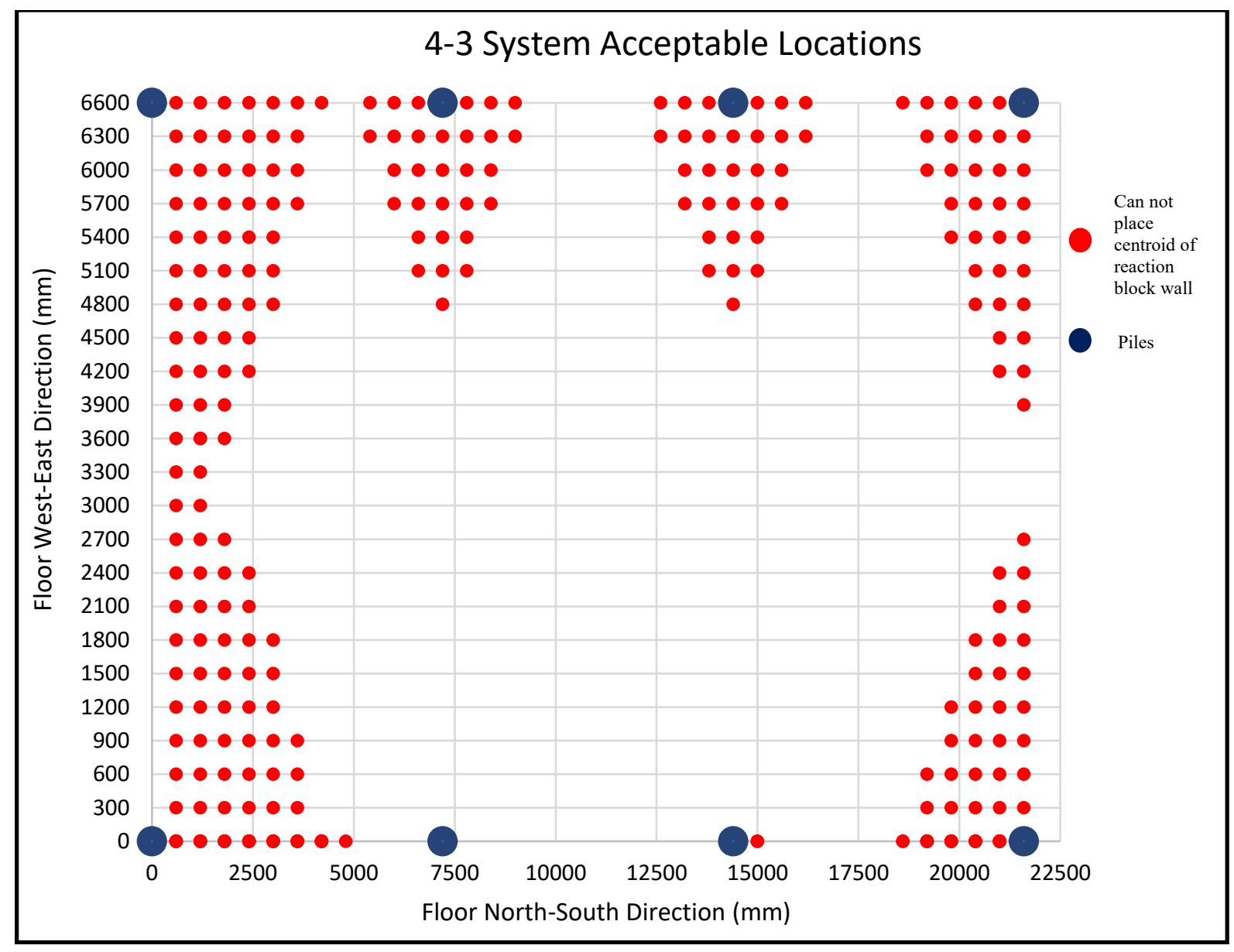

Figure 8-8: Locations for Placement of 4-3 System on Strong Floor

\section{Locations for Strong Wall (6-2 System)}

The possible locations that the wall can not be placed on the strong floor is represented by the dots on the graph. These dots were found using only the dead weight of the system. The 
centroid of the two stacks were found as $1.42 \mathrm{~m}$ from the outside edge of the taller stack. Therefore, the centroid of the system must be placed within the region of no dots with the smaller stack extending towards the region of dots.

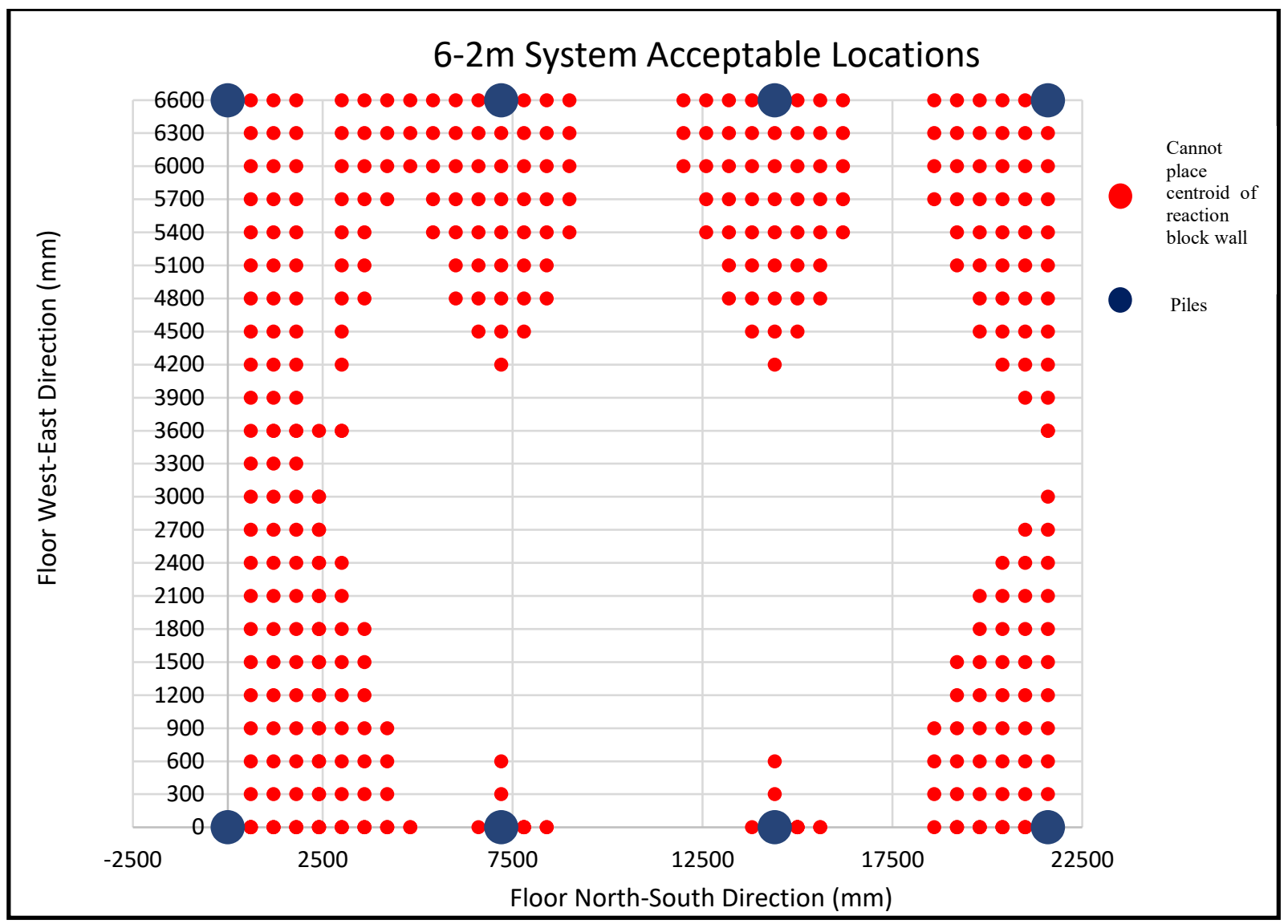

Figure 8-9: Locations for Placement of 6-2 System on Strong Floor

\section{System Configuration (4-3 System)}

The original design was to resist a $1000 \mathrm{kN}$ and a $500 \mathrm{kN}$ force applied horizontally at the top and halfway up the stack (respectively). The previous design involved two stacks side by side, one at $6 \mathrm{~m}$ in height the other one at $2 \mathrm{~m}$. as shown below. The new design has found the most effective system would be two stacks, a $4.2 \mathrm{~m}$ stack and a $3 \mathrm{~m}$ stack ( 7 and 5 blocks respectively). 
A comparable system with similar dimensions of the original concept is the new 6-2 system with two stacks, one at $6 \mathrm{~m}$ and the other at $2.4 \mathrm{~m}$ (10 and 4 blocks respectively) capable of a $400 \mathrm{kN}$ and $200 \mathrm{kN}$ load applied at the top of the wall and at mid height. The original system is shown below followed by the new 6-2 system configuration and the 4-3 system configuration in Figures 8-10, 8-11 and 8-12 respectively.

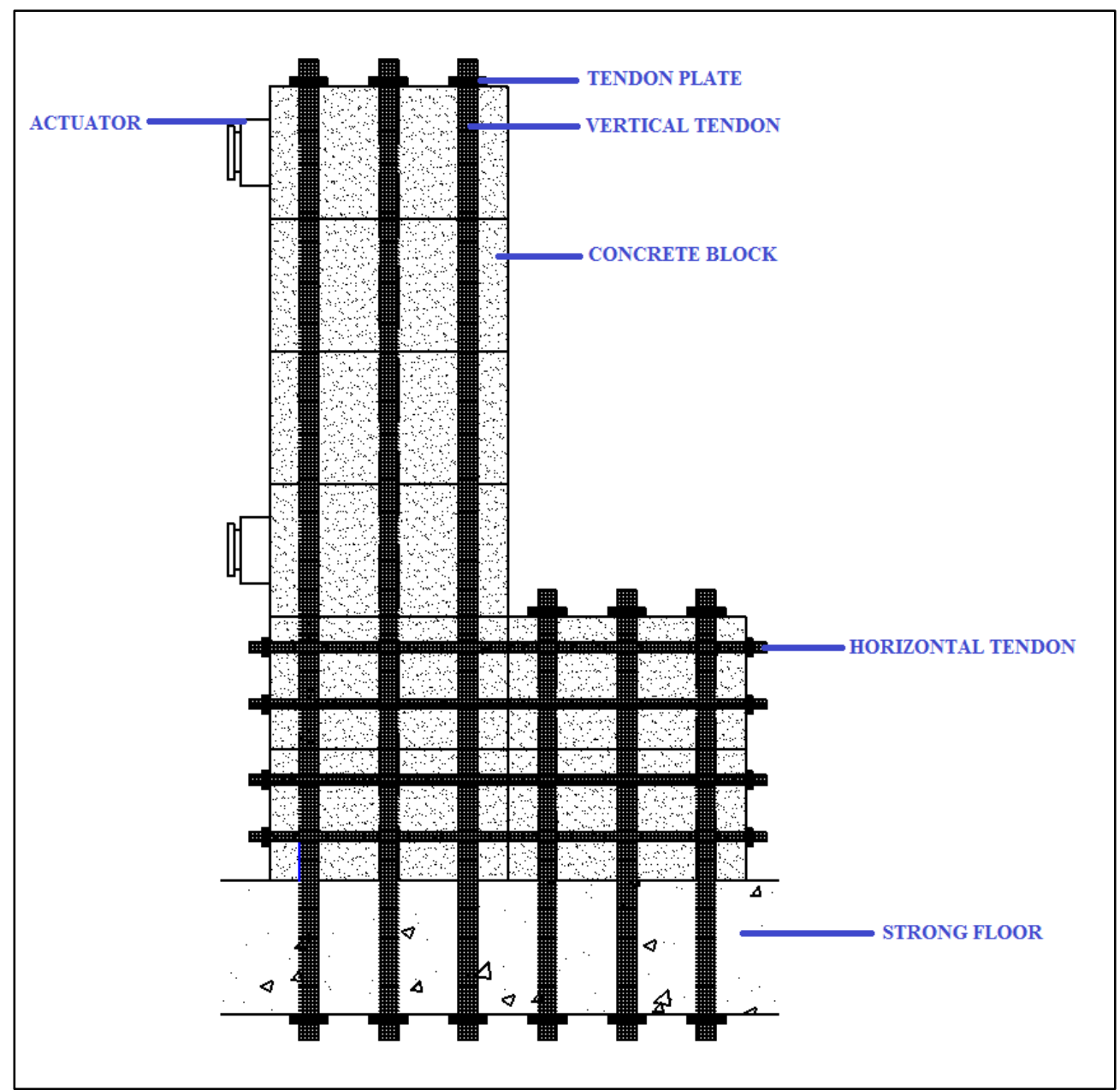

Figure 8-10: Fiszman's Original System (Fiszman, 2014) 


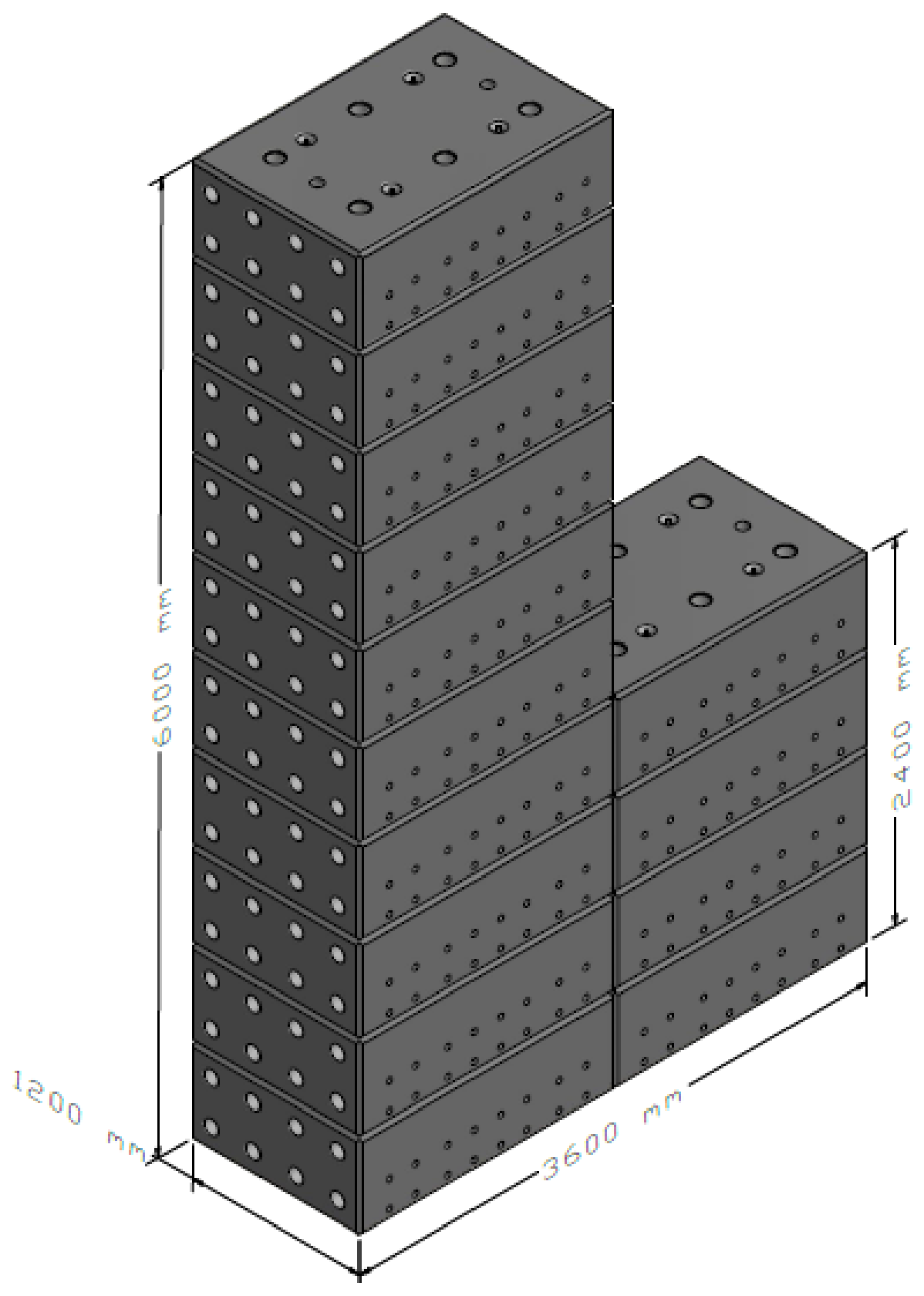

Figure 8-11: New System (6-2 System) 


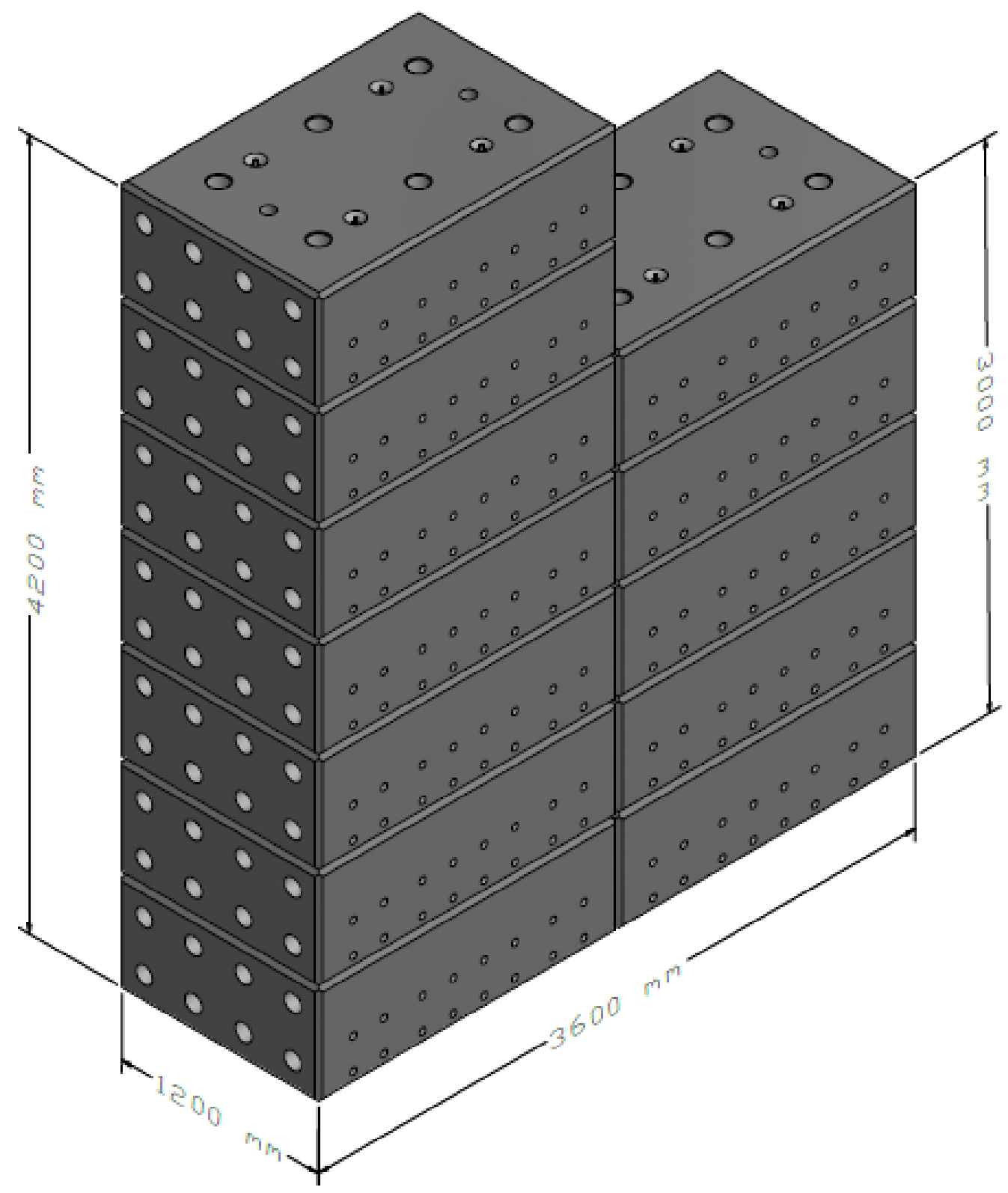

Figure 8-12: New System (4-3 System)

\section{$\underline{\text { System for testing of Self Centering Brace }}$}

The system designed consisted of using a layout of three blocks wide and two blocks high using six blocks total for the system shown in Figure 8-13. This system was designed to test a new prototype self-centering brace. The original design included three independent stacks; each stack was able to have an actuator located at any three heights along the stack $(305 \mathrm{~mm}, 605 \mathrm{~mm}$, 
$905 \mathrm{~mm})$. The maximum capacity of each stack was $1300 \mathrm{kN}$ at the top-most position of $905 \mathrm{~mm}$. The maximum capacity of each stack was $1900 \mathrm{kN}$ at the middle position of $605 \mathrm{~mm}$. The corresponding friction coefficient required between the Minto strong floor and the bottom block is 0.307 and 0.449 , respectively. The Blocks can withstand a vertical post tensioning force of $900 \mathrm{kN}$ however, all calculations on system capacity use the minimum force of $700 \mathrm{kN}$. After further design of the self centering brace and testing program, the configuration of the system was changed to only have three blocks total unstacked. The middle block held the self-centering brace which was connected to steel beam at its far end. The blocks on both ends held the actuators which were connected to the steel beam on either side of the self-centering brace. Figure 8-14 shows the constructed blocks being used to test a self centering brace.
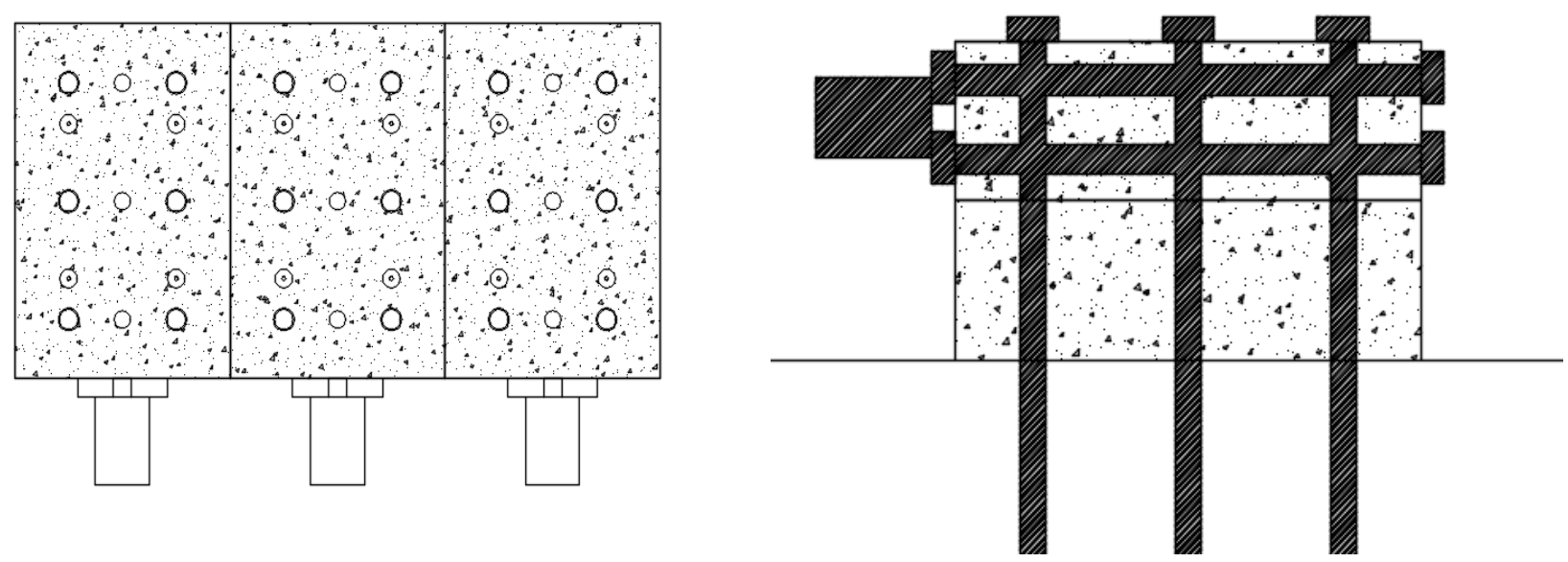

Figure 8-13: New System for Self Centering Brace Test 


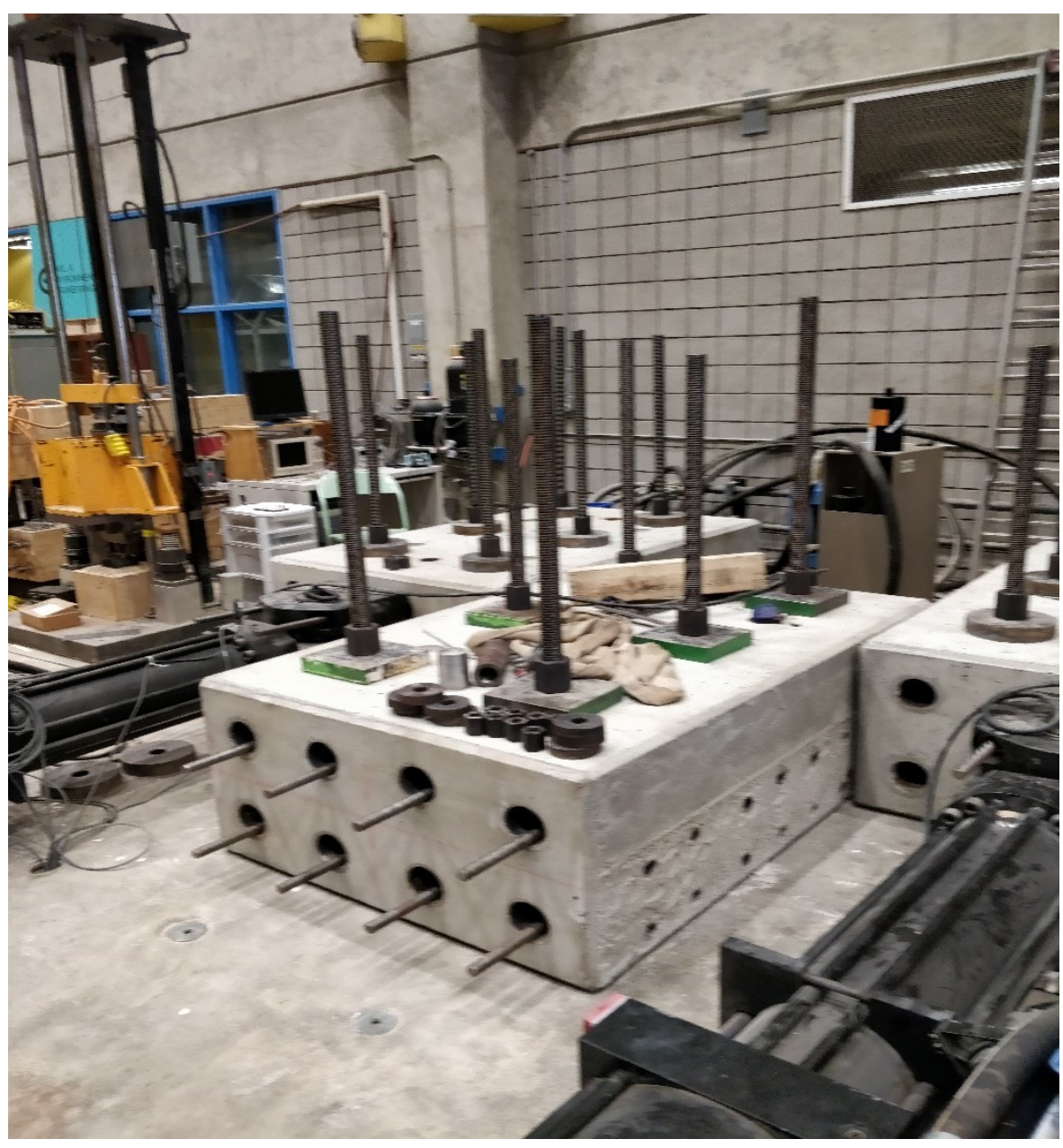

Figure 8-14: Setup of Blocks for Self Centering Brace Test (Ahmed Hassan)

In conclusion, a concrete block reaction wall was designed and constructed. The previous designs were revised and improved in order to create a reconfigurable block that were within the limits of the structural lab in terms of size and weight. The blocks were also designed in three different configurations to resist the reaction forces created by the actuators. These blocks will be used for future testing of structural and non-structural components with the hydraulic actuators. 


\section{Chapter 9: Summary, Concluding Remarks and Recommendations}

\subsection{Summary}

The purpose of this study was to initiate Carleton University's test program on the seismic performance of suspended ceilings in super-tall buildings. This study is part of a joint international collaborative research project with Tokyo Institute of Technology (Japan) and Tongji University (China).

An overview of suspended ceiling systems was presented including economic and life safety impacts upon failure of these systems. A state-of-the-art literature review was performed to investigate previous experimental shake table tests, numerical models, component testing and their conclusions. It was noted that in light of the high degree of variations in the configurations of suspended ceiling systems and the large number of different possible ceiling components involved, there was only a relative limited amount of research conducted on experimental tests and numerical modelling of suspended ceiling systems. The majority of previous tests followed the testing procedure outlined in the seismic testing of non-structural components. The applicability of the ICC-ES AC156 test procedure for testing of suspended ceiling systems was investigated in this study due to the concern that suspended ceilings do not meet the requirements expected in the ICC-ES AC156. Also, the majority of previous tests considered only horizontal input excitations which ignored the potentially significant influence of the vertical input excitations. New experimental research infrastructures that include a new multiple-unit shake table system and testing frame equipment were developed for future research on suspended ceilings to examine the applicability of testing procedure and impact of vertical and rotational support excitations from floor dynamic responses on seismic ceiling performance. The rotational floor response excitation 
may be especially important for tall and super-tall buildings that may have a significant influence on the seismic performance of suspended ceilings at high floor levels of these buildings. Previous numerical modelling research on suspended ceilings employed either simplified linear model or a non-linear model. The non-linear model was computationally expensive and still could not capture the progressive collapse behaviour of the ceiling system.

A summary of the requirements in the current installation standards and design codes of suspended ceilings were presented. The requirements of NBC design code were compared with the IBC design code to investigate variation in the seismic design force for variations of ceiling location in the building and mass of the ceiling. It was concluded that the NBC design load requirements of suspended ceilings resulted in a lower seismic design force of approximately $40 \%$ less than the IBC for lightweight ceiling systems with a weight less than $192 \mathrm{~N} / \mathrm{m}^{2}$ (4 psf). However, for heavier ceilings with weights above $192 \mathrm{~N} / \mathrm{m}^{2}$ (4 psf) the NBC requirements gave a seismic design force ranging from 10\%-30\% higher than the IBC for building categories and site classes that would typically contain suspended ceilings.

A shake table testing program of suspended ceiling systems at Carleton University was outlined with possible test configurations of suspended ceilings of different seismic categories following the current installation standards as outlined in the standards ASTM C635, ASTM 636 and ASTM E580.

A dummy payload design was adapted and constructed for the calibration and verification of the new multiple-unit shake table system at Carleton University. A stacking frame was designed and constructed for storage of the shake tables while not in active use to reduce the space usage in the structural laboratory. A $5.4 \mathrm{~m}$ x $5.4 \mathrm{~m}$ test frame was designed and constructed for future seismic testing of non-structural components including suspended ceilings, cable trays, medical 
floor equipment, etc. The test frame was designed to be lightweight in order to maximize the specimen payload capacity. The test frame was designed to have a high modal frequency in both the horizontal and vertical directions in order to minimize amplification of the input excitations. The frame was designed to resist the forces produced by the input acceleration at maximum table capacity while loaded with the maximum payload weight of the test specimen. The test frame members had a limiting factor of safety of 4.9 using unfactored design loads at maximum payload and maximum accelerations of dynamic testing.

A building was modelled in ETABS to generate floor motion response records based on scaled time histories of recorded earthquakes in both the west coast (Victoria, BC) and east coast (Ottawa, ON). These floor response motions were than compared to the required response spectrum outlined in the ICC-ES AC156 test procedure as used by the majority of previous researchers. The ICC-ES AC156 was developed to outline the required response spectrum and test setup for seismic testing of non-structural components. It was concluded that the AC156 testing procedure was not developed specifically for testing of suspended ceilings and thus its applicability for testing of suspended ceilings should be investigated further. It was also concluded that the floor response motions had much higher response spectrums at the top of buildings and in the vertical direction than the required response spectrum specified in AC156, which may lead to unconservative evaluation of suspended ceiling performance by the AC156 test procedure.

A non-linear finite element model was created using OpenSees software to model a single suspended ceiling panel which can be further developed for correlation study with results from experimental tests at Carleton University. The model can be improved using the results from experimental tests to create more accurate models for seismic performance analysis of suspended ceiling systems. This model investigated the dynamic response of a single suspended ceiling panel 
and investigated into the impact on the response when panel hold down clips are used. Panel hold down clips created additional displacement of the assembly. The suspended ceiling panel with no boundary supports experienced no lift of the panel off the grid members.

Finally, a concrete block reaction wall was designed and constructed as part of research infrastructure for testing of structural and non-structural components. The concrete blocks were designed for use as a reconfigurable reaction wall. Three different configurations of reaction walls were considered in the design of the individual concrete block in order to maximize the height at which actuators could be connected to specimens and magnitude of loads that could be applied.

\subsection{Conclusions}

$>$ Previous experimental tests have indicated that including vertical input excitations created more damage in the suspended ceiling system and produced results closer to that observed in the field.

AC156 Seismic Testing Procedure for Non-structural components was not intended for suspended ceiling systems and should be modified.

$>$ The NBC Seismic Design Force is lower than the IBC due to the minimum component weight $W_{p}$ in the IBC of $192 \mathrm{~N} / \mathrm{m}^{2}$ (4 psf) whereas, the NBC uses the actual system weight which is typically under $120 \mathrm{~N} / \mathrm{m}^{2}$ (2.5 psf). If the weight of the system is $192 \mathrm{~N} / \mathrm{m}^{2}$ (4 psf), the NBC produces a higher seismic design force for suspended ceiling systems located above mid height of a normal or high importance building.

$>$ The designed testing frame for the shake table tests was found to produce lower amplification of the input excitations than the majority of previous experimental tests that incorporated vertical input excitations. 


\subsection{Recommendations for Future Work}

Some recommendations for future researcher are noted below:

1-The AC156 testing procedure should be further investigated and developed for specific use on suspended ceilings attached to test frames.

2-The future experimental tests at Carleton University should use both floor motion response and simulated motions scaled to the AC156 RRS so that the results can be compared to see the possible impact on seismic design of suspended ceilings.

3-A compensation procedure could be developed if it is noted that the amplification of vertical input excitations is beyond what is desired.

4-The OpenSees model of the single suspended ceiling panel can be expanded to model a complete system of that to be configured for the experimental tests. Additional non-linear elements can be added to the model to investigate further dynamic characteristics of the suspended ceiling system such as progressive collapse. 


\section{$\underline{\text { References }}$}

Anchorage Daily News. (2018, December 12). Photos from inside earthquake-damaged schools in Southcentral Alaska. Anchorage Daily News. http://www.adn.com/alaskanews/2018/12/04/eerie-photos-from-inside-earthquake-damaged-schools-in-southcentralalaska/.

ASCE 7-16 (2016) Minimum Design Loads and Associated Criteria for Buildings and Other Structures

ASTM. (1996). Standard Practice for Installation of Metal Ceiling Suspension Systems for Acoustical Tile and Lay-In Panels. 1-4.

ASTM. (2010). Standard Practice for Installation of Ceiling Suspension Systems for Acoustical Tile and Lay-in Panels in Areas Subject to Earthquake Ground Motions (pp. 1-10).

Badillo-Almaraz, H., Whittaker, A. S., \& Reinhorn, A. M. (2007). Seismic fragility of suspended ceiling systems. Earthquake Spectra, 23(1), 21-40. https://doi.org/10.1193/1.2357626

Blackwell, A. P. R. (2017, September 19). People flee to streets after Mexico earthquake. $A B C$ News. https://www.abc.net.au/news/2017-09-20/people-flee-to-streets-after-mexicoearthquake/8962660.

Dhakal, R. P., MacRae, G. A., \& Hogg, K. (2011). Performance of ceilings in the February 2011 Christchurch earthquake. Bulletin of the New Zealand Society for Earthquake Engineering, 44(4), 377-387. https://doi.org/10.5459/bnzsee.44.4.377-387

Dhakal, R. P., Macrae, G. A., Pourali, A., \& Paganotti, G. (2016). Seismic fragility of suspended ceiling systems used in NZ based on component tests. Bulletin of the New Zealand Society for Earthquake Engineering, 49(1), 45-63. https://doi.org/10.5459/bnzsee.49.1.45-63

Fiszman, E. (2014). Reconfigurable Concrete Block Wall. [Master's Thesis, Carleton University]

Gilani, A. S. J., Reinhorn, A. M., Glasgow, B., Lavan, O., \& Miyamoto, H. K. (2010). Earthquake simulator testing and seismic evaluation of suspended ceilings. Journal of Architectural Engineering, 16(2), 63-73. https://doi.org/10.1061/(ASCE)10760431(2010)16:2(63)

IBC (2012). International Building Code

ICC. (2010). ( AC156 ) Acceptance Criteria for Seismic Certification by Shake-Table Testing of Nonstructural Components. ICC Evaluation Service, AC-156. 


\section{$\underline{\text { References (CON'T) }}$}

Ishioka, T. (2005). A Study on the Behaviour of Seismically Engineered Ceiling Systems of Large Open Structures Subjected to Earthquake Excitations. 15 Wcee 2012.

Jiang, W., Xie, W., Pandey, M. (2015). Generate floor response spectra: Part 1. Direct spectra-tospectra method, Nuclear Engineering and Design, 293 (2015): 525-546

Kasai, K. (2016), Current Status of Motion Control to mitigate Seismic Damage of High-Rise Buildings and Contents, $14^{\text {th }}$ International Symposium on Structural Engineering, Keynote Paper 21 pages, Oct. 13 to 15, Beijing, China

Lu, Y., Mosqueda, G., Han, Q., \& Zhao, Y. (2018). Shaking Table Tests Examining Seismic Response of Suspended Ceilings Attached to Large-Span Spatial Structures. Journal of Structural Engineering (United States), 144(9), 1-15. https://doi.org/10.1061/(ASCE)ST.1943-541X.0002140

Lu, Xilian, Jiang Huanjun, J. (2016). Seismic Damage Analysis of a Benchmark Model for Mega-Tall Buildings. Journal of Building Structures, 37(9).

Mccormick, J., Matsuoka, Y., Prevention, D., Pan, P., \& Nakashima, M. (2008). Evaluation of Non-Structural Partition Walls and Suspended Ceiling Systems through a Shake Table Study.

Miller, S. (2015). Reconfigurable Concrete Block Wall. Carleton University

Nakamura, Y. (2017, April 17) A year after Kyushu quakes, Sony's sensor business expands to $A R$, robots. The Japan Times.

https://www.japantimes.co.jp/news/2017/04/14/business/corporate-business/year-kyushuquakes-sonys-sensor-business-expands-ar-robots.

NBCC. (2015). Selection and Scaling of Ground Motion Time Histories (p. Commentary J).

Norio, O., Ye, T., Kajitani, Y., Shi, P., \& Tatano, H. (2011). The 2011 eastern Japan great earthquake disaster: Overview and comments. International Journal of Disaster Risk Science, 2(1), 34-42. https://doi.org/10.1007/s13753-011-0004-9

OBC. (2019). Ontario Building Code 2012 Part 4.

Pentangelo, V. (2010). University of N. Aples F.Ederico II Philosophiae Doctor Program on Seismic Assessment of Suspended Ceilings. 


\section{$\underline{\text { References (CON'T) }}$}

Pourali, A., Dhakal, R. P., Macrae, G., \& Tasligedik, A. S. (2017). Fully floating suspended ceiling system: Experimental evaluation of structural feasibility and challenges. Earthquake Spectra, 33(4), 1627-1654. https://doi.org/10.1193/092916EQS163M

Ryu, K P, Reinhorn, A. M., \& Filiatrault, A. (2012). Full Scale Dynamic Testing of Large Area Suspended Ceiling System. 15 Wcee 2012, 1.

Ryu, Ki Pung. (2009). Modelling and Seismic Evaluation of Testing Frame for Experimental Evaluation of Suspended Ceiling Systems.

Sen. (2016). An Investigation to the Influence of Cracked Moment of Inertia on Building' s Seismic Performance in the Light of Pushover Analysis. 3(7), 1594-1604. http://www.ethanpublishing.com/index.php? $\mathrm{m}=$ content\&c=index\&a=show\&catid $=255 \& \mathrm{id}=$ 715

Soroushian, S, Ryan, K. L., Maragakis, M., \& Wieser, J. (2012). NEES / E-Defense Tests : Seismic Performance of Ceiling / Sprinkler Piping Nonstructural Systems in Base Isolated and Fixed Base Building. 15 Wcee 2012, Kircher.

Soroushian, S., Maragakis, M., Zaghi, A. E., \& Echevarria, A. (2015). Numerical Simulation of Integrated Suspended Ceiling-Sprinkler Systems. Structures Congress, 1879-1890.

Soroushian, Siavash, Maragakis, M., \& Jenkins, C. (2016a). Axial capacity evaluation for typical suspended ceiling joints. Earthquake Spectra, 32(1), 547-565.

https://doi.org/10.1193/123113EQS301M

Soroushian, Siavash, Maragakis, M., \& Jenkins, C. (2016b). Capacity evaluation of suspended ceiling-perimeter attachments. Journal of Structural Engineering (United States), 142(2). https://doi.org/10.1061/(ASCE)ST.1943-541X.0001355

Soroushian, Siavash, Rahmanishamsi, E., Ryu, K. P., Maragakis, M., \& Reinhorn, A. M. (2016). Experimental fragility analysis of suspension ceiling systems. Earthquake Spectra, 32(2), 881-908. https://doi.org/10.1193/071514EQS109M

Suspension Ceiling Tee System. (2019, November 25).

http://www.greencyclevision.com/products/suspension-ceiling-tee-system/.

Takahashi, N., \& Shiohara, H. (2004). Life cycle economic loss due to seismic damage of nonstructural elements. Proceedings of the 13th World Conference on Earthquake Engineering, 203, Paper No. 203. 


\section{$\underline{\text { References (CON'T) }}$}

Takhirov, S., Gilani, A. S. J., Takhirov, S., Reinhorn, A., \& Mahin, S. A. (2010). Test Standard and Seismic Qualification Requirements for Suspended Ceilings. Structures Congress 2010, July 2014, 2555-2566. https://doi.org/10.1061/41130(369)230

University of California. PEER Ground Motion Database. Retrieved January 21, 2020, from https://ngawest2.berkeley.edu/

Wang, D., Dai, J., Qu, Z., \& Ning, X. (2016). Shake table tests of suspended ceilings to simulate the observed damage in the M s7.0 Lushan earthquake, China. Earthquake Engineering and Engineering Vibration, 15(2), 239-249. https://doi.org/10.1007/s11803-016-0319-z

Yao, G. C. (2000). Seismic Performance of Direct Hung Suspended Ceiling Systems. Journal of Architectural Engineering, 6(March), 1-11.

Zaghi, A. E., Soroushian, S., Echevarria Heiser, A., Maragakis, M., \& Bagtzoglou, A. (2016). Development and validation of a numerical model for suspended-ceiling systems with acoustic tiles. Journal of Architectural Engineering, 22(3), 1-13.

https://doi.org/10.1061/(ASCE)AE.1943-5568.0000213 